University of Louisville

ThinkIR: The University of Louisville's Institutional Repository

Electronic Theses and Dissertations

$5-2002$

\title{
Working class and working college : a case study of first generation, working class, first year, white male college students.
}

Robert Michael Longwell-Grice 1955-

University of Louisville

Follow this and additional works at: https://ir.library.louisville.edu/etd

\section{Recommended Citation}

Longwell-Grice, Robert Michael 1955-, "Working class and working college : a case study of first generation, working class, first year, white male college students." (2002). Electronic Theses and Dissertations. Paper 854.

https://doi.org/10.18297/etd/854

This Doctoral Dissertation is brought to you for free and open access by ThinkIR: The University of Louisville's Institutional Repository. It has been accepted for inclusion in Electronic Theses and Dissertations by an authorized administrator of ThinkIR: The University of Louisville's Institutional Repository. This title appears here courtesy of the author, who has retained all other copyrights. For more information, please contact thinkir@louisville.edu. 
WORKING CLASS AND WORKING COLLEGE: A CASE STUDY OF FIRST GENERATION, WORKING CLASS, FIRST YEAR, WHITE MALE COLLEGE STUDENTS

\author{
By \\ Robert Michael Longwell-Grice \\ B.A., University of Dubuque, 1978 \\ M.Ed., The Pennsylvania State University, 1983
}

\author{
A Dissertation \\ Submitted to the Faculty of the \\ Graduate School of the University of Louisville \\ in Partial Fulfillment of the Requirement \\ for the Degree of
}

Doctor of Education

Department of Educational and Counseling Psychology

College of Education and Human Development

University of Louisville

Louisville, Kentucky

May, 2002 


\author{
By \\ Robert Michael Longwell-Grice \\ B.A., University of Dubuque, 1978 \\ M.Ed., The Pennsylvania State University, 1983
}

A Dissertation Approved on

April 18, 2002

By the following Dissertation Committee:

Dr. Michael Cuyjet, Dissertation Director

Dr. Melissa Evvans-Andris

Dr. Ellen McIntyre

Dr. Bridgette Pregliasco

Dr. Steve Ryan 


\section{DEDICATION}

This dissertation is dedicated to those in my family who have gone before me who made it possible for me to achieve so much. It is dedicated to the everyday working class heroes I have met in my work, especially those like Henry O. Pinette, who taught me to always, "Respect that man in the ditch." Finally, it is dedicated to my daughter and my wife. Emily, you are and will always be the apple of my eye. Hope, you are my life partner, the one who has been with me throughout this long, strange journey. Most importantly though, you make the journey worthwhile. You're my home. 


\section{ACKNOWLEDGEMENTS}

I would like to thank my dissertation advisor, Dr. Michael Cuyjet, for his patience, guidance, and assistance. I would also like to thank the other committee members, Dr. Melissa Evans-Andris, Dr. Ellen McIntyre, Dr. Bridgette Pregliasco, and Dr. Steve Ryan for their help and support in making this dream become a reality for me. 


\begin{abstract}
Working Class and Working College: A Case Student of First Generation, Working Class, First Year, White Male College Students

Robert Michael Longwell-Grice
\end{abstract}

May 11,2002

This dissertation is a case study involving four, first generation, working class, college students. The dissertation study chronicled the experiences of these students during their first semester at the college. In order to more effectively focus on the aspects of social class and first generation status, the study was restricted to white males.

First generation, working class students must negotiate a difficult transition from their working class culture to the culture of academia, in order to be successful in college. This transition typically requires significant re-negotiation of relationships with family members and friends, who are not always supportive of their efforts. Research among first generation, working class students indicates that they face substantial barriers to earning a college degree, and are at a distinct disadvantage concerning access to college and degree attainment.

Case study methodology was employed for this study. Participants were interviewed every two weeks throughout the semester to chronicle their experiences. The research question for the study was: How do first generation, working class, first year, white male college students make the necessary academic, social and cultural adjustments to college? 
The study focused on these students' preparation for college, the support they perceived for attending college, their feelings of belonging to the college campus, and how their social class affected their college experience. The study found that this group of working class, first generation college students lacked significant support systems for their efforts during college. The study found that these students often lacked a sense of belonging to the college campus and indicated that administrators and staff in student services agencies had little, if any, impact on these students college experience. The study also found that their social class had a negative affect on these students ability to succeed in college. The study makes several recommendations for programs designed to help erase the perceived deficit working class, first generation college students have in order to help them succeed in college, and recommends that higher education also adapt its culture to meet the needs of working class, first generation students. 


\section{TABLE OF CONTENTS}

PAGE

ACKNOWLEDGEMENTS........................................................

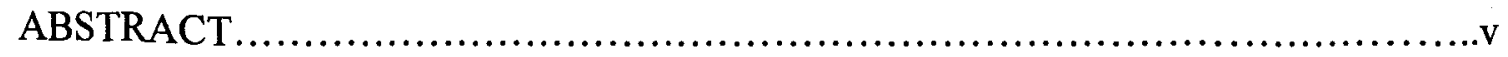

\section{CHAPTER}

I INTRODUCTION...........................................................

Statement of the Problem...........................................

Purpose of the Study..................................................

Significance of the Study ............................................10

Definitions.....................................................

II LITERATURE REVIEW...................................................

First generation College Students.................................15

Pre-College Experience.....................................15

Emotional Development and Transition to College................21

Attrition and Persistence......................................25

Suggestions for Improving the Campus for First-Gens.................29

Social Class and Education: Reproduction, Replication or Resistance? ....32

Historical Considerations of Social Class.......................33

Cultural and Social Capital............................................36

Occupational and Educational Conflicts.............................43

The Struggle of Working class Students Today..........................51

"White Maleness": A Nexus of Race and Gender.......................58

Conclusion........................................................62

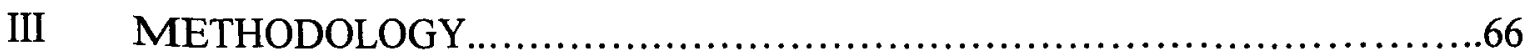

The Use of Case-Study Methodology in Qualitative Research............66

Research Questions..............................................67

Defining Working class...........................................68

The Setting..................................................... 70

Location................................................ 70

History ................................................... 71

Statistical Data.......................................... 71

Recent History ............................................. 72 
Sample Size........................................................... 74

Participant Recruitment............................................76

Participants, An Introduction......................................76

TJ............................................................ 77

Patrick.....................................................77

Bryant..................................................78

Joe...................................................... 78

Informed Consent........................................................

Data Collection........................................................

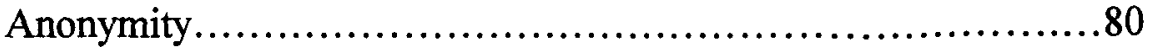

Data Analysis..................................................... 80

Coding...................................................... 81

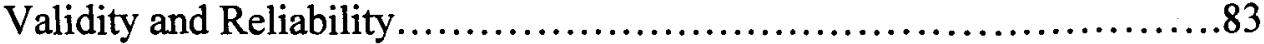

Researcher Bias................................................86

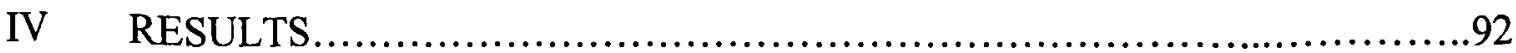

Participants, Redux.................................................93

TJ....................................................93

Patrick.....................................................96

Bryant.................................................99

Joe.........................................................

Participant Summary.......................................... 105

Campus Culture Course.............................................107

Preparation.......................................................108

Purpose of Attending College................................110

Motivation for Attending College............................115

Parental Involvement in Preparing for College...................119

Religion............................................122

High School Involvement in the College Preparation Process...125

High School Activities........................................128

Academic Preparation...........................................133

Feelings for and Perceptions about College....................137

Support........................................................... 143

Family Support........................................145

Support for a Better Life....................................146

Response to Crisis........................................ 150

Sibling Relationships.....................................155

Change in Family Support.................................162

Faculty Support.......................................... 171

Student Services........................................183

UPS.......................................................... 184

First-Gens vs Second-Gens................................189

Belonging.

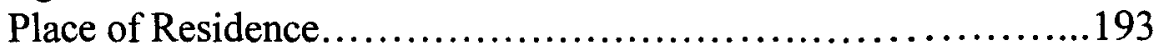

Friendships............................................203 
Campus Involvement...........................................210

Campus Culture.................................................2219

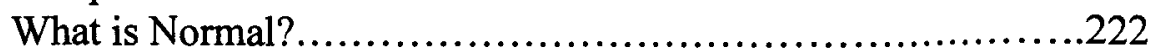

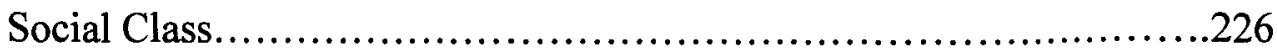

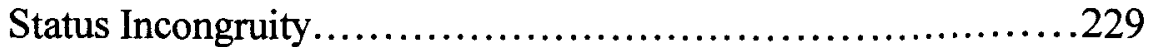

Financing the Dream........................................236

Avoidance of Debt...........................................236

UPS and the Military: For Now and for Later, Maybe?..241

College vs "Real Work"......................................245

The Development of "Back-Up Plans".........................248

Intrinsic Motivation.......................................251

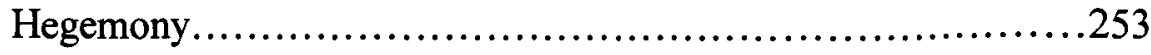

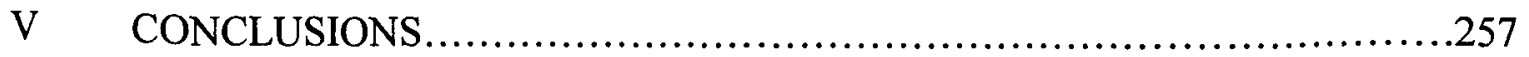

Important Findings............................................258

Social Class..............................................258

Faculty/Student Relations...........................260

The Role of Student Life..............................262

Financial Need......................................262

Preparation................................................267

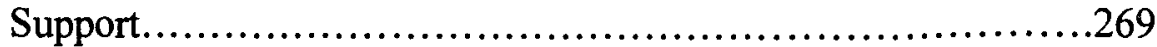

Belonging.................................................271

Recommendations..............................................274

National.................................................274

High School............................................276

College...................................................278

Faculty/Student Relationships........................279

Student Life...........................................283

Training......................................286

Student Service..............................286

Student Organizations...........................288

Financial Need........................................289

Further Research................................................290

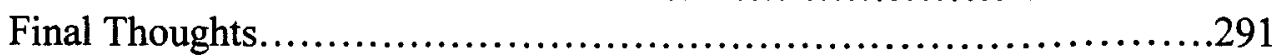

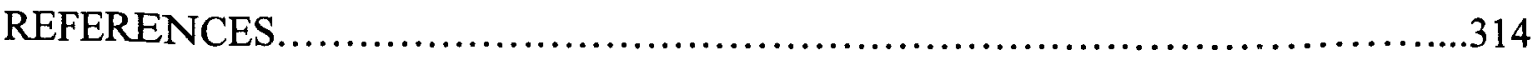

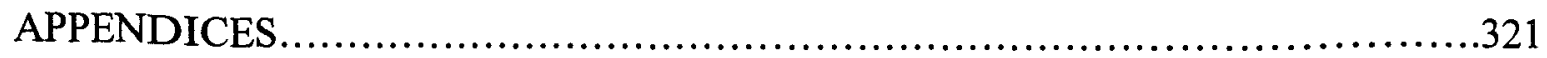

CURRICULUM VITA........................................................... 325 


\section{CHAPTER I}

\section{INTRODUCTION}

In the film Good Will Hunting (1997), there is a scene where Matt Damon and Ben Affleck, portraying two working class kids from South Boston, are talking about their future. Damon expresses to Affleck his desire to stay in South Boston where he can raise his kids and hang out with Affleck like he has for all of his life. To Damon's surprise, Affleck responds "If I find you in South Boston working at lousy jobs like this (construction) in 20 years, I swear to God I'll $\mathrm{f} @ \# \$$ kill you." Affleck goes on to say that Damon has a gift (mathematics) that none of his working class friends has and that he was throwing it away by not pursuing a professional career either in academia or in private industry upon graduating from college. This is a pivotal point in the movie where Damon is forced to choose between his old working class life in South Boston, or a new life.

This experience is not atypical of what many working class, first generation college students experience. College students whose parents have never attended college often feel that they are straddling two cultures (Hsaio, 1992) - that of the college community and that of their friends and family. Traversing the boundaries or living in and out of the borderlands (Anzaldua, 1987) between these cultures can be a painful experience for these students. 
This study looks at the experiences of a group of working class, first generation, white males in their first semester at college. The focus of the study is how the students' first generation status and working class backgrounds affect their ability to negotiate the changes they undergo as they move between their working class culture and the culture of academia. To understand the lived experience of first generation, working class college students however, one must first grapple with the complex nature of culture.

Kuh and Hall (1993) say a culture has shared traditions, values, beliefs and assumptions that serve to unify groups and subgroups, and provide guidance for the behavior of individuals within these groups. Culture is also useful in providing a frame of reference for interpreting the meanings of events and actions. In their study on college cultures, Kuh and Hall identify four levels of culture:

- Artifacts - tangible aspects of culture, the meaning and functions of which may be known by members

- Perspectives - the socially shared rules and norms applicable to a given context

- Values - espoused and enacted ideals of an institution or group

- Assumptions - tacit beliefs that the members use to define their role, their relationships to others, and the nature of the organization in which they live

"Cultures are created over time as people convene regularly, talk and do things over and over again. Clearly, colleges and universities are 'culture-bearing milieus"” (p. 9). It is important to understand that while cultures have often been portrayed as static in 
nature, in actuality they are constantly changing because of the influences of the people within the culture, and the societal influences on culture over time.

The college culture influences the behavior of students, both in and out of the classroom. At the same time, the college culture is influenced by the characteristics, attitudes, and behavior of its members - students, faculty and staff. As a result, Kuh and Hall (1993) say, "an institution's culture is both cause and effect, a college simultaneously exerts an influence on the behavior of students, faculty and staff while these same person's influence and define the institution's culture" (p. 3).

Similarly, Sennet and Cobb (1972) in their study of working class families found that within the working class there were shared values, beliefs, traditions and assumptions. McDonough (1997), in researching the college admissions process for high school students of different social classes, also noted that students from the same social class had similar values about education and expectations for college.

For purposes of this study, I defined first generation college students (first gens ${ }^{1}$ ) as students whose parents had not attended college (Willet, 1989; London, 1989; Nunez, 1998). Two of these students had an older brother attending college, but no family members of previous generations had graduated from post-secondary institutions.

Research on first gens shows that many of them find the college experience to be a difficult time and that they often drop out as a result (London, 1989; Terenzini, Springer, Yaeger, Pascarella, and Nora, 1996; Nunez and Cuccaro-Alamin,1998). The phenomenon of students with the necessary academic ability not continuing their schooling beyond high school, is referred to by Jordan and Plank (1996) as "talent loss."

\footnotetext{
${ }^{1}$ The term "first gens" is one I used for ease of reading. It refers to first generation college students as defined above. I have not found this term used elsewhere but adopted it during my research to facilitate conversations and writing.
} 
This "talent loss," Jordan and Plank maintain, is concentrated among poor and minority students. Jordan and Plank have also shown that students from lower socioeconomic classes have a higher percentage of "talent loss" than do students from middle and upper income families. Compared to students who are second or third generation college students, first gens are more likely to come from low income families, and thus are more likely to suffer from this "talent loss" phenomenon they describe.

First gens have been considered culturally under-prepared for college as well, because they may not have the cultural capital (Bordieu, 1977) or social capital (Coleman, 1988) necessary to be successful in college. Cultural capital refers to the exposure to art, classical music, theater, and literature that comes from attending museums, art exhibits, theatrical performances, and dance recitals. This exposure also comes from taking dance, music, acting and drawing lessons. Children from high socioeconomic classes are more often exposed to these types of cultural activities and thus acquire more cultural capital. Acquiring cultural capital has been shown to help students' academic performance in school and college (Kalmijn \& Kraaykamp, 1996; Lareau and Horvatt,1999; Stanton-Salazar and Dornsbusch,1999). These same studies have demonstrated that while whites generally have higher levels of cultural capital, and females more than males, social class is a greater predictor of the accumulation of cultural capital, with upper income families accumulating greater amounts than working class families.

Social capital is described as the intricate web of friends, colleagues, and general contacts one develops over time through school, work and extra-curricular activities (Coleman, 1988). These contacts can yield opportunities, information, and provide very 
tangible benefits. The purpose of receiving benefits from others, and bestowing benefits upon others, results in a feeling of obligation to reciprocate, and the essence of social capital. Jordan and Plank, in examining the relationship between "talent loss" and socioeconomic class, theorized that the relationship could be explained to some extent by students' lack of social capital. To Jordan and Plank (1996):

Discussions between adolescents and their parents about school events, encouragement from parents to prepare for the SAT or ACT, conversations between parents and school personnel about a student's postsecondary plans, and assistance from the school to a student in preparing college applications cannot occur for students without a certain level of social capital. That is, these items will be available only when relationships have been established to provide information and guidance. (p. 86)

Social class has been shown to be a major determinant of educational attainment for students, more so than race and gender (McDonough, 1997). Although there is no one universally accepted definition of social class, those who have attempted to define it in the research literature include the following in their definition: income, occupation, education, economic and occupational status, status in the community, values, beliefs, attitudes, child rearing practices and assumptions. As Okun, Fried and Okun (1999) contend:

Socioeconomic class refers to more that just level of income. It includes verbal and nonverbal language usage, dress and presentation styles, educational level, acceptable occupations, leisure and social time styles, and a mindset shaped by certain values, attitudes, interests, beliefs, and behaviors. In short, each socioeconomic class can be considered as a distinct culture group. (p. 215)

Similarly, Liu (2001) claims that social class is linked to almost every part of a person's life, including occupation and educational achievement. As one of the first people to research issue of social class, Karl Marx believed that society could be divided into two groups: owners who have the economic capital to buy labor, and non-owners 
who sell their labor (Jackma and Jackma, 1983). Van Galen (2000) and Wright (1997) used a definition in their research that stressed occupation and the possession of skills and/or expertise as key concepts that determine one's social class. In describing the middle and upper classes, Van Galen said, "Those with more authority and skill and expertise also experience more power in their social and civic lives than those on the lower ends of these continua" (p.3). Lareau (1987) defined working class as having parents with a high school degree or less, who were employed in skilled or semi-skilled occupations, who were paid hourly and were periodically unemployed. In contrast, she defined middle-class as having parents who were college graduates, with professional jobs with strong career opportunities who were less vulnerable to changes in the economy.

McDonough (1994; 1997) defined class by parental education and income. Using this definition, she operationalized the working class as having parents who did not have a college degree and were not professionally employed. The upper class was operationalized as having parents with college degrees and professionally employed.

I am drawing upon the work of these researchers in my definition of working class. For this study, I am defining working class as those students whose parents have skilled or semi skilled occupations that do not require college degrees; whose parents do not have a baccalaureate degree; and who self-define as being from the working class.

The primary research question for this study was:

- How and to what degree do first generation, working class, white male freshmen make the necessary academic, cultural and social adjustments to academic life? 
Secondary research questions were:

- Why do first generation, working class white males attend college if it requires considerable re-negotiations with family and friends?

- How do first generation, working class white males perceive that the college campus assists them in making the transition to college?

- What specific transitions do these students need to make to be successful?

\section{Statement of Problem}

First gens are a significant force in higher education. There is general agreement that the numbers of first gens are growing as a college degree becomes a prerequisite for more and more jobs (London, 1992; Terenzini, et al., 1996; Levine, 1989) and Nunez and Cuccarro-Alamin (1998) found that $43 \%$ of all students attending post-secondary institutions in the United States could be considered first gens. While all students encounter obstacles in completing their college degree to some extent, and undergo significant interpersonal changes, some students have more hurdles to overcome than others. First gens face unique challenges in their quest for a degree because they encounter conflicting obligations at home and at college, are straddling two cultures, lack much of the academic preparation needed for the work they are expected to do in college, and are not fully supported in their pursuit of a college degree by friends and family members (Hsiao; London, 1992). Richardson and Skinner (1992) cite time management concerns, economics, and the impersonal nature of higher education as additional concerns for first gens. 
In addition to the very real academic obstacles first gens face, there are obstacles they confront outside of the classroom. First gens may feel that they are on the border of two very different cultures. The college culture into which they are attempting to gain acceptance, may have one set of values and expectations, while the culture of their family and friends has another. College attendance may be seen as a rite of passage for some students, but it marks a significant separation from the past for first gens.

In attending college, first gens are starting down a path that no one in their family has gone before (London, 1992). Because their parents, siblings and friends have no experience with college or its rewards and demands, they can be seen as unsupportive or can sometimes become obstructive towards first gens. When these students live at home, as the majority of first gens do (Nunez), the situation becomes exacerbated. As first gens begin to take on the symbols of the college culture, dress, language, and music, they feel an uncomfortable separation from the culture in which they grew up. Most entering college students are adolescents or young adults who are dealing with issues of identity confusion (Erikson, 1964). As these adolescent college students confront these identity issues, they change in ways that are often confusing to their family and their friends. Under ordinary circumstances, these changes are hard for parents, but when the changes are due to circumstances the parents do not understand, it is even more difficult for them to comprehend. Changes in personality, style, talk and interest, due to adolescence generally cause conflict between all college students and their parents. Such conflict frequently requires students to renegotiate relationships with friends and family. Unfortunately, these renegotiations frequently end acrimoniously (London, 1992). Unlike the support Ben Affleck offered to Matt Damon in Good Will Hunting, many first 
gens feel alienated and unsupported by their non-college going friends and family members.

Astin (1993), Chickering and Reiser (1993) have described in detail the changes that occur among students as a result of college attendance. These changes are psychological, ethical, and attitudinal in nature. They affect students' ability to think abstractly and critically and can change students' values as well. The changes have been attributed to exposure to the curriculum, maturation while in college, quality of teaching and many other factors. Astin states:

For most prospective college students, [the decision to attend college] involves three issues: (1) whether or not to go, (2) where to go, and (3) how to go. The matter of "whether" is particularly critical for that substantial minority of young people whose academic interests and achievements are minimal or whose financial situation is tenuous. Will I be able to succeed? Is it likely to be a worthwhile investment in my time and money? (p. 1)

Many working class families think of college simply as a place that prepares students for a career, without realizing that it also is responsible for the other changes documented by Astin, and Chickering and Reiser. So, while the college experience can be an exciting one, changing the way students think and the way students perceive the world, the families and peers of these first gen students are unable to accept these difficult-to-understand, confusing, and often alienating changes. Never having been to college themselves, they are not mindful of the cognitive and developmental changes that occur during college.

\section{Purpose of the Study}

My dissertation study was a case study that explored the experiences of four first generation, working class, white males during their first semester in college. According to Yin (1994), case studies are the appropriate strategy when "how" or "why" questions 
are posed and when the focus is on a contemporary phenomenon within a real-life context. In my study, I sought to determine how a group of first generation, working class, white males made the necessary adjustment to college and why they made the adjustment when previous studies showed that it required significant, and often painful, renegotiations with family and friends, and that first gens are often socially and academically unprepared for the challenges that college provides. I tape-recorded the interviews and identified common themes among the four students, comparing these themes to the findings from previous research on first generation college students. The findings of this research contribute to the understanding of how the post-secondary first year experience differs for students as a result of their social class and first generation status. It will helps to validate theories on cultural capital and social capital as they relate to college students.

\section{Significance of the Study}

There are a number of reasons why it is important to study first generation, working class white male college students. In terms of sheer numbers, forty-three percent of students attending post-secondary institutions in the United States are considered first gens (Nunez and Cuccaro-Alamin, 1998), and there is a consensus that these numbers will continue to grow as a college degree becomes necessary for more entry-level jobs (London, 1992; Pascarella and Terenzini, 1991). And many college campuses are currently considering using first gen status as a means of ensuring diversity in their student population (Nunez and Cuccaro-Alamin, 1998) to avoid the bitter debates that race-based admissions has caused. 
For these reasons the issues facing first gens are important to examine. Research has shown that first gens as a whole, come from lower socioeconomic families, and are more likely to attend public, two-year colleges (Dougherty, 1987; Terenzini, et al., 1996; Nunez and Cuccarro-Alamin, 1998). In their study on the effects of affirmative action in higher education, William Bowen and Derek Bok (1998) found that the economic diversity among white students attending select colleges to be increasingly small. They discovered that as a white family's income increased, their chances of getting accepted into a selective college or university also increased. Similarly, as the educational level of the parent's increased, so did the chances that a white student would gain acceptance into a selective college or university, leading Bok and Bowen to voice concerns that working class first gens are increasingly left out of the process (personal communication, March 8, 2001).

Hassan and Reynolds (1988) reported, "white, working class high school seniors are increasingly electing not to attend costly, private higher educational institutions, and that the number of first generation students attending these selective colleges is also decreasing." As Rubin (1976) notes, for the working class parent, the question is: "Will my child attend college?" in contrast to the professional, middle class parent whose question is: "Which college will my child attend?" Gos (1995) states: "It is no secret that working class students who choose to pursue a university education begin their college careers in a deep hole relative to students with managerial/professional class origins" (p.30).

Jacqueline King, director of the American Council on Education's (ACE) Center for Policy Analysis found that "pockets of real problems exist among low income 
students of all races" who are attending post-secondary schools (Brownstein, 2000). In addition to differences in educational attainment and college attended by social class and first gen status, there is also a gender gap on some college campuses that is exacerbated by the issues of class and first gen status. In their study Gender Equity in Higher Education: Are Male Students at a Disadvantage?, the American Council on Education reported:

The number of women participating annually in higher education at all levels now equals almost eight million, while only 6.3 million men enroll. The number of male college students has hovered around 6 million since 1975, while the number of females has grown substantially, from 5 million in 1975 to 8 million in 1997. These statistics seem to suggest a large and pervasive gender gap, but they mask tremendous differences by academic level, age, race/ethnicity and income. (p. 5)

According to the ACE, the gender gap is substantial for most groups of low income students, but as income increases, the gender gap either decreases or reverses itself to favor males. "These data make the most compelling argument yet for the thesis that only some groups of men - namely low income - are at a disadvantage in the educational pipeline" (p. 6).

Research studies cited earlier (London, 1989; Terenzini, et al, 1996; Terenzini, Rendon, Upcraft, Millar, Allison, Gregg and Jalomo, 1994) have shown that, as a group, first gens often feel that they are caught between two cultures: that of their friends and families, and that of the college they are attending. The literature review I have conducted shows that much of the data on first generation students comes from national, longitudinal quantitative studies (Horn and Bobbitt, 2000; Nunez, 1998) conducted by the United States Department of Education (DOE). The qualitative studies (Terenzini, et al., 1994 ; Terenzini, et al.,1996; London, 1992) have used large samples and have not attempted to differentiate between the race, gender or class of the participants. These 
studies, therefore, have not researched what the experiences of the different subcultures within the overall population of first gens, is. As Terenzini, et al. (1996) note in their study of 825 first gens:

First generation students differ in many educationally important ways from the students higher education has traditionally served. Because of these different characteristics and experiences, they are also a group at risk. They are a group clearly in need of greater research and administrative attention if they are to survive and succeed in college. (p. 20)

By studying first generation, working class, white males college students, this study makes a significant contribution to the literature on the experiences of first gens. In doing so, it assists colleges and universities in designing programs and developing practices to make these students feel more a part of the campus. By providing additional support for these students, and making them feel that they belong to the campus, the chances that working class first gens will survive and succeed at college will be enhanced.

\section{Definitions}

First Gens - Students whose parents have not attended college. These students may have brothers or sisters who have attended or graduated from college.

Second Gens - Students whose parents have attended college.

College - As used in the text, this term refers to any two or four-year, degreegranting public or private college or university institution. However, when the term is used in regards to this specific study, it refers to the University where the study took place. 
Working Class Student - Having parents who (1) have not achieved a baccalaureate degree, (2) whose parents work in skilled or semi-skilled jobs that do not require a college degree and (3) who self-identify as working class.

Cultural Capital - Being socialized into cultural activities such as art, classical music, reading literature, and attendance at theaters and museums. Knowledge about these aspects of western culture is viewed as valuable by schools.

Social Capital - The intricate web of friends, colleagues, and general contacts developed over time through school, work, and extra-curricular activities. These contacts help students derive institutional help and support for college admission, and job placement.

Academic Community - The students, faculty and staff who attend and/or work for the college.

Support Systems - Familial and institutional support for students that enable them to be successful in college. Support may come from individuals, groups, institutional policies, programs and practices. 


\section{CHAPTER II}

\section{LITERATURE REVIEW}

\section{First generation College Students}

College enrollment rates vary considerably with parents' educational attainment. In 1999, 82 percent of students whose parents held a bachelor's degree or higher enrolled in college immediately after finishing high school. The rates were much lower for those whose parents had completed high school but not college (54 percent) and even lower for those whose parents had less than a high school diploma (36 percent). (p. xviii, Choy, 2001)

Recent national studies (Choy; Horn and Nunez, 2000; Nunez and CuccaroAlamin, 1998) show that students whose parents did not attend college are at a distinct disadvantage concerning access to college, attrition and degree attainment. These studies also show that the disadvantages exist even after controlling for important factors such as educational expectations, academic preparation, parental and school support for college, and family income. This section reviews the literature on first generation college students' pre-college experience, their emotional development, research on attrition and suggestions for making the campus environment more inviting for first gens. Pre-College Experience

Berkner and Chavez (1997) used data from the National Education Longitudinal Study of 1988 to examine access to postsecondary education of 1992 high school 
graduates by 1994 , two years after high school graduation. According to Berkner and Chavez, the path to college enrollment consists of five somewhat sequential steps. First, students must decide that they want to pursue postsecondary education. Second, they must make some plans about where to enroll. Third, they must take a college entrance exam such as the SAT or ACT. Fourth, they must apply for admissions and financial aid. And, fifth, they must gain acceptance and make arrangements to enroll.

Beckner and Chavez found that high school graduates whose parents have low levels of income and education are able to attend to four-year colleges at the same rates as students from middle-income families if they do what four-year colleges expect them to do. However, first gens are much less likely than second gens to complete each of the steps that Beckner and Chavez identified and thus lowered the likelihood of their being admitted to a four year college. According to Beckner and Chavez, low income, Black and Hispanic students are less likely to be well prepared academically to attend a fouryear college, and that the proportion of all students who enrolled in postsecondary education within two years of high school as directly related to family income. Of the students they studied, 64 percent of low income, 79 percent of middle-income and 93 percent of high-income students attended postsecondary education by 1994 .

Choy (2001) summarized the findings of three recent nationally representative longitudinal studies conducted by the National Center for Educational Statistics (NCES) - including the study that Beckner and Chavez used for their research - about the experiences of high school graduates and post-secondary students whose parents did not attend college (first gens). She found that, compared with second gens, first gens were about half as likely to aspire to a bachelor's degree in $10^{\text {th }}$ grade $(46$ percent versus 86 
percent), and, having completed all the necessary steps, about a third as likely to enroll in a 4-year institution ( 21 percent versus 65 percent). In addition, Choy reported:

- First gens tend to report lower educational expectations than their peers as early as $8^{\text {th }}$ grade.

- First gens are less likely than second gens to be academically prepared for admissions to college.

- Parents' involvement in their children's curricular choices increases with their education.

- First gens receive less assistance from their parents in applying to college.

- First gens are not more likely to receive help from their schools in applying to colleges.

- In families with the lowest incomes and least educated parents, students and parents know the least about the price of attending college.

- As a group, first gens at colleges appear to begin college less academically prepared than other students.

Horn and Nunez (2000) compared first gens with second gens, focusing on mathematics course-taking and planning strategies students used to prepare for college. Their report also examined the involvement of students' parents, teachers, and other "institutional agents" capable of helping students prepare for college. The report uses data from the National Educational Longitudinal Study of 1988, a survey that began in 1988 with a nationally representative sampling of eighth graders who were subsequently followed up every two years. Horn and Nunez found that, even after controlling for measures of academic achievement, family income, family structure (single versus two 
parents), and other related characteristics, first gens were less likely than their peers to participate in academic programs leading to college enrollment. Consequently they were much less likely to enroll in college within two years of graduating from high school. Additionally, Horn and Nunez found:

- Only 14 percent of first gens took algebra (considered to be a "gateway" to completing advanced math courses) at the eighth grade level (compared to 34 percent of second gens).

- First gens were far less likely to complete any advanced-level math courses.

- The more students completed advance-level high school math courses, the more likely they were to enroll in college within two years of graduating from high school.

- As the level of education increased, so did the proportion of eighth graders who reported that their parents encouraged them to take algebra in the eighth grade.

- As the level of education increased, so did the percentage of students who reported having frequent discussions with their fathers about their high school program.

- First gens were less likely to report choosing their high school program with their parents.

- First gens received little assistance from their parents about applying for college yet they receive no additional help from their school to make up for this. The help they did receive came very late in the admissions process.

- First gens consistently trailed their second gen peers in participating in curricular activities linked to college enrollment. 
Nunez and Cuccarro-Alamin (1998) found that first gens often have family and background characteristics that are associated with risk for attrition. Their research used data from two of the longitudinal research studies used by Choy (1989 Beginning Postsecondary Longitudinal Study, BPS: 90/94; 1993 Baccalaureate and Beyond Study, B\&B: 93/94) to examine the postsecondary experiences and outcomes of first gen students, relative to their peers. Many of the findings of this study were consistent with other research about first gen students. Among the findings of Nunez and CuccarroAlamin were:

- First generation students were more likely to be older, have lower incomes, be married, and have dependents than did second generation college students.

- First gens were more likely to enroll in postsecondary education part-time, and to attend public 2-year colleges; private, for-profit institutions; and other less-than-4year institutions that were second gens.

- First gens were equally as likely to be taking remedial classes as were second gens when they begin college. However, first gens at private, 4-year colleges were more likely to take remedial courses than were second gens.

- First gens were more likely than second gens to say that being very well off financially and providing their children with better opportunities than they had were very important to them personally.

- First gens were more likely to say that obtaining the amount of financial aid they needed, being able to complete coursework more quickly, being able to live at home, and being able to work while attending college were very important influences in their decision to attend their particular college. 
- First gens persisted in college, and attained credentials at lower rates than did second gens, regardless of the type of college they attended.

- Even when controlling for demographic, enrollment, institutional characteristics, levels of academic and social integration, first gens were less likely to persist in college than second gens.

In the report, Missed Opportunities: A New Look at Disadvantaged College Aspirants, the Educational Resources Institute (TERI) analyzed information from the Census Bureau and the U.S. Department of Education and spotlighted three factors that hinder access to and success in post-secondary education: welfare participation, first gen status, and parental divorce. The study found that all three of these factors exacerbated the obstacles confronting disadvantaged students. Their data found that, (1) First gens are less likely to complete the necessary steps to enroll in a four-year institution and (2) First gens are more likely to delay enrollment in college, behavior which inhibits degree attainment. Only 29 percent of first gens in their study, enrolled in any college immediately after high school graduation, compared to 73 percent of second gens. (p. 6)

Terenzini, Springer, Yaeger, Pascarella and Nora (1996) compared the entering characteristics and experiences of 825 first gens and 1,860 second gens from 23 diverse institutions after their first year at college. Their study was part of the National Study of Student Learning (NSSL), a three-year, longitudinal national study of students who entered college in 1992. The study found that first gens pre-college characteristics made them a group at academic risk. They were more likely to come from low income families, have weaker cognitive skills in reading, math and critical thinking, have lower degree aspirations, and to have been less involved with peers and teachers in high school. 
They also took longer to complete their degrees and reported receiving less encouragement from their parents to attend college.

All of these longitudinal studies using national data show that first gens are generally academically under-prepared for college, and apply to four-year colleges at lower rates than do second gens because they often fail to take the necessary steps to enroll in college. However, it also appears that first gens may be taking a less-traveled (non-traditional) approach to obtaining a college degree and this can be seen by the fact that many first gens begin college later in life, are more likely to attend college part-time, work more hours and take longer to graduate from college than second gens. The longitudinal studies cited, while yielding useful information, may be too preliminary to determine what the long-term effects of being a first gen are. Furthermore, these quantitative studies do not give us much insight into the decision-making process that first gens undertake.

Emotional Development and Transition to College

At first glance, the transition of first gens to college may not seem all that different from the transition their second gen peers experience. All students must learn to adapt to a new set of academic and social systems. For first gens, however, the transition is more difficult because going to college is not part of the family tradition or expectation (London, 1989; Terenzini, et al., 1994). First gens are setting a new course by attending college. College attendance, then, involves not just an academic transition, but also cultural and social transitions as well.

Drawing from her personal experiences as a counselor in a large, metropolitan, university counseling service Piorkowski (1983) observed that many first gens suffered 
from a concept known as 'survivor guilt'. Piorkowski felt that this survivor guilt helped to explain many of the academic difficulties that first gens experience. For first gens the issue is not death in the physical sense, but of leaving others (friends and family) behind as they (first gens) enter college. According to Piorkowski, first gens who attempt to improve themselves through education often grapple with frustration, loneliness, criticism and a lack of family support for their decision to enroll in college. As a result, many first gens find it difficult to concentrate on their academic work while they are dealing with this internal struggle.

Rendon (1996), in recalling her own transition to college as a first gen, wrote:

But like all of life's passages, my growth came together with loss. As I reflect back on my transitions, I think of the struggles, tensions, and traumas that made the passage at times so difficult to navigate. What do you say to your mother when she wants you to work instead of continuing your schooling because she is tired of working the grueling night shift as a waitress in a restaurant that pays her only $\$ 15$ per week? What do you say to your father when he refuses to assist you in financing your college education because you want to attend college far away from your hometown? How do you communicate with your sisters, who now see you so differently that they feel awkward starting a conversation with you? How do you grieve for the loss of a part of yourself when no one seems to understand what you are going through? Coming to terms with these kinds of psychological losses led to my newfound identity as a college student and later as an academic professional. (p. 15)

According to Rendon, when a student leaves home - physically or mentally - for college, the family is forced to reorganize. This reorganization creates turmoil for the family and puts pressure on the student and the parents not to separate. The student and parents must learn to deal with the loss that going away to college causes. Unfortunately many parents of first gens, having no experience with the concept of going to college, express their loss by placing guilt on the student. 
London (1989) interviewed fifteen lower and working class first gen students from a variety of colleges in the Boston area and attempted to record what he referred to as "their life histories." London sought to determine (1) how these student's social histories and family psychodynamics contributed to their matriculation and (2) how these first gens reconciled the conflicting requirements of family membership and educational mobility. Through these interviews, London wanted to learn "what is lost, gained, fought for, and given to compromise - when, for the first time in the history of a family, one of its members partakes of higher education" (p. 144). London came to believe "that family role assignments and separation dynamics were at the center of the drama of first generation students" (p. 147). He also found patterns among his students' stories about separation and parental conflict that paralleled the theories of Helm Stierling (1974). Stierling felt that there are three "transactional modes" that parents operate in when dealing with parent-child separations - be it in early adolescence as students struggle for identity or in late adolescence when students leave home, literally or figuratively, for college. These three modes were described by Stierling as: (1) bounding - keeping the child tied to the parents; (2) delegating - allowing the child to move away from the parents, but still tied to a leash held by the parents and; (3) expelling - neglecting and rejecting the children while pushing them away. London felt that many first gens are paralyzed by "breakaway guilt," the feeling that one or both parents are so dependent on them that they find it hard to leave. This notion is not dissimilar to Piorwski's "survivor guilt," the idea many first gens develop that somehow they do not deserve to go to college because someone else is not as fortunate. 
In all three of the familial reactions to which Stierling refers, London found a lack of support for first gen college attendance to be common, including outright attempts by family members to undermine their efforts at obtaining a degree. In addition London found that first gens from families who were delegators faced the most conflict, because the messages first gens received were so mixed. London also found that first gens had reasons other than family forces for matriculation. Career preparation, intellectual fulfillment, and social standing all were motivators for the first gens interviewed. London speculated that second and third-generation families also bind, delegate, and expel their children, but that their conflicts were more about where to go to college, and what to study in college, than about whether or not to attend college. London found that the family .conflicts with which first gens struggled occurred across cultures, being reported by White working class students, African-Americans, Native-Americans, Hispanics and Asians-Americans. If there was a common element, London felt, it was that the students in his studies lived on the margin of two cultures - never quite wanting or willing to break with their past, even if permitted to do so, and never being fully accepted into the college culture. It is interesting to note that none of the "modes" Stierling refers to are positive in nature. He seems to be indicating that the dynamics involved in the parent-child separation process that occurs when students go to colleges are always negative. If this is the case it has implications for all first year students. However, London (1996) also acknowledged that for some first gens, college is not particularly unsettling because they are the beneficiaries of structural mobility. They are living out the American dream by moving along and advancing beyond their parent's education. This might mean a change in family and class and home, but it is a change 
that they welcome. The first gens who do not find the experience exhilarating, who do not welcome all of these changes, however, find the college experience truly unsettling.

While not all first gens experience the college transition in the same way, London (1996) maintains that all first gens have one transcendent feature in common:

For these students, going to college is a point of departure that prompts and hastens movement into the culture of the "other." In short, for these first generation college students college is transformational, and their transformations require the playing out of powerful intellectual, psychological, cultural and family drama. (p. 18)

Attrition and Persistence

Studies among first gens indicate that they are at greater risk for attrition than are second gens (Billson and Terry, 1982; Choy, 2001; Horn and Nunez, 2000; Pratt and Skaggs, 1989; Terenzini, et al., 1996). Choy found that first gen status is associated with leaving a four-year institution (but not a two-year institution) before the second year, with twice as many first gens dropping out as second gens ( 23 percent versus 10 percent).

Horn and Nunez (2000) found that first gens were much less likely than second gens to have either attained a degree or to be enrolled in college five years after their initial enrollment. They found that as parental education levels rose, so did the likelihood of persistence. "Almost half of first generation college students had attained no degree and were no longer enrolled [after five years] compared with less than one-third of other students" (p. 13). Horn and Nunez also found that first gens were less likely than second gens to persist at four-year colleges, but first gens enrolled at two-year public colleges had similar persistence and attainment rates than second gens.

The Education Resources Institute (TERI) (1997) examined information from the Census Bureau and the U.S. Department of Education to research factors that hinder 
access to and success in post-secondary education. Their research showed that three factors significantly hindered this access and success: welfare participation, first gen status, and parental divorce. These three factors, they concluded, exacerbated the obstacles that continue to confront low income, minority and disadvantaged students. Regarding attrition, TERI found that only 15 percent of first gens attained a bachelor's degree within five years, as compared to 36 percent of second gens.

Billson and Terry (1982) surveyed both enrolled students and dropouts from one private residential college and one public commuter college to determine how family influences affected the educational experience. In addition to surveying these students, Billson and Terry also interviewed those students who completed the survey and who had persisted in college and had not dropped out. Similar to Choy, and Horn and Nunez, they found that first gens were more likely than second gens to leave college before graduating. Billson and Terry's research discovered that first gens have more internal conflict over whether to pursue a liberal arts education or a more vocational education than do second gens. First gens are less likely than second gens to join student organizations, are more likely to make their best friends at work and not at college, to work more hours, and to work off-campus, meaning that they are less integrated into campus life, according to Billson and Terry. First gens also see education as less necessary for success, and report less support, financial and emotional, for college from family and friends for college than do second gens. Overall, Billson and Terry wrote, first gens have less of a commitment to the role of student - which causes them to not join student clubs, socialize with other students, or study as hard as second gens. 
"Dropping out then becomes the logical consequence of role distancing in a setting that demands role enhancement" (p. 70).

Pratt and Skaggs (1989), utilizing data from the Cooperative Institutional Research Project (CIRP) Survey in September of 1988 at the University of Maine, compared first gens' and second gens' predisposition to leave college prior to graduation, using Tinto's (1975) model of college attrition as a framework. Pratt and Skaggs surveyed 1,035 first year, full-time freshmen at the University of Maine to determine if first gens were at greater risk for attrition than their peers. The research question for their work was, "are first gens at greater risk for attrition than second gens?" Of the subjects surveyed, 26.9 percent were first gens and 73.1 percent were second gens. They found no differences between the two groups in the academic course work taken in high school. However, the first gens in their study reported more doubt that they were adequately prepared for college. A higher proportion of first gens also limited their aspirations for higher education to an undergraduate degree than second gens. In contrast to the findings of Billson and Terry, the results of Pratt and Scagg's study suggested that first gens are not at greater risk to leave college prematurely compared to second gens. Pratt and Scagg's study suggests that first gens are less likely than second gens to drop out:

A possible explanation for this finding is that first generation students are very aware of the opportunity for socioeconomic mobility offered by their graduation from college. Their strong commitment to the University of Maine might reflect a singleness of purpose compared to continuing generation students' more diffuse reasons for college, and therefore a weaker commitment to a single institution. Additionally, since first generation students appear to experience less parental encouragement for their college enrollment than continuing generation students, their aspirations may be more internalized, and therefore more focused. (p. 33) 
By contrast, Richardson and Skinner (1992) found that first gens held multiple responsibilities making it more likely that they would attend college part-time, transfer, or stop out one or more times during their college career. Richardson and Skinner conducted 107 in-depth interviews with African-American, Hispanic, and Native American students from ten different public universities who had recently received their baccalaureate degree. The focus of the interviews was the personal, educational, and societal variables that contributed to these students' decisions to persist in college. Fiftyeight percent of these students were first gens. The first gens who were interviewed described disorienting experiences dealing with time management, scheduling, financial aid, and academic advising. Their second gen peers appeared to them to be knowledgeable about how to manage the realities of college life. First gens, by contrast, found college to be intimidating, confusing and impersonal. Because all of the students in this study are students of color, an argument can be made that the experiences felt by first gens cuts across racial lines.

Richardson and Skinner also found:

- First gens had minimal involvement with the campus - especially commuter first gens. They came almost solely to take classes, know only a small part of the campus, and had little involvement with instructors or other students.

- First gens felt that busy faculty and academic counselors were not interested in "wasting time" with them.

- First gens gained the services they needed, such as academic counseling, financial aid, tutoring, and job placement, primarily through their academic departments. 
Finally, the first gens in Terenzini, et al's (1996) study not only have pre-college characteristics that put them at a potential disadvantage compared to second gens, "the two groups also differed in their curricular, instructional, and out-of-class experiences, as well as in their perceptions of the environments of the institutions they were attending" (p. 17).

According to Terenzini, et al.:

In their out-of-class lives, first generation students were also less likely than traditional students to have experiences associated with success and persistence in college. First generation students worked more hours off-campus, and they were less likely to attend a racial/cultural awareness workshop, to perceive faculty members as concerned with student development and teaching, and to receive encouragement from friends to continue their enrollment. Overall, the picture suggests these students less well prepared and with more nonacademic demands on them, and they enter a world where they are less likely to experience many of the conditions that other research indicates are positively related to persistence, performance, and learning. (p. 18).

\section{Suggestions for Improving the College Campus for First Gens}

Based on their studies, several researchers have suggested programs that high schools and colleges can implement in order to help ease the transition to college for first gens and to increase their persistence to graduation. For example, Choy (2001) suggests that "programs and practices that encourage first gens to take academically challenging courses in high school and counsel students and their parents about preparing for college may hold promise for broadening the access of these students to postsecondary education and helping them succeed once enrolled" (p. xxxix). Horn and Nunez found that first gens consistently trailed second gens in taking advanced level math courses and were less likely to participate in curricular activities linked to college enrollment. Like Choy, they recommend that first gens take more advanced math courses in high school. In addition, 
providing first gens and their parents with more information about choosing courses might better prepare students for college, they feel.

Nunez and Cuccaro-Alamin (1998) recommend that colleges learn more about the unique needs of first gens - who they are and what their experiences are - in order to help them overcome the barriers they face in becoming academically successful. London (1992) also feels that colleges need to learn more about first gens and states:

It is only when we see that negotiating cultural obstacles involves not just gain but loss - most of all the loss of a familiar past self - that we can begin to understand the attendant periods of confusion, conflict, isolation, and even anguish reported by first generation students. (p. 10)

Piorkowski (1983) recommends that university counselors, many of whom come from middle-class backgrounds where upward mobility was strongly encouraged, learn more about the concept of survivor guilt as it applies to first gens. By understanding this concept in greater depth, she argues, counselors (and the university in general) can create a more therapeutic environment for students who are struggling with conflicts about upward mobility. Students who learn more about this concept will be better able to handle difficulties that arise as they pursue the "American dream," she contends.

Billson and Terry made a number of suggestions for institutions that want to assist first gens in their quest for higher education:

- Lessen the financial aid burden first gens have that requires them to work so many hours off-campus.

- Encourage residential living and participation in on-campus events/activities in order to more fully integrate first gens into the life of the campus. 
- Provide more on-campus work study situations so first gens need not leave campus to earn the money they need for college.

- Provide specific counseling and peer support systems for first gens dealing with conflicts.

According to Billson and Terry:

The overall approach toward improving retention for first generation students should be to increase their institutional commitment, improve their structured (affiliational) integration, and expand their support network in the academic setting (p. 75).

Finally, Terenzini, et al. (1994) identified several themes that they feel have implicit implications for college faculty and staff:

- Promote awareness of how the transition process affects different kinds of students differently. Compared to second gens, first gens undergo a dramatically different transition, yet most campuses' policies and procedures recognize few differences.

- Early validation appears to be a central element in students' successful transition to college. Academic validation appears to be particularly important for first gens, for whom college attendance is an emotionally risky venture.

- Involve faculty members in student orientation programs. Faculty members play an important role in the lives of students, and it is important that faculty make contact with first gens as early as possible.

- Orient parents as well as students. Parents of all students, but particularly first gens, must be helped to understand the time demands that will be 
place on college students, the changes these students will experience, and how to deal with the stresses that will occur as a result.

- The transition to college involves both in-and-out-of-class experiences. Academic and student affairs divisions must recognize this and consider how their programs and activities relate to each other.

- Institutions must change to accommodate the students. They must find ways to change in order to accommodate the transitional and learning needs of first gens.

- Somebody has to care. Students need to feel competent. They need to feel as if their presence on campus matters. All students, but particularly first gens, need a variety of people willing to help them succeed.

\section{Social Class and Education: Reproduction, Replication or Resistance?}

While many campuses have drawn attention to the interplay of ethnicity and gender in shaping the educational experiences of college students, colleges have paid limited attention to the complex issues of social class itself (Van Galen, 2000; Soliday, 1999; Faulkner, 1995; Odair, 1993). While educators continue to stress the importance of a college degree for achieving success and class mobility, for low income and working class students, obtaining a college degree is becoming increasingly difficult and their numbers on college campuses have decreased in the 1990s (Soliday). Meanwhile, working class students are uncomfortable questioning a system that they are trying so hard to learn, and_most teachers have bought into the myth of the U.S. as an, "open class" society which considers hard work sufficient for upward mobility. Liu (2001) maintains that social class is a pervasive and important dimension in one's life, yet it seems to be 
one of the least understood constructs in psychology. He argues, "often social class is treated as a singular variable, used to infer a person's social class 'thinking'” (p. 127), rather than as just one part of a person's lived experience.

Social class, Liu claims, is linked to almost every part of a person's life, affecting occupational attainment, job satisfaction and educational achievement, among other areas of ones' life. Along with first gen status, social class is one of the key components of this study. Because social class affects so many parts of a person's life, and because it is a key component of the study, I have chosen to discuss social class as a separate concept in detail in the next section of this literature review. This section discusses Marx and Weber to give historical background of class, explains the concepts of cultural and social capital, explores the research of Bowles and Gintis, Blau and Duncan, and Willis, and discusses both the decline of working class students at four-year colleges, and the barriers working class students face in gaining admissions to these colleges.

Historical Considerations of Social Class - Karl Marx and Max Weber

The discussion around social class began with the theories of Karl Marx and Max Weber, and the disagreements between them (Jackma and Jackma, 1983). Marx (in Jackma and Jackma) claimed that classes were simply determined by their relationship to the means of production. There were clearly defined distinctions between owners and non-owners of capital, Marx felt, and these distinctions separated the two groups from each other while bounding each group together. The two groups - having mutually opposed economic interests - gradually evolved into distinctive social and political communities locked in conflict (Jackma and Jackma). Thus, the capitalists who owned the means of production were in one social class, and the workers who owned their labor 
and sold it to the capitalists were in another. Further, Marx argued that these classes were impermeable and unjust, since benefits accrued only to the owning class.

Weber (1946) disputed the simplicity of this model, however. He argued that there were other aspects besides relationship to the means of production that could produce class structures, and introduced the concept of class stratification (Jackma and Jackma). Weber also introduced the concept of status to groups as something separate from economic class, which helped to stratify social classes. To Weber, economic classes were "groupings of people according to their economic position. Class situation or membership is defined by the economic opportunities and life chances an individual has in the labor, commodity, and credit markets" (Gilbert and Kahl, p. 8) while class status is a "shared lifestyle and opportunity between people in a certain class" (Liu, 2001, p. 131). These lifestyles and opportunities, Weber claimed, can stratify people within the same economic class. For example, although a professor and a university electrician may make roughly the same income, their lifestyles and opportunities allow them to occupy different statuses. "Lifestyles are then linked to the life chances and the kinds of social class mobility that one has. In effect, then, although income may help to situate a person within a particular class, other variables play a role in prestige, mobility and life chances" (Liu, p. 131).

Education is one of the "lifestyle" choices to which Weber refers. The type of education one receives helps determine one's social position and can serve as a stratifying issue. Weber argues that all economic classes have an interest in maintaining the status order and react sharply when it is disturbed. The upper classes in particular, Weber maintains, guard against the "pretensions of purely economic acquisition", and 
will not accept a person as their own until s/he has been educated according to the conventions of the status group. Simple acquisition of wealth is not sufficient to change one's status, Weber maintains, but it may be sufficient to alter one's economic class. Working class students then, according to Weber's theory, are unlikely to be accepted into the middle class until others in the middle class are satisfied that working class students have been properly educated into the norms of the middle class. As an example, Marinara (1997) claims that freshmen writing classes are "introduction to academic discourse" classes, where the knowledge working class students bring to college is not given much credence. Marinara claims that the norms of the college community are unlikely to be the norms of the working class students, but that this does not matter to the college status group since one of their goals is to educate them into another social class.

Liu (2001), Jackma and Jackma (1983) maintain that because class stratification is multi-dimensional, having aspects of income, education, and occupation, among others, and because there is no one single criterion for determining social class, many researchers have abandoned the concept that it is an issue around which people form their identity. This is especially true, Liu, Jackma and Jackma argue, as race, gender, sexual orientation, religion, etc. become more significant as identity issues. In addition, both Marx and Weber's theories suggested that classes were primarily economic in nature, and that they were impermeable and caste-like. Now, however, social classes are perceived to be more fluid. Because Marx and Weber failed to account for the impact of race and gender on class, Liu claims, this makes their theories somewhat limited in application in the United States. However, social class determines the type of education one receives (Anyon, 
1980 ) and the type of college one attends (McDonough, 1997), and these two factors play a crucial role in defining one's class, as will be shown in the following sections.

\section{Cultural and Social Capital}

Cultural capital, according to Kalmijn and Kraaykamp (1996), Lareau (1987), and Bourdieu (1977), refers to socialization into cultural activities. For example, in Western societies art, classical music, reading literature, and attendance at the theater and museums have been constructed as "cultural capital." These categories and processes have a value in our society beyond their monetary worth. Further, being knowledgeable about, or participating in these aspects of culture is viewed as valuable. Schools have long educated in ways that support this knowledge and participation as valuable (Hirsch,1997). Children from middle and upper income families are more often exposed to these types of cultural activities at home, acquire cultural capital at home, do well in school as a result, and subsequently have better chances of achieving high levels of education (Lareau). Thus, as Weber indicated, educating students about these activities may be educating them appropriately for entrée into the middle class. Further, if education works as Weber assumes, differences in cultural capital can help to explain the association between the differing social class positions of parents and their children according to Bordieu, and Kalmijn and Kraaykamp.

There is one caveat to this notion of cultural capital that must be raised. Cultural capital is situationally valuable. That is, the value of cultural capital depends on the social setting (Lareau). For example, at a Yankees game, raising discussion about the finer points of Beethoven's Fifth Symphony with random fans may be viewed at best as inappropriate and valueless. However, knowing the recent batting average of Bernie 
Williams and Derek Jeter would be highly valued. As this research project is focused on students experiences in higher education settings, the cultural capital focused on will be that valued in higher education.

Students with more valuable cultural capital fare better in school as indicated by their grades, freedom in the classroom, and attrition rate, than do their otherwisecomparable peers with less valuable cultural capital (Anyon, 1983). There is though a difference between the possession and the activation of cultural capital. People who have cultural capital may choose to activate it or not. Additionally, individuals vary in the skill with which they are able to activate it. In a qualitative study of family-school relationships among white working class and middle-class communities, Lareau found that social class provides parents with unequal resources to comply with teacher's requests for parental participation. She found that middle class families have cultural resources that become a form of cultural capital in specific settings such as schools that working class and low income families lack.

Lareau and Horvat (1999) conducted a case study of parental involvement in a third grade classroom. Using interviews and classroom observations they analyzed differences in classroom and school involvement between black and white parents, taking into consideration issues of social class. The results of this study highlight the differences between possession and activation of cultural and social capital. In the study, cultural capital for the parents include a sense of entitlement to interact with teachers as equals and social capital included networking with other parents to obtain informal information about teachers. Lareau and Horvat observed that white became a type of cultural capital because black parents begin the schooling process suspicious and critical 
of the risk of unfair treatment for their children. However, social class made a difference with both black and white middle-class parents being able to activate their social and cultural capital more easily than working class parents. "The middle-class parents were more likely than the poor parents to maneuver and "customize" their children's experience (p. 44). Lareau and Horvat concluded that the process of social reproduction, the idea that education works to reproduce the current class structure in society, is not a continual, deterministic one. An individual's class and race affect social reproduction, but they do not determine it. Each person, through the skill with which he or she activates capital, influences how characteristics such as race and class will matter in interactions with social institutions.

Cultural capital is an important form of capital and is often translated into elite educational credentials. Individuals with high cultural capital have clear investment strategies of how much and what kind of schooling they or their children should have.

McDonough $(1994 ; 1997)$ conducted a case study of four California high schools which were a mix of not only high and low social classes, but also high and low college guidance operation. She conducted in-depth interviews with twelve white females who were middle range academic performers, and twelve college-bound senior girls. McDonough also interviewed the college-bound senior student's best friends, parents, and high school counselors. Her study addressed three questions: (1) How does a high school senior in today's admissions environment make decisions about where to go to college; (2) How does this decision-making process vary by the student's social class makeup of the student's high school, and the structure and context for guidance available in the high school and; (3) Why, if there is a single opportunity structure for American 
higher education, do individuals perceive it differently? The main purpose of McDonough's study was to understand the interaction of social class, and the high school context. In order to understand these two variables, McDonough controlled for ability, race and gender. Across all achievement levels, McDonough found, students from the lowest socio economic status (SES) groups were less likely to apply to and attend college than were the highest SES students. Regarding cultural capital, McDonough found that some college aspirants, fearful of being frozen out of certain types of colleges thought to be their birthright, mobilized economic capital in an effort to enhance their cultural capital and thereby maximize their socioeconomic advantages. Parents with high cultural capital attempted to secure for their children as prestigious a college education as possible because they believed that an education at a particular type of college would pay off in later job success and social status. Girls from high SES families and/or schools applied to more colleges, visited more colleges, thought about applying to college earlier, took the ACT and SAT tests on time, met the required deadlines, interacted more with school counselors and often hired personal counselors for the purpose of getting into schools, McDonough found.

The usefulness of these patterns are supported by former Secretary of Labor Robert Reich (2000) who wrote that this investment in cultural capital will pay off for middle-class students as "the current competitive rush toward selectivity will make it even less likely that lower-income children will gain access to higher education" (p. B9) because college administrators have incentives to spend more resources to attract "the best" students, instead of accommodating more low income and working class students. 
However, cultural capital does not capture how middle and upper-class families negotiate college admissions. In their article, Working class students at selective colleges: Where have they gone? Hassan and Reynolds (1987) wrote that admissions offices at competitive colleges are alarmed by the dwindling number of white, working class applicants. They contend that although the nation's white, working class population is shrinking, it still does not explain why this particular population does not apply to or attend competitive, expensive schools. Hassan and Reynolds contend that researchers have consistently shown that the greatest influence on whether a student attends college is the parents' level of education. "Simply, children of non-college educational parents are less likely to attend college" (p.5). And, Hassan and Reynolds argue, when white, working class, first gen students do apply for college, their parents cannot help them differentiate between a local community college and a prestigious university. Hassan and Reynolds also contend that a lack of social and cultural capital among working class families works against them in applying for and being accepted at these prestigious schools:

High school students who are "in the know" are paying private organizations thousands of dollars annually in the hopes of increasing their standardized test scores and to discover inside tips about competitive admissions operations. In contrast, the working class applicant is unaware of the degree to which their savvy competitors are spending time, money and effort to win the selective admissions games. (p. 7)

Coleman (1988) introduced the concept of social capital as a way to explain a particular kind of resource. Social capital refers to assets gained through membership in networks and social relationships. People who do favors for each other is the heart of social capital. When people do favors for each other, they earn "credit slips." These credit slips can be "cashed in" at opportune times when help is needed. Where 
individuals are more self-sufficient, and depend on each other less, there are fewer "credit slips" outstanding. Social capital depends on the trustworthiness of the social environment. There must be trust that people will repay the slips. The actual extent of obligations held is equally important. There must be a belief that an obligation has been incurred in order to feel the necessity to repay it. Without a high degree of trustworthiness among the members of the group, the institution of social capital would not exist. Stanton-Salazar and Dornsbusch (1995) contend that working class youth are dependent upon the formation of these social relationships that create social capital:

Supportive ties with institutional agents represent a necessary condition for engagement and advancement in the educational system and, ultimately, for success in the occupational structure. For working class and minority youth, however, these supportive ties are mainly found outside the family, in school settings and community organizations. To complicate matters, initiating such ties outside the family has been found to be no easy task, even for majority group members. (p. 117)

Regarding social capital, McDonough $(1994 ; 1997)$ observed that the middle class and upper-income families in her study attempted to establish networks beyond the neighborhoods in order to extend their social capital. In contrast, low income and working class families restricted their networks to their neighborhood. This enables middle-class parents to use their social capital even if their child attends college out of state. As an example, the middle class families in her study often asked the school counselors at their children's high school for the name of a contact person at the school their child was interested in attending. If they knew of another family whose child attended the same school, they would ask for the same information. The middle class family then would make contact with the person in an attempt to increase their social capital in hopes that it might prove to be an advantage in the admissions process. Middle 
class Americans, she found, dread the possibility of downward mobility and take steps to insure that this does not occur. These steps include obtaining degrees and credentials. Physical capital is embodied in tools, machines, and other productive equipment. It is created by changes in materials to form tools facilitate production. Human capital is created by changes in persons that bring about skills and capabilities that make them able to act in new ways. Economic capital is money. Cultural capital is ideas and knowledge and "ways of knowing" that, when accessed, give you an advantage in certain settings and contexts. Social capital is less tangible, for it exists in the relations among persons. Social capital comes about through changes in the relations among persons that facilitate change. The next section discusses three more recent studies of social class: Blau and Duncan (1967), Bowles and Gintis (1976), and Willis (1977).

\section{Occupational and Educational Conflicts}

I have chosen to highlight the work of Bowles and Gintis, Blau and Duncan, and Willis because they demonstrate three major theories of how education and social class are intertwined. These three studies show a transition of thinking from the belief that social class is determined by societal pressures, and that the role of education is to replicate the social class system (Bowles and Gintis, 1976), through the belief that class mobility can and does occur, however slightly with education playing a role in this mobility (Blau and Duncan,1967) to a fuller understanding of what role self-determinism and education plays in determining social class mobility (Willis, 1977).

Bowles and Gintis (1976) argued that social mobility in the United States was virtually non-existent. Bowles and Gintis maintained that substantial inequality of economic opportunity exists in the United States and that the educational system was a 
major vehicle for the transmission of economic status from one generation to the next.

Bowles and Gintis maintain:

The undoubtedly progressive force of education in furthering material welfare, democracy, and tolerance, has been blunted and indeed overwhelmed by its use as part of the apparatus of perpetuating a class system based on economic dependence. (p. ix)

Bowles and Gintis argued that education became the "new frontier" for capitalism in the early twentieth century. Capitalists produced new arenas - schools - for discovering the limits of one's talents. In providing these new arenas, Bowles and Gintis claim, educational reformers attempted to make an "end run" around economic strife by offering all children an equal opportunity to make it. Those who did not make it, these educators claimed, had no one to blame but themselves. However, Bowles and Gintis wrote:

For half a century, the educational system provided an admirable safety valve for the economic pressure cooker. But by the late 1950s, the educational frontier was pressing its limits. The once relatively homogeneous appearance of the system of high education was rapidly giving way to a hierarchy of colleges, dominated at the top by the elite Ivy League schools and descending through a fine graduation of private schools, state universities, and community colleges. (p. 4)

According to Bowles and Gintis, the capitalist system in the United States maintains that significant social progress can be achieved through a combination of enlightened persuasion and governmental initiative in the area of education and vocational training. Yet, they wrote, "Education has never been a potent force for economic equality" (p. 8). In fact, they insisted, economic mobility is independent of family background and that the probability of a high school graduate attending college "is just as dependent on parental socio-economic status as it was thirty years ago" (p. 8). They insisted that the substantial equalization of educational attainment had not led to 
equalization in income among individuals. They contended that, rather than add to or subtract from the overall degree of class inequality in the United States, education as an institution serves to perpetuate and maintain the social relationships of the various social classes, by facilitating a smooth integration of youth into the labor force. Schools legitimate inequality, Bowles and Gintis wrote, reinforce patterns of social class, and create surpluses of skilled labor that allows employers to maintain the "prime weapon" they have at their disposal: the power to hire and fire. According to Bowles and Gintis, the only purpose education fills is to prepare workers for the capitalist system. Class thus becomes highly deterministic. Bowles and Gintis' theory assumes a high level of collusion between educators and corporate heads. It also does not allow room for working class students who break free of this cycle, obtain college degrees and move into the middle class.

In comparison to Bowles and Gintis feeling that education served to replicate the social classes in society, Blau and Duncan (1967) found that social mobility does occur in the U.S., albeit not to any large degree. Blau and Duncan's assessment of the work force shows that social mobility is difficult, but it does still happen in some cases. And, because it does happen, it argues for a degree of individualism on the part of students, who have the ability of self-determination in their lives, even if it may be to a limited degree. Blau and Duncan (1967) undertook a systematic analysis of the American occupational structure that is the major foundation of the stratification system in our society. Processes of social mobility from one generation to the next and from career beginnings to occupational destinations were considered by Blau and Duncan to reflect the dynamics of the occupational structure. By analyzing the patterns of these 
occupational movements, the conditions that affect them, and some of their consequences, Blau and Duncan attempted to explain part of the dynamics of the stratification system in the United States. Their research is based on empirical data collected from a representative sample of over 20,000 American men between the ages of 20 and 64 , in 1962 . Their basic question was: How is the status that individuals achieve in their careers affected by the statuses ascribed to them earlier in life, such as their social origin, ethnic status, region of birth, community, and parental family? Blau and Duncan contended that while occupational structure is not identical either with economic class or prestige status, it is closely connected with both, particularly with status. Blau and Duncan further asserted that class is primarily a function of occupation with education playing a major role.

Unfortunately for the working class, Blau and Duncan found that simply gaining academic credentials is not enough to move one from the working class into the middle class and it certainly is insufficient to achieve mobility into the upper class status groups. Credentials, e.g. a college degree, were required for social mobility to occur. However, according to Blau and Duncan, parental occupation is also a key factor as is position on the occupational ladder when one begins the ascent. The further away from the white collar, middle and upper class one's parents are occupationally speaking, the less likely one is to achieve middle class status.

But these class issues are not played out neatly in the United States. Race and geography seem to effect class mobility as well. Blau and Duncan found that southern Whites and southern Blacks were hampered by the inferior education they receive in the south. Thus they were unable to compete with their northern peers for high-status jobs. 
And since many jobs in the south are low-status, this makes it difficult for southerners to move up the economic and occupational ladder. Blau and Duncan discovered that whitecollar workers would rather take less money in order to remain in a status-level job, while blue-collar workers see the money as more important. And, since it is necessary for white-collar workers to vacate their jobs to create vacancies in the status-level occupations, by not leaving their white-collar work, middle class people with status are able to maintain it.

Willis' (1977) research among working class "lads" demonstrates the influence of self-determination on ones' education and social mobility. Willis conducted one main case study and five comparative studies for his study, "Learning to Labor: How Working Class Kids get Working Class Jobs." The main study was of a group of twelve nonacademic working class lads from a town he called Hammertown, who attended a school he called Hammertown Boys school. Willis began following these lads during their final year in high school in Britain, through six months after their graduation. During the same time period Willis conducted comparative case studies with five different groups of students: a group of working class "conformist lads," students who readily abided by the class rules, and who lived in a nearby Hammertown school; a group of working class "non-conformist lads," students who did not abide by the class rules, who lived in a local grammar school; a group of working class non-conformist lads in a local middle school; and a mixed class male non-conformist group in an exclusive local grammar school. These groups were selected to give a comparative dimension to the study. The main group was studied intensively by means of observation and participant observation in class, recorded group discussions, informal interviews and diaries. By outlining a careful 
structural analysis of the school and the society in which the lads lived, Willis examined how students produce both resistance to and compliance with the dominant social relationships in school to arrive at their decisions to take working class jobs. The lads were a group of white, working class males who disqualify themselves from opportunities to enter the middle class by refusing to acquire the skills required for middle class jobs. For Willis the question that was at the heart of this study is: Why do some students aspire to the rewards and satisfactions of mental labor that they know will lift them into the middle class while others do not? A secondary question was: How and to what degree does the school help in reproducing the class structure?

For the lads, rejection of the school is rejection of mental activity in general and of the middle class in particular. The working class to which the lads belong, is marked by an assertion of racism, sexism and homophobia. Working class jobs have a physicality that is inherently masculine while white collar, mental jobs are generally seen as feminine and inferior. Fighting and violence also marks working class male school culture. Shortage of cash is the single biggest pressure in the life of the lads and the urgency to obtain money often leads them to leave education for jobs as a result. This is similar to working class American college students who take longer to obtain their degrees because they stop out or attend part time in order to work to pay their bills (Terenzini, et al, 1996). The lads in Willis' study also feel a sense of superiority over teachers. They believe that the teachers did not know what it is like in "the real world" since the teachers had been in school all of their lives. In Willis' study, the lads attempted to take control of their classrooms to control the routine and to make sense of the experience: 
Practical ability always comes first and is a condition of other kinds of knowledge. Whereas in middle class culture knowledge and qualifications are seen as a way of shifting upwards the whole mode of practical alternatives open to an individual, in working class eyes theory is riveted to particular productive practices. If it cannot earn its keep there, it is to be rejected. (p. 56)

Willis found that education was acceptable to the middle class only because it gave them choices in their occupations.

In the working class families Willis studied, the families worked to strengthen the class feelings and ties that were evident in the home. This increased as the students and the families began to withdraw trust from the school. These feelings helped the lads with their struggles against the school culture by reinforcing their negative feelings about school. Willis found that working class values and feelings worked against the school and this allowed the lads to "differentiate" themselves from school. Differentiation is the process by which the typical exchanges expected in the institution (school) are reinterpreted with respect to working class interests, feelings and meanings (Willis). The opposite of Differentiation is Integration. Integration is the process by which class oppositions are broken down. Resistance and opposition are common in differentiation, but not in Integration. Once the differentiation process begins in school, there is a powerful push for working class students to complete the process, and to resist or oppose the integration goal of education (Willis).

However, Willis differs from Bowles and Gintis in that Willis contends there is a level of self-determination involved for the lads and that schools are not acting conspiratorially to keep working class students "in their place" for the benefit of the capitalist system. In fact, Willis argued that middle class parents were more likely than 
teachers to insist on the importance of the school as a source of qualifications that would serve as a means of mobility in society.

Willis contended that working class culture denies that academic knowledge - as opposed to work knowledge - is in any sense meaningful to working class kids. Working class parents do not put their trust in diplomas and certificates, Willis found, while middle-class parents do. Blau and Duncan, and Weber contended that it was unwise for working class kids to put their trust in diplomas and certificates as a way to achieve social class mobility. Blau and Duncan, Weber, and Willis all argued that simply obtaining qualifications is not sufficient to move into the middle class or to obtain a status-level occupation. Certificates and diplomas do not always act to push people up the economic and occupational ladder - they also serve to maintain the status of those who are already at the top. Working class students thus need to overcome the disadvantage of possessing the wrong class culture (Willis).

Willis argued that a few working class lads can make it periodically, but the entire class will never follow. It is through a good number trying, however, that the class structure is legitimated. Because a few working class kids "make it" into the middle class, it "proves" that the system works and that the class structure is not impermeable. The middle class then believes that it enjoys its privilege not by virtue of inheritance or birth, but by virtue of greater competence and merit. The refusal of the working class lads in Willis' study to compete in a 100-yard dash where the middle class enjoys a 50yard advantage is seen by Willis as a radical act because they refuse to collude in their own educational suppression. The way in which all students are expected to pursue the same aims suggests that those at the bottom of a class society are there because of their 
own inability to achieve these aims. Willis maintained that education helps to instill in everyone the idea that it is the mental abilities of the working class - not capitalism - that keeps them in their lower class position.

Willis argues, however, that there is no inevitability of outcomes when it comes to determining ones' social class: "Capitalist freedoms are potentially real freedoms and capitalism takes the wager, which is the essence of reproduction, that the freedom will be used for self-damnation" (p. 175). While Willis does not argue that capitalism uses education to replicate the social class system, he does argue that forces other than selfdetermination are at work to make it difficult for working class students to succeed in school. This is similar to the findings of Lareau and Horvat (1999), who contended that issues of cultural and social capital were also hampering the progress of working class students in school. These three studies, as well as the work of McDonough (1997), and Lareau and Horvat, addressed the issues of how K-12 education affects social mobility and class reproduction. But the intent of this particular study, was to analyze how and to what degree higher education affected social mobility, especially that of working class, first gens? This will be the focus of the next section, which discusses the decline of working class students on four-year college campuses and the barriers working class students face at college.

\section{The Struggle of Working class Students Today}

Across all achievement levels, students from the lowest social classes are less likely to apply to or attend college than are the students from the highest social classes (McDonough, 1997). Studies have also shown that there is a link between having a college degree, the type of job one obtains, and level of income (Blau and Duncan, 1967), 
which are associated with social class. But, as McDonough stated (paraphrasing Gertrude Stein), "a college is not a college is not a college" (p. 2). Higher education has become increasingly stratified, with negative results for working class, first gens. Hassan and Reynolds (1987) report that as a whole, admissions officers at selective colleges have observed a decline in the number of working class students attending their colleges, and that there are fewer applicants overall coming from white, working class backgrounds. Harvard University was the first college to become alarmed by this trend, and called for increased national attention into the issue in 1986. Bok and Bowen (March 6, 2001, personal communication), former presidents at Harvard and Princeton Universities', respectively, observed this trend as well while researching their book, The Shape of the River (1998). Bok and Bowen contend that the lack of attention to issues of social class, combined with a decrease in need-based aid have made it difficult for students from the working class to attend selective colleges.

Low income and working class students are less likely to attend the more selective and affluent institutions, according to Hearn (1984) because the inequity in the college choice process is class-related. Students from lower classes are more particularly likely to attend lower-selectivity institutions, regardless of their levels of academic ability, achievement, and expectations. Institutions are clearly ordered by prestige and levels of resources and an institution's place in this order tends to be inversely related to how open its admissions policy. Contrary to the norms of meritocracy, entry into the most prestigious and selective colleges has not been found to be a function of test scores, and grades. The largest barrier to meritocracy is one's social class. "Compared to the effects of race, ethnicity, and gender, the effects of social class stand out as both stronger 
and more consistent" (Hearn, p.134). McDonough (1994) found that most low income and working class students, as well as the high schools they attended did not participate in college choice behaviors that would gain them admissions into selective colleges. Instead, they were more influenced by their limited financial resources and by the admissions opportunities that were offered by local universities. This behavior McDonough describes exemplifies how working class students lose out on opportunities that middle-class students have, primarily because of the working class student's lack of cultural and social capital.

According to Robert Reich (2000), less than 30 percent of children from families with income in the bottom quarter enrolled in postsecondary education - a percentage that has been dropping since 1993, even as college enrollments among more affluent students has been rising. Hassan and Reynolds contend that it is the high price of selective colleges that discourages students from working class families from applying to these schools. Since Ronald Reagan was president, Hassan and Reynolds assert, financial aid has shifted from grants to subsidized loans, which severely harms lessadvantaged students. Colleges need to reaffirm the nations' underlying commitment to providing higher education for its working class, Hassan and Reynolds wrote.

Another issue working class students face in gaining entry to selective colleges is rigid adherence to standardized testing for college admissions. While research has shown these tests to be racially biased, this same research has also demonstrated that parental education and wealth are powerful predictors of test performance (Saks, 2001). Social class increasingly stratifies post-secondary education, as institutions narrow access by raising admissions standards (Soliday, 1999; Thomson, 1992). Selective private colleges 
have always set the bar high but now public colleges are trying to emulate them. At the same time that many public colleges are limiting the size of their entering class to brag about the number of students they reject - thus increasing their selectivity rating - they are raising the GPA requirements and the SAT scores in an attempt to bring themselves closer to the standards set by selective private colleges.

Gos (1995), Bernstein (1971) and Valadez (1996) maintained that behavior, communication, manner of speaking, and values are all social class markers. Middleclass children demonstrate the types of markers that are honored and respected by academic institutions. This, in order to succeed in college, working class students must overcome these markers and adopt those of the middle class. Otherwise, working class students, who continue to exhibit their working class markers, are at a disadvantage while attending college. As working class students enter territory where their own cultural resources and values are not celebrated or even recognized, their cultural capital remains subordinated to that of the middle-class students (Hanson, 1994).

Valadez maintained that the cultural capital of the upper classes is legitimized and reinforced through school textbooks, teaching styles, curricula and classroom discourse. According to Gos, working class students are reluctant to challenge statements made in class because their upbringing maintains that when a statement is challenged, it is the relationship that is challenged, not the statement itself. The authoritarian environment of working class families discourages questioning, Gos contended. This then limits working class students' ability to think critically, to analyze and to question what is being presented. Gos argued that working class students are under intense pressure to successfully achieve a "border crossing," which may not be possible for most working 
class students. Gos recommends spreading this border crossing period out into a longer period of time so that working class students who are facing the difficulties associated with this phenomenon may have more time to adjust to it. In describing her collegiate experience bell hooks wrote:

I learned how deeply individuals with class privilege feared and hated the working class...I began to understand fully that there was no place in academe for folks from working class backgrounds who did not wish to leave the past behind. That was the price of the ticket. Poor students would be welcome at the best institutions of higher learning only if they were willing to surrender memory, to forget the past and claim the assimilated present as the only worthwhile and meaningful reality. (p. B9)

In contrast to the idea that the environment plays a significant role in the success of working class students in school, is the ideology of developmental psychology, which argues that the individual has meaningful choices to make if they only exercise their capital. This ideology is predominant in middle class culture, Willis contends, and is reflected in the wording used by Tseng (1971) in his study of vocational choices among high school seniors. Tseng tested 179 high school boys to measure levels of occupational aspiration, perception of occupational prestige, achievement motivation and fear of failure. The primary question for Tseng was: what are the similarities and differences among the middle, lower, and lower-lower SES high school student groups with regard to these four measures? According to Tseng, lower class individuals did not attempt to get the necessary education or training needed for high level jobs. Additionally, Tseng wrote that students of lower class tended to select lower level occupations, and that significantly fewer students from the lower class sought career counseling. According to Tseng:

It appears that the individual's socioeconomic status does have a great deal to do with occupational aspiration, perception of occupational prestige, and achievement motivation. In order to stimulate social mobility in the lower socioeconomic groups, therefore, it would be necessary to help improve the goal 
they set for the attainment of higher level occupations, change their perception concerning the world in general and on the world of work and education in specific, and acquire a stronger urge to approach success. (p. 91)

This approach ignores the cultural barriers that keep working class students from participating in the type of education that would cause them to be successful. The conflicts that many first gen, working class students experience within the college setting revolve around their ability to position themselves in ways that do not violate their own cultural integrity (Soliday, 1999). As London $(1989 ; 1992 ; 1996)$ has shown, first generation students are struggling to negotiate the conflicting demands of two cultures, academia and home, and working class students are similarly negotiating this same struggle (hooks, 2000; Kadi, 1993; Grant and Sleeter, 1996).

Sennett and Cobb (1972) conducted a series of 150 in-depth interviews between 1969 and 1970 with working class men, women and their older children in Boston to learn about these people's life experiences as working class men and women. Sennett and Cobb also acted as participant-observers in the communities, schools, clubs and bars in which these families lived, worked and congregated. Although they interviewed men and women in equal numbers, the study reflected primarily the experiences of the men. The primary research questions for Sennett and Cobb's study were: How and to what extent is your life different from your parent's? How to what extent does the class structure in the United States limit freedoms for working class people? Through their research, Sennett and Cobb found that many working class family members - including college students suffered with "status incongruity." This is a feeling caused by not knowing the rules of a new position. It is also a feeling that one is caught between two worlds, which results in a sense that "something" is wrong. The image of working class students trying to 
"better" themselves often ignores the conflict between working class culture and the academic culture - or of the conflict between students and home that occurs as a result of the changes college students experience. College students are not always aware of the changes that are occurring. Education can bring respect, but Sennett and Cobb, and Willis argued that members of the working class do not always see education and whitecollar jobs as "real work," and therefore do not always see that they are bettering themselves occupationally.

Status anxiety, unsure of which class they belong to, the economic realities of paying for college, the feelings that they are not as prepared for college as their middleclass peers, the lack of family support for college and the lack of cultural/social capital, could all be a reasons why low income males lag behind their female peers in terms of educational attainment and are far outpaced by middle-class men and women (King, 2000). The American Council on Education (ACE) analyzed recent data from the National Center for Education Statistics (NCES), the statistical arm of the U.S. Department of Education, by race, gender and social class to determine levels of college attainment by these groups. According to the ACE, statistics on educational attainment demonstrated that low income and working class white and African-American students are half as likely to transition to college, as are middle and upper-income students. Additionally, in low income and working class families, women are far more likely to attend college than men regardless of race (King). As income level increases, however, this apparent gender gap disappears. The ACE report stresses that it is the low income and working class males in the study that require assistance, not the males in the middle and upper classes. 
But the question is, does it really matter what type of college students attend, so long as they attend a college? The answer is "yes" and the reason is that different colleges have different graduation rates and if a student does not graduate, the student is unable to obtain the benefits of a college education. And without the benefits, there is unlikely to be any social class mobility. Elite colleges have graduation rates of between 85 and 95 percent. Four-year public colleges have graduation rates of approximately 45 percent (Snyder, 1987 in McDonough) and community colleges, which enroll over half of first-time freshmen, have transfer rates of about 20 percent (Adelman, 1988, in McDonough). Baccalaureate degree completion rates for those students who begin college at community colleges are even lower (Brint and Karabel, 1989, in McDonough). So the bigger question becomes: why do working class students (and first gens) who attend "less prestigious" colleges graduate at these lower levels?

\section{"White Maleness": A Nexus of Race and Gender}

Although this study focused primarily on the issues of social class and first gen status, I cannot ignore the fact that the students in the study are white males, since race and gender also contribute to our culture and our identity. Just as social class influences values, attitudes and beliefs, so does race and gender. To many people the fact that the participants in the study are white males means that they are a privileged group and any research study suggesting otherwise is suspect. McIntosh (1989) refers to the "backpack of privilege" that whites are given in our society: "White privilege is like an invisible weightless knapsack of special provisions, maps, passports, codebooks, visas, clothes, tools and blank checks" (p. 1) and contends that males similarly hold a privileged position within our society. This privilege, McIntosh argued, allows white males to: be 
in the company of other white males most of the time; not have to worry about being treated unfairly in daily interactions with others; see themselves represented in texts, on TV and in the media positively, and on a daily basis; not have to speak for their race and/or gender in classroom settings. These situations, McIntosh maintained, allows white males to take for granted their gender and race, to the point where white males are unaware that they are being afforded these privileges. Likewise Ortiz and Rhoads (2000) contended that in American society, and on college campuses, whites are afforded unacknowledged privileges because their race is universally accepted as "the norm."

However, white males are not a monolithic group and, as the studies cited previously show (McDonough, 1997; Jordan and Plank; Lareau, 1994), social class is a stronger determinant of educational and economic attainment in American society than is race or gender. So, while white males might seem to be privileged due to the larger amounts of cultural and social capital their race and gender affords them, their social class mitigates it. Furthermore, longitudinal studies (Horn and Bobbitt, 2000; Nunez, 1998) have shown that white male students from working class families, who are also first gens, are at a disadvantage within the college culture when compared to students who are from middle and upper class families and whose parents have graduated from college.

As will be discussed in my methodology chapter, race and gender are not the main constructs for this study, social class and first gen status of the participants are. For my research, race and gender are two of the ways in which I have chosen to "bound" the case (Yin, 1994). However, it is important for the reader to understand the lens through which I perceive the race and gender of the participants. This section discusses the notion 
of the social construction of race and gender and, reviews relevant studies on white male privilege. Because many theorists talk about oppression in terms of white male oppression, and because of the way I employ the constructs in this study, I chose to discuss the two concepts in this one section.

The statement made by physical anthropologist Jean Hiernaux (cited in Guillaumin, 1999) that "Race is not a fact, but a concept" is at the heart of my argument. As Torres, Miron, and Inda (1999) argue, "scientists and social scientists generally agree that 'race' has no validity as a biological, natural category in the human species" (p. 3). "[R]acialized categories are socially created, transformed and destroyed through historical time" (Mills and Torres, p. 30). Mills and Torres argue that people do not see "race." Rather, "they observe certain combinations of real and sometimes imagined somatic and cultural characteristics, to which they attribute meaning with the idea of 'race"' (p. 32).

Similarly, Fernstermaker, West and Zimmerman (1991) maintain, "Increasingly, it is acknowledged that gender is a social construction" and "there is no evidence to suggest an absolute or determinant relation between biological sex and the social meanings attributed to it" (p. 290). Likewise, Biklen and Pollard (1993) state, "Gender is a category of analysis that refers to the social construction of sex. What we have come to identify as belonging to men's or women's behaviors, attitudes, presentation of self, and so on is produced by social relationships and continually negotiated and maintained within cultures" (p. 2). Furthermore, Biklen and Pollard argue, we are not merely neutral men or women: "We are also African-American, or Latino, or European-American men or women. We are working class or middle-class men or women" (p. 2). 
Solomos and Back (1999) maintain that there is a need for a research agenda that looks at the way in which, "whiteness is manifested in discourse, communication and culture" (p. 75) because for too long sociologists studying race have focused on the victims of racism, rather than the perpetrators. However, Solomos and Back also caution that there is a danger of "reifying whiteness and reinforcing a unitary idea of race" ( $p$. 75). They insist that whiteness is a political definition and that racism cannot be separated from class and gender. It is in this vein that I have chosen to look at working class, white male, first gens.

Even though race and gender are social constructs, this does not mean that race and gender are meaningless. Guillaumin (1999) believes, "Whether race is or is not 'a fact of nature,' whether it is or is not a 'mental reality,' it is today, in the twentieth century, a legal, political and historical reality which plays a real and constraining role in a number of societies" (p. 45). Oppression on the basis of race and gender occur in our society. Given the same situation, people of differing races and genders often interpret things very differently and attach varying meanings to behavior. Indeed race and gender are very meaningful and help us interpret our experiences, whether we acknowledge the existence of these constructs or not.

This is typified in McIntosh's (1989) belief that white males are given a "backpack of privilege" to use throughout their lives that other races and women are not given. White males, she argued, are often unaware that they have this privilege and so deny that they are privileged in our society because of their race and gender. Katz and Ivey (in Helms, 1984) also charge that whites deny that they belong to a race and that certain prescribed attitudes and values are associated with belonging to the White race. 
This denial, Katz and Ivey suggest, permits whites to avoid acknowledging personal responsibility for perpetuating a racist system. So, according to Katz and Ivey, when you ask a White person what race they are, you are as likely to get the response "Irish" or "German" or "Jewish" or even "Catholic" as you are to get "White" (p.155).

Helms (1984), hypothesized that Whites may develop racial consciousness via a progression through five stages. However Helms - like Katz - maintained that Whites, as the dominant race in the U.S., could choose environments that allow them to avoid contact with other races, thus allowing whites to remain unconscious about their whiteness. White identity, Helms argued, was contingent upon contact with Black people. Otherwise, according to Helms, Whites might never need to question the racial attitudes they (Whites) hold.

Giroux (1997), however, argues:

Rather than being invisible, as critics from the left such as Richard Dyer and bell hooks have claimed, Whiteness was aggressively embraced in popular culture in order to rearticulate a sense of individual and collective identity for "besieged" Whites. Both Dyer and hooks have argued that Whites see themselves as racially transparent and reinscribe Whiteness as invisible; that is, it rarely occurs to White people that they are privileged because they are White. While this argument may have been true in the 1980s, it no longer makes sense as White youth, in particular, have become increasingly sensitive to their status as Whites because of the racial politics and media exposure of race in the last few years. (p. 287)

Implied in the arguments presented by McIntosh, Katz and Ivey, and Giroux, is the idea that white males have more cultural capital (Bordieux) at their disposal. However, this is not necessarily the case when social class is factored into the equation. In their extensive and significant research, Sennett and Cobb (1972), Willis (1977) and Blau and Duncan (1967) give us examples of how social class works to mitigate the privileges white males have in western societies by virtue of their race and gender. 
Rothenberg (1998) contends, "Racism and sexism can obscure class differences by allowing relatively powerless groups feelings of superiority over certain other groups or by directing attention towards race and gender and away from issues of class privilege that remain unnoticed and uncontested" (p. 114).

\section{Conclusion}

This chapter began with a review of the relevant studies that have concerned first generation college students. These studies indicate three main areas where first gens differ from their second gen peers:

1. Preparation for college.

2. Support systems for attending college.

3. Sense of belonging to college.

The second part of the chapter addressed theoretical and empirical scholarship related to cultural and social capital. Although the studies cited in this section were helpful in that they clearly showed how the issues were at play in the educational setting and benefited some students more than others (partly due to students and parents ability to exercise their cultural and social capital), the studies explored these issues primarily through the experiences of students in elementary and secondary schools, and not on students attending college.

Thirdly, this chapter addressed the issue of social class and education - focusing specifically on the works of Bowles and Gintis, Blau and Duncan, and Willis. In addressing the issue of social class and education, the chapter demonstrated a continuum that has been developed over time from a point where social class was once seen as fully determined by society, to a point where it is now acknowledged that social class mobility 
exists to a limited degree, partly due to one' own self-determination. Again, none of the studies dealing with the intersection of these two issues dealt specifically with collegeage students.

In the fourth section studies were reviewed that were germane to the issue of social class on the college campus, focusing on the concept of how stratification among colleges has affected working class, first generation college students. Specifically, this section discussed how working class, first gens are being harmed by this stratification. This section also related that white, working class, first gen males in particular, are being negatively affected by this stratification.

Finally, the section discussed critical race and gender theories as a way to help explain the context for this paper. Since social class and first generation status were the two main constructs for this dissertation study, the issues of race and gender, while important, were not analyzed.

The literature review led to the following propositions, which helped guide the study:

- First generation, working class white males are not academically or culturally prepared for college.

- First generation, working class white males have fewer support systems for attending college.

- First generation, working class white males do not feel a sense of belonging to the academic community.

This research study, then, was a qualitative case study, which focused on college students for an extended period of time, dealing primarily with the issues of social class 
and first generation status, and the cultural and social capital these students brought to college. It sought to contribute to the literature on first generation, working class students on the college campus.

The issues it sought to explore were: what are the experiences of working class, first generation, first year, white males at college; how and to what degree were the students in this study socially and culturally prepared for college; what support systems did they have to help them transition to their new culture and; what were these students feelings related to their sense of belonging to the college campus? 


\section{CHAPTER III}

\section{METHODOLOGY}

According to Yin (1994), case studies are the appropriate strategy when "how" or "why" questions are posed, and when the focus is on a contemporary phenomenon within a real-life context. Merriam (1998) argues that although case studies have "illuminated education practice for over 30 years and are prevalent in the field of education" (p. 199), there is still confusion as to what constitutes a case study, how it differs from other forms of qualitative research, and when it is most appropriate to use. This chapter discusses why case study methodology is appropriate for this study, identifies the research questions and propositions for the study, defines working class, and addresses the issues of sample size, participant recruitment, reliability and validity, and researcher bias of the study.

\section{Use of Case Study Methodology in Qualitative Research}

In this study I sought to determine what the adjustment issues are for first gen, working class students, how first generation, working class white males make the necessary adjustments to college, and why they attempt these adjustments when previous research studies (London, 1992; Terenzini, et al., 1996) suggest that college attendance requires often painful renegotiations with family and friends and that first gens are often academically and socially unprepared for college. As a research endeavor, case studies contribute uniquely to our knowledge of individual and social phenomenon (Yin) and it is 
the phenomenon of being a first gen, white male student from a working class background that I intend to explore. I chose not to do comparative case studies because as Stake (1995) points out, "comparison is a powerful conceptual mechanism, fixing attention upon the few attributes being compared, and obscuring other knowledge about the case" (p. 242). Miles and Huberman (1994) graphically present a case study as a circle with a heart in the center. The heart is the focus of the study, while the circle defines the edge of the case and bounds the case. What is outside the circle will not be studied.

\section{$\underline{\text { Research Questions }}$}

The primary research question for this study was:

- How do first generation, working class, white male freshmen make the necessary academic, cultural and social adjustments to college?

Secondary research questions were:

- Why do first generation, working class white males attend college if it requires considerable re-negotiations with family and friends?

- How do first generation, working class white males perceive that the college campus assists them in making the transition to college?

- What specific transitions do these students need to make to be successful?

The literature review led to the following propositions, which helped guide the study:

- First generation, working class white males are not academically or culturally prepared for college. 
- First generation, working class white males have fewer support systems for attending college.

- First generation, working class white males do not feel a sense of belonging to the academic community.

My conceptual framework was how the student's first gen status and working class background interacted with each other to affect their college experience. The components of my study were the students, who were the heart of the case and the unit of analysis, the students family and peers, and the students, faculty, administrators, and staff in the students' college community.

The case was bounded in the following ways:

- By the three components to which I restricted the study. These were the students, their families, and the college community.

- By time. I interviewed the students at least four times during their first semester at college. This occurred in the fall semester.

- By the generational, race, gender, and socio-economic status of the participants. Social class is a crucial factor in determining student's success in college and by focusing on one race and gender, I was better able to isolate the issues of class and first gen status on my participants, thus avoiding the confounding effects of race and gender. (Lareau, 1987; McDonough, 1997)

\section{Defining Working class}

As stated in chapter one, there is no one universally accepted definition of working class. In fact some researchers argue that it is preferable to use socio-economic 
status (SES) and obtain data on family income. However, many researchers do use class as a reference and I also chose to do so. Karl Marx (1907) divided society into two economic classes: employers who had the capital that enabled them to buy labor and employees who had labor they could sell to employers. Weber (1946) contended that one's social class was more complicated than this and introduced the concepts of status and stratification to the discussion on social class. Status, Weber felt, was determined largely by consumption and lifestyle. Weber also maintained that education played a role in determining social class. According to Weber, it was not the level of education that was important, but how one was educated. Entrée into the upper class can only be completed, Weber said, when one is educated in the way that the "status groups" prefer.

Blau and Duncan (1967) stressed that occupation was the most significant determination of ones' social class and divided the classes into three groups: white collar, blue collar and farming. Blau and Duncan found that for white collar workers, the fear of falling out of the white collar group was so strong that white collar workers would accept a job that pays significantly less but that keeps them in a white collar profession before they would take a higher-paying job in a blue-collar profession. More recently, Hassan and Reynolds (1988) determined that social class was primarily the combination of one's income, occupation and education and used the following definition of working class for their research: "non-college educated, income below middle-income families, blue-collar employment." Van Galen (2000) and Wright (1997) use a similar definition of social class that stresses occupation and the possession of scarce skills and/or expertise: "those with more authority and skill and expertise also experience more power in their social and civic lives than those on the lower ends of these continua" (p. 3). 
Lareau $(1987 ; 1999)$ used two definitions of working class in her research: (1) Having at least one parent graduated from high school, or dropped out of high school, who is also steadily employed in a skilled or semi-skilled position, including lower-level white-collar work and (2) having parents in a skilled or semiskilled occupation that is paid hourly, with periodic unemployment. Finally, McDonough $(1994 ; 1997)$ used no college degree and not professionally employed as her criteria for determining working class. The definition of working class that I used in this study was: students whose parents had not attended college and whose parents were employed in a job that did not require a college degree. In addition the students I chose for the study needed to selfidentify as working class. The next sections describe the setting where the study took place, how the participants were recruited, and a description of each participant. At the end of the description section is a chart that summarizes each participant.

\section{The Setting}

In describing the college where the study was conducted, I have included its location, a description of the city in which the college is located, programs offered by the college, enrollment information, and some of the issues that the college has been dealing with recently.

Location

The college described itself ${ }^{2}$ as a state-supported metropolitan research university, located in the largest urban area in the southeast United States. The main campus was comprised of 177 acres and was located three miles from the downtown area. It also had a medical complex, which was located downtown, and a smaller campus located in the

\footnotetext{
${ }^{2}$ All information in this description is from the college's website and from conversations with college officials.
} 
suburbs of the city. There were approximately one million people in the metropolitan area where the college was located.

History

The college recently celebrated its bicentennial anniversary and was in the middle of a ten-year strategic plan to put the college on course to achieve the state legislature's goal of becoming "a premier, nationally recognized metropolitan research" college by the year 2020. The college was originally a "municipally-supported, public institution" but joined the state university system in the early 1970 s. At the time of the study, the college offered more than 170 degrees in its 11 schools and colleges. According to its website the college, "has become known especially for teaching, research, and service to its community, and the advancement of educational opportunity for all citizens thereof. With an enrollment of 21,000 , its academic programs attract students from every state and from all over the world."

Statistical Data

The average age of the undergraduate student at the college was 27. In the fall of 2001 there were 2,362 first-time freshmen. Of these approximately $40 \%$ were first gens. Forty-nine percent of all first-time freshmen resided on campus. The average ACT score was 22.6. The graduation rate for undergraduates after six years was approximately $30 \%$. Seventy percent of first year students re-enrolled in the college for their sophomore year, overall. The re-enrollment rate for first year Black students was $77 \%$. For White students the rate was $68 \%$. Overall, 46 percent of the students at the college were male and 54 percent were female. Twenty-one percent of the overall student population were students of color. 


\section{Recent History}

There had been a push by the college during the time of the study to raise the admissions standards for its incoming students. The argument being presented was that the low graduation rate at the college was due to students being admitted with low ACT scores and low GPAs. If the college admitted incoming students with higher ACT scores and GPAs, the administration argued, a greater number of students would graduate. Under an administrative proposal, students who needed to take remedial courses in mathematics and English would be accepted conditionally into the college, but they would first need to take the remedial courses at a local community college and complete their first two years there. Upon successful completion of their first two years at the community college, they would then be able to enroll at the college.

The college had a contractual agreement with United Parcel Service (UPS), which was headquartered in the city. Under this agreement students who worked for the company at its midnight to four a.m. shift would be eligible for free tuition and an $\$ 8.50$ per hour stipend. This program appeared to have mixed results, and people had mixed opinions about it. One opinion was that this relationship provided a tremendous opportunity for students to get their tuition paid while working part-time. The other opinion was that the program exploited students, particularly working class and low income students, making it hard for students to fully participate in college by taking part in co-curricular activities (Gose,1999).

During the semester of this study, several significant events occurred that affected the campus. The first occurred when the local newspaper released the results of a "campus climate" poll that compared all of the state colleges in terms of how their alumni 
viewed their college experience. The alumni of this college rated it near or at the bottom, in comparison with other public colleges in the state, in terms of their overall satisfaction with their experience. And the alumni were the least likely of any other institution's alumni to recommend the college to others as a good place to attend college. The college's response to the publicity generated by the results of the poll included releasing the findings of an internal task force that had studied the institutional environment. According to the task force, the college had been focusing on the undergraduate experience in recent years, but additional attention needed to be paid to academic advising, academic standards, instructional quality and faculty availability.

The second event was also a poll, commissioned by the college, which asked faculty and staff about their satisfaction with the college. The results of this poll were also not entirely favorable towards the college, and again appeared in the local press and showed that while $78 \%$ of the faculty and staff, overall, liked their jobs, only $57 \%$ would recommend the college as a good place to work. Only $59 \%$ of the employees felt welcomed and encouraged at the college as well. But the statistic that caused the biggest discussion, when it was released to the press, was the statistic showing that only $60 \%$ of the employees would recommend the college as a place to enroll for a college degree.

A third event that occurred concerned a fraternity party on campus where several white students attended the party dressed in black face. The incident raised concerns among black students about the level of commitment the college had towards issues of multiculturalism. As a result of this incident the college president sent out an email to everyone in the campus community with the college's "vision for diversity" attached. It read, in part: "The college strives to foster and sustain an environment of inclusiveness 
that empowers us all to achieve our highest potential without fear of prejudice or bias. This includes race, ethnicity, gender, socio-economic status, national origin, sexual orientation, disability, and religion. We expect every member of our academic family to embrace these values."

\section{Sample Size}

My sample was four, first generation, working class white males enrolled in their first semester at the college. I initially had seven students volunteer to participate in the study. However one did not fit the definition for working class. Thus I began the study with six students. Two of the students selected for participation dropped out prior to the beginning of the interviews, leaving me with the four who stayed with the study throughout the semester. According to Merriam (1998) there is no concrete answer to the question of how many people to include in a case study such as this one, and that what is needed is an adequate numbers of participants to answer the question. Lincoln and Guba (1985) recommend sampling until redundancy occurs, with the sample size determined informally, based on what one thinks is enough. However, Merriam recommends that in a multi-case study such as this one, "several" cases should be selected, and that these cases should be purposefully selected. The goal is to learn as much as possible about the issues being studied. The obligation of the researcher, according to Stake is to understand this one case. So, while it might be of interest to learn how the experiences of this group of first gen, working class, white male freshmen compared to another group composed of another race and gender, that was not the purpose of this case study. The purpose of this case study was to learn about the experiences of this particular group at 
this particular time, in as much detail as possible, in order to answer the research questions.

Unlike Merriam, however, Yin (1994) is very specific about sample sizes for case studies. Yin states that for "typical" cases, where the study is seeking literal replication, two or three cases are sufficient. For case studies being used for comparison, four to six cases are necessary. Fewer than two or three would not result in the redundancy that Lincoln and Guba describe, and would not yield sufficient data that Stakes feels is necessary to understand the case. Having more than this number, Yin feels, would have the effect of overwhelming the researcher with too much data and make it impossible to focus the study sufficiently to explore the issues that arise during the study. The participants in this study were viewed as "typical" cases.

A "typical" case, as the word implies, is one, which occurs on a regular basis. This is in contrast to an "atypical" case, which would only be found in rare circumstances. For example, I expected that there would be a fairly large number of students who fit the description of first gen, working class, white male who would be eligible to participate in this study. However, if I added to this description students who also had a physical handicap and who were from divorced parents and who were living in rural areas and were only children, this sample would have been fairly atypical and unusual of the college student population. I attempted to interview the participants every two to three weeks throughout the fall semester, interviewing each of the four students at least four times during the study. 


\section{Participant Recruitment}

Since the study analyzed the experiences of students in their first semester at college, I conducted this study during the fall semester. My recruitment efforts began during the second week of the fall semester. By the end of the fourth week of classes I had recruited all four of the participants and had begun to interview them. My interviews lasted until the end of the fall semester and each student was interviewed at least four times. To recruit the research participants I worked with the faculty members who taught a campus culture class that was required for students new to the college, with instructors who taught freshmen English at the college, and with other faculty members who taught introductory humanities courses with large numbers of first year students. Altogether I visited approximately 35 different classes in the beginning of the fall semester. The campus culture and English courses were required for all new students. The faculty members and instructors in these courses allowed me to come and speak to their students about my study. I initially was able to recruit six students who qualified to participate in the study, but two of them failed to keep any scheduled interview appointments and were eventually dropped from the study. The participants were paid five dollars per interview. Each student completed an information sheet, which contained a brief summary of the project, along with my name and phone number (see Appendix 1).

\section{Participants, An Introduction}

This section provides a brief introduction to the four students who participated in the study. It provides the reader with background information about each of the participants. This information includes age, family background, major, information about their employment status, where they lived and other pertinent demographic data. In 
chapter four I have provided a more detailed description of the participants for the intention of giving the reader a "feel" for each of the students, and an indication of some to the issues they dealt with during the time of the study. Also in chapter four is a grid that lists this information in an abbreviated version. TJ

TJ was 18 years old and was from a rural town several hours south of the metropolitan area. He attended a large, regional, public high school prior to enrolling in the college. TJ had two younger brothers, one in middle school and one in elementary school. His parents were divorced. $\mathrm{TJ}$ and his brothers lived with their father. $\mathrm{TJ}$ was employed by UPS and also worked briefly during the semester as a telemarketer and at the Six Flags theme park on weekends during the fall. TJ was an accounting major. He lived in an off-campus apartment. TJ's score on the standardized ACT entrance examination was 19 , and his high school grade point average (GPA) was 3.3. I interviewed TJ four times during the fall semester beginning on September $17^{\text {th }}$. Patrick

Patrick was 19 years old and was also from a small rural town several hours south of the college. Patrick also attended a large public high school in his hometown. Patrick's parents were married. He had one younger sister in high school, and an older brother who was attending the same college as Patrick. Patrick was employed briefly as a waiter at the beginning of the semester but for most of the semester he was not employed. At the very end of the semester Patrick joined the Air Force Reserve Army Training Corps (ROTC) for a variety of reasons related to social class, support and belonging. Patrick was a justice administration major. He lived in a house that he rented with his 
older brother and two of his brother's friends from high school. The house was in walking distance of the college. Patrick scored a 26 on his ACT and had a high school GPA of 3.3. My first interview with Patrick occurred on October third. I interviewed Patrick five times during the semester.

Bryant

Bryant was 18 years old and was a resident of the metropolitan area. Bryant graduated from a large, public high school. Bryant was the oldest child in a family of five. His parents were married. Bryant had a job working 15 hours per week for an insurance company off-campus. He worked all day on Mondays and Fridays during the time of the study, assisting the company with their computer management system. Bryant was a marketing major. He lived at home with his parents. Bryant's ACT score was 17, and his high school GPA was 2.6.

Joe

Joe was 18 years old and was a resident of the metropolitan area. Unlike the others in the study, Joe attended a small, private, Catholic high school. His family consisted of his mother, his stepfather, and his one older brother. His older brother was also a student at the college where Joe was enrolled. Joe was employed by UPS and was majoring in business. At the beginning of the study Joe was living at home but mid-way through the semester he moved into an off-campus apartment several miles from campus. Joe scored a 24 on his ACT and had a 3.8 high school GPA.

\section{Informed Consent}

The informed consent letter that I prepared (Appendix 2) was distributed to all participants. If they had any questions about the project, they were able to contact me, or 
the chair of the university's Human Studies Committee, or my supervising faculty member. Prior to my study, I had received the approval of the Human Studies Committee (Appendix 3).

\section{$\underline{\text { Data Collection }}$}

Once participants were named, I met with each participant at least four times during the semester. Interviews were scheduled at the participants' convenience for approximately one hour. We met in a study carrol in the library. I used a structured interview format to ask similar questions of the students during my initial interviews with them. The initial interviews were designed to collect demographic data about the student, their reasons for attending college, and their feelings about attending college (Appendix 4). Each interview was audio taped and transcribed verbatim. Each interview yielded approximately 25-30 pages of transcription per interview. Subsequent interview questions were modified based upon the data received in the previous interview. When I transcribed the tape questions emerged for the next interview. In addition, when I found that an issue being discussed by one participant pertained to a second participant, I would make a point of asking similar questions of both participants. At the end of each interview, I would schedule the next interview with the participant for about two weeks later. These interviews were my primary data source.

After each interview, the audio tapes were transcribed verbatim. Each participant's transcribed interview was shared with him. The participants were told that my intent was to share the data with them to ensure that I was a) getting it right and b) ensuring their anonymity. I endeavored to deliver the transcripts to the participant, via email, during the off week. If I did not understand something that he said or if I had a 
follow-up question related to something the participant said, I posed questions to him in the body of the transcript. Participants responded to these transcripts via email or at our next meeting. The sharing of the transcribed interviews served as a source of triangulation.

In addition to the emails related to the transcripts, the participants were asked to keep in touch during the off week to keep me updated about events in their lives. This communication was voluntary and occasionally participants did contact me with "facts" about their college experience. They also informed me about their reactions to and feelings about certain events during our time apart. Periodically, I asked the students to share academic papers and syllabi with me as I felt they related to the research project. These papers came primarily from three classes, Campus Culture, English and Sociolegy. Several papers, particularly ones written by Bryant and Joe, became interesting points of discussion during the interviews. The emails and documents served as secondary sources of data collection for this study.

I did not share my analysis of the interviews with the participants. After discussing this idea with several qualitative researchers, I decided against doing this. The participants were told that I intended to use the data for my dissertation, and that I would probably be doing presentations and articles based on the information I obtained. All participants seemed quite pleased to be participating in a study that might be used to help others understand the experiences of working class, fist gens.

I interviewed the participants throughout the fall semester. My final interviews took place prior to finals week. In the spring semester I continued to meet with the participants on an informal basis approximately once a month, usually for lunch or over 
coffee. This allowed me to follow-up with them on issues that were presented during our last interview, and provided for a smoother ending to the study.

\section{Anonymity}

The participants were students and I changed their names and altered some personal information about them (eg., names of siblings, names of high schools) in order to insure their privacy and anonymity. This was especially important because their comments about family, faculty, and peers was used in the study, and some of their comments might be construed as hurtful to certain individuals.

\section{Data Analysis}

A separate section on data analysis can be misleading because collection and analysis of data needs to be a simultaneous process in qualitative research (Merriam, 1998). Failure to do so undermines the research project. Qualitative researchers do not know ahead of time what questions to ask and what areas to prove, they are directed by the data collected. After one interview is conducted it is necessary to transcribe the tape and analyze what was said. This helps guide the second interview and helps in data analysis of journals and papers that are also collected. Merriam argues that in data analysis of qualitative research there is a clear right way and a wrong way. The right way is to analyze data simultaneously with data collection. The wrong way is to wait until all of the data are collected before attempting to analyze it.

In analyzing the data I employed elements of narrative analysis (Merriam), which relies heavily on first-person accounts through interviews, journals and papers. I was interested in the perceptions of these students and how they viewed their college experience. Therefore my interviews with the students were my primary sources of data 
collection. Their course work and email correspondence were secondary sources. I also used the constant comparative method developed by Glaser and Strauss (1967) by comparing the analysis of my interviews with one participant with my analysis of my interviews with the other participants. This was done in order to establish themes. Coding

The codes I used during the study were related to my propositions, P1 (preparation for college), P2 (support for college attendance), and P3 (sense of belonging). In addition I added P4 (social class).

I defined preparation for college as issues related to these students pre-college experience as described by Choy (2001), Horn and Nunez (2000) and Cuccaro-Alamin (1998). This included their high school activities, their academic experience in high school, the assistance they received from their parents and their schools in applying to and preparing for college, and their thoughts/feelings about college before they entered college.

Support for college was defined as any emotional, academic and financial assistance that these students perceived from their families, the college, their peers, work, church, other individuals and other institutions during college. For the area of support I used the work of London (1992; 1996), Terenzini, et al. (1996), and McDonough (1997), among others.

I defined belonging to the college as the feelings these students had for college while they were in college, their level of interaction with the college community, who they lived with and who they interacted with on a regular basis. Tinto (1987) and Astin (1993) provided me with a strong theoretical basis fir this area of study. 
The definition of social class that I used drew heavily upon the work of Sennett and Cobb (1972), and Willis (1977), but it also incorporated aspects of Blau and Duncan (1967), Bowles and Gintis (1976), Lareau (1999) and McDonough (1997). I also used the work of Marx (1919) and Weber (1946) in my analysis. Social class was often inextricably intertwined throughout these students experience. Many of the issues presented in the study overlapped into more than one category, and this was especially true in regards to social class. Using these theorists work, I endeavored to assess how social class affected these students high school preparation, their career aspirations, their experience in college, the level of support they received for attending college, how they felt about being in college, what they saw as the purpose of college and how they financed their education.

After an interview, I would transcribe the tape verbatim, and place one of these four codes next to the data when I thought it related to one of the four major areas. Yin refers to a major area as a "bin" and I attempted to sort the data into one of these four major bins simultaneously with my interviews. At the end of the study, I then looked at the data and divided the data using the following sub-categories:

P1 - preparation for college

- High School

- College

- Home

P2 - support for college

- From Family \& Friends

1. Emotional support 


\section{Financial support}

3. Academic support

- From College

- From Work

P3 - belonging

- To College

- To Home

P4 - social class

- Related to Preparation

- Related to Support

- Related to Belonging

Inevitably other sub-themes emerged that I did not anticipate and these were categorized accordingly. Where the sub-themes were not related to the propositions or the issues under study I considered them as outliers and did not address them in this study.

Early in the study it became clear that many issues and incidents related to more than one theme. Therefore I had to embrace the overlapping nature of the data. This is reflected in chapter four where I discuss my research findings. This overlap was inevitable because in many ways I was attempting to separate out issues related to these students that were inseparable. Issues of support were also issues of belonging. Issues of preparation overlapped with issues of support. Social class was intertwined with aspects of preparation, support, and belonging. Where the data overlapped I endeavored to place it into the single most appropriate area. Inevitably, however, some pieces of data were 
placed into two or more areas. The participant interviews were the primary sources for my data. I was interested in obtaining the student's perceptions.

\section{Validity and Reliabilty}

One of the many ways in which qualitative research differs from quantitative research is in the issues of validity and reliability. Since the researcher is the primary instrument of study, quantitative researchers question whether there is indeed any validity to qualitative research and cast doubts about its reliability. The ability to reproduce findings gives the original findings credibility. However, Strauss and Corbin (1998) stress that reproducing social phenomena can be difficult because it is nearly impossible to replicate the original conditions under which data were collected or to control all the variables that might possibly affect findings.

While quantitative studies portray the world in terms of static variables, qualitative studies describe people acting in events. Merriam (1998) lists eight questions commonly posed to students attempting qualitative research:

1. What can you possibly tell from an $n$ of $1(3,15,29$, etc)?

2. What is it worth just to get one person's interpretation of someone else's interpretation of what is going on?

3. How can you generalize from a small, nonrandom sample?

4. If the researcher is the primary instrument for data collection and analysis, how can we be sure the researcher is a valid and reliable instrument?

5. How do we know the researcher isn't biased and just finding out what he or she expects to find? 
6. Doesn't the researcher's presence so alter the participant's behavior as to contaminate the data?

7. Don't people often lie to field researchers?

8. If somebody else did this study, would they get the same results? (Merriam, 1998, p. 202)

Since understanding is the primary rationale for undertaking a qualitative case study, the criteria for trusting the study is different than it is for a quantitative study. What makes the case study valid is the observer's critical presence in the context of occurrence of phenomena, observation, hypotheses-testing (by confirmation and disconfirmation), and triangulation of participants' perceptions and researchers' interpretations (Kemmis, 1985, in Merriam). While validity and reliability are concerns to be addressed, there is as yet no consensus among qualitative researchers on how best to address these issues. Merriam does, however, recommend several strategies which I employed to address concerns over reliability and validity.

To enhance internal validity, I used the following strategies:

1. Triangulation - I used multiple methods of data collection, and multiple methods to confirm the emerging findings. Among the methods of data collection were interviews, and academic papers the participants shared with me. I asked the students to read the transcriptions of their own interviews.

2. Member Checks - This method involves taking data and/or tentative interpretations back to the people from whom they were derived and asking them if the results are plausible. I shared the interview transcripts with the participants throughout the study, but I did not share my analysis with them. 
3. Peer Examination - As I analyzed the data, I shared my findings with qualitative researchers at the University and had them comment on my tentative findings to ensure that my analysis was accurate.

4. Research Bias - This topic is explored in more detail in the next section of this chapter. Suffice to say here, I continually challenged my own perceptions as I listened to participants, read and reread data sets and wrote and revised this document.

To enhance the reliability of the study, I used the following strategies recommended by Merriam (1998):

1. I explained the assumptions and theories that guided the study and the basis for selecting participants. I also described the participants in detail.

2. I used multiple methods of data collection and analysis as a form of triangulation in order to strengthen both reliability and internal validity of the study.

3. I described in detail how the data were collected, how the categories were derived, and what coding was used, in order to leave an audit trail that other researchers can follow if they choose to authenticate the findings.

Finally, to enhance the external validity of the study, I utilized the following strategies:

1. I attempted to provide enough description so that readers will be able to determine how closely their situations match the research situation, and whether the findings can be transferred. 
2. I described the participants in enough detail to show how typical they are as compared to others in the same category so that readers can make comparisons with their own situations.

3. I used several cases to allow readers to apply the results to a greater range of situations. I was unable to utilize the technique of maximum variation because I was only able to recruit six participants who met all of the criteria, and two of them dropped out of the study. Therefore I was forced to use the remaining four students who fit the criteria for the study.

\section{$\underline{\text { Research Bias }}$}

In qualitative research, the investigator's role can be compared to that of a detective (Merriam). Time, patience and a tolerance for ambiguity are required tools as the researcher sifts through the clues to put the pieces together. In conducting qualitative research, the researcher is the primary instrument for gathering and analyzing data and thus must be sensitive to the context, the setting, the participants and the participants' verbal and nonverbal behaviors. Additionally, the researcher needs to be aware of any personal biases that exist and how they might influence the investigation.

While I agree with Merriam that there may be multiple interpretations of reality, it is still important to remember that because I was the primary instrument for this research. All observations and analysis were be filtered through my "lens." I am human and I have a particular set of values, attitudes and perspectives that affected the study. I also agree with Stake (1995) that subjectivity is not something that needs to be eliminated, but rather is an essential element of understanding. For this reason it is difficult to know exactly how to deal with the issue of researcher bias. It is unethical to exclude or include 
data that either contradicted or supported my personal biases without clear justification. However, these biases were not always apparent to me. Because I may not be aware of them, I attempted to follow the advice given by Diener and Crandall (1978, as cited in Merriam):

There is simply no ethical alternative to being as unbiased, accurate, honest as is humanly possible in all phases of research. In planning, conducting, analyzing, and reporting his work the scientist should strive for accuracy, and whenever possible, methodological controls should be built in to help... Biases that cannot be controlled should be discussed in the written report. Where the data only partly support the predictions, the report should contain enough data to let readers draw their own conclusion. (p. 216)

My lens was a potential bias. I attempted to focus on the issues of social class and first gen status. The race and gender of the participants were two ways that I have bounded the case. Therefore, I may not have paid as much attention to issues relevant to the race and gender of the participants as I could have, in order to focus on my main constructs. The manner in which I bounded the case had the potential for affecting the results by limiting the participants so that only the viewpoint of white males was heard. Although it is impossible to completely avoid the affects of race and gender, by limiting the study to one single gender and race, I attempted to limit their affects as much as possible (Lareau, 1987).

Having said this, the reader should know that these students viewed themselves as working class, first generation, white, male, first year college students. This was their expressed identity and it was how I viewed them as well.

Another area of potential bias was the fact that I am also a first gen, working class, white male and some of my own experiences were similar to those of the participants in the study. For example, during this study $\mathrm{TJ}$ and Joe experienced 
difficulty balancing working at UPS and attending college. This was an area where I related to both Joe and TJ. When I was a sophomore in college, I worked at UPS in New York State from 4 a.m. to 8 a.m. during the week and then commuted to campus. At the same time I participated in intramural activities and belonged to the college tennis team. I was also in a serious relationship. It was tremendously difficult for me to balance all of these obligations and I often missed my early morning classes, or was too tired to attend my late afternoon classes. My nightlife diminished considerably, affecting my friendships. My grades remained adequate, in the 2.7 GPA range, but not outstanding. Twenty-five years later I went to work for UPS again, this time at the same plant where $\mathrm{TJ}$ and Joe worked. I intended to enter graduate school at the beginning of the semester and I wanted to see if I could possibly handle working for UPS and going to graduate school. Within two weeks I knew that I could not manage both. The work was too difficult. I met a few students working with me on the line who were in the UPS/college program and I thought at the time, "My gosh, how do they do this?" Of course, I was older than most of them. But still, the thought of doing homework, going to work, then going to class was too much for me to consider. Instead, I was offered and accepted a graduate research assistantship on campus and took out some student loans. TJ and Joe opted to stay with UPS, although it appeared to be more of a "forced choice" due to their limited options.

A third area of potential bias is the notion that my presence alone might have been enough to alter the experience for these participants. For example, if one of these students was considering dropping out of college, could my interest in him have somehow influenced him to remain in college? Or could my being available to him and 
my willingness to listen to him about his conflicts help him negotiate these conflicts to the point where the conflicts were manageable, while another first gen might not have had this same opportunity and thus have had a different experience?

In Merriam's (1998) eight questions about qualitative research, there are two that relate to the issue of research bias. Merriam asks, "How do we know the researcher isn't biased and just finding out what he or she expects to find? Doesn't the researcher's presence so alter the participant's behavior as to contaminate the data?" (p.202)

Certainly an argument could be made that by participating in the study these students' lives were affected in a way that other working class, first gens were not. Both Patrick and Bryant said that when I came to their class to talk about the study, they wanted to participate partly because they felt the need to talk to someone about what was going on in their lives. In fact, all four of the participants made comments similar to Joe, who said that he really enjoyed being a part of the study and that he looked forward to our interviews. "Where else can you go and talk to someone and let it all hang out? Where can you go and someone actually wants you to talk about yourself? Where it is all about you," he said.

At various points it was clear that the students were becoming familiar with some of the "jargon" associated with the study and had done some analysis of the topic themselves. For example, Patrick said during one of our interviews that he and his brother on occasion what discuss the phenomenon of being a first gen, working class student after Patrick and I met and talked. Patrick then offered some of the insights he and his brother had. 
But even if there were signs that my presence affected these students, there were also clear examples of how my presence, and the student's participation in the study, made little if any difference in their behavior. One example is that they all failed to show up for at least one meeting with me. This showed that they were treating me just like another part of their life, such as class or work that they also occasionally missed. Another strong example was that in virtually every meeting I asked them to tell me (1) if they had met with any faculty members outside of class lately and (2) if they had joined any clubs or organizations. By their responses they showed signs that they thought they should do both, partly due to my continued questioning. But, except for Joe's pledging a fraternity, none of the four did either of these two things. Curiously, in his final campus culture course paper, Joe mentioned as part of his academic "plan for success" for the spring semester, that he intended to meet with each of his faculty members outside of class to get to know them better. But when I asked him about this, he did not attribute my comments as planting the seed for this part of his plan. The potential for researcher and research bias was present, just as it is in any study whether qualitative or quantitative. Most likely it did, to some degree, affect the study, but in all likelihood it did not affect the outcome of the study in any substantive manner. I encourage the reader to read this study with an eye for this and a sensitivity for the nature of this type of work. 


\section{CHAPTER IV}

\section{RESEARCH FINDINGS}

Sometimes I do think that this semester is telling me that this is the big leagues up here, and I need to do bad this semester to wake me up. And maybe something is trying to tell me that this isn't for me. I just haven't really figured it out yet. I haven't figured it out. (Patrick, 10/31/01)

The metaphor of viewing college as the "big leagues," that Patrick used in referring to his decision to attend college seemed applicable to all of the participants at one point or another during this study. Whether discussing issues related to their preparation for college, their feelings about being supported for their efforts at college, or their thoughts about belonging to the college campus, the students wondered at various times if they were capable of succeeding at college. Although Patrick was speaking for himself at the time, for these students college indeed was "the big leagues."

In this chapter, I evaluate the data I collected for the dissertation study. The first section provides the reader with additional information about the participants, including a chart that contains this information in an abbreviated version. The second section contains a brief discussion about the campus culture course that three of the four students were required to take during their first semester. Following these two sections, data are then presented on the three main propositions for the study. These propositions, which provided the structure for the interviews, were:

- First generation, working class, white males are not academically or culturally prepared for college. 
- First generation, working class, white males have few support systems for attending college.

- First generation, working class, white males do not feel a sense of belonging to the academic community.

These provide the titles for the three main sections of this chapter on research findings. The titles are, preparation for college, support for college and belonging to college. There is one additional section on social class as well since social class was one of the two main constructs under investigation in this study, the other being the effect of being a first generation college student. I would again remind the reader that I viewed these students as first generation, working class, white males who were in their first year at the college. While some of the data are viewed under a separate lens, for example social class, it is important to keep in mind that the lens being used was one aspect of their identity as I viewed it, but not their only identity.

\section{Participants Redux}

TJ

TJ's parents divorced when he was young. He and his brothers chose to live with their father when their mother moved to the east coast after the divorce so that they could remain close to their friends and stay in the same school. As a result, TJ did not have a lot of contact with his mother. In an interview after the Thanksgiving break, TJ talked about how he was unable to reach his mother during the vacation, and was unsure of what her circumstances were:

R: Did you talk to your Mother over the Thanksgiving break?

TJ: I've been trying to call her and I can't get hold of her. She is hard to get hold off. She has a cell phone and a home phone and I get the answering machine for 
both so I don't know what is up with her. My dad thinks that she might be moving out from her new husband, but that is just a rumor. (11/26/01)

Neither of TJ's parents attended college. His father was employed at a federal penitentiary as a guard. The last he heard, his mother was living on the east coast and driving eighteen-wheelers with her new husband.

TJ worked at UPS and actually gave partial credit to the UPS "recruiters" for providing him with incentive to attend college. This seemed to support the argument made that the arrangement between UPS and the college provided opportunities for students to attend college:

R: How did you decide to go to the college?

T.J.: Well, actually I decided my sophomore year because before that I wanted to go to another college in the state and then my sophomore year, I guess you could call them recruiters from UPS, went to our high school and started talking about their program and I got interested in that and then my junior year, at the end of my junior year I heard that the college had one of the top 10 business schools. $(9 / 17 / 01)$

UPS provided TJ with the financial support needed to attend college. However, the work schedule and the physical requirements of the job caused $\mathrm{TJ}$ to struggle during the semester to balance work and school. TJ's struggles provided support for the counterargument that the arrangement with UPS exploited students and made it difficult for them to take full advantage of everything that the college had to offer students.

$\mathrm{TJ}$ began the semester as a business major, and expressed interested in being an actuary when we first began. However, near the end of semester he expressed doubt that he wanted to continue studying business:

$\mathrm{R}$ : And how did you find out information about becoming an actuary as a career? TJ: I had a math class and we had to do a math-related topic. Actually, I looked through the internet and it was the first one that I saw on the list and I got that one. And then I started reading about it and it looked interesting. But the only thing that drew me to it, and the only reason I thought it was interesting was that it 
was the highest paying job. So now I don't think it is what I want to do, but it is just that being an actuary paid a lot. (11/26/01)

TJ lived in an off-campus apartment with a friend of his from high school. His friend attended the local community college, and also worked at UPS. If his friend was successful at the community college level he hoped to attend the college next year as a sophomore. TJ also had a girlfriend who was a senior in high school back home that he had been dating for over a year. He visited his hometown frequently on weekends to see her, spend time with her, and attend her high school activities.

TJ often appeared unsure of himself and came across as polite but unassertive. As a result of car problems he had throughout the semester, he missed a few of our appointments but he was always apologetic, to the point where I needed to remind him that it was he who was doing me the favor by participating in the study, not the other way around. Although talkative in the interviews, he was never as verbal as the other three participants. Although unsure about many things in his life, TJ was very sure that he needed to complete college:

I like to work. I hate not working, but the only reason I am going to college is to get a job. And I really have never been that into school. But I guess college is a higher priority than UPS. The only reason that I am working at UPS, even though I like the job, is so that I can pay for my college. I mean, if I had a choice of a part time job I would still go to UPS just cause I like it but college is my main priority. $(11 / 26 / 01)$

Although TJ considered college to be his main priority, when he had to make a choice between the two, he consistently chose work. When TJ had car troubles, he missed a number of classes, but he never missed work. At one point in the semester TJ was working three jobs, and had chronic car problems, both of which were a large part of why TJ struggled throughout the semester at college. Ultimately much of the TJ's 
struggle, such as his need to work three jobs to pay for college, seemed related to his social class.

Patrick

Patrick was a transfer student. This initially caused me concern because I intended to interview only first year students, which to me meant students who had never been to college before. When I made my presentation to the classes, Patrick was enthusiastic about wanting to participate. After he had completed the biographical data sheet, he explained to me that he although he had recently transferred to the college, he considered himself to be a new student who was "starting over" at the college. The college had not yet accepted his credits so in their eyes he was considered a first year student. Patrick also said that because he had never been to either the college or the city until he decided to transfer, and because of its newness, he felt like a first year student. This convinced me that Patrick was indeed a first year student and thus fit the profile for the study.

Patrick's mother was a medical transcriptionist who worked out of her home in order to take care of Patrick's father who was disabled and unable to work. His father was a diabetic and had chronic gout. The gout left his left leg with no feeling. As a result of these illnesses, Patrick's father was on permanent disability. Prior to this, Patrick's father had a job working for the coal mining industry. Patrick's brother was a senior at the college. His sister was in high school and intended to attend college as well. Patrick was hopeful that his attendance at college would somehow "pave the way" for his sister to attend college. Patrick felt throughout the semester that he was in conflict with his parents about their lack of understanding as to what, exactly, college was all about. 
As Patrick explained his reasons for wanting to transfer to this college, he talked about wanting to change majors to justice administration, which was not offered at his previous school. He also said that he was very unhappy personally at his previous school. It appeared that his parents never really supported his first choice for college. During the study, however, it seemed that the change in schools did not necessarily alter Patrick's outlook towards college. Patrick was majoring in justice administration at the college but was previously a business major. He had a keen interest in American history, particularly in Abraham Lincoln, the Civil War, and reconstruction. Patrick decided to major in justice administration, though, partly because of his interest in it, partly because his parents approved of it, and partly because his utilitarian outlook towards college made him feel that he needed to get a degree in something tangible that would lead to a job:

R: So tell me what appeals to you about justice administration.

P: I just always kind of had a fascination about law enforcement, criminal investigation. I've always thought the FBI, things like that always appealed to me for some reason. My mom and dad always thought it would be something, they wanted me to be a preacher or something to keep me out of trouble, I guess so if I am a law enforcement agent I have to run the straight and narrow, and a lawyer or something, although some people might disagree, with the lawyer being on the good side of the track, and I guess the prestige that goes along with it really appeals to them, for me and for them I guess. To me it is just something that I have always wanted to do since I was little.

$\mathrm{R}$ : It sounds like part of the reason is that it appeals to them as well.

$\mathrm{P}$ : Right, it is something they find interesting, but they also can say, "My son is an FBI agent." (10/03/01)

Periodically Patrick talked of quitting college and joining the military, and at the end of the semester he had gone so far as to meet with an Air Force recruiter to see about joining the Air Force ROTC program on campus. He held off making the decision, though, until he had a chance to talk about it to his family over the semester break. 
Patrick often talked about how he didn't fit in at college or even in the city because of his rural upbringing. This lack of belonging was one very compelling reason why the military appealed to him. The students in ROTC, Patrick felt, were more "like him," not like the "typical college students" that Patrick talked about. The ROTC also served as a back-up plan for Patrick. In case college did not work out, he could always serve in the military, he told himself. Additionally, ROTC offered a number of financial incentives that were enticing to Patrick.

Patrick's orientation towards his hometown and away from campus was exemplified by his living situation. He resided in a house that he rented with his older brother, and two of his brother's friends from high school. Everyone in the house was from the same hometown as Patrick and his brother, which enabled Patrick to remain apart from the college.

Patrick was probably the most vocal of the participants and was able to articulate his issues quite clearly at times. In our first interview we discussed his reasons for wanting to attend college:

$\mathrm{R}$ : What do you think you would be doing if you weren't in college?

P: Working in a convenience store, or a grocery store, 'cause if I wasn't in coliege I' $\mathrm{d}$ be back in my hometown. I'd be working at Texaco.

$\mathrm{R}$ : At any point did you consider not going to college, or dropping out?

P: Never. I guess mom and dad really put the fear of God in to me. They said, "You can go work up there at dairy mart the rest of your life, go right ahead."

R: So, what would you say your feelings are about going to college?

P: Well, I'll be honest with you. Sometimes I wonder if this is what I need to be doing. $(10 / 03 / 01)$

Patrick had very mixed feelings about attending college. On the one hand he recognized that without a degree, he would have limited career opportunities. On the other hand, he did not feel that college was where he should be. However, his parents 
made him feel that he had no choice in the matter. They supported his attending college, but they also attempted to us a version of the "scared straight" approach to keep him in college whenever he questioned his decision to attend college. Throughout the semester, Patrick struggled with issues of support and belonging but was also reluctant to share these feelings with his parents because he felt that he knew that their reaction would not be one of empathy.

Bryant

Although Bryant was a first gen like the others in the study, his family's income was significantly higher than the other participants. When I went to Bryant's campus culture class, I specifically said I was looking for first gens from working class backgrounds. When Bryant completed the release forms, he explained that although his father had made a fairly high income during the past three or four years, he felt he was working class because while he was growing up, his family was fairly poor. The students in this study were able to self-define their social-class background, and Bryant felt he still was part of the working class, despite his father's income. As we talked about his social class status, Bryant recalled times when he was young and his family was, in his recollection, fairly poor:

I never knew 'cause I was real young and I was the only child at the time, but apparently we were dirt poor and I realize that now thinking back on some of the stuff. Like one year we couldn't afford a Christmas tree so relatives had to buy us a Christmas tree. And they probably brought us the presents that I got. So I now realize that. And I always knew that my dad was in a business and I even asked him, "So what did you do in Baton Rouge?" and he said, "Well, I was a construction worker." And I said, "So you were in charge of everybody?" And he said, "No, I was actually the worker." So anyway, after that we moved up here, this is where all of my mom's family is from, and we moved up here and my Dad got a job with United Van Lines. He was an actual mover, and a couple of months after he was doing that, the owner of this particular franchise realized What his skills were as far as communicating and being a sales person. So he got 
hired on as the person who went house to house pricing what it would cost to move and stuff like that. And he did that for a couple of years and then some friends at our church up here said they were starting a new logistics company and asked my dad to be VP, which would be a huge increase in pay. $(9 / 13 / 01)$

Religion in general, and the church Bryant belonged to specifically, played a large role in Bryant's life. In the previous quote the reader can see how the family benefited from the connections the family made as a result of belonging to the church. In this case the church provided valuable social capital that enabled Bryant's father to obtain a job that substantially increased his father's pay, and changed the family's life. Despite this change in family income, however, Bryant still considered himself a "red neck" and said that although he often felt like he was "the rich man's son," he still enjoyed recreational activities that he associated with the working class, such as "four wheeling" and hunting. Bryant also described many of his uncles and cousins as not having finished high school and as "red necks." While Bryant described these relatives as uneducated, he also felt that they had done well for themselves without going to college. When Bryant felt frustrated by college, he would refer to these relatives, as well as his father, and ask himself, "If they could succeed without a college degree, why can't I?"

College isn't as glamorous as everyone made it out to be all throughout high school. Everyone said, "Oh, high school is so much fun!" and college guys coming to our high school telling us how great it was and how much fun, but it is just like school to me. Only you don't have to go to class. And sometimes it is just me personally, me talking too much about it. I think all of my family seems to be doing well and not going to college and I think, "Do I really have to go?" $(9 / 27 / 01)$

Bryant lived at home with his family and commuted to the college during the study. When I asked Bryant if he ever thought about living on campus, his voiced a utilitarian attitude towards college that looked at the cost/benefit ratio and the bottom line. He weighed the cost involved in living on campus, which he saw as significant, 
against the potential benefits to living on campus, which he saw as negligible, and concluded that living at home was the better option. Having no one who had gone to college before, he was unaware of the potential benefits of living on campus.

Bryant spent almost all of his spare time with his best friend, Eric. Eric and Bryant attended the same high school. Eric was also a first gen, but he was an engineering student. Although Bryant was always extremely talkative in our interviews, he reported that he felt uncomfortable around strangers, around people his own age, and in social situations, and was somewhat introverted.

Perhaps partly due to living at home, Bryant seemed to be the participant who wanted to have the least to do with college after classes:

B: I never sat down for hours flipping through the book like maybe you're supposed to, I don't know. I was more like, 'OK, school's over, let's go out and play." And I went out, went with Aaron to the stores, and watched TV... R: So you wouldn't come to the library and study before and after class or on weekends?

B: No, oh no, not on weekends, never. Weekends there was always stuff to do. Between classes, every day I would come to the library and either studied or typed up a paper. And that is where I did all of my homework. Except for I would type some papers at home if I got a chance. Most of the time I typed them here, in the library, or looked over math. And I would go to the math lab a bunch. I used that seven times. I worked on math problems there and studied for each test. So I felt like I used some of the resources here. I am sure there's a lot more, but I used the math lab, I used the computers here in the library, and I used the library to sit and study. But once I got home I didn't study at all.

$\mathrm{R}$ : School was a distant memory.

B: Yeah, exactly. School, when that day was over, depending on what day it was, I didn't have to go back to school. So I was looking forward to work, or looking forward to the day that I had nothing to do. (12/06/01)

Bryant's attitude towards school as just one part of his schedule meant that Bryant spent as little time as possible on the college campus. This also meant that Bryant's orientation became directed towards the community and not towards the college. During the time of 
the study Bryant never indicated a desire to get involved in any clubs or organizations on campus.

Joe

The fact that Joe attended a high school that was different from the others' became significant during the study, particularly in the area of preparation for college. The high school Joe attended had college preparation as a major component of its program, and as a result Joe did not have to take remedial classes as the others did. Joe also came to college prepared to get involved in campus activities because his high school encouraged him to do so. Joe received a scholarship to attend his high school from an anonymous donor. Without this scholarship his family could not have afforded to send him to this high school. He never found out who this anonymous donor was. In describing his family, Joe said:

My dad is not in the picture. It has probably been about two years since I have seen my father. I don't really consider my stepfather my father, either. I consider my brother my father figure. $(9 / 21 / 01)$

Joe's older brother was a senior at the college Joe was attending. His older brother was an engineering student at the college who was doing well academically, while Joe struggled academically. Another difference between the two was that Joe's brother did not drink or smoke while Joe did. To Joe, his brother appeared "flawless." Consequently, Joe said that his mother and stepfather often accused him of being lazy and irresponsible. Like Patrick, Joe did not find that having a brother precede him at college was necessarily positive.

Joe was a business major who desired to become a manager or CEO of a company, and had a strong desire to take liberal arts and humanities courses in order to 
become a well-rounded, educated person. Joe also wanted to become actively involved on the college campus and take advantage of what the college had to offer.

Joe worked at UPS and expected to work there for his entire college career. This seemed to contradict some of Joe's goals because his work schedule continually forced him to alter his plans for college involvement, and had a direct, negative affect on his courses. Yet, the fear of assuming debt, which would be necessary if Joe quit UPS, seemed to outweigh the advantages gained by quitting and getting involved in the campus community to the extent Joe desired.

In my first interview with Joe, he said that he loved college. But in our fifth interview, closer to the end of the semester, he stated, "I am having a hard time here at college." He was attempting to balance working from 11 p.m. to 4 a.m. at UPS with joining a fraternity and attending all the fraternity's required meetings and activities, while still attending classes.

In the beginning of the semester Joe was living at home, but by the end of the semester he had moved into an apartment with friends from work. This move necessitated a commute of 10-to-30 minutes, depending upon traffic, to campus and work, which also added to the difficulties Joe was having at the end of the semester achieving balance in his life.

This section provided the reader with additional background on the four students who participated in the study. The goal was to provide the reader with sufficient background information about each of the participants, in order for the reader to gain a "feel" for each of the students. This will be helpful as these student's stories unfold. The following grid lists some of this information in an abbreviated version. 


\begin{tabular}{|c|c|c|c|c|}
\hline Topic & Patrick & Bryant & & Joe \\
\hline $\begin{array}{l}\text { Place of } \\
\text { Residence }\end{array}$ & $\begin{array}{l}\text { Commutes from apt. } \\
\text { in the city; lives } \\
\text { with h.s. friend }\end{array}$ & $\begin{array}{l}\text { Lives in apt. with } \\
\text { older brother }\end{array}$ & $\begin{array}{l}\text { Lives with } \\
\text { parents } \\
\text { and commutes } \\
\text { from home }\end{array}$ & $\begin{array}{l}\text { Lived at home } \\
\text { but moved to } \\
\text { apt. with work } \\
\text { friends mid-semester }\end{array}$ \\
\hline Hometown & $\begin{array}{l}\text { Small, rural town } \\
\text { two hours south } \\
\text { of the college }\end{array}$ & $\begin{array}{l}\text { Small, rural town } \\
\text { three hours south } \\
\text { of the college }\end{array}$ & $\begin{array}{l}\text { From the metro- } \\
\text { politan area }\end{array}$ & $\begin{array}{l}\text { From the metro- } \\
\text { politan area }\end{array}$ \\
\hline Work & $\begin{array}{l}\text { UPS, tele-marketing; } \\
\text { Six Flags }\end{array}$ & $\begin{array}{l}\text { None during } \\
\text { semester;ROTC at } \\
\text { end of semester }\end{array}$ & $\begin{array}{l}\text { Computer } \\
\text { tech job in } \\
\text { the area }\end{array}$ & UPS \\
\hline Age & 18 & 19 & 18 & 18 \\
\hline Family & $\begin{array}{l}\text { Two younger } \\
\text { Brothers; parents } \\
\text { divorced }\end{array}$ & $\begin{array}{l}\text { One older brother, } \\
\text { at the university; one } \\
\text { younger sister; } \\
\text { parents married; } \\
\text { Father in ill health }\end{array}$ & $\begin{array}{l}\text { Five younger } \\
\text { siblings } \\
\text { parents } \\
\text { married }\end{array}$ & $\begin{array}{l}\text { One older } \\
\text { brother at } \\
\text { the university; } \\
\text { parents } \\
\text { divorced }\end{array}$ \\
\hline Major & Business/Accounting & Justice Admin. & Marketing & Business \\
\hline
\end{tabular}




\begin{tabular}{|c|c|c|c|c|}
\hline Topic & TJ & Patrick & Bryant & Joe \\
\hline Parents Jobs & $\begin{array}{l}\text { Dad is prison } \\
\text { Guard }\end{array}$ & $\begin{array}{c}\text { Dad on Disability; } \\
\text { mom home health } \\
\text { Nurse }\end{array}$ & $\begin{array}{l}\text { Dad is head } \\
\text { of a logistics } \\
\text { co.; mom is } \\
\text { Homemaker }\end{array}$ & $\begin{array}{l}\text { Mom works } \\
\text { as bookkeeper; } \\
\text { stepdad is pipe } \\
\text { fitter }\end{array}$ \\
\hline Friends & $\begin{array}{l}\text { Roomate and } \\
\text { h.s. girlfriend }\end{array}$ & $\begin{array}{l}\text { Brother and h.s. } \\
\text { people from } \\
\text { his hometown }\end{array}$ & Eric & $\begin{array}{l}\text { Fraternity; } \\
\text { work; grade } \\
\text { school }\end{array}$ \\
\hline $\begin{array}{l}\text { Hobbies or } \\
\text { Interests }\end{array}$ & $\begin{array}{l}\text { Work; } \\
\text { girlfriend }\end{array}$ & Civil War & $\begin{array}{l}\text { Hunting; } \\
\text { Religion }\end{array}$ & $\begin{array}{l}\text { Fraternity; } \\
\text { Work }\end{array}$ \\
\hline $\begin{array}{l}\text { ACT and } \\
\text { GPA }\end{array}$ & $19 ; 3.3$ & $26 ; 3.3$ & $17 ; 2.6$ & $24 ; 3.8$ \\
\hline $\begin{array}{l}\text { Interview } \\
\text { Dates }\end{array}$ & $\begin{array}{l}9 / 17,10 / 1 \\
11 / 12,11 / 26\end{array}$ & $\begin{array}{l}10 / 3,10 / 17,10 / 31 \\
11 / 14,11 / 26\end{array}$ & $\begin{array}{l}9 / 13,9 / 27,10 / 11 \\
11 / 1,11 / 14,12 / 6\end{array}$ & $\begin{array}{l}9 / 21,10 / 16,10 / 30 \\
11 / 14,11 / 30\end{array}$ \\
\hline
\end{tabular}




\section{Campus Culture Course}

Three of the four participants were enrolled in a required campus culture course during the time of the study. This course became a topic of conversation in several of the interviews, so it is important that the reader have some background information about the course. Previously the course was centralized out of the provost's office and there was one common syllabus. In this particular year, however, each academic unit was allowed to set its' own goals for the course. Three of the students in this study had businessrelated majors. Although they were in different sections, they all had the same syllabus. Patrick, who was majoring in justice administration, was not enrolled in the course.

According to the course syllabus, the main purpose of the course was to help students successfully make the transition to the college and to provide a basic introduction to their respective majors. One of the desired outcomes of the course was that students would have an understanding of basic study strategies that will enable their success. And one of the policies of the course was that each student would attend at least one meeting with their course instructor to discuss their final project and anything else they wanted to discuss. Interestingly, the syllabus had no identifying information on it as to the faculty member's name, phone number, email, or office hours. Although this information might have been given out at the first meeting, at the end of the semester, when Bryant learned that he had failed the course, emailed me to ask for help in contacting his instructor. This led me wonder how accessible the instructors were in a course whose main goal was to help with transition, knowing that contact with faculty is a crucial component of making this transition work. 
The next three sections of this chapter present data related to the three propositions of the study. Each of the sections also contains sub-themes that emerged from the interviews as they related to these propositions.

\section{Preparation}

Going into college, I really had no idea what to expect. Some teachers were telling me, "It's gonna be hard. It is nothing like high school and we are trying to help you act like a college student." And then there were students who came back from college and told us, "It is so much fun, it's a blast, it's not all that hard." I had teachers telling me it is extremely hard, and my parents telling me, "We don't know but you just better be prepared for whatever." And that is probably the best advice I ever got, just be prepared for whatever. I didn't really pay too much attention to that, but I should have. I should have, but I didn't. So, coming in I had no idea what to expect. I just had no idea what to expect. (Bryant, 10/11/01)

Bryant felt that he received mixed messages from his parents, his high school teachers, and the college representatives who spoke to him, about the college experience. In the end, Bryant felt confused about what to expect from college and was not prepared to face the obstacles that confronted him. The students in this study in general felt unprepared for college, academically and socially. They saw the purpose of college as preparing them for the workforce, which both focused them on their studies, but also ended up limiting them. The students felt that they received little assistance from their parents in preparing for college or applying for college, and while some of them saw their high schools as helpful in assisting them in their preparation for college, others felt that their high schools did little to prepare them. Their involvement in high school was limited, and this was a pattern that they would continue to follow in college.

First gens are much less likely than their peers to complete each of the five steps Berkner and Chavez (1997) found to be necessary for successful college enrollment. These steps are: (1) students must decide that they want to pursue postsecondary 
educational what type; (2) students must prepare themselves academically for collegelevel work; (3) if students want to attend a 4-year institution, they must take the SAT or ACT entrance examination; (4) students need to choose one or more institutions and file an application and (5) students must gain acceptance and make the necessary arrangements.

Choy (2001) reported that compared with their peers, first gens are about half as likely to aspire to a bachelor's degree in $10^{\text {th }}$ grade, and about a third as likely to enroll in a 4-year institution, largely because of the difference in the two groups preparation for college. In addition, Choy found that first gens were less academically prepared for college than second gens and that first gens received less assistance from their parents in applying to college and did not receive any additional help from their high schools to make up for this lack of parental assistance. As a group, first gens at colleges appeared to begin college less academically prepared than other students, Choy also found.

Regarding issues of preparation for college, Horn and Nunez (2000) found that first gens were less likely than their peers to participate in academic programs leading to college enrollment. My interviews tended to support the findings of both Choy, and Horn and Nunez, and also show how these issues affect first gens.

In analyzing the data related to the issue of preparation for college, I grouped them according to the following the themes:

- Purpose for attending college.

- Motivation for attending college.

- Parental involvement in preparing for college.

- High school assistance in preparing for college. 
- Involvement in high schools.

- Feelings about being academically and socially prepared for college.

- General feelings about college.

This section is organized according to these themes.

\section{Purpose of Attending College}

In response to the question, "What do you see as the purpose of college?" all four participants had a ready response. The boys verbalized a perspective that I would call utilitarian. The purpose of college was to prepare them for work. The differences in the boys' responses were minimal, but demonstrated that even with a range of beliefs/theories about the purpose of a college education the boys were positioned at a disadvantage to access the possibilities of the college experience.

$\mathrm{TJ}$ expressed a belief about the purpose of college that focused little on the hereand-now during our second interview. Education had a purpose and the purpose was to prepare him for what was to come:

I feel like all school is to get you prepared. Pre school is just getting you prepared for an elementary school where you get into the classroom type setting, and like elementary school is teaching you the basics of learning for the next step, so on and so on. And I feel like the reason why you pick your times and days and pick your hours for college, is to prepare yourself for a job when you pick the times and days when you want to work. And I feel like college is mainly just to give you the knowledge and skills that you need for the job that you want to have. $(10 / 01 / 01)$

$\mathrm{TJ}$ talked specifically about how picking the times and days of his classes related to work, as opposed to it being a sign that he was mature enough to handle the responsibility of deciding what classes to take and when to take them. He saw college as relating to preparation for work. As TJ described picking the times and days of work, it seemed that 
TJ was envisioning a job where he would have a lot of control over his work

environment. This would be a radical departure from his father's job as a prison guard.

While TJ's response indicated a tight link between college and work, Patrick's

response to this question was the only one not immediately linked to the issue of work:

$\mathrm{R}$ : What do you think the purpose of college is?

P: To weed out the weak. To weed out the ones that, don't have maybe the work ethic maybe to survive or who couldn't do good. Of course to get an education, that's a given. I think what it does is take people, pretenders, the ones who say, "Well, I'm gonna' do this," but they don't have what it takes. And really the ones who graduate are the ones that are cut out for these jobs, and it makes the quality of life better, I believe. The people that actually wanted it, you know? 'Cause there is no way to influence your way through college. You either got it, you either do it, or you don't. You know? I believe that is the purpose. Just that. And that way we don't have a bunch of, you know, people who really have no clue what they are doing in these positions. Like our teachers, our doctors, uh, cause it is so strenuous that only people who really want it will do it, and will be the ones that are good at it. So it benefits us all that college does that. And that's the purpose.

$\mathrm{R}$ : To make you prove that you have got what it takes.

P: Make you prove it. Make you really dig down and do what you can. It's the only time when you are going to try $100 \%$ to do everything you can. High school you can BS your way through it. In college you can to a certain extent but once it gets up there, you gotta' do it. (10/17/01)

Patrick's first reaction, that the role of college was to weed out the weak, showed the antagonistic attitude he had towards college, and the oppositional stance he held, much like Willis' (1977) "lads." The lads strongly resisted becoming active members of their school, and held deep resentment towards their peers who embraced the school culture. Patrick seemed to perceive college faculty and administrators as "gate keepers" whose job was to make him prove he was worthy of being there. In conversations I had with the students about their attitudes towards their faculty members, it was clear that at best the boys saw their faculty as indifferent, but most saw them as overtly hostile. Patrick also held the attitude that it was up to the individual to make it. College's role was to make it 
hard for him, not to help him make it through. So when Patrick was frustrated during the semester by various aspects of college life, both in the classroom and outside of it, he reminded himself that the college was trying to make him prove himself. He would tell himself that he was not going to let "them" weed him out. College was linked to work for Patrick, but only in the indirect manner that college served as a filtering system, ensuring that if he did get through, society could have some sense of confidence that he was good at what he was trained for. Because the process of obtaining your degree was rigorous, a sort of "boot camp" for whatever profession he entered, he would be sufficiently ready for his occupation.

In our third interview, I asked Patrick if he thought he was being weeded out from the college. His reaction, "Sometimes I feel like I am being weeded out and sometimes, sometimes I think it is a test of my resolve" $(10 / 31 / 01)$, showed both his feelings that faculty were working against him, and his feelings that he was being tested and made to prove himself.

Like TJ, Bryant also tied his response directly to work. The responses from TJ and Bryant might be indicative of the fact that they were both in business-related majors. Business and marketing, their intended majors, were practical in nature. Patrick's choice of a major, justice administration was similarly practical, and his intended career path was also practical. However, corporate involvement in education is aimed at preparing educated students to be effective workers, and this was reflected in Bryant's response:

The main purpose of college is to study, and do good, and get more developed as far as knowledge, to go into the business world. To start working. After this, you work for the rest of your life until you retire and you are too old to do stuff that you would have done when you are younger. I would like to make lots of money. My dad has done it and I would sort of like to top him, somehow. $(9 / 27 / 01)$ 
Bryant was very specific that the purpose of college was for him to gain knowledge that he could use in the business world. This outlook became difficult for Bryant as he was "forced" to take classes in the humanities that did not directly connect to the world of business. Bryant had a singular focus on learning business and marketing. This reflected closed-mindedness on Bryant's part. This close-mindedness became an issue in Bryant's English class when his peers disagreed with some of Bryant's thoughts and opinions, and in Bryant's campus culture class, which he came to regard as "useless."

The issue of social class was present in the respective responses of these students. In contrast to TJ and Bryant's response was Joe's response. Joe, who stated his desire to become a "well rounded" person, and aspired to work his way into management, welcomed the idea of taking courses in the humanities:

The purpose of college? Expand minds. Prepare people for the work force. Make them better at their job. I guess on a bigger level to make the country better, smarter people, and I think it really helps with the transition from adolescence to adulthood. From high school to living on your own, working, paying rent, you know, teaching you to be responsible and the consequences of slacking off or not getting your work done. $(10 / 16 / 01)$

Joe's answer to the question was more nuanced than the other's responses, yet it still included the idea that college was responsible for preparing people for the world of work. It also indicated that Joe saw the role of college faculty and administrators as parental since they will be the ones to "teach you" to be responsible. Joe seemed to see college as responsible for developing the whole person. Yes, college was preparing him for his career, but it was also guiding his intellectual development and personal development through the teaching of responsibility. In our very first interview, Joe and I discussed why he selected business as a major and in his response he talked about his aspirations of being a CEO: 
My first job was at a local department store. I was real close to my manager and all of the employees. I just wanted to be the top dog and make the choices and run the company. There is nothing like running a company and making a profit. And I just really admired my manager. At UPS they say that you can also make a lot of money if you move up the chain there and they love to hire from within... There wasn't any other major that I was interested in, and even if there was I don't know what I could do with a degree in that. So with this business degree, I could get a good job and I know what I can do and where I can go and make the money to go with it. Plus I just love working with people, meeting new people, working for a company. $(9 / 21 / 01)$

Joe's response to the purpose of college indicated that college had a responsibility for citizenship development. Yet when he talked about his choice of a major, he focused on wanting to become the head of a company or a store. He wanted to work his way up the corporate chain in order to be the "big dog" and to have control over the company decisions. He also wanted to make a good income.

Joe's feeling that college was also for self-development was one reason Joe was attempting to join a fraternity as well. By comparison to Joe's desire to become a wellrounded person, Patrick's family saw education as a way to learn a trade. When Patrick talked with his grandparents about going to college, their reaction was, "Why don't you learn a trade?" After all, his grandparents indicated, wasn't that the point of obtaining an education? And the state motto, "Education Pays" reflected the attitude that the purpose of education was utilitarian, to earn more money. The notion of going to college to "become a better person" is hard to state in a catchy, pop ad for education. And it does not resonate in the homes of first generation, working class students. When the students in this study had conversations with their parents about college during the breaks, they indicated that the parents wanted to know two things: what were their test scores; and what were they planning to do when they graduated. They rarely reported any in-depth discussions about what they were studying in sociology, or what they were reading and 
discussing in English. Growing up in a working class, first gen household, these boys were oriented towards the idea that the purpose of college was to prepare them for work. And their high schools, with the possible exception of Joe, reinforced this. Further, the state itself was telling them that the main purpose of education was to earn more money. Not to better society by becoming a well-rounded person and contribute to the common good. No, it was about bettering yourself as a person and getting a bigger paycheck. Any alternate thoughts these boys had about the purpose of education were not reinforced.

Motivation for College

There was commonality among these students' reasons for wanting to attend college as well. They expressed feelings that college was a dream for them, and that they were fulfilling a family destiny. Several of them spoke of the pride they felt at being the first in their family to attend college. However, along with pride they also felt pressure to succeed because of their first gen status:

I feel like I could make a life for myself if I stay in college. And plus I am the first one that tried to go to college. Cause I have two younger brothers and see, none of my other family has even gone to be able to drop out. But if they hear that one of us tried and then dropped it would look worse that we couldn't take it. And I would be worried that they wouldn't want to go cause I didn't go. $(11 / 12 / 01)$

TJ may have had the dream of getting a college degree, but he did not say he enjoyed the experience. In this quote he seemed to be saying that he felt obligated to attend college. It sounded like at this point in the semester he did not necessarily want to keep going, but he felt like he had to. An additional motivating factor for attending college stemmed from these boys desire to avoid something, be it the lifestyle that their parents had, or the type of job they knew they would have without a college degree. 
TJ talked in our first interview about his motivation for college as being purely

utilitarian. He wanted to get a good job:

I began thinking about college in eighth grade. Middle school. My mom and dad started talking about it. And I wasn't really for sure since it seemed like just more school. So then later on in high school I realized that I wanted to do something with business, and I knew there was no way I could do it without a degree. So I went to college mainly so I could get a good job. (9/17/01)

TJ saw no difference between high school and college, as he showed in his statement that college "seemed like just more school." But because college would ultimately lead to a good job, whereas graduating from high school would not, he decided to go. TJ aspired to more than just "a job," he aspired to a "good job," and his expectation was that college would lead to the fulfillment of his dream of obtaining a good job. By the end of the semester TJ had talked to the UPS administrators to ask if it would be possible for him to work there even if it took him six years to graduate from college because he saw that the dream of a college degree was not going to be easy for him to attain. As early as the first semester TJ could tell that his motivation for college was not enough to overcome the obstacles he had in order to graduate in four years as he had originally planned.

When Patrick described his motivation for attending college, he almost sounded like he was fulfilling a family destiny. But it was clear that his parents had some pre-set ideas for how Patrick should attend college, because when Patrick and his brother chose their schools, their parents, according to Patrick, were not supportive of their choices:

My grandparents believed you should just go and learn a trade and do that, you know, not foreseeing any you know, changes. But Mom and Dad, said, "We have made a lot of mistakes and we want you to learn." They always said that each generation builds on the generation before it. You know, each generation makes it better for the next. And they said, "That is why you have to go to college. Our generation learned the importance of education. Now you are the ones that are going to reap the benefits of it." I said, "OK." But when my brother John moved off to go to college, there was quite a bit of tension in the house, with John 
wanting to strike out on his own and mom and dad not understanding. And when I decided to go to college, I wanted to blaze my own trail so I went to a different college than John. Mom and dad didn't understand. It was real hard. (10/03/01)

The impression Patrick gave is that he wanted to attend college partly to satisfy his parent's wishes. His parents saw him and his brother as fulfilling the next part of the journey. But then, when Patrick's brother went to college, Patrick's parents began to send mixed messages about his attendance at college. When Patrick decided to enroll in college as well, Patrick's parents questioned Patrick's choice of a college, causing Patrick to question whether college was indeed what his parents wanted after all. And since Patrick was attending college partly to fulfill the family destiny, Patrick began to wonder if it was what he wanted. Patrick's quotation does not let us know how he thinks this tension might be perceived by his parents, but it could have been that Patrick's parents expected both he and his brother to attend college closer to home and were hurt when they chose colleges that were over three hours away. Patrick's father could not travel to see his sons because of his illness. And because his sons were going to college several hours away from home, there would be infrequent visits home by both sons. It could also have been that Patrick's parents were comfortable with the idea of college but the actual concept of what college meant was not acceptable because of the changes that would occur within the family as a result. What does seem clear in Patrick's choice to "blaze his own trail" is that he heard his parents express a desire that he attend college, and he acted on what he heard. Throughout the semester, though, their actions would conflict with their initial words of encouragement.

Bryant's comments about attending college showed that he was motivated to go to college largely because of his dream of obtaining a white-collar job with an office of his 
own. Bryant also talked about wanting to avoid doing the kind of work he would be relegated to if he did not have a college degree. This quote, then, from our first interview showed the interplay between chasing the dream, and avoiding the nightmare:

If I didn't go to college? The worse-case scenario I guess is that I would be homeless and out on the streets. And my parents would not support me if I wasn't going to college. But it was pretty much decided that I was going. But I probably would have gotten a one-way ticket to Alabama if I did not go, and I know my uncle and my grandparents, they would have helped me out. My uncle does that with a lot of boys down there in Alabama. He gives them a second chance. So I guess that would be my first chance and I guess I would work construction for him and live with him. Of course, I really don't want to do that. I like working at my desk, and working on computers and having my own phone line and internet access. I will go to college. (9/13/01)

When Bryant said that, "It was pretty much decided that I was going," it was unclear as to who made this ultimate decision. But he indicated that his parents would not support him if he were not going, so he knew precisely where they stood in regards to whether or not he should attend college.

Joe also was chasing a dream when he expressed the desire to acquire the knowledge that would make him a well-rounded person. However, Joe also expressed a desire to "avoid" his parent's lifestyle, having seen the limitations of only having a high school diploma:

R: What do you think influenced you to go to college, if your parents didn't talk about it that much?

$\mathrm{J}$ : Seeing their lifestyle. My mother comes home from work and she is dead tired. And she is stressed. And she doesn't get the money to make up for it. Her lifestyle is what made me decide to go...I believe that money does buy happiness to some extent and that it does make the world go 'round. My mother and father, not going to college, growing up with a high school diploma I could see where they had been, the occupations they have, and it is not fun. I want to have that knowledge. You can just tell when someone is on a different level of education. When they are college graduates, especially with a liberal arts education, they are pretty well rounded. So, I just want to have that solid grounding so people admire me, look up to me. $(9 / 13 / 01)$ 
Joe expressed two very different goals for himself within the same conversation. He wants to avoid the lifestyle that his parents have, and to gain knowledge that would make people look up to him. He also expressed a combination of both extrinsic and intrinsic motivators in this statement. The extrinsic motivators included money and his desire to make money, while intrinsically, Joe desired, "just to have that knowledge." This intrinsic desire, to have that knowledge, if pursued, may make Joe feel part of the college culture, but it may also put him at odds with his family. London (1996) said first gen students who become part of the college community and immerse themselves into the learning community, often have serious conflicts with their families who feel that the students are pulling away from them. This was a conflict that Joe faced throughout the semester.

All four of the boys in this study reported that their parents verbally expressed their desire to have their sons attend college. Unfortunately, this desire, while expressed verbally, did not result in any tangible work on the part of the parents to help the students enroll in college. Parental involvement in the preparation for college is the next theme for this section.

Parental Involvement in Preparing for College

In this study I found that the students received a great deal of verbal encouragement to attend college initially from their parents. Piorkowski (1983) found that first gens who attempted to improve themselves through education often feit that while their family supported their attempts to apply for college, this support disappeared once they enrolled in college. The initial encouragement that the first gens in this study received was not backed up with any tangible efforts on their parent's part to help them 
actually enroll in college. This seems consistent with Horn and Nunez's (2000) findings that first gens receive little assistance from their parents about applying for college and also receive no additional help from their school to make up for this.

TJ's recollection of how his parents helped him prepare for college was an example of how these boys received verbal support and encouragement for college, but no tangible help in preparing for college:

Really my parents did not do a lot to prepare me for college. They more or less just tried to get me to go because I had no idea of what it would be like. I mean they gave me money support but nothing really school-wise. Just more or less provide me with money. $(9 / 17 / 01)$

Since TJ's mother was no longer living at home, if he felt that he could not talk to his father he had no one else in the household to turn to. This added another hurdle TJ needed to overcome in his quest for a college degree. Specific to TJ, and to the issue of gender, Horn and Nunez (2000) found that as the level of parental education raised so did the percentage of students who reported having frequent conversations with their fathers. $\mathrm{TJ}$ and his father were both in positions outside the norm with nowhere to turn for help.

Both Patrick and Joe had an older sibling in college. Theoretically, their brothers could have helped them with the college application process. However it did not appear that either of the older siblings helped with preparing these participants for college.

Patrick and Joe relied almost exclusively upon their high school faculty and guidance counselors because they felt their family could not help. Patrick expressed it this way:

Going to college really didn't hit me until my junior year, near the end, and mom and dad were like, "Why haven't you filled out these college applications?" And I was like, "Do I have to do that now?" And they kind of said, "This is the first time it has ever been laid down to you like this." It was my first shot of reality. Kind of, you know, "What is that?" And they said, "Look, we cannot put you through college. The only person who can put you through college is you. We can't help you. We don't know how to help." (10/03/01) 
Patrick's parents did not hide their inabilities in this area, at least that was Patrick's perception. Patrick saw it as his job and his alone to successfully complete the college admissions process.

Likewise, Bryant's decision on where to attend college was primarily his to make. He reported in our first interview that his parents had encouraged him to attend college, but they left the decision entirely up to him:

R: At what stage did your parents start talking to you about going to college?

B: Really, I guess in high school. I was never a very good student. I wasn't a bad student, but I guess I was lazy. I did the work in classes I liked. My parents were telling me the whole time, "You are going to have to get ready because college is coming up." But I was, "Yeah, well..." Anyway, my freshmen year they said, "You are going to college." And then my junior and senior year they said, "You need to think about where you want to go. We got the money to send you where you want to go." If I had the grades I could have gone somewhere else. I mean this college is a great school, but I could have gone to another school if I had applied myself. But they are proud of me.

$\mathrm{R}$ : So your parents were telling you that you could have gone anywhere to college?

B: They said just make sure that it is what God wants you to do. Just talk to us and we will pay for wherever you should go. $(9 / 13 / 01)$

Bryant's experience supported the findings of Choy (2001), and Horn and Nunez (2000) that first gens receive limited assistance from their parents in applying for college. Verbal support for college attendance was present for Bryant, and his parents did offer financial support for college. However, choosing which college to attend, and applying for admission, two major life decisions, were left entirely up to Bryant. Both Patrick and Bryant "dragged their feet" when it came to filling out the college admissions applications. While this may not be uncommon for many college seniors, these parents have little recourse other then verbally telling their sons "it's time." If their sons 
continued to procrastinate, they had no personal experience to draw upon for help, unlike second gen parents.

Finally, Joe's mother was relatively uninvolved in his decision about attending college, although she expressed a strong desire that he stay locally so he could live at home. Like the other parents in the study, Joe's mother did not attend college and did not appear to know how to prepare Joe for going to college. However, Joe's circumstances were slightly different in that Joe was attending a private Catholic high school, which emphasized college preparation. In Joe's perceptions, his mother selected this school, at least in part, for this very reason. In describing his mom's attitude towards his high school, Joe said, "My mom was a big fan of my high school. She knew they would prepare us for college." $(10 / 16 / 01)$

\section{$\underline{\text { Religion }}$}

One sub-theme within the issue of parental preparation for college was the role that religion played in these student's lives, and what role the parents wanted religion to play, as the students prepared for and attended college. The college was located in the "Bible belt," so it was not surprising that religion would be a part of their lives, and that religion would be a theme. All four of the participants said that they were Christian. Two of the participants talked about religion as part of the preparation process, and the other two, I specifically asked how important religion was to them. For TJ and Joe religion served more as a backdrop. While $\mathrm{TJ}$ was raised Baptist and attended church when he was young he was not actively involved in church during the study:

I am a non-denominational Christian, and I haven't been to church since my mom moved out. I don't go to church as much as I should. I am just a Christian, not a Baptist or anything. My dad was not involved in the church when I was young, but my mom was. And I went with her and I liked going to church. And my 
mom and my dad were Baptists. Actually where I lived was a small community and the majority of the people there were Baptists, but I didn't go just cause my mom went. I went by myself, but I guess I just got away from it. (11/26/01)

TJ emphasized that he didn't go to church just because his mother went. He went by himself, too. But he also stated that he stopped going to church after his mother moved out of the house. His father did not demonstrate support for TJ's participation in the church and eventually his religious involvement diminished. Still, TJ claims Christianity as part of his identity.

Joe was raised Catholic but, like TJ, he also stated that he was not currently practicing his religion:

My mother and her mother are very church going, and very faithful. And, I believe in God, you know? I believe he is looking over on me at all times, and that angels are by my side making the world go round. But I hardly ever' go to church. I do not follow the bible, as in to do and not to do. The main thing to me that I think God wants from us is to love and be kind to each other, which I do. I am known for being very friendly and nice and considerate and not selfish. That is what I strive to be. That is what I think God wants from me. Yet when it comes to alcohol and premarital sex, I know not to do it, but I still do it. I don't go to church but I pray a lot. And that is about as far as it goes. $(10 / 16 / 01)$

Joe seemed conflicted about his religion. He knew that his religion said that he should not partake in alcohol consumption or pre-marital sex, yet he still did. Joe consoled himself with the idea that he was acting on the higher principles of love and kindness, which is ultimately what he thought God wanted from him. But Joe's mother did not put pressure on Joe to participate in church while he was in college. Joe's mother trusted her son's judgment, unlike Patrick's parents, who told him:

When you get up there, you get involved in that BSU, that Baptist Student Union. 'Cause we get letters from them, and we think that would straighten your brother out. And it would straighten you out if you get off of the beaten path. $(10 / 17 / 01)$ 
Patrick's parents encouraged him to remain active in church activities while at college, but he was not receptive to their encouragement. Patrick's parents thought that if Patrick and his brother participated in the BSU, they would be more likely to turn out OK. The BSU could act "in loco parentis," they believed. They saw the BSU as a support system for Patrick while they were not there. Patrick's parents also saw Patrick's brother as already "off the beaten path," and they were concerned that Patrick would follow the same pattern. Rather than rely on his brother for support, though, Patrick's parents were now putting the burden of acting appropriately on Patrick. With the BSU there to oversee Patrick, his parents could feel better about Patrick being away at college. They were preparing Patrick for college by encouraging him to use the BSU as a means of social capital while he was in college.

Religion was important to Bryant and his family, to the degree that Bryant's parents were willing to put the decision of where to attend college, not only in Bryant's hands, but also in God's hands. "Just make sure that it is what God wants you to do," they said. Bryant relied heavily on his church for both preparation and support. He attended church services almost every week, and went on a church retreat for adults every fall. His aunt, who attended the same church as Bryant, got him involved in the single, young adult group in his church and he regularly participated in their activities. In our fifth interview Bryant and I discussed his living on campus, and Bryant talked about how he believed living on campus would be problematic due to his Christian beliefs:

If I had to live on campus, I don't know. I don't see how much it would change things. And I probably would get paired up with someone that I don't like, or who is a complete opposite. I am pretty Christian, and a strong conservative, and I have my feelings about certain topics, and you can't change me at all. (11/14/01) 
For Bryant and Patrick, religion was much more than just a backdrop. It was an important part of their family life. For Bryant it was a source of preparation and support, but it also limited him to certain activities. Bryant's parents either could not or would not intervene, either, to change his mind or to persuade him to be more open to new experiences. Patrick and Bryant's parents used religion to prepare them for college, and were also hopeful that religion would be a source of support for them as well.

High School Involvement in the College Preparation Process

The two students who reported that they received significant assistance from their high school in preparing to attend college were Patrick and Joe. Patrick's high school counselor found him the money to attend college, and also guided him towards the college he initially attended before transferring:

I had a guidance counselor who was really good about financial aid. She really liked me a whole lot. She had attended that college, too, and she was the one who came up to me and said, "If I can get you a scholarship, would you go to my alma mater?" She knew that I had applied to another college but I was $\$ 2000$ short, which meant loans. And I had already taken out one big loan so I was like, hmmm. You know? So, she said, "If I get your college paid for, will you go to my alma mater? Will you take a look?" And so I did. That is kind of what I did every day, go in and ask her, "What about this, can I do this, how about this?" And we formulated how we'd get college paid for in the least amount of damage. And at the time her alma mater college was my only option, if I wanted to not lose my thumbs later in life. $(10 / 03 / 01)$

Horn and Nunez (2000) reported that first gens received little assistance from their parents about applying for college and received no additional help from their school to make up for it, but in this case Patrick appeared to have gotten a great deal of assistance from his high school guidance counselor. Of course one could speculate about how much assistance Patrick would have received from his counselor had Patrick chosen to attend a school that was not his counselor's alma mater. Fear of going into debt was 
embedded in Patrick's comments, and this fear was also voiced by several of the other students in this study. Patrick was very concerned about the amount of debt he would incur as a result of attending college, and he became more and more interested in joining the AFROTC program, largely because they would pay for his schooling.

As mentioned, Joe's parents did little to prepare him for college. But, unlike the others his high school appeared to have done a great deal to prepare him for college. In our first interview Joe described his high school like this:

I went to a small, private Catholic high school in town. So you knew all of the teachers on a first-name basis. And we also had a guidance counselor who had assemblies and workshops. They asked us where we wanted to go, and what we wanted to do and why we wanted to do it. They were pretty serious about us going to college. $(9 / 21 / 01)$

The help that Joe received from his high school in preparation for college was similar to what McDonough (1997) found in her study among high school seniors. Students from more prestigious, private high schools interacted more with school counselors than did students from less prestigious, public high schools, McDonough found. Joe stated that his guidance counselor organized assemblies and workshops for the students at the school, while the other participants in this study never mentioned that these occurred in their schools. The support offered by Joe's high school was also backed up with strong peer pressure to attend college:

$\mathrm{J}$ : A lot of people in my high school never thought about going out into the work force or into the military. Everybody was college bound for some reason. I guess in junior high school is when I began to think about attending college.

$\mathrm{R}$ : Did your parents talk to you much about going to school?

J: Not much. They knew that I wanted to go. They knew how my school talked to us about going to college, and how they talked to us about the future and so forth. So, I think my mom knew that I was headed that way. Of course she never doubted me, so it was a known fact.

$\mathrm{R}$ : Did you ever really talk about it, though?

J: About just going? No, it was never brought up. 
R: So, how did your parents know, and how did you know, that you were going to college?

$\mathrm{J}$ : They knew what went on in my schools. And they knew that with technology getting more advanced, that jobs were demanding college educations. And they knew that I wanted the money, and wanted to be prestigious and successful in my future as well. But they never heard me talk about going, or not talk about going. I think my mom had enough faith in me, and she knew I had enough brains to make something of my life and go to college and get that good job and the family and kids, and white picket fence, and so forth.

$\mathrm{R}$ : It sounds like they more or less left it up to you and to the high school to figure out.

J: Yeah.

R: Do you think if you were at a different high school things would have been different? 'Cause it sounds like almost everybody at your high school went to college.

J: I believe she would have followed-up on what was going on in school, "And are they talking to you about college?" But I went to a local Catholic grade school and a lot of guys from my grade school also went to my high school, and my mom knew their mom, from parish church, and she knew what went on in our high school. She had a sense of what went on before I even went there.

$\mathrm{R}$ : So by talking to other parents she knew what would go on in your high school? J: Right. (10/16/01)

Joe's mother showed a great deal of faith in the high school to get her son prepared for college. However, Joe believed his mother would also have "made it happen," if he had attended a different high school. His mother took advantage of the social capital she had available to her through the Catholic-church-school network to make sure that Joe would get prepared for college. Joe was also the recipient of this social capital, as well as cultural capital, when an anonymous benefactor paid his full tuition to this catholic high school, making his education possible.

Joe's mother seemed to feel that Joe had a great deal of intrinsic motivation to attend college. This can be seen in Joe's statements that his mom "knew that I wanted the money" and "knew I had enough brains to make something of my life." Joe showed a combination of extrinsic and intrinsic motivation when he talked about his desire to attend college, and his mother felt that he had enough motivation for college. The 
previous excerpt from Joe was fairly complex. Joe had not really analyzed his situation and although I thought he was giving credit to his high school for preparing him for college, he seemed to want to give his mother equal credit. At one point he stated that his mom "never doubted me," although by his own admission there were never any memorable conversations about college. His mother chose his high school because of the social and cultural capital that was available to her, and because of her perception of how to achieve her son's dream of college. Although several times I appeared to be encouraging him to give his high school credit during the conversation, Joe said, "Yeah, but..." and still wanted to credit his mother for her insights. This shows how difficult it was to separate out family attempts at preparing students for college, from the school's attempts.

Joe did not appear to receive any "special" treatment from his guidance counselor in getting ready for college. According to him, everyone at his high school received help with his or her college applications and financial aid. Patrick, on the other hand, appeared to have received special attention, which he may not have received had he opted not to attend his counselor's alma mater. And neither TJ nor Bryant reported that they received any help from their high school counselors.

High School Activities

Lack of involvement in high school can set a pattern that is difficult to break when college begins. Without the experience of being involved in high school it is difficult to take the risk of joining a club or an organization of strangers without repeated encouragement or being forced to do so. Yet Tinto (1987) says that this involvement is a key ingredient for both student retention and student satisfaction. 
Horn and Nunez (2000) found that first gens consistently trailed their second gen peers in participating in curricular activities linked to college enrollment. In discussions with the students in this study, I found that they had fairly low levels of high school involvement overall. Terenzini, Springer, Yaeger, Pascarella and Nora (1996) found that first gens tended to be less involved with peers and teachers in high school, and this seemed to be true for the students in this study as well. This was TJ's response to the question of how active he was in high school:

TJ: In high school I went to FCA (Fellowship of Christian Athletes) and I was in the band in school.

R: But you don't do either of those here?

TJ: I don't do either of those here. I probably will wait until the first semester is over before I get involved.

$\mathrm{R}$ : And did you play sports in high school?

TJ: I didn't play for the school, I played in some town recreational leagues a little, soccer and baseball and some basketball. (9/17/01)

TJ's response showed that he was involved to some extent in high school, although his athletic involvement showed more of a community orientation than a school orientation. He expressed some desire to get involved in college activities but was holding off getting involved until he saw how well the first semester went. TJ did not want to commit himself to any activity that would detract from work or his studies, or his going home on weekends to visit his girlfriend. He was not oriented towards the campus other than for his classes.

Patrick received considerable attention from his high school counselor in applying for college, but his high school involvement was virtually non-existant. Here he talked about how different he and his sister were in terms of their high school experience, and how he was confused about her ambition: 
P: My sister is very ambitious. And have I talked to her and told her a million times, "Don't do what I did in high school." And she is not. She is making good grades and she is in the top ten percent of her class. She is following in her older brother's footsteps, not in mine. I told her that it will be nine times easier on her to bust her ass now, get the money, and don't worry about it. I am going to be paying back this shit for the rest of my life. High school is when you get to earn your money, so do it now and then relax later so you don't have to worry about it. And I think she took that to heart, at least I hope she did.

R: She still has a couple of years in high school to go.

P: Yeah, and we will see about senior year. 'Cause senioritis sets in and you don't want to do nothing. Hell, I didn't do anything my senior year, but then I never really did anyway. My sister is a lot more ambitious and driven than Joe and I. It is like she has chip on her shoulder, and I really can't explain it. It's weird. It's like she has to succeed just to spite me and Joe. That's great if that's what it takes. By all means use me as a tool to succeed but I just want to know why that is? I guess I will figure it out one day. $(11 / 28 / 01)$

It is unclear exactly what Patrick was referring to when he told his sister not to be like him, but he expressed regret for not doing better in high school, and for having to take out school loans. Much of his regret seemed to be around not doing well in high school so that he was eligible for the merit awards that the state gave to students as a reward for doing well, academically, in high school. This again reflected Patrick's utilitarian viewpoint of education. The goal of getting good grades was not necessarily to get into a good school, it was to get money and avoid loans. And when Patrick said, "Hell, I didn't do anything, but then I never really did anyway," he was referring to his lack of involvement in high school, a pattern which carried over into college for him.

Bryant's response during our second interview showed that he was initially fairly involved in high school activities, but became less involved after his freshmen year when he, "Just went to school." Bryant's comments at the end of this quote also indicated that while he met his friends at school, their activities occurred away from school:

R: Last time when we talked it sounded like you weren't all that involved in high school activities. Is that accurate? 
B: Nah. Freshmen year I played freshmen golf, and freshmen baseball. Baseball sucked horribly. The coaches were jerks and we lost every one of our games, and it just wasn't a good situation at all. I didn't care for the players on our team too much, so after that I just went to school. I did meet Eric, who is probably my best friend now, during high school. We had a class my freshmen year, and we had at least one class every year, or two, and we just sort of hit it off. I guess that was the one time that I did just go out and meet someone and we just hit it off. We really didn't do too much together, though. Like in my junior year we went to the movies one time together but it wasn't until my senior year that we started going to each other's house and hanging out. $(9 / 27 / 01)$

Bryant seemed to be blaming his coaches and his fellow players for his lack of involvement in high school athletics, but this did not explain his lack of involvement in non-athletic activities. Bryant tried athletics, it didn't work out, so after that he "just went to school," as if school was only classes. Bryant admitted that he was not always open to new things so once he tried something and was unsuccessful at it he generally closed his mind towards trying it again. This is the same way that Bryant approached his college experience. College, to Bryant, was "just school," and college activities were not a consideration for him. During this same interview Bryant talked about how he was more inclined to be involved with people who were older than he was, and how he was involved in his church as well:

This sounds really weird, but other than Eric most of my friends are older than 21 . Like I went camping with a bunch of guys this past weekend and everyone was between ages of 22 and 28 or something like that. I have always seemed to connect with grown-ups better, even as a little kid. I don't think it is because I am mature. I am far from that and they probably tolerate me sometimes more than they are my friends, but I still have always seemed to connect with older people in general and I don't do very well meeting people my own age, unless I am specifically introduced to them by friends. Like my aunt, who is one of my friends? She is one of the people I hang out with, and she introduced me to the single young adult group in my church. They are older than me. They range in age from 22 to 30 something, and I hang around with them. (9/27/01)

Being very involved in his church, and feeling more comfortable with older adults has developed a community orientation in Bryant, which meant that he was not overly 
motivated to become involved on the college campus. And his aversion to meeting new people in general played a factor in his meeting new people at college specifically.

Bryant was very reluctant to take a risk and meet new people at college. This extended to his relationships with his faculty as well. While Bryant felt that he had established relationships with his teachers in high school, he was unable to do this in college.

Of the four participants, Joe appeared to be the most involved in his high school, but he acknowledged that his involvement occurred towards the end of high school. Of all the participants Joe was also the one who expressed the greatest interest in getting involved in college:

From my high school I learned a valuable lesson, what you put into it is what you get out of it. I missed out on a lot in high school. I didn't get involved until late in my latter years, and I saw how much fun it was, so I am mad at myself and I want to make the most of my college experience. $(9 / 21 / 01)$

Joe was determined to become involved in campus activities at college. He recognized the importance of being involved and saw it as an integral part of his college experience. This is one reason why Joe chose to join a fraternity. He knew that the fraternity would quickly and successfully provide him with a link to the campus. However, no one prepared Joe for the fact that he could not "do it all," as he attempted to do once he started college. Inevitably, Joe was thwarted in his attempts to get involved on campus, largely due to his work commitments.

High school activity was placed in the section on preparation because part of going to college is becoming involved in the college community through social activities. Just as these students prepared for college by selecting their classes and majors, so too were they encouraged to join clubs and organizations during their high school assemblies prior to their enrollment, and at summer college orientation after their enrollment. 
However, lacking anything more than verbal encouragement to get involved, lacking much experience in high school at being involved, and lacking the time to get involved due to work and off-campus commitments, these students were unable to get as involved as they might have liked. The issue of these students' college involvement in clubs and organizations is explored in more detail under the section on belonging.

Academic Preparation

The first gens in the study conducted by Pratt and Skaggs (1989) reported more doubt than did their peers that they were adequately prepared for college. Similarly the participants in my study also seemed to question whether they were prepared for "the big leagues," as Patrick referred to college. In answering the question of how academically prepared these boys felt for college, I focused on the amount of math these students took in high school. Horn and Nunez (2000) found that only 14 percent of first gens took algebra, considered to be a "gateway" to completing advanced math courses, at the eighth grade level, compared to 34 percent of second gens. They also found that in high school, first gens were far less likely to complete any advanced-level math courses. The first gens in my study took algebra later in high school, and did not appear to take advanced high school math classes either. Perhaps due to this, TJ, Patrick and Bryant were all required to take remedial math.

The following excerpt with $\mathrm{TJ}$ is from our second interview where $\mathrm{TJ}$ talked about his high school math courses:

TJ: The college messed up my math scores on the placement test. And the English placement test really surprised me, cause I always do worse in English. So, English was the only real class that I got. It is the only one that actually counts for credit towards graduation. But I also have courses for reading and one for math but they don't count towards graduation.

$\mathbf{R}$ : And in high school what math classes did you take? 
TJ: In high school I had algebra II. In my school, measurements and geometry were separate classes. So, I didn't take pre-algebra in high school, I took algebra I, and I took the measurements class, and then geometry and then algebra II.

R: So you ended up taking 4 math classes?

TJ: Yeah. $(10 / 01 / 01)$

TJ expressed surprise about how well he did on the English placement test because he saw himself as weak in this subject area. And when he talked about how "they" messed up his test scores, it showed how he had already divided the campus into oppositional campus, "them" and "us." Because TJ only had one course out of four that actually would count towards his graduation, his progress towards graduation had already been affected, and he lacked the social capital to find someone who could help him deal with the issue. His father was unable to tell him whom to talk with about it. TJ also lacked peers who were at college who might have helped him. TJ talked about the remedial courses as not being "real" because they did not count towards graduation. If TJ had taken algebra earlier in school, it was possible that he could have gone as high as at least pre-calculus in high school. By doing so he would have most likely avoided taking the remedial math, and would not be as far behind in his graduation requirements.

Patrick only went as far as algebra in high school and was also required to take remedial math in college as a result:

I took algebra II twice in high school and failed it miserably the first time. After that there is a class, but there was no way I could do that class. My math skills are very bad and I went and took this advanced topics class, which is kind of a slower version of algebra II, which would give me some new problems and that is about it. At my previous college I took math 091, I believe. It is the lowest level, the introductory algebra. I said, "Well, I need a math credit and they said this would count and I am taking. it." And I passed it with a 98. (10/03/01)

Patrick considered his math skills to be very weak and so he avoided taking advanced math in high school. Now that he was in college he was avoiding math as well. Had he 
taken math earlier in his high school, he might have overcome this weakness and built up more confidence in his ability. Since Patrick obtained a 98 on the remedial math, he was clearly capable of doing higher-level math work.

Math and English placement tests are an example of how college campuses begin to stratify students from early on. Students who are accepted into honors programs on campus are not required to take these placement tests, and thus do not even run the risk of being placed into these remedial courses. But the students in this study did not have the option of avoiding the placement test. As a result of their scores on the placement tests TJ, Patrick and Bryant were all placed in at least one remedial class, which meant that they were already behind their peers in terms of credits earned towards graduation, because the remedial credits did not count towards graduation.

Like TJ and Patrick, Bryant also was required to take remedial math in college. Algebra II was the highest-level math Bryant completed in high school. In this excerpt Bryant talked about the math he took in high school. In it he showed that he was conflicted about his potential for math, and when the college contacted him about a mistake they made, he assumed he would need to take a lower lever math.

B: I got to algebra II my junior year and, technically, I didn't have to take math my senior year so I took a finite class instead. And I sucked horribly in that. I didn't do good at all. So, that was difficult. I should have taken something else. $\mathrm{R}$ : Did you have to take a math placement test here for orientation?

B: Yeah. And originally they told me I had to take like 070 , but then two weeks before school started they told me, "We made a mistake in grading your placement test." And I was thinking, "Great, I did worse!" But they said, "We see that you would be capable of doing 080 ." And I am. I just need to study more instead of watching TV. (9/21/01)

Like Patrick, Bryant avoided taking an advanced math class his senior year. While Bryant felt that his while his math skills were questionable, his statement that he could do 
the math if he "watched less TV," also indicated that he felt his success was all up to him. It is not about the level of preparation he received from his school, or the quality of his education, or his parent's ability/inability to help him. It was about him watching less television.

In my second interview with Joe, it appeared that while he initially felt academically prepared for college, having never received a $\mathrm{C}$ in his life prior to college, he did have some social concerns about college:

I was concerned about going right from adolescence straight to adulthood and not having my mother around. I had more social concerns than academic concerns. I was concerned about my priorities and responsibilities and finances. That is the big thing, finances. I just thought it would be too overwhelming my first year, being away from my mother and taking on all this. And with the academics, too, I am having a hard time here. And, if I went away, you know, things wouldn't be so good. (10/16/01)

In some respects Joe was the "counter-example" to the others in this study. He went to a private, Catholic high school, which appeared to do a good job preparing him for college academically. As a result, Joe did not need to take any remedial math or English classes. Joe was more concerned that he would not do well socially on campus, and he acknowledged in this interview, which occurred about half way through the semester, that he was having difficulty at college. And he felt that if had gone away to college, and did not have the support of his mother nearby, he would be doing even worse. Joe represented those first gens London (1996) discussed who saw college as an endless source of opportunities and who attempted to enjoy the college experience to the fullest. However, London admits that even these first gens, who are excited about college often experience emotional and academic set-backs. This was true for Joe was well as he encountered obstacles during the semester that kept him from achieving the 
kinds of grades he desired. Although Joe began the semester confidant that he was academically prepared for college, by the end of the semester he had earned several C's. Feelings For and Perceptions About College

The parents of the first gen students in this study, having never attended college, were unable to do anything to assuage their son's worries about college or to reassure them based on their own experiences at college. And the students were nervous about what college would be like for them. Some felt that it would just be more school, while others felt that it would be like "Animal House." Bryant recalled receiving the advice, "Be prepared for anything," from his parents, which he felt was good advice. However it was not very specific and seemed unlikely to help this nervous 18 -year-old who was embarking on a journey that no one in his family had ever attempted before. How could Bryant prepare for everything that was he was going to experience? I recognize that I did not have access to the boys prior to their beginning college, and acknowledge the risks involved in discussing their hindsights on their perceptions and feelings regarding college. However, in this study their perception is their reality.

TJ saw the purpose of college as preparation for college. This outlook did not encourage TJ to seek out activities that would make the college experience enjoyable, and during the study TJ was not, in fact, enjoying his college experience:

$\mathrm{R}$ : Is college what you expected?

TJ: Well, I didn't expect to have this much work. The math is harder than I thought it would be and the reading I expected that to be easier than what it was.

R: When people told you about college, did they tell you that it would be work, or that it would be fun? Did anyone say anything about college?

TJ: Well, no one ever really talked to me about it much. Some people said it would be really hard, and you have essays all the time. But so far the only class I have had to do that in is in my writing class. And I kind of liked my college class better than in high school cause you have different times and different days and you don't have to be there every single day. It feels like time flies faster. I mean 
it is already almost mid terms in a couple of weeks. So, I like it better 'cause it goes through quicker. And I guess it is about the same difficulty. But they never really said how hard the work was, they just said that there is a lot of it and I am finding that to be true. $(10 / 01 / 01)$

$\mathrm{TJ}$ was not prepared for the amount of work he had to do because no one explained to him that college was more difficult than high school. And it appeared that he enjoyed college not because of the learning that went on, but because of the variety involved in the class schedule and the fact that the time went by faster. His statements about not liking his classes, and not expecting to have this much work gives an undercurrent that he was not really pleased that he had this much work. Since TJ did not see a huge distinction between high school and college, the recognition that college was different, and required considerable more effort than he was prepared for, might have come as quite a surprise to him.

Patrick said that he was both scared and nervous about coming here to live and study. This was so even though he came to see the college during the summer, and that he had a brother here who was also enrolled in the college:

I was scared about going to college, but I was prodded. I had someone who was prodding me to go to college. It was a shotgun college. "You will go or else." College was not an option. $(10 / 31 / 01)$

Patrick's used the metaphor of a "shotgun college," to compare his parents forcing him to attend college, to the experience of having someone's parents forcing him to get married because he got a girl pregnant. He had no choice in the matter. Feeling that he had no choice in the matter could lead to resentment because Patrick did not necessarily go willingly to college, by his account. Patrick was scared of going to college, he did not feel he was academically prepared for college, and now his parents were forcing him to go to college. 
As Patrick analyzed his anxiety about college, and compared his feelings to what he imagined other first gens felt about going to college, he came to the conclusion that part of the anxiety first gens felt stemmed from a small town/big city cultural divide:

P: I think a lot of it is, at least from my experience and what I know of the parents of my friends and what not, that a lot of first generation students are from small towns like I am from. And their parents are reluctant to let their children go off to the big universities because maybe, they that their kid is not ready to go off. R: They want to protect them.

P: Right, it is protection. Like my parents, they are very confident in my and John's abilities, but they are not confident in our judgment, I don't think. $(11 / 28 / 01)$

Patrick's analysis could certainly be the situation at this college where many of the white students come from small, rural, mostly white towns but the college is located in the center of the largest metropolitan area in the state. Patrick indicated that it was the size of the college that was intimidating. Although speculative in nature, the student body itself, with its substantial black and international student populations, might also cause considerable culture shock for white students from rural towns. While Patrick did not specifically talk about any discomfort he felt related to this, he did acknowledge that he was having trouble adjusting to college:

It's weird, this whole thing. I get to thinking about it a lot. The whole concept of being here and going beyond your friends and everything, and it just seems odd, all of it does, 'cause I am out here by myself, and I never could think of myself as being on my own. It seemed like something that was so far away. And it happened so quickly. I am still trying to adjust to it a lot. I think I am still adjusting. I think I am still adjusting to college life. (11/28/01)

Patrick felt as if he had gone beyond what his friends had accomplished in life, and he was not sure that he liked how it felt. He felt alienated from his friends. He never envisioned himself as separating from the crowd and now he found himself "going 
beyond" his friends. He did not feel that he was prepared for what happened, and was surprised by how quickly it occurred as well.

The first gens in this study often felt they were "pushed" to attend college because they felt that they had limited options awaiting them if they did not attend college. This was one reason for the development of the utilitarian perspective towards their college education that these students expressed. Instead of feeling excited about college, and looking forward to it, the participants in this study began to see college as something they needed to get out of the way. Instead of being the exciting, life-altering time that it could be, it became, as Bryant said here, a source of stress and anxiety:

Coming in I had no idea what to expect. I didn't know whether to expect everyone to be extremely wild, and partying like they portray in movies and on TV, or if it is going to be like our teachers were saying where girls wouldn't like guys who are just obnoxious. The teachers said that college girls wanted smart people and I was like, "Well, that doesn't sound right." That was the biggest load of crap I have ever heard in my life. Socially, I didn't know what to expect. I didn't know if everyone was just gonna be like, "Hi, how you doing? Come to our party," or something like that. And Eric was going there and I thought, "Well, as long as I know at least one person." I knew other people going here but it wasn't like I was huge friends with them in high school. I was just never a social butterfly. $(10 / 11 / 01)$

Bryant expressed discouragement about not being a social butterfly, knowing that this limited his social interaction. His teacher's comments about the type of man that college women are looking for caused him to wonder, "Am I that type of man?" There was also concern expressed by Bryant about how college was represented on television, and relief that his friend, Eric, a major source of support for Bryant, was attending the same college as Bryant. 
In this last excerpt, Bryant expressed his feeling of disappointrnent that he still had not found college to be the "huge thing," he was expecting it to be, and perhaps hoping it would be:

Everyone talked about how college is going to be this huge thing, and it is going to be so much fun, but I am not finding that to be true. I mean it is just not the greatest thing. It is just more or less school for me, which is good in some ways. But as I said I have trouble just going up and meeting people. Now if I had something where I was invited, just a group of people, a big get-together, like orientation, I would go. I went to orientation you know, but I did not go out of my way, I guess. I was just there to get the information. (9/27/01)

Bryant indicated that he was waiting to get involved in college so that it could be "this huge thing" for him, but he needed help in doing so. His interest in becoming involved on the campus was tempered by his reluctance, as shown when he talked about orientation. He said that he went to orientation, and that he would attend an event similar to orientation if the college held such an event. But at the same time he said that he did not go out of his way to meet anyone while he attended orientation. And then he admitted that he was "just there to get the information." Bryant saw orientation in the same light that he saw high school, and now college. He had one reason to go to college: to get a job in business. Similarly, he went to orientation just to get the information he required. Anything other than this would be a very risky venture for Bryant.

These students felt that the purpose of college was to prepare them for work, and provide them with opportunities for a career. Joe also saw the purpose as making him a more well-rounded individual, which reflected his greater access to cultural capital. These students began to develop a sense of internal motivation for attending college, which was based on the belief that their success was up to them. This belief was partly fueled by the perception these students had, that they received relatively little assistance 
from their family and their school, and they could not count on receiving any once they entered college. All of these students acknowledged receiving verbal encouragement for attendance at college from their family and their school, but this verbal encouragement did not generally result in any tangible help in preparing for college. Having said this, however, there were two notable exceptions. Joe attended a small, private, Catholic high school that had a goal of preparing students for college. Because of this, Joe seemed to have been better academically and culturally prepared for college. He did not need to take remedial classes as the others did, and he entered college prepared to get involved in campus life because of the preparation he received from his high school. This supports Anyon's argument that student's are educated differently according to their social class. Anyon's work was done in a K-12 setting, and now we see this being extended into the post-secondary arena. Patrick was the other exception. He seemed to receive a great deal of personal attention from his high school counselor because he initially intended to enroll in her alma mater. It did not appear, however, that the other students in Patrick's high school received this same level of personal attention.

These students had low levels of involvement in high school activities. Entering college, these students did not indicate they had any intention of becoming involved in clubs and activities either. These students also felt that they were generally academically, socially and culturally underprepared for college, with several of them indicating that they had no idea what to expect from college. Robinson (1996) says that colleges tend to focus on the academic underpreparedness of first year students, without recognizing that many first gens are "culturally clueless" about what to expect in college. The participants generally felt a certain amount of fear, anxiety, and unsuredness about attending college, 
and several also felt they received mixed messages about what to expect from college. Although these findings seem to generally support the proposition that first gens are not academically or culturally prepared for college, there are also indicators that it is not the preparation of the student that is necessarily in questions. For example, Joe attended a high school whose goal was to prepare him for college, both academically and culturally, and yet Joe struggled throughout the semester to maintain a 2.0 GPA. Although Patrick was a first year student at this college, because he had experience at a previous college, it might be expected that he would be able to successfully navigate the system, yet he too did not feel prepared for what he experienced at the college. Whose obligation is it to prepare students for college? The students themselves? Their families? The high school? The college they are attending? Is it an instance of individual or institutional failure when students are not successfully prepared for college?

We will now turn our attention to the issue of support for college. These students felt they were fulfilling a dream, and were excited about the possibility of becoming the first generation in their family to receive a college degree. Two of them, TJ and Bryant, were actually the first in their family to ever enroll in college. Unfortunately for these students, the verbal encouragement they initially received for enrolling in college did not result in a great deal of tangible support from their family or from the college.

\section{Support}

I like to know that I am not the only one going through this struggle. It really helps me to know that I am not the only one going through this, that I am not the only one who feels weird up here, or feels on the outside constantly. It makes me feel better knowing that there are other people who come up here, and have the same issues. That have some of the same issues and it is not just me and my family. It is comforting to think that at least in some measure I am not alone. (Patrick 11/28/01) 
Patrick shared these thoughts with me during our last interview. Patrick wondered about how he "looked" as compared to the others in the study. He specifically asked me if he was "a freak." Knowing that he was not the only first gen dealing with a perceived lack of support helped Patrick feel he was not abnormal.

Throughout most of the study, Patrick and the rest of the participants felt unsupported by both their families and the campus. The participants reported that they received verbal support for the idea of attending college from their family and the college prior to their enrollment. But this original network of support disappeared quickly after the semester began. Family conflicts emerged that had the students questioning whether or not college was worth the trouble it seemed to be causing. Further, the students' perceptions that the faculty were there for the purpose of "weeding them out" if the students were not serious about their education, made the students hesitant to seek the help, guidance and support of their faculty members.

After Thanksgiving break, however, the nature of the family dynamics seemed to have changed, leading the students to feel as if their parents were somehow beginning to appreciate how difficult college can be. Reflecting on this change, Patrick said, "My parents trust my abilities but not my judgment" (11/28/01). He suggested that his parents knew he could do well at college, but they were unsure of whether or not he would do. But the changes in their relationship at the end of the semester seemed to indicate that they were beginning to trust his judgment as well as his abilities.

The themes that emerged from the interviews related to the issue of support for college included the following:

- Family Support 
- Faculty Support

- Work/UPS Support

These themes will provide the structure for this section.

Richardson and Skinner (1992) found that first gens dealt with disorienting experiences concerning time management, scheduling, financial aid, and academic advising upon enrolling in college, while their second gen peers appeared to the first gens to be knowledgeable about how to manage the realities of college life. As a result, the first gens in Richardson and Skinner's study found college to be intimidating, confusing and impersonal. These feelings were also echoed in my interviews with the boys. They considered their faculty to be hostile to their efforts, in an attempt to "weed them out" if they were not serious about attending college. At the same time the boys often felt a lack of support from their family that could have been helpful to balance the lack of support they felt from their faculty. Working at UPS certainly provided financial support for two of these students, but it also failed to support their academic efforts at college, and their attempts to become fully integrated into the college. The four students in this study continued to develop and draw upon intrinsic motivators as supports to help them negotiate college. This intrinsic motivation was present in the students as they prepared to enroll in college, and it continued to develop after they enrolled in college.

\section{Family Support}

According to Rendon (1996), when a student leaves home for college the family is forced to reorganize. This reorganization creates turmoil for the family and puts pressure on the student and the parents not to separate. Both the stud ent and his parents must learn to deal with the loss that going away to college means. Unfortunately many 
parents of first gens, having no experience with the concept of going to college, express their loss by placing guilt on the student. As a result, London (1989) said, family role assignments and separation dynamics become the center of the drama for many first generation college students.

Within the first gen participants talk about family support, there were sub-themes. Their talk seemed to be grouped around ideas of support for a better life, support as a response to crisis, issues of siblinghood, and change in the nature of support over time. In this section I will explore in greater detail the complexity of family support through these sub-themes.

\section{Support For a Better Life.}

In one interview $\mathrm{TJ}$ talked about how his father had grown introspective about his own life as it compared to TJ's:

Sometimes he looks at my girlfriend and me and he flips out, or it bugs him that he is divorced and partly he thinks about what we could have had, or did have, and when he thinks about that he thinks about everything under the sun, like how he didn't go to college and things like that. $(11 / 26 / 01)$

TJ's perception was that his father was upset about what he was able to provide for his family, and that he could have done more for himself and his family. While TJ's father was supportive of TJ's efforts to get a college degree, he also appeared resentful of what $\mathrm{TJ}$ had and what $\mathrm{TJ}$ was going to obtain.

The students in this study perceived their parents as sending mixed messages such as the ones that TJ's father was sending. There was support from TJ's dad, but there appeared to be resentment as well.

First gens who attempt to improve themselves through education often grapple with frustration, loneliness, criticism and lack of family support for their decision to 
enroll in college. Piorkowski (1983) had observed that many first gens suffered from a concept she termed "survivor guilt," that had a significant, negative affect on the academic performance of first gens. Piorkowski said that for first gens the issue is not death in the physical sense, but more a figurative death as first gens leave their friends and family behind to enroll in college. Not surprisingly, then, many first gens find it difficult to concentrate on their academic work while they are dealing with this internal struggle. The data from the interviews appeared to support these findings.

The notion of going beyond what the previous generation has done is very much in the lore of American culture. Parents for generations have wanted their children to have "better lives" and more of these "things" that indicate the betterness. In an interview conducted right before the semester break as Patrick talked about going home for the semester break, it was clear that Patrick believed his parents wanted that for him, too:

$\mathrm{P}$ : But one thing is, my parents are very demanding. 'Cause they want us to go beyond what they did, and what my friends are doing, or what anyone else in the family is doing. (11/28/01)

Patrick saw his parents as wanting more for him, something better. Still he interpreted this wish as problematic. He saw his parents as demanding because they wanted Patrick to succeed. The nature of these wishes for Patrick's success became more convoluted when Patrick shared the following:

My parents are very confident in my and John's abilities, but they are not confident in our judgment, I don't think. They are confident in our abilities but they think our judgment lacks. They think that we are mature enough to handle college, but we have not had enough life experience to know better. When we make bad life decisions they think, "That is where we come in." (11/28/01) 
Patrick saw his parents as fearful that he was not going to succeed and continue the family advancement. Patrick interpreted his parents' behavior as supportive, even if he did not always appreciate how they showed their support. He felt that his parents wanted to protect him. He also was trying to understand his parent's motivation. As he saw it, they considered it their job to step in when he made a bad life decision, but Patrick's parents often assumed Patrick was making a bad decision when Patrick did not think that he was. Patrick's parents' assumptions were based on their experience with Patrick's older brother, John. And his parents assumed that John was not making good decisions.

Patrick looked to his brother for support and also held his brother in high esteem. But Patrick and his brother did not appear to spend much time talking about their relationship with their parents. His brother seemed to have taken the avoidance mode, rarely speaking to his parents on the phone and rarely going home to visit, while Patrick was trying to struggle through the conflict that he and his parents were experiencing. Perhaps it was because Patrick still intended to eventually return to his hometown while his brother did not, that explained this difference in behavior. At the end of the semester Patrick attended a birthday party for his brother. He was reluctant to attend initially, however, because Patrick did not see himself as a real social person. But despite his reservations about going, Patrick said, "I am glad that I went to the party. I had a really good time, and Joe kept telling me that he was glad I was there, 'Dude, I am just happy you're here." The reference to "here" that his brother made had a double meaning, possibly. On a literal level it meant that his brother was happy Patrick was at the party at that moment. On a deeper level it might also mean that his brother was happy Patrick and he attended the same college. 
Bryant also experienced conflict with his parents during the study. Bryant's parents questioned Bryant's motivation for college and pressed him to do his best:

R: So, you do talk to your folks, periodically? Do they show interest as well? B: Yeah. I mean, they want me to do good. They want me to strive to be the best, not just settle for Cs and Ds. They would like me to get straight As. That's the ideal thing, but I guess, I don't know. We don't sit there around the table and say, "What are you doing?" It is just, "Are you doing good?" "Yep." "Do you like it?" "It is just school." (9/27/01)

Bryant had developed a mantra that college was "just school." This seemed to be his way of convincing himself that college was not all that important. When Bryant was not doing well in college he could also use as a way to ease his stress about college. When his parents became angry with him about college, he could also use it as a way to shrug off their concerns.

Bryant perceived that his parents were supportive of his efforts, even though he admitted that they rarely discussed what he was doing in college in any depth. At the end of our conversation, Bryant had internalized the idea that it was up to him to be successful by studying more and memorizing more. His parents were supportive, he felt, but it was up to him to succeed in college.

In Joe's description of what he saw as the purpose of college, and why he enrolled in college, he talked about it from the perspective of making a better life for himself. $\mathrm{He}$ saw the kind of lifestyle that his Mother was living without having a college degree, and he knew that he wanted to go beyond what she had in life. Joe's Mother wanted this for Joe as well. She wanted Joe to attend the local Catholic high school because she knew that they would make sure that Joe was prepared for college, and that they would ensure that he attended college. Although she was unable to pay for his schooling at the high school level, she had the appropriate social capital that enabled her to get him into the 
high school. As a result, she was able to support Joe as he pursued his dream of a college degree.

\section{Response to Crisis.}

All the participants had some upset or crisis in their first semester. I may not have heard all of them, but those that I heard about often brought about shows of support from the parents. These supportive responses may not have been surprising, but how the first gens interpreted their families' actions were important.

In Patrick's opinion, his parents considered it their job to step in and take over when Patrick made a bad decision regarding college. When Patrick began to stumble during college, rather than offering the support Patrick wanted, Patrick perceived his parent's response to be, "See, we were right, you aren't ready." It was not the response that Patrick needed to feel supported. In our third interview, I asked Patrick what his parents might be feeling that caused them to lash out at him in anger when they thought that he had made a bad decision:

R: What else do you think they could be feeling? 'Cause a lot of people would say that anger is a masking emotion, that they are feeling another thing and then they turn it into anger 'cause they don't know how to express the other.

P: Fear.

$\mathrm{R}$ : Fear of...?

P: Fear of us doing badly. Basically complete fear. Anger is just one of those ways they respond to things that they don't have any control over, 'cause they really don't. My brother and I feel it is our responsibility. And rightly so. And if I fail out, it is my fault. 'Cause I am the one doing the work.

$\mathrm{R}$ : But do they look at it that way? Or do they see it as their responsibility?

P: They see it as their responsibility to prod me. To keep me going.

$\mathrm{R}$ : So, not necessarily responsible for you failing out.

P: 'Cause it is like they said, "We can't be up there doing these things for you, but we can be there to push you." And that is what they see their role as. And when we are doing badly they see it as they are not pushing enough.

$\mathrm{R}$ : They are not doing enough.

P: They are not doing their job so they step it up and it causes problems 'cause I am almost 20 years old and I don't like thinking that I have to dread a phone call 
from my parents. I think I earned the right that...It has been shown that I will do the work, but sometimes things aren't working out and sometimes the work comes a little too much and I think it is fear that we are going to do bad and that proves a lot of people right that they don't want to be proven right. $(10 / 31 / 01)$

Patrick perceives that his parents see prodding him as their job. He thinks that his parents feel responsible not necessarily for Patrick's success, but for at least doing what they could to help Patrick succeed. Although Patrick acknowledged that his parents might feel responsible, and see that they had an obligation to prod, he also felt that it was his responsibility to be successful in college. So, he was resentful that they attempted to assume responsibility for his success in times of crisis. Instead of providing support, Patrick's parents were responding in a manner that drove a wedge between Patrick and his parents, the people from whom he needed support from the most. In addition, Patrick believes his parents are fearful that Patrick and his brother will not be successful in college. He indicates that his parents are afraid of the brothers' failures because of how it might look to others. Patrick's success or failure becomes, at least in Patrick's mind, the success or failure of his parents. So, to insure that they all succeed, Patrick's parents' phone calls become events to dread rather than moments of celebration.

College was an unknown experience for Bryant's parents as well, so conversations about college seemed fairly limited. However one day Bryant's parents just happened to find out that Bryant was performing poorly in his classes. Following this "discovery," they had a heated conversation with him because they felt that Bryant's grades were unsatisfactory. Bryant's father had developed the "While you are under my roof, you will abide by my rules" philosophy and Bryant seemed accepting of that philosophy. Bryant had said that his parents opened his mail regularly, especially if the mail was from the college. When I asked how he felt about this, he said that at times it 
bothered him but when he mentioned this to his parents, his father said, "I pay for your tuition, your car, you eat my food and live in my house. So what's the problem?" To which Bryant told me, "He has a good point:"

R: Give me an update on school.

B: Classes are going OK but I got into an argument with my parents over the way that I was approaching school. They think that I am not putting in enough effort so, they sat me down and talked to me about it. I thought they were being a little harsh but everything is OK now. They said that I need to do better or I should consider dropping out. This came about because I failed a math test last week. R: Do they usually ask you about how you are doing in school? Do you usually show them your test results?

B: No, they usually don't ask but it just so happened that I had just gotten this math test back that day, and they asked me if I had taken any tests recently. And I had that test so I showed it to them and they got mad. And I am not doing well in science either. I am getting $40 \mathrm{~s}$ and 50 s there. Fortunately, we have a substitute for three weeks because the teacher was not very good. Hopefully I will do better with this teacher. $(11 / 1 / 01)$

Bryant's parents perceived the math grade as a crisis or possibly the straw that broke the camel's back. Either way, the incident caused conflict in their relationship. Not only was Bryant not putting in enough effort according to them, this math grade proved it. Like Patrick, Bryant perceived that his parents reacted harshly. Bryant's parents saw it as their job to step in and prod Bryant to do better in school. Initially Bryant said that classes were going "OK," but then he goes on to say that he had failed a math test, and he was doing poorly in science as well. Bryant may not be as aware of his struggles as he needed to be or as aware as his parents seemed to have been. If his initial response to my question was that things were fine, was he trying to ignore the warning signs of academic failure or was he unaware of them? In my fifth interview with Bryant, I followed up on this situation:

$\mathrm{R}$ : So your parents thought that you were showing a pattern?

B: Yeah. Like I said, I was a horrible student in high school. Not that I was stupid, but I was lazy, and I am still lazy. I put stuff off so much. I mean my 
parents are proud of me and they say, "We love you and we are very proud of you and you don't cause us any grief except for in school, and you don't talk back." Of course every kid is a little disobedient but they are proud of me and the way that I have grown up and stuff, but they say that I have to work harder or something cause, "We don't have to stand for this anymore, you are 18." $(11 / 14 / 01)$

On some level, Bryant saw that he might have been following a pattern set earlier in his academic life. He also seemed to see the parental commentary as driven by love and pride.

In times of crisis, the parents of these first gens resorted to occasional threats. But "crisis" for parents of first gens appeared to some of the young men to be a part of college life in general. In this excerpt, Patrick described how his parents saw social life at college as a potential threat to him:

$\mathrm{R}$ : It sounds like the theory of college is a good idea for your parents, but then when it comes to the practice of what it means for you to go to college, that's not so good: living in a dorm, maybe having a social life, those sorts of things.

P: Yeah, yeah. Going out and staying out late. Just doing things. Maybe, not necessarily, you don't have to, you know, drinking doesn't necessarily have to be everything you do. You can have a good time without drinking. I believe that $100 \%$. I don't drink, you know, I don't do much of anything, really. It's just nothing that appealed to me, but, ah, they're just saying that if you're out late, you're drinking. "So, maybe this college thing isn't a good idea so why don't you come home." You know? The solution is always, "Why don't you come home?" That's what they say whenever they got mad, "Why don't you come home?" Then they said, "If you think that you're gonna come home and run around with your buddies instead of going to school, we got, you know, you're gonna be workin' at McDonald's 40 hours a week, and we're gonna get you fitted for a uniform." You know, they're trying to scare me and I know exactly what they're doing, and I'm just laughing, saying "What?" (10/17/01)

It was hard to see how Patrick could win in this scenario. If he did badly, or "bad," which in this instance referred to him partying or drinking, his parents suggested that he come home. But then they said that if he did come home, they would make him work at McDonald's. These were very mixed messages. There was one message designed to 
encourage him to come home, followed by a message designed to scare him into staying in college where he is. His parents felt it was their responsibility to prod him but was this truly support for Patrick's efforts? Further, might it have been their lack of knowledge or their stereotypes about college that hindered their abilities to support Patrick in more useful ways?

In my fifth interview with Bryant, I followed up on the argument between him and his parents. In our discussion it became clear that one way Bryant's parents were attempting to show their support was via threats. And I sensed defensiveness on Bryant's part when I brought the topic up, as if he didn't want to go over this painful topic again. This pattern of frustration felt by parents, due partly to their lack of knowledge about college and their feelings that they cannot do anything tangible to help their child, was visible with both Bryant and Patrick:

$\mathrm{R}$ : How is everything at home? Are your parents over their anger at you?

B: They're not mad now, but they were pretty ticked off for a little while. I thought we talked about that last time, didn't we?

R: Right, right.

B: I guess maybe I wasn't showing enough initiative in my school work and they were just upset, which obviously they have a right to be, 'cause they are paying for college. They pretty much said that, "You are going to either start working harder, and showing that you can buckle down and do it or go ahead and drop out and leave "cause we are not going to fool with this. It is ridiculous, you have been doing this your whole life." And I said, "Sorry." (11/14/01)

To call what Bryant had with his parents a "conversation" is a misnomer. What appeared to have happened is that his parents yelled and he sat there and listened. He had mixed feelings about what was happening between them: (1) his parents did not understand college, (2) it was his fault for not studying hard enough but (3) his parents were proud of him. To a certain degree there seemed to be truth in all three. Bryant's parents did not understand. They had never been to college so how could they understand what college 
was like? But they knew their child. And for them, a large part of the academic success or failure on the part of Bryant was due to the individual behavior he displayed.

In the parents' responses to their sons in crisis there was frustration, due in part to their lack of knowledge about college. However, there were also institutional and cultural factors working against these students, which did not provide them with a "level playing field." Lack of preparation for college, lack of support from family and faculty are two of these institutional supports. These institutional and cultural factors seemed to drain the motivation from Bryant at times, making it difficult for him to feel that he wanted to do well at college. Although Bryant recognized the need to obtain a college degree, he also seemed to suffer from a low self-image when he said that he was "lazy," which could conflict with the college's high expectations. Without sufficiently high motivation to succeed, Bryant might not be able to overcome the barriers he faced. Bryant was also showing signs that he felt responsible for doing well at college because his parents were paying for his degree, which meant that he also felt his parents had the right to get mad at him if he was not doing well.

\section{Sibling Relationships}

Patrick and Joe both had older brothers who had enrolled in college prior to Patrick and Joe's enrollment. In attending college before Patrick and Joe, these brothers helped blaze a path for Patrick and Joe, in theory. But in reality it was unclear whether having an older brother enroll in college before them was help or a hindrance to Patrick and Joe, and whether it was a source of support or conflict for them. In our second interview Patrick related a time when his parent's anger at this brother ended in his 
parents suggesting that Patrick should go to college closer to home and commute to college:

Mom and Dad suggested that I move back home and commute to college because, if my memory serves, they were angry at my brother John over something and they decided, you know, this is one of those, "We're angry, let's lay down some sort of stupid directive." They said, "Uh, why don't you go to the local college extension for a semester or two, get used to college life, and you can commute and everything?" And I was absolutely adamant about, you know, leaving. So I said, "No." And they kept saying, "Well, you have never been away from home. How are you going to do it? How are you going to fight the homesickness?" And I said, 'I don't care, I'm leaving, I'm going to live on campus 'cause that's the experience that I have wanted to have for a long time." So, that's all I was going to say about it, really. $(10 / 17 / 01)$

The desire by Patrick's parents to have Patrick stay closer to home could have been because they saw changes in Patrick's brother that they did not like. The implication was that they did not want the same changes to occur with Patrick. Or they could have been angry about one of Patrick's brother's "bad choices" and they wanted Patrick closer to home so that they could influence Patrick's choices. However, their desire to have Patrick stay closer to home could also have been out of a genuine concern that Patrick was not ready for the challenges that would confront Patrick at college, such as homesickness. Patrick perceived that his parents felt it was their job to intercede when they thought he was making a bad choice. And, in his parent's opinion, going away to college had been a bad choice for the older son. Thus it was seen as a bad choice for Patrick. Patrick's parents felt this way because of their experience with Patrick's older brother. They did not like what they perceived the brother was doing, and they wanted to prevent Patrick from doing the same thing. So having an older brother at college was more problematic for Patrick than helpful. His parents had a limited amount of knowledge about college prior to the older brother going away to college. Now they had 
some knowledge, but the knowledge was negative, based on what they perceived Patrick's brother was doing. Patrick's parents then, wanted to ensure that Patrick did not follow his brother's path. This meant that if Patrick tried to take advantage of his brother's experience, he might have to choose between his parents and his brother, because the two were in conflict with each other. This added another layer of stress as Patrick negotiated the middle ground between his parents and his brother.

Despite the problems that occurred between Patrick and his parents as a result of having a brother at college, it seemed that Patrick was attempting to rely on his brother for support at various points during the semester. During our first interview Patrick talked about the relationship he had with his brother:

John and I didn't really keep in contact until I came up here. When we moved out after high school he went here, and I went to the other college my first year. And now I am up here and things are definitely different. Of course things have always been different since high school ended. Nothing has ever been really the same. There is a lot of strain in our relationship. But me and John kind of decided that we need to be together. So we can help each other out instead of be separate, I guess. $(10 / 03 / 01)$

Patrick and his brother had a complex relationship. At the same time that he talked about wanting to be with his brother for support, he also talked about their relationship as being strained. He also saw the relationship as symbiotic since he talked about them helping each other out. As Patrick continued to talk about his brother in this same interview, issues of sibling rivalry and Patrick's low self-esteem also emerged:

My brother is very intelligent. He is one of the smartest people I have ever met in my life. And his high standards I think sometimes would come down on me as Well, "cause people would say, "Well, if he can do it, so can you." So, there was constant comparison. Not within my own house, but outside. "Oh, you are John's brother. You are smart like him." You know? I did all right in school but by no means am I on his level. He made all As in college, and in high school and never brought a book home. It was one of those, he could hear it and just 
remember it. He taught himself to read you know? And things like that. But it just didn't work for me. (10/03/01)

Because Patrick's brother was so intelligent, according to Patrick, it was difficult to follow behind him. Instead of receiving support from his brother, Patrick felt he was in competition with him. Patrick felt looked down upon when he did not do as well as his brother. In our fourth interview the topic of Patrick's brother came up again. This time, as Patrick talked about his brother, it became clear that his brother was not the type of person who would be inclined to lend support, even to Patrick:

My brother is not a very personable person sometimes. And he is hard to get to know. And he puts on this façade for people to let them know that anything beyond a laugh or a joke with him is a no-no. He says that he has enough problems of his own without having to deal with anyone else's. And he feels like if he can deal with his, they can deal with theirs. He sees friendships as just something that shouldn't be...He has his close friends that he will talk to, and that he will get in-depth with, but there are not that many. And, in fact John is someone who, when something is bothering him, will not tell you, 'cause he does not believe that he is incapable of dealing with anything. He says that there is nothing that can come along that he cannot deal with, and that going to someone is a sign of weakness. "Cause he is very arrogant about his intelligence. He knows he is a genius. That is one thing that always irked me. But when something is bothering him, he says, "I can handle it, I don't need anyone telling me what to do." He does not like to be told what to do. He thinks he can handle it himself. Now me, if I think that if someone is qualified enough to give me advice, then I would ask them. Like my brother, on those rare opportunities when I could get him to tell me something, "cause generally he just shrugs his shoulders and looks at you like you are an idiot and goes back to watching Jeopardy and that is the only answer that I get. 'Cause he believes that if he can deal with his, you can deal with yours. (11/14/01)

Patrick's brother had developed the attitude that he did not need help from anyone.

Further, Patrick's brother had no desire or intention to help anyone either. In contrast, Patrick admitted that he would accept "advice" from someone qualified to give it.

Patrick admired his brother and wanted to be closer to his brother but his brother did not go out of his way to be helpful. Patrick had picked up strong messages that his brother 
felt that Patrick should handle his own problems by himself. Thus, another potential source of support turned out to be a disappointment for Patrick. Patrick's brother was role modeling a pattern of behavior that was based on rejecting support from the college. Instead, Patrick's brother had surrounded himself with people he knew before college, and then had invited Patrick into the circle. Patrick's interpreted his brother as showing a distrust of "them." Another potential problem was that should Patrick have felt the need to talk to someone such as a counselor about his problems, he could not have expected support for this by his brother. If Patrick had sought help, he would have been defying his brother, which would have been a very risky thing.

Like Patrick, Joe had an older brother who is also at the college. And like Patrick, Joe also had difficulty negotiating the changes in the relationship that were occurring between Joe and his brother once Joe started college. At times it appeared that Joe's brother took sides against Joe, rather than providing him with much-needed family support:

$\mathrm{J}$ : I want to move into a dorm on campus. My friends from work and I are going to try and move into a dorm. When I am done with classes, I just don't want to leave. I just am involved here. I am in the library constantly. I want to come here to study constantly. When I get home, I can't study. So, I think if I live on campus that will even be better. But my brother, who I said is my father-figure, he tells me that if I move out, I don't know if the door will be open to me if I want to come back. So, that is really scary. If I move out, if I make this decision, I have to support myself or get an apartment this semester or what not, so I got a lot of thinking ahead of me.

R: So, he thinks that your mom or stepdad wouldn't accept you back if you said that you changed your mind or after graduation if you didn't get a job? J: Yeah, the whole, "You are on your own now." They say if I can move out one semester, I can do it for more. But I haven't talked to my stepfather yet. And this is an experience. And just give me a semester. And if I like it, maybe I will come home for a little while and save up so I can move out again. But if I don't like it, I want to stay home. My brother, I think he wants me to be like him. 
R: I wonder if he is expressing his own feelings, like, "If you move out I won't necessarily accept you back if you are not like me." But he is putting it in different terms.

$\mathrm{J}: \mathrm{He}$ is 23 and has lived home all of his life.

$\mathrm{R}$ : And you are taking a different path.

J: Yeah! So I don't know how to respond to him or act accordingly. We will just have to see how it goes. $(9 / 21 / 01)$

It appeared that Joe's brother was attempting to put fear and doubt into Joe to prevent him from moving out, rather than supporting his desire to move out. In this way his brother also seemed to be siding with Joe's parents since Joe was assuming his mother and stepfather would be against his move.

Regarding his brother, Joe's relationship with him seemed to mirror Patrick's relationship with his brother. In this excerpt from our very first interview Joe talked about how he and his brother were different and what affect this difference had on their relationship:

How do I put this? To me, my brother is flawless. The whole cigarettes and alcohol thing, for example. And he is studying engineering. He works his butt off. He is financially sound. So, the expectation has been raised for me. And my family sees me as not striving to get there. It is kind of, "You are lazy." "You are irresponsible." And all this, "cause I don't have his lifestyle. I am supposed to follow in his footsteps and I am not. That is where the major conflict comes from. $(9 / 21 / 01)$

Joe saw himself as flawed because he did smoke and drink, while his brother did not drink or smoke. And Joe studied business, while his brother studied a harder subject, engineering. And his brother studied hard while Joe did not. So, if Joe's family held his brother up as the model, and Joe was the opposite of this model in many ways, what kind of support could Joe expect if he did not change to resemble this model? From Joe's quote, the "model" was based on a combination of refraining from vices, adopting the Protestant work ethic, selecting an "acceptable" major, and being thrifty. But even 
though Joe saw himself as flawed as compared to his brother, he still attempted to adhere to some of the model that his brother had set. Joe considered himself Catholic, he was working, and he had refused to take out loans other than the ones UPS offers, thus showing his financial soundness. Even so, this still may not have been enough to satisfy his family.

In contrast to Patrick and Joe, TJ felt that he had to remain in school because he was the very first one in his family to attend college. He felt he was responsible for blazing a path that his two younger brothers, as well as others in his family, could follow. This led me to wonder what Patrick and Joe's brothers felt as they headed off to college, knowing that they were the first ones in their immediate family to do so?

My third interview with $\mathrm{TJ}$ was held at a point in the semester where he had been talking to his father about possibly dropping out of school and moving back home. But he had also been talking to UPS about having his schooling paid for even it took him six years to graduate:

I feel like I could make a life for myself if I stay in college. And plus I am the first one that tried to go to college. 'Cause I have two younger brothers and see, none of my other family has even gone to be able to drop out. But if they hear that one of us tried and then dropped it would look worse that we couldn't take it. And I would be worried that they wouldn't want to go 'cause I didn't go. $(11 / 12 / 01)$

TJ was not enjoying college. He was experiencing financial problems and health problems, both of which affected his work and his academics. He did not necessarily want to keep going to college, but he felt as if he had to for several reasons. The first one he verbalized was to "make a life" for himself. He perceived that without a degree, his opportunities for a good life were diminished. Second, he felt pressure to succeed because of being a first gen and having to be a role model for his younger brothers. TJ 
was truly blazing a path different from anyone else in his family. And he expressed hope that his path blazing would somehow make it easier for his younger brothers when they began to consider enrolling in college.

\section{Change in Family Support}

Another sub-theme imbedded in the discussions about family support was that the participants perceived that their parents support for efforts at college seemed to change over the course of the semester. The students indicated that their parents were supportive of their initial efforts to enroll in college. All of the parents supported the idea of college for their sons. But, once college began, the students did not feel that their parents were particularly supportive of their efforts, and the students often felt that their parents did not understand what they were doing in college. However, as the semester wore on, the students thought that they saw some perceptible changes in their parents' levels of support.

TJ felt that he received mixed messages from his father about attending college during the study. In some situations, TJ perceived his father to be sympathetic to his efforts at college:

At one point I got so stressed out I was just like, "I am just going to go back home and live with Dad." "Cause he said I could go back if it got too hard. But then I thought that I would have to do college all over again later so I just figured I would deal with it. (11/12/01)

But at other times TJ felt that that his dad did not understand how stressful college could be:

TJ: He knows I am really stressed out but he doesn't understand why.

$\mathrm{R}:$ He does not understand why?

TJ: Well, he understands about work and the car, but he doesn't think it is enough to get as stressed as I am. So he thinks I am over-stressing but he doesn't know everything. 
$\mathrm{R}$ : He doesn't know how the academics play in?

TJ: No. He just thinks I am doing...I only tell him how I am doing grade-wise. And grade-wise I am doing great.

R: So, what would he do if he found out the details of your class work? He would just yell at you? 'Cause you said if he got mad he would start yelling.

TJ: Yeah. He does yell at me. 'Cause he thinks that this college stuff is not hard. $(11 / 12 / 01)$

In the end, the father's reaction of yelling had forced $\mathrm{TJ}$ to avoid conversations with his father about college except for when $\mathrm{TJ}$ reported positive things like his grades. Yet, it was probably difficult for his father to fully understand the kinds of stress TJ felt while attending college. Work problems and car problems were tangible issues that were, comparatively speaking, easy to solve. But his father was not equipped to solve TJ's college problems which might made his father feel frustrated. TJ admitted in this interview that, "The only person I would really talk to about issues related to college at this point is my girlfriend." TJ could not turn to his Mother for help because she was not available. Because $\mathrm{TJ}$ had been home over the Thanksgiving break just prior to this interview, he had the opportunity to see relatives for a longer period of time than he had earlier in the semester when he would only go home on the weekends. Given this longer time period, he had more opportunity to talk to his father and his other relatives about his life in college. Still, it appeared that TJ's family showed little interest in how he was doing in college, which showed a lack of support for TJ's efforts at college:

$\mathrm{R}$ : Your parents never ask you about college or anything?

TJ: No. We really don't talk about it that much. We act like it is just another school, I guess. $(11 / 26 / 01)$

This statement that college was "just another school," was similar to Bryant's "mantra" that college was "just school," and indicated that both TJ and his family did not see college as a major life change. In this same interview though, which was our final one of 
the semester, TJ talked about how his Dad seemed to be changing in the way in which he related to $\mathrm{TJ}$ :

TJ: Me and my dad have been talking, and he has actually been asking me how I have been doing lately.

$\mathrm{R}:$ Oh, really?

TJ: It just started to happen, like, I guess, and he has been asking me a lot, too, and saying that if something goes wrong I am welcome to come back to the house and live with him. So I don't know if he is worried, or what. It just came out of the blue, 'cause before when we were talking about it, he wouldn't really say much.

R: A few weeks ago in our other interview, I think you said that he just asked you, "How are you doing?" And, "How are your grades?" And that was it. But now there is more interest?

TJ: Yeah, now it seems like he is really interested. I guess, I don't know.

Sometimes he looks at my girlfriend and me and he flips out, or it bugs bim that he is divorced and partly he thinks about what we could have had, or did have, and when he thinks about that he thinks about everything under the sun, like how he didn't go to college, and things like that.

$\mathrm{R}$ : So, he is doing some real introspection about his own life.

TJ: That's what I think, but I don't know for sure. And he does get real angry sometimes, like about the car, but then he will call back later and apologize. And I will say it is ok. He was always there, but sometimes he didn't have a good way of showing us he does care. But I think he is trying to let me know. He has not always been interested, and he might not be, really, but I think he is starting to feel bad, and he is starting to try and show that he cares, and that he is thinking about us...It is like a sudden change. Even when he was in school before he told me how he used to party and didn't pay attention to his grades, trying to get across to me how I should strive for a better education. It's either that or, he has been helpful with the car a lot and he might have felt like, when I moved away, I got away from him cause we didn't talk much. And with the car and the truck and him letting me borrow the truck, he might feel more or less like a parent again. Trying to be more like, "You are my child." So it could be that, too. So I am really not for sure. I am going to wait and see, and try to slowly tell him about the chiropractic thing. And see how it goes from there. (11/26/01)

TJ was noticing a change in the support that his father was showing him, but he was also skeptical that it was permanent or real. TJ also was perceiving his father as saying, "Do as I say, not as I did," which TJ perceived as stemming from his father's looking back on his own life and not feeling good about what he saw. The "chiropractic thing" that TJ referred to was a career change he was considering. Near the end of the semester TJ 
talked about his interest in doing massage or becoming a chiropractor but he was unsure how to obtain information about this possible career change. He was also fearful of telling his father as was evident by his last statement. He was going to test his father to see if the changes in support that TJ saw were real by telling his father about this potential career change slowly. If his father supported his decision in that area, he might feel that he could then open up more to his father and count on him for additional support.

Patrick felt a lack of family support for his initial decision to enroll in college. Early in the semester Patrick talked about some of the conflict he experienced with his parents when he went to college, and inn our second interview the issue of Patrick's parents giving him conflicting messages about their level of support for his attendance at college was evident:

P: My parent's attitude towards college has completely changed since I came here. And you know, it is just little things like that, constantly changing their minds. I mean, you can change your mind, but you don't, you know, proclaim something as the only right way to go, and then as soon as one little thing goes against plan, scrap the whole thing. And they don't understand that I am up here and I finally have adjusted to this, and they want to rip me out and put me somewhere else and I'm not gonna have it. You know? I'm not. (10/17/01)

Patrick indicated that his parents were initially supportive of his plan to transfer to the college where his brother was enrolled. But, once college began and something occurred that went against the parent's "plan," Patrick felt that they quickly withdrew their support. This was immensely frustrating for Patrick. Patrick's comments were made shortly after the college's fall break and Patrick had traveled home to see his parents during the break. Upon his return, we talked about the kinds of discussion he and his parents had about college while he was home: 
P: Um, I try to stay away from the topic. I really didn't want to discuss it with 'em. 'Cause being in the home, and talking about college would only cause problems.

R: Did they try to bring it up at all?

P: Yeah, they tried but I steered the subject away. Always asking where my friends were going to college. "If they're going blah blah blah. If they're going here, or going there. Or, "How are they doing? What are they doing?" And I just always said, "I don't want to talk about that."

$\mathrm{R}$ : What are they trying to get at by asking?

P: I don't know. It just seems like they're either being nosey or they want to know what my friends are doing out of concern. Or they just want to spark the topic. And I'm just adamant that I'm not gonna have it. I do not at all want to go to that subject.

$\mathrm{R}$ : You want to avoid it at all costs.

P: Yeah, I want to avoid it. 'Cause I do this college thing five days a week, and then you know, I struggle with it, and then I have to hear them, you know, harp at it, and give me one of those lectures, you know. And I...You know, when I go home I want to relax. Peace and quiet, you know, run around with my friends. Just get away from it.

R: Right. (10/17/01)

Patrick assumed that any conversations he had with his parents about college would result in a fight so he stayed away from having one with them, although they continued to try and bring it up. To Patrick, his parents were not asking about college out of support for him. They were either being nosy about his life, or showing concern for his friends. Patrick was not going to take the chance of getting into an argument about college. He had already indicated that college was his responsibility and, following his brother's lead, he was not about to accept their help at this point in the semester.

R: So, who do you have conversations with about college?

P: My brother, mostly. And my friends. Close ones. Fellas I live with.

Basically just people who know "cause trying to explain it to mom and dad doesn't work. Mom and dad get it, but they don't at the same time. It is like, "Well, why don't you study more?" I say, "Well, I'm doing my best, mom and dad." I've said this so many times the past few days, "Mom and dad, I'm doing my best." "Well, apparently it's not enough. Study more." "Well, would you like me to sleep?" "Well, if that's what it takes." That doesn't work. That sounds good. It sounds like a great idea. It really does, but it doesn't work. $\mathrm{R}$ : They see it as a fairly simple solution. 
P: Yeah, they think everything can be solved just by more determination on my part, or more studying when really I am studying about as much as I can get in a day, so...

$\mathrm{R}$ : But they see it all as your fault.

P: Right. I could be doing more. Always could be doing more, always. $(10 / 17 / 01)$

The message to Patrick from his parents was that the institution was doing things right, and Patrick needed to adapt to the institution, even if it required not sleeping. Support has to come from within, and no one was responsible for Patrick's success except Patrick, they were saying. As Patrick stated, college was not there to help him, it was there to weed him out if he was not serious. Patrick's parents were suggesting that he was not giving it his all, which could lead to his being weeded out, they feared.

In our final interview of the semester, however, Patrick, felt that his parents were changing. This conversation was held shortly after the Thanksgiving break:

P: Mom and Dad were really happy to have John and I home, and I was happy to be there, so it was very, very, very pleasant. We just talked a lot about school, but they didn't ask me too much about grades. They said that if I did bad, it would be OK cause they know how hard it is.

R: Your jaw must have dropped.

P: I was like, "Who the hell are you?" That is just not something that my parents would ever say. They see me as...They know that I work hard. And I think they know that when they accuse me of not doing what I should be doing, and what not, that it doesn't do anything but detract from my performance, 'cause it does. It gets me angry and I get all pissed off and everything. And when you are focusing on being pissed off and not focusing on what you need to do, it messes things up.

$\mathrm{R}$ : So how did this change happen, because this is the opposite of what you were saying before?

P: It just, I don't know. A lot of it was that they talked to my brother. (11/28/01)

This was a significant change in Patrick's attitude towards his parents, and represented a major shift in how he perceived his parents level of support for his efforts in college.

Patrick indicated that his parents did not ask much about his grades, but showed interest in other issues surrounding college, which Patrick appeared to appreciate. Furthermore, 
he perceived that his parents truly understood how difficult college was for him. He gave credit to his brother for helping change his parent's outlook.

The perceived change in the parent-child relationship indicated to these students that their parents were making some attempt to understand the issues their sons were dealing with while enrolled in college. As the semester wore on the change in relationship between Bryant and his parents seemed to be marked by an increased feeling of obligation on Bryant's part not to disappoint his parents with his academic performance:

B: I feel a little bad cause my parents are paying for college. And this hunting trip I am going on is going to cost a couple of hundred dollars to get down there and back, and I bought a bunch of new clothing with money they put out for me, and they are going to shell out a lot of money for Christmas, and we are going to my grandma's and we are going hunting again which is going to cost even more money. If I fail a class I will feel real bad, like I am letting them down, so I am so nervous right now.

R: Have you prepared them at all for that possibility?

B: They have asked me how my grades are, and if all goes the way I am hoping, I will have a ' $D$ ' in Science. I mean I told them that I could fail that class. But all the other classes I should pass. If I was to fail any other class, I would be completely shocked.

$\mathrm{R}$ : And what did they say?

B: They were like, "Well, that's fine."

R: So they didn't get upset about the possibility of failing the one?

B: They were like, "Well, whatever." They weren't as mad as I thought they would be. $(12 / 6 / 01)$

Bryant continued to feel that he "owed" his parents because they were paying for his college. Because this was more of an extrinsic motivator, it was unclear that it was having a strong affect on Bryant to perform better in his classes. But he was fearful of disappointing his parents. Bryant expected his parents to be angry about his poor performance in science and was surprised when they were not. Earlier in the semester Bryant and his parents had gotten into an argument about Bryant's performance in his 
classes, but now they did not seem as angry, even though it appeared Bryant's

performance had not improved. This could have been an indication that his parents were beginning to understand how hard college was for Bryant. But will Bryant perceive this as a change in support, or might he feel like his parents now have lowered expectations? And does it signify a shift in responsibility from the parents to Bryant?

During this same interview, Bryant talked about other conversations he had with some of his relatives over Thanksgiving break. Bryant's response to his relatives questions about college, and his statement at the end, showed his continued ambivalence about college even as the semester was nearing its conclusion:

R: So, did you have any conversations about college over Thanksgiving?

B: Yeah, my family was asking me, "Do you like college?" and I was like, "Oh, yeah."

R: What did you tell them?

B: "It's alright." "It's not the greatest thing." "I'm there." And they all said, "Give it time." But I was honest. I was like, "I just don't care too much for it." I mean, I am gonna go, but they were like, "Isn't it fun?" and I was, "Well..." R: So, you told them that it's OK, but not great.

B: Yeah, and they said, "Well, keep at it." And I said, "Well, I am." I didn't know what else to say. I know that I have my classes set up for next semester, but to be honest I thought college sucked. I haven't enjoyed myself. And if I had my own personal choice, I would be in school somewhere down South. I told them, "It is nothing against this place. It is a nice school and all, but I don't know if college is for me." No one in my family has gone to college, but they have all been successful in their own right. (12/6/01)

These conversations made it clear that Bryant felt he did not belong in college. His relatives had the impression that college was supposed to be fun, but it was not fun for Bryant. This message that college was supposed to be fun had been delivered to Bryant since he was in high school, and it contributed to Bryant's feelings that he was abnormal because he had not found college to be fun. At the end of the semester, even as he picked out his classes for the spring, Bryant was still questioning whether or not he needed to be 
in college. He again referred to his father and his uncle as having achieved success without a college degree, and he continued to wonder why he wouldn't be able to do the same.

Partway through the semester, Joe moved into his own apartment. This was different than the desire to move into a residence hall that Joe had mentioned at the very beginning of the semester, but it still was a move out of his parent's home. Joe felt that his family was not supportive of his decision to move out, which made him vow to do well on his own, even without their support:

I am in my own apartment now, and it's wonderful. It's extremely hard getting adjusted to my new financial responsibilities, but that'll come to me. I vowed to prove everyone wrong, because they think this experience will put me under, but I choose to think differently. I am missing home life in a sense, mainly just missing my family. In all, though, the freedom thing gives me a high. I love it. $(11 / 18 / 01)$

In this statement Joe expressed a feeling that "no one" supported him so he was determined to prove he could succeed. He also expressed concerns about his new financial status. But his financial concerns and the lack of support he felt were balanced by his excitement over having an apartment and by his new found freedom. By the end of the semester, Joe felt that his family had accepted his decision to move out, and he perceived a change in their level of support:

$\mathrm{J}$ : Another interesting thing is with my stepfather. He is kind of a hard-nose. And I mentioned that we were a little floored at his response to our proposal to move out.

R: Right.

$\mathrm{J}$ : Well now it is like he has this whole new respect for me 'cause I am managing. Like, when I was at home, he is kind of mister fix-it, knows everything about everything, and I don't know how to fix anything around the house. And I know nothing about cars, and he is always working on the car, or around the house, so he feels like I am kind of a mama's boy.

$\mathrm{R}$ : 'Cause you don't do that stuff. 
J: Right! Now there will come a time when I will have to get the manual or whatever and do it, when I am on my own later in life with a wife and kids, but right now...

R: Unless you have enough money to take it to the mechanic.

$\mathrm{J}$ : That's another thing, he is afraid that I am going to spend all of my money having people do stuff for me. He wants me to do everything myself. Change my own oil. But now that I haven't crawled back, he seems fine and maybe even impressed with me.

R: So he was half expecting you to say that it was too tough.

$\mathrm{J}$ : And to fail. So now when we see each other, he is actually hugging me now. Physical contact with him is rare. And he is joking around, and I said to him the other day, "See you Jim-Bob." I call him Jim Bob. And he said, "See you, man." And he was all happy! So I love going home now cause of the response from everyone. And my brother and I have been getting along, and he was cutting up with me the other day. It was like, "Wow!" Like I was in the military or something. It is cool. (11/30/01)

But the support that Joe received from his stepfather did not appear to be at all related to how well Joe was doing in college. In what appeared to be an issue related to social class, Joe's stepfather was more concerned that Joe learn how to change his own oil, or fix something around his apartment, than that Joe does well in college.

Joe was managing his finances and he had become independent so he was no longer seen as a "momma's boy" by his stepfather. Joe's upbeat feelings were based upon his sense of relief that his family had finally accepted his decision to move out. He felt that by proving his family wrong about his ability to become independent, he had gained their support. However, it also appeared that it was Joe's stepfather and his brother, not his mother, whose opinions mattered the most to Joe.

\section{Faculty Support}

An important theme related to the issue of support for college, was the nature of these students' respective relationships with their faculty. While it also goes to the issue of belonging, the relationships these students made, or failed to make, with faculty, were closely linked to the issue of support for these students. A supportive faculty is key to an 
institution's retention of college students, yet none of the students in this study met with his faculty members outside of class. Further, most of them felt that there was no point in meeting with his faculty outside of class, even when they were in danger of failing a class. Conversely, the students who were in danger of failing reported that none of his faculty members had been in touch to discuss their grades or attendance, leading the students to feel that the faculty were not particularly interested in developing a relationship with them.

Generally speaking, I asked the participants to update me about their classes in each of our interviews. Following this update, I then I made a point of asking them if they had met with their faculty members outside of class. The answer to this second question was usually, "No." TJ's comments about his feeling towards his classes, which also indicated his feelings towards his faculty members, are worth repeating in this section:

TJ: I can't really say that I enjoy any of my classes really, right now. In my business class we don't do anything really. And in my reading class I really don't care for the professor much, so...

$\mathrm{R}$ : So other than English, none of them is a lot of fun.

TJ: Yeah, and I don't like English that much, but the professor, I really like how she works. So, if it wasn't for the professor, I wouldn't like that class. $(10 / 01 / 01)$

In his comments, TJ made it clear that he did not enjoy any of his classes. And the one class that he seemed to dislike the least was English, solely because of his faculty member's style. Since he did not enjoy his classes, it was not surprising that TJ had no desire to meet with any of his faculty outside of class. And he thought that they had no interest in meeting with him, either:

I didn't talk to them any, mainly because they don't really care to meet with us as long as we do what we have to do. I feel like if I told them about problems I was having, they would say, "So why are you telling me?" (11/1201) 
TJ used the word "they" in discussing the faculty and the word "us" to talk about students. He could have been talking about "us" as in all students, or "us" as in students like him, first gen students. Regardless, the "they" and "us" in the phrase, "they don't really care to meet with us," puts faculty and students in opposition. There was, to TJ, no reason to seek support from his faculty because he believed that the support would not be there. Further, TJ did not feel that his faculty cared about him, or about students in general. When he said that he felt "they" would say, "So, why are you telling me?" he was intimating that his faculty did not care about anything that students would come to talk to them about, whether it be personal or academic.

During this same interview, which occurred late in the semester, TJ and I also discussed how TJ had been dropped from a course because he missed too many class meetings due to car problems. He tried to get back into the course but had to talk to three different people, his advisor, his instructor, and the instructor's supervisor, before he could do so. In discussing the incident, he recounted how he felt his faculty member was working against him:

R: Do you feel like those people were helpful to you in sorting this out? TJ: Well, the way my teacher was talking to me she didn't seem like she really did. It was kind of weird 'cause she didn't talk to her supervisor about me in a good way. She said, "He has been stressing me out for a week." And, "He has been doing this to me."

R: That's what she said to him about you?

TJ: That's what she said. I think she was trying to talk to him just to get it off her back cause the way she sounded to me she didn't think I was going to get in the class. She was telling me she wanted me in, but I don't know how much she really did. She was like, "You know, you probably won't let him get back in but I just wanted to tell you." But luckily her supervisor let me back in anyway. But my advisor really tried to get me back in the class. But she wasn't able to get hold of the supervisor.

R: So, you are not sure your instructor even wants you in the class right now? TJ: Yeah, but I'm in now, and I have proof now. (11/12/01) 
TJ felt like he needed proof that he could stay in the class in case his faculty member said that he could not stay. This showed the antagonistic stance that $\mathrm{TJ}$ and his instructor had towards each other. And it was part of developing an intrinsic support system in TJ. TJ wanted to stay in the class so that he could receive the credits. It was not easy for him to get permission to stay in the class, but he did it with the help of his advisor.

Relationships with faculty were virtually non-existent for Patrick from Patrick's perspective. In several of our interviews Patrick talked at length about his feelings towards his faculty members:

P: My supposed advisor, they call them a faculty mentor, I emailed him a couple of days ago so I am waiting on him so that we can meet and talk. And, of all the professors I actually know up here, there is only one, in the classes I have anyway, professor that I really enjoy and it is my other justice administration teacher. I really like him so if I actually had a question, I would go to him. And talk to him. But thus far I haven't really had to. 'Cause I figure if anyone would know, he would, 'cause he knows his way around and stuff.

R: But you haven't gone out of your way to meet with your faculty?

P: No. I talked to my corrections teacher over that failing grade I received earlier in the semester, and that's about it. And that was before the last time you and I talked, so that was the last time I met with any of them. (10/31/01)

Patrick perceived a "couple of days" as a long lag time before he received a response from his advisor. Although this may not actually be a long lag time for some, it helped substantiate Patrick's perceptions that faculty did not care, and that they considered students a nuisance outside of class. He also felt like he needed a specific reason to contact his faculty members, otherwise he would not do it. Patrick was very reluctant to visit his faculty outside of class:

I think a lot of it is that we students feel like we are bothering them. If something is wrong, by God, you have every right in the world to see them. But I just hate feeling like I am annoying anybody. And if I am annoying a professor, especially someone that can come back and kick me in the butt? I am very wary of that. So, I think that is why a lot of people like us, who don't really know what we are 
doing up here, feel like we are bothering people. People who know say, "You need to go talk to the professor." Maybe people who have had that teacher, or who has been through this college experience, knows. It helps to have someone who not only went to college, but who actually made it through. And he'll say, "Hey, if you have a problem, there is no other way." So, then, you go talk to your professor. When I go to class, that is our time. It is time for us students. And outside of that it just seems weird and I don't want to bug them. I just have this idea in my head that if I do go to their office, they are going to harangue me. They will say, "What are you doing here? You are a failure. Get out of here. What do you want?" And that is not something that I want to hear. And that is a big reason for me not to see them. I am not sure how other people look at it, but that's the way I look at it. (10/31/01)

Patrick was hesitant to go see his faculty outside of class because he was afraid that the repercussions for doing so would be negative, not positive. Patrick also assumed that if the faculty felt bothered, they would retaliate against him, making it very risky for him to visit his faculty unless he had a specific reason to, a reason the faculty member would not object to. Patrick expressed feelings similar to TJ that faculty were not just disinterested in him, they were overtly hostile towards him. Patrick's words and feelings also showed a real fear of not being competent or worthy of faculty attention. So, with his assumption that faculty were hostile to students unless they had a good reason to "bother" them, and feeling unworthy of taking up faculty time outside of class, it would take a lot of encouragement from a particular faculty member, or a mandatory meeting, to get Patrick to the point where he would see his faculty outside of the classroom. In his comments, Patrick also compared himself and his first gen peers to the second gens who had a parent graduate from college, and indicated a certain level of jealousy over the fact that second gens had someone to show them what to do in times of crisis. Patrick felt that he received no such guidance, but he recognized that he could use it. 
In the next excerpt, there is a significant transition in Patrick from a feeling that the faculty did not support him, to his belief he had to prove himself, to feelings of frustration and self doubt which led to feelings of not caring:

My brother said, about teachers up here, that a lot of the more "low level" ones who are teaching the 100 and 200 level sections, will try to weed out those who aren't serious enough. So I am taking that information in and saying, "All right, I can do this." Doing all that I can. Sometimes I feel like I am being weeded out and sometimes, sometimes I think it is a test of my resolve. And I will get through it like I always do. I always seem to come out OK. Sometimes I have my doubts. I seriously doubt myself right now 'cause the more I study, the worse I do, especially with my sociology class. And it's getting frustrating and it is getting to the point where I am just not caring. I am just not caring whether I am doing good or bad 'cause it seems like any road I take leads me to the same place. I am not doing good. By no means am I doing good this semester. (3/31/01)

Once again Patrick assumed that the faculty members were not here to help him.

This belief was grounded in personal experience, and his brother's attitude. Patrick saw faculty members as having the purpose of gatekeepers, making sure that students were serious about being at college. This feeling was different from Patrick feeling that the faculty didn't care. Indifference would be easier to deal with in some ways. The faculty was more than indifferent. Patrick saw them as being purposefully antagonistic. This in turn caused a lack of motivation, which in turn affected Patrick's grades and the way that he regarded his college experience.

In our fourth interview, Patrick and I again were discussing faculty members. In this interview, talking about student-faculty interaction, Patrick said:

I don't have to like the teacher, but I have to know that they know what they are talking about. I have to know that they, at least, want me to do well, and will make every effort to meet me after class. My sociology professor seems very...I don't know what your take on him is, you know him better than I do, but the way I look at it, I have been in that class so the feeling that I get from him is, "I have a doctorate, fools, don't talk directly at me, talk to my assistant who will relay the message to me." But I guess that is an issue of mine that I need to get over. $(11 / 14 / 01)$ 
Patrick knew that I knew his sociology professor and I wondered if he had tempered his comments somewhat because of this, or perhaps just because of whom I was, a representative of the college. Regardless, he had a strong negative opinion about his professor, and Patrick's comments again reflected his feelings that his faculty held him and his fellow students in contempt. Patrick also continued to feel that it was his obligation to work through these issues, not something his faculty member needed to work on.

Like the others in the study, Bryant had limited relationships and interactions with his faculty members. During our second interview, Bryant was reflective after failing two tests, one in math and one in science, earlier in the week:

In high school, I didn't really have to study 'cause it was pretty simple stuff. In high school you just go in there and take the information and the teachers do a lot better in going over it and reviewing it. These teachers here at college, when they are through talking about it, it is like, "Ok, see you all." That is something I am trying to adjust to. It is not exactly all the one-on-one that you had in high school. $(9 / 27 / 01)$

A major issue for Bryant was the lack of individual attention that he had been used to receiving in high school. He expected his faculty members to come to him and to attend to his needs, as he perceived his high school teachers to have done. By his own admission, Bryant was not a "social butterfly," and this introversion caused him to resist getting to know his faculty outside of the classroom. During our third interview, Bryant talked about another science test he had just taken, when he mentioned a concept similar to what Patrick had voiced. Namely, faculty members who teach the lower-level courses intentionally try to fail students. In this case the reasoning is different but the perception is the same, the faculty are not here to help you: 
I was thinking of failing the course instead of just dropping, because if I dropped it, that would put me at a part-time student. I heard that being part-time is bad to be for some reason, but I haven't figured that out yet. I was talking to one of the ladies at work, she helped me get the internship in high school, and she said that a lot of teachers try to fail out everybody in the beginning, and say they won't give a curve and I should hang in there. (10/11/01)

Instead of talking to his faculty member about his concerns or his advisor, Bryant relied on a woman he worked with who he knew from high school. He had more confidence in her than he had with the faculty and the administrators on campus whose job it was to help students like Bryant.

The following exchange shows the complexity of the expectations Bryant, and perhaps TJ and Patrick as well, had for their faculty members:

$\mathrm{R}$ : In our last interview you were talking about how high school and coilege were different. Do you still feel this way?

B: It has changed a little. My science teacher is still like that. It is still like, "If you need me, come see me. My office hours are whenever, look at the syllabus." R: So, you would not feel comfortable going to him.

B: No, I would not feel comfortable talking to that man. He is just a little too stuffy, I guess. But my math teacher, he has changed a lot. And my English teacher too, she is real nice and she has been helping me with my writing. She thinks I've been doing real good in that class. And my volleyball teacher, he is a lot cooler. We have been playing volleyball, and it has changed a bit from the first weeks, which is nice 'cause I feel more comfortable now, talking to him. Like in English class, at first, I didn't want to raise my hand to answer questions, I was real quiet in there. But now I am talking just like I should, answering questions, and giving ideas and being more open. And I think she likes that, 'cause still not too many people do that.

R: So, have you been to visit any of your professors outside of class, then?

B: I did my English teacher one time. She had a little conference. That was about it.

$\mathrm{R}$ : What would the science teacher need to do to help you feel as comfortable as the math and English teachers?

B: I think a lot of it is the class is really big. I think when I first started the class, that it was 170 students or something like that. And it is really weird being in a class that large. 'Cause all of my other classes are like 30 and less, and then to have this one class that is just a lot larger than any other class I have been in, I think that is a lot of it. It is just very awkward. I mean, if you raise your hand out of a hundred people, you sort of feel weird. Everyone looks at you and you have 
to yell down in this huge auditorium a question, and he says, "I can't hear you," and he walks up and gets right up so he can hear it. So...

$\mathrm{R}$ : And then you get embarrassed.

B: Yeah, it is like, "Aargh." He doesn't seem to make it too comfortable to answer questions. (10/11/01)

Bryant wanted to "feel at home" right away at college. His expectation was that college would follow the high school model, with daily interactions between student and faculty that would create a certain type of student/faculty dynamic that college is not designed to replicate. Class size mattered to Bryant as well. The number of students in his class intimidated Bryant. Even when his faculty member came to him in class to answer his question, Bryant was uncomfortable, and this perhaps made the situation worse for Bryant. Bryant's gut-level interpersonal response mattered and the limited contact he had with his faculty allowed the first impression to linger and potentially interfered with his learning. It certainly interfered with his desire to see his faculty outside of class. The context of the class size also made it impossible for Bryant to interact with his faculty member, despite his feelings that he should do so.

In my fourth interview with Bryant, he commented on how faculty relationships helped him in some courses:

R: It seems that having a good teacher is important for you to do well.

B: I think so. They helped me get better grades in high school, I think. And the classes I think I am going to do well here, English and Math, I feel like it is partly because of the teachers. (11/01/01)

Near the end of the semester Bryant became concerned that he, like $\mathbf{T J}$ in his English class and also Joe in Joe's campus culture course, had missed too many campus culture classes and was in danger of failing the class:

B: Campus culture I found out that if you miss more than two classes you are supposed to fail. And I have missed three.

$\mathrm{R}$ : Have they said anything to you?

B: No. Every time I miss it is because of traffic. I get up at 8 a.m. or 8:30 a.m.

Try to leave at 8:45 a.m. or 9 a.m. but there is just traffic. 
R: Class is at 9:30 a.m.?

B: Uh huh. And usually I have done it where I come in late, but this time I was so late, that there would have been only five minutes left of class.

R: So, are you going to talk to your professor about it?

B: Yeah. I am going to get up super early this next Tuesday. I don't try to miss class but I come from the other part of the county and it is such a jam, especially at rush hour in the morning. (11/14/01)

But, despite his good intentions, he admits in our final interview, that he had failed to talk to his campus culture instructor:

I woke up late and I went to class late. That was great. I got up there and he said during class, "Just turn your papers in and I will email you with some comments." We all wrote our emails on the paper but I haven't gotten an email from him so I don't know if he is waiting until all the classes are over, or what. 'Cause he said he might want to talk to some of us. And I was thinking that if he emails me and says, "What's going on? You don't seem like you like college. Maybe you shouldn't be here," that I will tell him, "I am going to be here. I don't have to like it, but I can go here and pass." (12/6/01)

It is interesting to note that Bryant seems to have rehearsed this conversation, thinking that the professor might tell him that he doesn't belong here at college. It again is another example of how Bryant assumed that his faculty members were adversaries, not supporters. And it is another example of how the students in this study felt that they were going to succeed despite the faculty hurdles, not because of the help the faculty could provide. Bryant did receive a "fail" for the campus culture class, but he was unaware of this until he received his semester grades. Bryant's faculty member forced him to re-do his final paper as a condition for his passing the course.

Like the others in the study, Joe did not seem to feel connected to the faculty. He pointedly said that he saw no point in meeting with faculty outside of his classes:

In the biology and sociology classes there are over 300 students, so in those classes I am just another face. And I just haven't taken the time either. Personally, I don't see how it could benefit you, unless you were working on something where you needed to be tutored. But just to go and introduce yourself? I don't see how it can have an effect. (10/30/01) 
Part of Joe's response related to preparation in that no one had told him that it was a good idea to get to know his faculty members, particularly in large classes like the ones he was describing. There were also issues of belonging here as well in that Joe did not feel his presence made a difference to his faculty in these classes. Feeling like his presence did not matter made it easier to miss class, which eventually led to academic difficulty in several of Joe's classes. Regarding the issue of support, Joe felt he was "just a face in the crowd" to his faculty members in these classes. What was different about Joe, however, was the absence of feelings that his faculty was working against him. He was speaking about their indifference towards him, but he did not assume, as the other three did, that the faculty would be hostile towards him should he go to their office. He simply saw no point to it. This could be a result of the differences in high school education and preparation between Joe and the others. Joe came from a high school whose main goal was to prepare students for college and to support them in going to college. As a result Joe had come to see college in a positive light, and this included his faculty members.

Richardson and Skinner (1992) found that first gens had minimal involvement with the college campus, especially commuter first gens. They came to college almost solely to take classes, knew only a small part of the campus, and had little involvement with instructors or other students. According to Richardson and Skinner, first gens also felt that busy faculty and academic counselors were not interested in "wasting time" with them. Terenzini (1996) stated that first gens perceived faculty members as unconcerned with student development and teaching. The four students in this study clearly felt that their faculty members were unconcerned with them, at a minimum, and more likely were working actively against them to make sure they were meant for college. 
Anyon (1980) found that students with more valuable cultural capital fared better in school as indicated by their grades, freedom in the classroom, and attrition rate, than did their otherwise-comparable peers with less valuable cultural capital, and this is reflected in Joe's statement as well. Although Joe's grades at the end of the semester were no better than the others in the study, his high school preparation had allowed him to perceive the campus as a welcoming environment, despite the obstacles he continued to face. During our fifth and final interview, Joe talked about how he had stopped attending his campus culture class:

R: So tell me what happened with campus culture?

$\mathrm{J}$ : Sheer laziness. Class is once a week but it was so worthless of a class. The teacher that we had, it was her first year doing it. At the point where we were going over each part of business, and when we got on to marketing and management, she was like, "I don't have anything to say. Does anyone who is majoring in those two have anything to say? No? Then class dismissed." But when economics came up she had a lot to say about that because she is an economics person. I don't know. Plus that class is at one on Tuesdays and I have math lecture at four so I have to come up for that class and then hang around for two hours.

$\mathrm{R}$ : And how many classes did you miss for that course? You cannot miss more than three, right?

J: You can't miss more than two.

$\mathrm{R}$ : So after the third one what happened?

$\mathrm{J}$ : After my third absence, I was gone.

$\mathrm{R}$ : And did they send you a letter?

J: No, I haven't heard anything.

R: So you just assumed...

J: Well, she stressed that after two you would fail, so...

R: But you didn't go and talk to her after the third class?

J: No. $(11 / 30 / 01)$

Joe needed to accept some personal responsibility for his non-attendance, and he did to some degree. However, he also attempted to put some of the responsibility for his failure on his faculty member. Joe's professor made no attempt to make contact with Joe to try and find out why he was not attending class. This course is designed to help first year 
students transition to the college, which would seem that in this course more than any other, the faculty would take a particularly strong interest in how the students are doing. Instead, there was a lack of contact by the faculty member even as Joe was ready to fail the course. Joe would have to re-take the course in the spring but I had to wonder what the point is in making him take the course, other than to fulfill a requirement. Curiousiy, in a final paper Joe wrote for this campus culture course but never submitted, he wrote that in the spring he intended to meet with his faculty to get to know them better.

Unfortunately he never submitted the paper because he stopped attending the class.

\section{$\underline{\text { Student Services }}$}

Related to the issue of faculty relationships is the sub-theme of student services. The students talked about their classes and their faculty much more than they did the administrators on campus. They came to perceive the staff and administrators at the college as the nameless, faceless "they" and made references to "them" during our interviews. When Patrick had trouble getting registered for the spring semester, and had trouble getting his credits transferred, he felt as if the campus itself was unsupportive of his efforts to earn a college degree:

P: They have yet to put my credits on my transcript so that is why I got the letter sent to my parents saying I was failing that one class. I am still considered a freshman, even though I have earned enough credits to get myself out of the freshmen category.

$R$ : They haven't transferred your credits yet?

P: They said they lost something, and it is the third time they have lost my transcripts so I am kind of getting ready to staple it to someone's forehead and say, "There it is." I have to pay $\$ 2$ for every transcript so I am not gonna keep sending money, and say, "Send me a transcript."

R: Every time they say they lose it, they force you to go get another one?

P: Yeah. They say, "Well, you gotta go get another one." And sometimes it is my high school transcript, which they got you know, back when I applied for this college back in April. I don't know where this stuff is going, but it's getting annoying very quickly. I go back to my high school every now and then and ask 
'em for another transcript. A student who graduated two years ago asking for transcripts? I mean I'm sure the high school has it, but Lord. And they're saying I can't register for spring 'till all this stuff is found. And I'm like, "Well, I've given it to you three times." You know? I feel like telling them, "Take a step for yourself, and make sure you have this stuff instead of totally screwing me over for next semester." Well, we'll see what happens. (10/17/01)

Patrick was unable to register for classes for the spring because, according to Patrick, the registrar never did find his transcripts. Patrick's persistent use of the pronoun "they" to reference all of the staff in the registrar's office seemed to indicate another example of how the boys perceived themselves to be in an adversarial relationship with the institution. While he might not have bothered to learn the individuals' names, he also didn't perceive that there was a reason to. He was frustrated and angry. Patrick felt that his faculty was openly hostile to him, and now he was saying that he felt that the administration on campus was also working against him. "They" were screwing him over and costing him money. He was angry and frustrated at what was happening. $\mathrm{He}$ was also embarrassed to have to keep going back to his high school for transcripts as well. And because "they" had not accepted his transcripts yet, Patrick ended up in conflict with his parents about his grades when the college sent a letter home about his failing grade in the one class. This is a letter that Patrick would not have received had the college accepted his credits and had him listed as a sophomore, and to Patrick it was yet another example of how the college was not being supportive of his efforts to earn a college degree.

$\underline{\text { UPS }}$

TJ and Joe both were part of the college's partnership with UPS. Their work at UPS had a significant affect upon their college experience. Because it had such an affect, work as an issue came up in several of our interviews. UPS served as a significant source 
of financial support for TJ and Joe. Without this financial support both of them felt that they might not have been able to attend college. However this support also came with hidden costs for them. The costs were time, the physical demands of the job that caused a lack of sleep, missing classes and the learning opportunities associated with class, a false sense of financial independence, and the fun that they missed out on.

The arrangement the college had with UPS required TJ and Joe to work from 11 p.m. to 4 a.m. five days a week, in exchange for free tuition, $\$ 8.50$ per hour stipend, and assistance with money for books and rent. An additional enticement to work for UPS was a "loan" that UPS offered to students after their first semester, which, if the student worked for UPS long enough, was forgiven. The enticement worked for both TJ and Joe, who saw the possibility of free tuition, a stipend and no loans as too good a deal to pass up. This decision of theirs greatly impacted their college experience.

In contrast, Bryant also worked, but his job was mentioned far less frequently and was never really a significant issue affecting his college experience. Billson and Terry (1982) found that first gens worked more hours than their peers, were more likely to work off-campus, and ended up being less integrated into campus life as a result. This led Billson and Terry to suggest that colleges lessen the financial aid burden on first gens so that they would be less likely to work as many hours off-campus in order to pay for their education. Terenzini, et al, (1996) found that first gens worked more hours off-campus than did their peers and that it negatively affected their academic progress. Similarly, Richardson and Skinner (1992) found that first gens hold multiple responsibilities such as work, that made them more likely than their peers to attend college part-time, to transfer, or to stop out during college. 
Working for UPS provided TJ with an opportunity to attend college and he also saw it as a "fall back plan" in case his attempts at college failed. TJ also did not want to rely on his parents for financial assistance. This attempt at independence took its toll on TJ when he found that he needed to work two additional jobs besides UPS to make ends meet. At the same time that the job at UPS was providing TJ with the financial support to attend college, it also appeared to be preventing him from taking advantage of everything college had to offer. On one level UPS was a source of support, but working at UPS created a complexity that TJ was not prepared for. Initially it seemed simple: work part-time at night and get college paid for. But it did not play out quite as simply as TJ expected.

TJ's work commitments prevented him from being a full-time student, and caused him to consider taking five or six years to finish his schooling. TJ limited himself to ten credit hours in the fall, which automatically placed him behind his peers in regards to graduating on time. And the grueling nature of the work at UPS made it difficult for TJ to study at times, a hidden cost $\mathrm{TJ}$ had not anticipated:

TJ: I don't really like the hours that I have to work, especially if you are going to be a full-time student. And if you are studying there is no way you could work at UPS. I think working for UPS and doing all that is hard. And I guess if you can make it through that you can make it through later on so I guess in a way, it is good training for later life.

R: But it sounds like UPS limits you to certain majors?

TJ: Well, I know some people that have other majors, but they don't have any time to do anything else. Because I know that going to the engineering school you barely have enough time to do anything anyways, and you have to take classes really early in the morning, so to have to do UPS as well...

R: So, do you have to stay awake for, like, an 8 a.m. class after getting out at 4:30 a.m. or 5 a.m.?

TJ: Yeah.

$\mathrm{R}$ : And are you finding it hard to go to college and work at UPS?

TJ: I can do the classes OK, and I can do the job OK. And I can even have enough time to do another job. But it is just that when I have to do the work, I 
don't have enough time to study. I mean, I have the time, but the way things are set up, you always feel tired and you don't want to study. You don't want to study and you don't want to do your homework. And, knowing that you have so little free time, you procrastinate to the very last minute 'cause you have this free time now. And when I get home I want to sleep for a little bit, or sometimes I want to eat. But you kind of got to force yourself to study.

R: You feel like something is always hanging over your head, so if you goof off at all, you're going to be behind?

TJ: Yeah. 'Cause like every now and then I will come home and watch TV or watch that show, the Amazing Race. But after I watch it I feel bad cause I feel like now that I watched that, I missed something, so what I have been doing is waking up early to finish my homework, or staying up late to finish my homework. Like this week, I got kind of behind, and I am trying to make up everything now. It is hard to miss a day and make it up in college, anyway, but then with this schedule, especially, it is really hard. (10/01/01)

TJ said that he did not like the hours he had to work, and in response to my question, he felt that working at UPS limited him to certain majors. But he also talked about how the hard schedule he had might build character when he said, "If you can make it through..." But in orientation, as Bryant told us, college was described as fun. Yet nowhere in his description did TJ indicate "fun". Fun did not seem to be the operative word. TJ recognized that he did not have any time left for studying, let alone try getting involved in a clubs or an organization that might add some fun to his college experience. It was easy to see how TJ could have fallen behind his peers at college, given his work schedule. At the end of the conversation he was saying that falling behind was exactly what was happening to him.

Joe also had problems handling the work schedule at UPS while attending college. In the middle of the semester, Joe was forced to drop his plans for becoming an orientation assistant because it conflicted with work. Joe also found that he was unable to attend many of the social events sponsored by his fraternity due to work. These were two of the unanticipated hidden costs that Joe faced during the semester. UPS provided 
strong financial support for $\mathrm{TJ}$ and Joe, but there was no academic support for them, it appeared. The work at UPS affected what majors TJ was willing to consider, and it determined Joe's class schedule as well:

R: Do you find hard to work, is it midnight to four, and study? $\mathrm{J}$ : Yeah. I leave at 11p.m. and get home around 3:30 a.m. I don't want to say yeah, but like this sociology class? It meets at noon on Mondays, Wednesdays, and Fridays. And it is my earliest class, but I have missed a bunch of classes for that course. But other than that, it is pretty easy. I have a one o'clock class that is the next one after sociology. I don't know why it is hard since it is only an hour earlier, but when I get up and take a shower and get ready for the noon class, I have to get up at $10 \mathrm{a} . \mathrm{m}$., and whew, it is hard. Being a teenager I need the sleep, and the work you do at UPS is so physical, it is tiring. Next semester I already have gotten my schedule written out, and I like it. Two o'clock is my earliest class. So, that will be better.

$\mathrm{R}$ : I would imagine at sometime, though, you will have to take an 8 a.m., or a 9 a.m., or a 10 a.m. class, right?

J: I hope not. There might be, but I don't know what I would do then. I have a friend who works at UPS and he decided to enroll here really late. So, he was one of the last ones to enroll. Most of the classes were filled so one of his classes is at 8 a.m. and he gets out of UPS later than I do so he has to stay up between that gap and go to class. And he doesn't get to go to sleep until after that class. I don't see how he does it. $(9 / 21 / 01)$

Joe tried to convince himself that he could balance work, academics, and a social life, and was dismissive when he found that he missed classes due to work, saying "Other than missing sociology classes," balancing work and school is easy. He saw UPS as a higher priority than class and was more willing to miss class than to miss work. He saw missing class as no big deal. Joe feared that he would have an early morning class because he knew what the result would be if he was forced to take an early morning class while he worked at UPS. Yet, he planned to work at UPS until he graduated:

$\mathrm{R}$ : And are you definitely doing UPS again next semester?

$\mathrm{J}$ : Oh, yeah. I plan to do it for as long as I am in college. $(11 / 30 / 01)$

Unless something changed, it seemed unlikely that Joe would be able to achieve all of his goals of working at UPS, avoiding college debt, living in an apartment, being 
involved on the college campus, and doing well academically. The odds were simply not on his side.

\section{First Gens vs Second Gens}

The participants in this study occasionally compared their experience to the experience they perceived their second gen peers were having. There was a feeling by some of them that second gens received more support for college, and that they, as first gens, had to succeed on their own with little or no support. During the study Patrick was dating a woman whose parents attended college and at times he was jealous of his girlfriend because her parents had attended college:

I kind of feel like, if Mom and Dad had only gone to college, it wouldn't be so difficult for me. They didn't even have to finish. They could have just gone a semester and learned, you know? It doesn't take that long to figure out how this stuff works up here. And I just think that it would have been a lot easier on me, and I might, well... but they didn't and I don't hate them at all. Where they came from and attitudes back where they were from, things were different so it wasn't their fault. But I do think that if they had gone to college things would have gone a lot easier on me and Joe. So, sometimes I feel anger towards my girlfriend. It just would have been so much easier if they had just gone to college. They would have been telling me, "Oh, it's alright, we understand," and then I wouldn't have felt so, "Oh, God, I have to do good." (10/31/01)

Patrick believed that if his parents had gone to college for at least a short while, he would not have felt so pressured to do well at college. He believed that they only needed a short time to "figure it out," yet Patrick was at his second college and still did not appear to have "figured it out" so why did he think it would have taken them less time? He seemed to think that he would have figured it out faster if his parents had gone to college because they could have helped him to figure it out, instead of his having to figure it out by himself. Patrick believed that parental support should look more like what his girlfriend received, then what he received. 
Patrick felt pressure to succeed as a first gen, and he felt disappointed by his parents as well. His parents did not attend college and so, to Patrick, they were unable to understand what he was experiencing. Patrick felt he had to do well at college because he was a first gen and people were watching him. He wanted to be successful to prove "them" wrong, to show "them" that he could do it, but he also had an internal fire that was fueling his desire to succeed despite the lack of support he felt.

At various points in this analysis there were pieces of data that could have been included in more than one section. For example I found that many issues of support for college could easily fit into the category of belonging to college. The issue of faculty support is one such issue. While these students generally felt unsupported by their faculty, they also felt that they did not belong in class or at the college, either, based on their comments. The next section deals with the issue of belonging to college and will discuss their feeling related to this issue, and explore some of the reasons why they might have felt as they did during the semester.

\section{Belonging}

Hell, I don't feel like I belong, but it beats the alternative. I don't think I can do college, but it beats the alternative. (Patrick, 10/17/01)

I really feel that I am just here to get a sheet of paper and then leave the place. I mean, it's just school. I have my routine and it is school, work, home and TV. I don't live for school. There don't seem to be any "life lessons" to be learned by going to school. At least not for me. (Bryant, 11/01/01)

As these quotes demonstrated, college was not something these students perceived school as something to be tolerated, not enjoyed. Their preparation for college did not allow them to participate fully in everything that the college had to offer, and the support that they received for attending college was at times inadequate to allow them to 
take the risks necessary to become more acculturated. Both Patrick and Bryant expressed feelings that they did not feel they belonged on the college campus. But when Patrick looked at what his alternatives were, college was the better choice. He felt "pushed" towards college because of the lack of options, rather than "pulled" to enroll in college because he was excited about what the college experience meant. Bryant never fully committed himself to the idea that college was going to be a life-altering event. $\mathrm{He}$ attempted to avoid the painful conflict that many first gens feel as they enroll in school. This section discusses issues relating to these students feelings of belonging to the college. It analyzes some of the ways that the campus worked at making the students feel that they did not belong, and ways in which the participants actively disengaged from the campus as well.

Several themes emerged from my interviews with these four students related to the issue of belonging. Because of the complexity of the issues being dealt with, there is some inevitable overlapping with the previous themes of preparation and support. For these students to be successful in college they needed to feel that their presence mattered. They needed to feel that they belonged to the campus (Tinto, 1983). But all four of these students felt at various times that they were not truly part of the college. Joe was the only participant who actively attempted to join an organization during the study, which was a very tangible way that he sought to become an active member of the college community. However, Joe struggled to balance fraternity life, work life, school life and home life and the conflicting demands these aspects of his life placed upon him.

These students did not make connections to the faculty, either in or out of the classroom. This lack of connection caused these four students to feel like they were "just 
another face," as Patrick described himself in one of our interviews. While this was an issue of concern related to these students' feeling unsupported, it also led to them feeling like they did not belong.

The students in this study mentioned that they were insecure about making friends at college. This was evidenced early in the semester when with all four of the students either living with friends of theirs from high school, or living at home. Three of the four students seemed to have only one close friend with whom they spent virtually all their off-campus time, and this was someone that they knew from before college or from work. The enactment of a sense of belonging these students felt seemed to be directed somewhere other than college, such as at work UPS, or in Bryant's case, the church.

The pressure to succeed at college because they were the first in the family to attend college was something that several of these students felt. They seemed to expect to fail at college because they carefully devised "back-up" plans if their demise occurred. This anxiety over whether or not they would be successful combined with their feelings that they did not belong to the college or on campus, and was disorienting to them.

In analyzing the data I found that the following themes emerged from my interviews with these students around the general area of belonging:

- Place of residence

- Friendships

- Involvement

- Campus Culture Course

- What is "Normal"

This section is organized according to these themes. 


\section{Place of Residence}

The students in this study felt more of a sense of belonging to places other than the college. They roomed with friends of theirs from their hometowns, with their brothers, with their families, or with people from work:

TJ: I have an apartment with a friend from my high school and we live together.

We are from a really small town so we both went to the school.

$\mathrm{R}$ : Is he a freshman also?

TJ: Yeah, he goes to the community college here, and he is going to try to transfer here next year, but he is still not sure. $(9 / 17 / 01)$

TJ's friend lived with him and worked him at UPS as well. TJ's choice of who to live with limited him in several ways. For one, he could not live on campus in a residence hall because his friend was not a student at the college. Secondly, because they both worked at UPS, they had to move into the off-campus apartments that UPS authorized, in order to receive the monthly rent stipend from UPS, which required TJ to live about twenty minutes from campus. The amount of driving TJ did eventually damaged his car, causing him to miss a number of classes during the semester. And being so far offcampus caused him to not get involved on the campus.

In several of my interviews with TJ, he would talk about his trips back home to visit his girlfriend on the weekends. On one particular weekend he attended a festival in his hometown, demonstrating his attachment to home. TJ's girlfriend was planning on enrolling at the same college as TJ when she graduated, and intended to major in accounting like TJ as well. She also, according to TJ, expected to work at UPS, all of which meant that TJ would continue to feel a sense of "belonging" more to home, or at least to his girlfriend, than to the college:

R: So, you went home over the weekend?

TJ: Yeah, and last weekend, too. I just got back this morning again.

R: So you went back the past two weekends? 
TJ: Yeah. The last weekend, I went with the high school band to help them because my girlfriend is in it, and I spent most of the day doing that. I saw my dad a little bit, not really much. I went just driving around, just to take my girlfriend out. We really didn't do that much, but it flies by even though we didn't really do anything. I usually leave Saturday morning right after work. I go into work about 11:30 p.m., and then I leave UPS about 4:30 a.m., or 5 a.m., and drive the two hours straight there and go to sleep. And this weekend, I went to the chicken festival. That's the big thing in our town and they have it every year and I went this weekend with my brothers and my dad. It is kind of corny, when you think about it, but it is something the whole town does. I don't really care for it a whole lot but it something my family does. They only have it for the weekend and the students get off school for it. Then I came back Monday morning, right before class because we don't have to work weekends.

$\mathrm{R}$ : Oh, ok. So your girlfriend is in high school?

TJ: Yeah. She plans to go to $U$ of $L$, and she plans to be in the same program, and to major in business as well. She would also be the first in her family to attend college as well. It seems like a lot of my friends in high school, I really don't have too many friends that I can think of whose parents went to college. $(10 / 01 / 01)$

TJ seemed to show that he had been thinking of this study outside of our interviews when he mentioned that a lot of his friend's parents are first gens. Peer support was very influential during adolescence and if TJ's friends were predominantly first gens, this added another dynamic to his attempt to obtain a college degree. The majority of first gens attend community colleges, as $\mathrm{TJ}$ did, and he was breaking from his peers in a very significant way.

During the study $\mathrm{TJ}$ missed a number of classes due to car problems and his having to commute to campus. During one of our interviews I asked TJ if he had ever thought about moving closer to campus since it seemed that living closer might solve some of his commuting problems:

As a matter of fact, when my alternator broke down, I had a guy who gave me a ride home and he offered me a house for $\$ 400$ a month and it was right near the campus. And it would be real close to UPS and right near the school. But the house was smaller than our apartment. So, it wouldn't be much of a change. And we would be paying the same amount so we figured it would be best to stay where we are for now. $(11 / 12 / 01)$ 
TJ's utilitarian attitude caused him to pass on the house that was closer to campus. $\mathrm{He}$ balanced the amount he paid in rent and the relative size of the apartment, with the convenience of living closer to campus, and chose the monetary aspect. Even though he recognized that the house would move him closer to campus and knew that there was a bus that went right past the house that could take he and his roommate to work, he still opted to stay in the apartment. This was another potential difference in first gens and their peers. The parents of second gens recognize the educational benefit of living on or close to campus, and encourage their children to do so. The first gen parents of the boys in this study did not encourage their children to take advantage of the opportunities living on campus provided.

Unlike TJ, Patrick lived within walking distance of the campus, although Patrick was similar to $\mathrm{TJ}$ in that he lived with people that he knew from his hometown. Patrick lived with his brother, and some of his brother's friend, all of whom Patrick knew from his from high school. Patrick felt conflicted about where, exactly, he belonged. Unlike his brother, who seemed to have made a complete break from home, Patrick seemed to want to negotiate the family conflicts so that he could return home. But even so, though, he was never really sure that he could return home. During my interviews with Patrick, it appeared that he relied on his brother for help in negotiating the college experience:

P: Well, my brother called one night and just started talking, you know? We used to be close when we were younger, but these tensions started happening? Joe wanted to be independent but mom and dad knew they couldn't get him so things would trickle down on me, although they would argue with me about this point. And, it kind of strained the relationship I had with my parents, greatly. And my brother and I would start talking and laugh about these things and he said, "Look, I know you don't want to go home and stay another summer at home, there is no place to work, so why don't you come here? Transfer up here. We have a house up here now, and we have an extra room. You can stay with me and it will be like 
it was before all the trouble." I said, "Well, all right." So, I came up here and been here ever since. $(10 / 03 / 01)$

The conflicts Patrick had with his parents seemed to bring him closer to his brother. His unhappiness at his previous college, caused him to consider that he would be better off living with his brother and attending a different college. He saw it as a way to start over. His brother seemed to be doing well at the college, so perhaps that was where Patrick belonged. He knew that he did not belong back at home, nor did he feel that he belonged at the college he was currently attending. But despite having these reasons for transferring, and having what appeared to be a strong support system here, Patrick still did not feel comfortable:

P: I'm not a fan of the big city. I've never lived in a town of more than 5,000 people. My hometown was about that size, maybe a little bit bigger. Coming up here, I had never been in a big city. I had never even seen this city until I came up here. It was a big risk, but you know, it was something that I felt I needed to do at the time. But I miss my small town life.

R: How does it feel to be here, then?

P: Sometimes I don't like it. Most times I don't, actually. I don't talk about it much, though, cause I was the one who choose to come up here. But I can't look you in the eye and tell you honestly, if I had to do it over again, that I would. I probably might, but it would be very doubtful. I would probably choose a simpler existence. But, then, but I have chosen my path and something for some reason keeps me on it. I don't tend to try to change things too drastically. I try to keep things simple, but it is impossible in a city like this at times. $(10 / 03 / 01)$

Patrick transferred because he felt like he had few options. And now that he was here, he was re-considering his choice. His dilemma was similar to the dilemma many first gens felt. London (1992), Piorkowski (1983), Terenzini (1996) all wrote that many first gens feel caught between two cultures, the culture of home and the culture of the campus. Although many first year students feel this way, working class, first gens feel it more deeply because of the social class differences between home and college, and the perceived lack of understanding by their parents about what the college experience is. 
Patrick was living in and out of the borderlands of both cultures (Anzuldua). He no longer felt that he belonged home, and he saw limited opportunities for him at home. But he did not feel as if he belonged on campus, either. In his struggle to figure out why he did not feel comfortable here, he considered that it was the big city, or perhaps his desire for a simpler existence. But in fact he did not feel that he belonged at his previous college, either, which was considerably smaller and located in a small town as well.

During our interviews, Patrick vacillated back and forth about where he felt he belonged. In our first interview, when I asked Patrick about his feelings towards his hometown, he seemed to still feel attachment to it, even if he also felt there were limited opportunities there for him:

I think if I go off, become successful, make some money, when I retire, I will definitely go back to my hometown. Cause regardless of my attitude towards it, and what other people say about it, it's home. You know, it is all I know. $(10 / 03 / 01)$

Then, during our second interview Patrick seemed to be saying that he actually felt more a sense of belonging to the college, than to home. At this point in the semester he seemed to be torn about where he belonged. Similar to the notion of being "pushed" to attend college, he seemed surer of where he did not want to be. So, even though he talked about not fitting in at college in a previous interview, in this one, he said:

$\mathrm{R}$ : So where would you call home right now?

P: Here. I don't want to go home right now. I was missing home and then I got a real quick reminder of why I don't want to be back. $(10 / 17 / 01)$

The conflicts Patrick was having with his parents at that point in the semester kept him from feeling a sense of belonging to his hometown. His brother, on the other hand, did not feel the same way. This could have led to Patrick's conflicted feelings as well. If 
Patrick had chosen college over home, he might have felt that he was choosing sides with either his brother or his parents:

R: It sounds like your brother has really made a break from your hometown.

P: He says, "There is no reason for me to go home. All of my friends have moved off. There is no reason."

R: So, do you still have friends back there, though?

P: I do. Most of my friends have yet to move off. A lot of my friends either go to colleges around the area, or have just decided that maybe college is not the best idea for them right now. They are working down there right now, so when I go home, all my close friends are still there. So there is still that attachment to my hometown that makes me want to go back. (10/17/01)

When we re-visited this topic again though, it was clear that Patrick was troubled by the conflict he felt about home and college. He was troubled and upset because two women from his hometown, women whom he had graduated from high school with, and that he expected to go to college, did not go. To Patrick, they ruined their lives:

P: My parents don't know what they are going to do with my brother and I.

'Cause they know that our hometown has no opportunities. Where am I going to go? I am not saying that people who go to college are brave. It doesn't take braves, but for some people it is brave to go. I can understand if you are the first. But I think it just takes desire. It is a risk, oh yes. But it also takes desire to want to make something of yourself, and to get out of your surroundings. I mean everyone knows that there is nothing there in my hometown. It is not a secret that there is nothing there for anyone. Anyone who lives there says, "Oh, I gotta get out of this place. I can't wait to get out of my hometown." Everybody. Those girls included. But when it comes right down to the time, it was a risk they didn't know if they were willing to take.

R: Your hometown was pushing them out, but it probably wasn't clear what they were being pulled to.

P: And, college was pushing them back, is what they saw. Cause they felt like they didn't belong in college, and they felt like they couldn't do that. Hell, I don't feel like I belong, but it beats the alternative. I don't think I can do college, but it beats the alternative. $(10 / 17 / 01)$

Patrick felt that he did not belong at college, but what he also felt that he had few other choices. While he acknowledged that it took some bravery to go to college, especially if you were a first gen, he was not willing to let go of his feelings that all it really took, 
when you got right down to it, was desire. If you really wanted to make it, you could, he felt. He was developing an intrinsic motivation for himself that would help him prove that he could make it in college, even if he did not feel he belonged there.

In talking to Bryant it was clear that he felt more of a sense of belonging to his family and the city than he did to college. His mother's family was from the area, and Bryant's immediate family had lived in the area for approximately nine years. Consistent with his religious orientation, Bryant and his family attended the same church virtually every Sunday for all of these nine years. Although Bryant said that he applied to another college in Alabama, he admitted that he was glad he chose to attend college locally:

B: But I am glad that I stayed home. My mom wanted me to stay home the first year. She says that since I didn't do so good in high school, she wanted to make sure that I would be OK, but I think that really since I am her first born, and also that I am going to be leaving, she wanted me to stay. It is a little weird for her, but not so much for my dad. But I am sure he thinks, "I like you being here," since I am the one who helps the family. (9/13/01)

Bryant was guessing that his father felt glad that he stayed at home, and although his mother said that she was concerned about Bryant's academics, he felt that her real issue was that she did not want him to leave home. When we discussed his living at home as opposed to his living on campus in this same interview, it was clear that Bryant never seriously considered living anywhere but home, which is where he feels he belongs:

B: Sometimes I will say, "When I get an apt and move out," And they will say, "You're not moving out." "Well, why not?" "You're just not. We don't think you're ready."

$\mathrm{R}$ : Did you consider living on campus?

B: Here? No. I mean, I guess I could have if I wanted to, but it would have been more money they would have had to spend and it is sort of pointless when they live 15 minutes away, and we just finished the basement and that is pretty much an apartment for myself. And that has a room, bathroom and kitchen down there, so I was not looking forward to leaving after we did that. $(9 / 13 / 01)$ 
The utilitarian point of view is evident when Bryant talked about not living on campus. His rationale was that it was "pointless" to live on campus because it cost money and, since he had a nice apartment at home, it did not make any sense. There was no consideration of the potential academic or educational benefits that might be derived from living on campus. And his family did not encourage him to live on campus either. When leaving home was discussed, his parents told him that he was "not ready yet." There are a number of mixed messages involved in this dialogue Bryant had with his parents. His parent's verbalized support for college, but only if it meant not moving out. Bryant is mature enough to attend college, but not mature enough to live on his own. And Bryant's need for independence is balanced against his desire to have the conveniences afforded to him by living at home. He wanted to have a car, to have his meals prepared for him, and to have a nice room without a roommate. Thus Bryant was willing to tolerate the intrusions of having his father open his mail without Bryant's consent, in exchange for having a place where he felt a strong sense of belonging.

On another level, leaving home and living on campus represented a risk that Bryant and perhaps his family were not willing to take. Bryant admitted that he felt uncomfortable in social situations and living on campus would thrust him into the midst of forced social interaction. Additionally, because Bryant was not involved on campus to any great extent, commuting did not pose a tremendous hardship. This was in contrast to Joe, who was trying to become involved and found that the commute was an impediment to this involvement. 
In the beginning of the study, Joe was living at home and commuting to college.

In his explanation of why he chose to attend the college, he talked about his nervousness

for attending college, his finances and his attachment to the community:

I wasn't too sure about going away my first year of college. I thought it might be too much. Financially I couldn't afford it. I wanted to be home. I love it here. I love the city. Plus, after orientation, because they did a great job, they made me feel comfortable with my choice. I guess since it was here at home and I think it is a nice little school. I had read up on it and it explored my options. My parents weren't too excited, but they were happy since my brother going here and everything. It was no big deal. Again, my mom didn't want me to leave home. $(9 / 21 / 01)$

Joe's concern for his mother was evident. He mentioned her twice during this conversation as a reason for his wanting to stay in the area. And in the same interview when Joe and I were discussing his plans to move out of his mom's house, his concern for his mother was also evident. But Joe changed his plans from moving into a residence hall in favor of moving into an apartment with a 20 -minute commute so that he could live with some work mates:

R: Why didn't your mom want you to leave home?

$\mathrm{J}$ : Empty nest syndrome, 'cause I am her last one. She is hiding it but it is so obvious that it is almost funny. And my brother, you know, he is on the verge of getting his degree so she knows he will be moving out soon. If I come home, and I miss supper, and she has already cooked it and put it away, she is like, "Nobody was home for supper." And I am like, "Aww. I'm sorry." She doesn't want to let go of me and my brother. I think that is it.

$\mathrm{R}$ : And last time you were talking about maybe moving out and moving into the residence halls?

$\mathrm{J}$ : Well, that has changed. Hopefully, I am moving in with a friend of mine that I work with, into an apartment within the next month. We approached my mother with it this weekend, me and my friend from work, and she was, "Yeah, sounds fine." But we could tell she was still hurt by it. But I am really excited about that. $\mathrm{R}$ : So it is about 20 minutes away? At one point, you were saying that you wanted to live on campus.

$\mathrm{J}$ : Yeah, I am contradicting myself. But, this apartment is really big and the dorm it is like a hotel. And I really hit it off with the guy I am moving in. He just started work at UPS about a month ago and it is like we are best friends. He has two other roommates but one is moving back home. So he needs another one and 
he said that I am the only one he wanted to move in. But I won't abandon my mom. $(9 / 21 / 01)$

Joe is torn with wanting to move out and establish ties with his friends from work and school but at the same time he felt like he was abandoning his mother. He was conflicted about leaving home but he wanted to establish a closer sense of belonging to his friends and to the college community. Joe and I also discussed his upcoming move from home to his apartment during this interview. In this discussion were conflicting issues of support and belonging for Joe, issues which most college students face. However, according to London (1992), first gens feel conflicts more acutely:

J: When I proposed to move out, my buddy that I work with and I approached my mother and stepfather. And I said to my stepfather, "Jim, if I move out, you know, and try it for a semester, can I come back, and start over, and try to save some money later? Or if I fail am I on my own?" And he was like, "Yeah, it sounds like a good idea. Sounds like a good experience." And he was really open. Guess I caught him on a good day. And my mother was kind of floored, too. He was so...OK.

R: 'Cause you were fully expecting him to say, "Look, pal, once the door hits you in the ass, you're on your own?"

J: Yeah. "See ya." That's what I thought. Actually, that's what my mother and brother thought, too. That's what all three of us thought.

$\mathrm{R}$ : So that must have been a relief.

J: Oh, yes. Oh, yeah, it was a good day after he said that. I was celebratin'.

Cause my mom was taking his point of view. But my brother, I don't know, it is shady. I think he is mad that I am moving out before him.

$\mathrm{R}$ : Oh, really?

$\mathrm{J}: \mathrm{He}$ is 23 and still living at home. And I think he didn't like it. I said, "Do you have anything to say?" And he said, "We have to go through clothes before you move out and decide which ones are staying here." And l'm like, "That's it?" And he said, "Yep." And I said, "OK." There is a real difference between my brother and some of my friends about involvement. I just love being involved and they are just here to get grades and go home. To them it is just school. It is just four years of work. That is how they look at it. $(9 / 21 / 01)$

To Joe, his brother and his friends have a more limited view of school. Early in the semester when Joe was asked what he thought the role of school was, he mentioned "educating yourself" as well as preparation for a job. So while his fri ends might think 
that it is "just school," which is almost exactly what Bryant said about college, Joe really wanted to belong to campus. At the same time, though, he was struggling with which group to belong to, and it was unclear which group gave Joe the most support for what he was going through.

Friendships

Several of the students in this study mentioned their insecurity about making friends at college as an issue, and this was evidenced in that all four of the students either lived with friends of theirs from high school, or lived at home. Billson and Terry (1982) found that first gens were less likely to join student organizations, and were more likely to make their best friends at work, not at college, and the two issues could be connected. If you have pre-existing friendships, there is less of an incentive to join clubs or organizations where a primary purpose is to make friends. TJ, Bryant and Joe all had significant work responsibilities off-campus. All of them had friendships with their work peers. With the exception of Joe, the boys also seemed to have only one close friend they spent most of their off-campus time with, and this was someone that they knew from before college or from work.

In our first interview Patrick was quite vocal about his feelings of not belonging, his feelings that maybe he had made the wrong choice by transferring, and his feeling "trapped" between not wanting to attend college, and his realization that there was no clear alternative. This lack of an alternative provided further evidence of the "push" to attend college that Patrick felt:

P: I always felt on the outside here, 'cause I haven't really made any college buddies. With my accent, people up here ask me, "Are you a hick?" "Does your mom wear shoes?" You know, things like that. I have always felt looked down upon, like I am not intelligent. That's fine, that don't bother me. But at the same 
time I don't feel like college is for me. Of course if I said that at home they would laugh at me. They would say, "Oh, you are being stupid." They overestimate my intelligence greatly. Yeah, my brother is a genius, but I am not him, you know? There is nothing similar between us at all, and I don't feel college is for me a lot. I don't feel like this is for me a lot but I know that there is no alternative and it makes me feel trapped. And that's the way I have felt since I graduated and enrolled in college. I would never go back to high school, but I haven't felt good about things. That's kind of the way it's been.

$\mathrm{R}$ : Does it feel to you like the other people here at college are adjusting and you are not?

P: Yeah. $(10 / 03 / 01)$

Patrick's poor self-image helped prevent him from taking the risk of making friends outside of his immediate circle. He assumed that when he opened his mouth, and people heard his thick southern accent, that they would assume he was stupid, and would make fun of him. Patrick assumed that his faculty held him in contempt and now he indicated his feelings that his peers held him in contempt as well. Adding to this was his statement that he felt he and his brother had nothing in common, which was problematic since his brother had become Patrick's main source of support at this point in Patrick's college career.

In the section on support, we saw that Bryant felt more belonging to preestablished friendships that to college friendships. Since Bryant knew his self-described best friend, Eric, in high school, and now went to college with Eric, this may further prevent Bryant from developing a sense of belonging within the college community:

B: Eric is probably my best friend. I have known Eric since my freshmen year in high school but we really did not start doing stuff until our senior year. I was a little picky. We have a lot of interests and we spend a lot of time camping and most people think camping you go out with beer but we go actually go out back packing. We are into hunting and fishing and that whole off road, outdoors thing. It is more like my Alabama roots. He goes here to college but he has a different major than I do. He is at my house or I am at his every day of the week just hanging around. I would have to say that he is my best friend. My best friends at one point were my youth group, and we used to do everything together until we all had to get jobs. I was a lot more fortunate than most kids are. I mean I didn't 
have to pay for insurance on my car, or my car, or gas, and they had to work to pay for all of it. That was weird for me because they were upset that I could skate by without paying much and they had to work and that sort of grated on our friendship. Not that we disliked each other but it was just uncomfortable talking about our jobs. $(9 / 13 / 01)$

Bryant talked about hunting and fishing and off-roading and his "Alabama roots" with great pride. These activities were the same ones that caused Bryant to consider himself a "red neck" and a member of the working class. At the same time, however, Bryant showed signs of social class conflict with his previous friends. Now it appears that his only friend is Eric, who is also a first gen. The influence of religion in Bryant's life is also clear when he talked about how most of his earlier friends were from his church youth group. This continuing reliance about church as a source of his friendships could be another reason why Bryant did not make any friends on campus. He felt he had sufficient friendships off-campus.

Judging by Bryant's earlier references to the fact that college was "just school," it appeared that Bryant did not accept that going to college was a significant step, requiring a significant commitment. This commitment would require Bryant to make new friends at the college. This lack of commitment to college allowed Bryant to feel that he really "belonged" to his family, his church, etc, and not to the college so he avoided the conflict that London (1992) discussed and that Patrick seemed to experience. This lack of commitment on Bryant's part, combined with what he saw as his inability to make friends with people his own age, caused him to not have any college friends:

B: I really only have my one friend, Eric, and we pretty much said that we were going to be best buds. I know this sounds really weird, but other than Eric, most of my friends are older than 21. Like I went camping with a bunch of guys this past weekend and everyone was between ages of 22 and 28 or something like that. I have always seemed to connect with grown-ups better. Even as a little kid. I don't think it is because I am mature, I am far from that and they probably tolerate 
me sometimes more than they are my friends, but I still have always seemed to connect with older people in general and I don't do very well meeting people my own age, unless I am specifically introduced to them. I hang out with the single young adult group in my church, who range in age from 22 to their late $30 \mathrm{~s}$. $\mathrm{R}$ : So you really haven't connected with anyone here, either in class or outside activities?

B: No, I just find it difficult to go up to someone, especially females. Like just to go talk to girls. Unless I am specifically introduced or something, I just stick to myself or to the friends I know. I don't know. I am a little weird I guess. And I wish it wasn't like that but it is something that I just can't do. (9/27/01)

In this interview, Bryant saw himself as connecting with older people. He talked about how he found it difficult to connect with peers his own age. At the same time he gave the appearance that he did not look to his college peers for friendships or support, however. He described himself as "weird," not stopping to think that perhaps he was more the norm. However, because he did not talk to others at the college he did not have the opportunity to see how normal his feelings actually were. Bryant also expressed a desire to not be so "weird," so that he could make more friends on campus but unless he was specifically put in a position by a friend or someone else he felt unable to connect with his peers on the campus on his own.

In our fifth interview, Bryant indicated that indeed he not only desired college friendships, but he was finding it hard to be at college without them:

B: A lot of times I just think, "This sucks. It is not fun. It's just a pain. I am going here "cause I don't have anything else to do."

$\mathrm{R}$ : What keeps you going?

B: I don't know. I don't really want to be working full time right now. I like being able to go out and go to school and come home, and have fun with my friends and then sit and sleep. So right now it is just convenient, I guess. I try to like college, but a lot of times it is just boring. It is just more school to me. Personally I liked high school better. I had my set amount of friends in high school. We didn't always hang around on weekends but we hung out during school, and everyone was friendly. And we had our clique, and that is what we did. We talked, we hung out together, we had classes together, we ate lunch together, and that was good. But now I have one guy that I went to high school with that we are pretty good friends. He is in my English class and if he wasn't in 
my English class, I think I would have been bored out of my mind. 'Cause I hate going to class and not knowing anyone and just sitting there and no one is talking and everyone is just sitting there, and just listening, and then we get up and go. But since I have a friend in my English class I talk to him and I seem to have branched out, which I guess is why I don't talk to more people than I have, but now I have a springboard. It just seems to me that when we are with a big group of people, and I know someone, I am able to talk to everyone else just cause I know someone there.

$\mathrm{R}$ : You have a connection and then you can branch out.

B: Right. That is what's happening in my English class. I am very glad that I know someone. That's what I am worried about next semester. If I don't know anyone, I have to take all these classes and it would not be fun at all. $(11 / 14 / 01)$

Bryant's overwhelming concerns seemed to be having fun, and not being bored. He wanted to connect with his classmates but he wasn't sure how. Since he was not involved in any clubs or organizations on campus, he had no opportunities to meet people outside of the classroom. When Bryant talked about going to college because he "doesn't want to be working full time" it gave further credence to the "push" notion that he felt in regards to college attendance. Bryant did not want to be working full-time, and college was a convenient choice. Still, Bryant continued to insist that college was "just more school," as if to emphasize that he was not willing to commit himself fully to college. This could be more than "just college" if he wanted it to be, and if he could figure out how to connect with his peers, but Bryant was also hesitant because he was not sure he would be accepted by his peers.

When Joe and I discussed the issue of who his friends were, he did not say that they were from his fraternity, or from work. Instead he said that the majority of his friends were from his grade school:

$\mathrm{J}$ : The majority of my friends are from my Catholic grammar school. There are about 10 of us that are really close. Our parents see us, and they can't believe that we are so close.

$\mathrm{R}:$ Are they all here at the college? 
$\mathrm{J}$ : Most are, but one is a major league baseball player and a couple of others are in college somewhere else. Those of us who are here get together every weekend. We hang out, go out to eat. The thing is, though, the thing that is hard to deal with is to have my grade school buddies, and then have my fraternity friends, 'cause the two groups don't really get along. It's hard. (10/30/01)

Joe had a history with his elementary school friends that he did not have with his fraternity brothers. Due to the social capital he had access to as a result of his years within the Catholic grade school and high school, Joe developed an extensive web of friends and contacts. But it was awkward to be with these friends at the same time that he wanted to be with his fraternity brothers. On the other hand, what Joe did with his fraternity brothers did not really interest his grade school friends, causing him to have to choose between the two. Joe wanted to be an active part of the campus but he struggled with feelings about which group he should belong to.

This next excerpt from my final interview with Joe was descriptive of the essential conflict that many first gens feel. In it, Joe is worried about his brother attending a fraternity party that Joe had invited him to attend. The conflict was that Joe now "belonged" to both groups, the fraternity/college and home. But in this setting, the fraternity party, the two groups were in conflict and Joe had to choose which one he belonged to:

$\mathrm{J}$ : We are having a party at my fraternity house Monday night and I invited my brother to come. He is anti-Greek but I said, "Hey man, we are having a party Monday, you know? Why don't you come by?" And he said, "All right." And that just floored me.

R: He's gonna come?

J: Yeah. He said he is going to bring his whole crew. He has five friends that are real close-knit, and I said, "Good, bring them along." And he said, "OK, see you there." That will be interesting. But my brother doesn't drink or smoke or anything and I do. That may be weird cause I plan on having a few drinks, and seeing him might be weird.

R: 'Cause you don't know if he will partake or not. 
J: Yeah. I won't know whether to steer clear of him or not. If I steer clear, it might make me feel like I am being too good for him. I don't know. He knows that I drink and he has seen me a few times when I have been drinking, but this is somehow different. $(11 / 30 / 01)$

Besides belonging, this was also an issue of support. Joe was concerned whether or not his brother was going to support his fraternity behavior and Joe wanted his brother's support. The conflict Joe felt reflected London's (1996) research findings on first gens. London said that first gens found the college experience to either be one of great exhilaration, or one of great conflict. Joe talked about being in love with college, but at the same time he found himself in conflict when he found it difficult to hold on to his former friends, while he formed new friends through his fraternity. Joe did not voice that he had to choose yet, but it began to appear that he would have to choose between his college friends, his brother, and his grade school friends because of the conflict that was occurring between the groups.

In this final piece of dialogue, Joe talked about how he "fits in" with his fraternity partly because, "most of them are middle class," the social class he felt that he belonged to at that moment. This was in contrast to his earlier statements that he felt he was a member of the working class. Rita Felski (2002), in discussing the desire of most Americans to belong to the middle class, said, "By describing themselves as middle class, poor people can persuade themselves that they have made it." Middle class, she said, simultaneously conveys success and modesty, achievement and ordinariness, adjectives Joe might have used to describe himself:

J: Our fraternity is a mixture. We do have the rich, and we also have some that are barely getting by. I would say that most of my fraternity brothers are middle class. So, yeah, I fit in.

$\mathrm{R}$ : So, you feel like a proportion of them are from your same social class?

J: Yeah. (11/30/01) 
First Joe described his fraternity as primarily middle class. Then he said he fit in, indicating that at this point in the semester he considered himself to be middle class. Joe was striving to rise above his working class culture by enrolling in college and now wanted to feel that he was part of the middle class. Since this was where he saw the majority of his fraternity brothers, being middle class allowed Joe to comfortably belong to this group. His grade school friends, in the meantime, did not approve of his joining the fraternity. Part of this disapproval could have been linked to social class. Many students consider the Greek system elitist and Joe's attempt to join a fraternity could have signaled to his friends Joe's overt desire to leave his working class background behind. This may have fostered resentment in them towards Joe, a resentment based on issues of social class.

Campus Involvement

With the exception of Joe, none of the participants were involved in any oncampus clubs or organizations on campus. Joe's efforts were often stymied because of the demands put on him by his job at UPS and his fraternity. Research on attrition shows that students who belong to clubs and organizations feel better about their college experience and are more likely to graduate (Tinto, 1987). However, the students in this study lived off-campus and worked long hours off-campus, making participation in campus activities a luxury they sometimes felt they could not afford.

Billson and Terry (1982) found that first gens were less likely to join student organizations, to work more hours than second gens and were more likely to work offcampus, which meant that first gens are less integrated into campus life. Billson and Terry also felt that first gens have less of a commitment to the role of student and thus do 
not join student clubs or socialize with other students to the degree that their peers do. "Dropping out then becomes the logical consequence of role distancing in a setting that demands role enhancement" (ibid, p. 70).

As mentioned, TJ did not belong to any campus clubs or organizations. This was consistent with Horn and Nunez (2000) findings that first gens tended to have lower participation rates in campus clubs and organizations than their second gen peers. It was also consistent with TJ's low level of high school involvement:

R: Are you involved on campus with any clubs or organizations on campus? TJ: I haven't done anything yet. I am interested in volleyball and I am getting into fencing a little but I haven't really gotten into anything, I have just been thinking about it. $(9 / 17 / 01)$

TJ was waiting to see how his first semester turned out before he committed himself to anything. Partly this was because he did not have the time to participate in any cocurricular activities. He was working at UPS, and had decided to get a second job working weekends at Six Flags, which left him little time for activities besides his coursework. However, TJ never expressed a serious interest in becoming involved on campus, either. For TJ, college meant academics. The co-curricular part of college was of little interest.

Patrick also failed to join any campus clubs or organizations during the semester. Given Patrick's oppositional stance towards the college, it was not surprising that he did not feel any compunction to join any co-curricular activities. Patrick saw the college as hostile towards him, and he wanted to limit his contact with the college:

$P$ : I was going to get involved in the justice administration club, but I didn't $\mathrm{R}$ : What is the justice administration club?

P: It's this honors society for justice administration majors, if you have a certain GPA in the $j$. a. classes. I didn't feel that at this point, when I've only had two classes, that I wanted to commit myself to it. I want to leave myself open for 
change, you know? I don't say I'm going to do anything, "Yeah, that's what I want to do." I look at things realistically, you know? Realistically, only two percent of people who want to be FBI agents actually become one. What is it about me that I think gets me in that two percent? I think about that and I think, "Not much." So, I keep myself open. I'm not gonna corner myself into anything just yet. $(10 / 17 / 01)$

In this statement Patrick was devising "back up" plans in case things did not work out.

He didn't want to commit to justice administration in case it didn't work out, and joining the justice administration club was a sign of commitment. Patrick held back from getting completely involved on campus. He also showed signs of the poor self-image discussed earlier when he said that he considered it unlikely he would be in the two percent that made it into the FBI. So he also was reserving the right to change his major, and his career. All of this was out of his fear of being "cornered" into something he did not like. But while commitment can feel like being cornered, the lack of commitment Patrick demonstrated also helped lead him to feel he did not belong on campus, and led him to look for alternative ways to get more involved on campus. While Patrick did not participate in any on-campus activities, or show a desire to be involved on campus, his thoughts about getting an on-campus job were linked to his getting to know people on campus in order to help resolve some of the irritation he was feeling:

I was actually thinking of getting a job 'cause as long as I am not working, it begins to feel weird to me after awhile. I kind of miss working. It would get me out of the house and maybe my irritation with certain things would wane a little bit and get away from things for a little bit and earn a little money enough so I don't feel so helpless. I do have some money in the bank, but I don't like having to dig into it every other day for food and money and everything so I am thinking about getting a job right now. (10/30/01)

Since much of Patrick's irritation was directed at the college, he was indicating a desire to "get out of the house," which he thought might resolve some of the antagonistic feelings he has towards the college. But, as Willis (1977) found, resistance and 
opposition to education are common in working class cultures, because they do not feel that they belong to it, or want to become a part of it. Working class students attempt to differentiate themselves from the educational culture. Integration into the academic culture is difficult for working class students, and it means letting go of these attempts to differentiate themselves from their peers. Once the differentiation process begins in school, there is a powerful push for working class students to complete the process, and to resist or oppose the integration goal of education (Willis). This was one of the conflicts Patrick faced. His brother nurtured Patrick's sense of "us vs. them," while Patrick seemed at times more interested in negotiating this conflict. While Patrick did not have an acute shortage of cash at the time he talked about getting a job, he was saying that he placed work and obtaining money ahead of campus involvement.

All semester long Patrick contemplated going into the military. He specifically talked about joining the Air Force Reserve Officers Training Corps (AFROTC) on campus. The AFROTC was one campus organization that Patrick saw as providing a sense of belonging that Patrick found appealing, and he pondered the pros and cons of signing up during the study:

$\mathrm{R}$ : Sometimes it sounds like you are still not totally sure that college is for you. The fact that you are still considering the Air Force makes it seem like you are undecided.

P: Yeah, the Air Force makes me think that still. But I am using the AFROTC program as a tool to make me want to do college. To make me want to attend. The AFROTC program will give me that sense of belonging. It will give me that sense of direction. It will make me feel like, "This is where you need to be." And it will give me a sense of pride. (11/28/01)

Patrick could sense that something was missing. He articulated his desire to belong to something that would provide him with a sense of direction and a sense of pride. College alone was not able to provide Patrick with these things. He did not feel that he belonged 
on campus, and he did not feel much pride at being a college student. But joining the AFROTC, he felt, would give him back his sense of accomplishment. As Patrick got closer to making a decision about the AFROTC late in the semester, it appeared that this decision was largely due to his need to feel a sense of belonging that was so elusive to him at college.

The AFROTC program was an organization Patrick felt he could commit to because of all the benefits it offered. It was only loosely affiliated with the college, but it would provide him with the means, he felt, to accomplish his goal of finishing college. No other club or organization on campus could do that for him. The overlap with issues of support are here. Joining the AFROTC program may provide Patrick with a sense of belonging, but it also would provide Patrick with a level of support he needed to complete his college degree. This support was crucial to Patrick, and while it is crucial to all college students, it is especially crucial to first gens who feel they don't belong on a college campus to begin with.

Bryant's work schedule was not as demanding as TJ's and Joe's work at UPS, but it did involve him working off-campus all day Monday and Friday. This work schedule could be seen as one reason for his lack of campus involvement. However, Bryant vocalized that he just was not interested in being involved on campus:

R: Do you anticipate that you will get involved in anything at the college? B: Maybe. I don't know. I am just here for the schooling. I probably should get involved. That is what they told us at orientation. "Get involved. Try new things." But it is just that I am not always open to new ideas and sometimes I find it difficult if people don't think the same way I do, you know? I tend to shy away from that. 'Cause it, I don't know... I don't know. (9/27/01)

Earlier, when Bryant talked about not wanting to live on campus, he said that he was not open to new ideas. Now he mentioned not being open to new ideas in the context of 
campus involvement. Bryant assumed that his peers were not like him. Not the ones who lived in the residence halls, and not the ones that belonged to clubs and organizations. This was similar to Patrick's feelings that he was not a "typical" student. However, Bryant did recognize there were benefits to being involved. He just did not know how to go about getting involved, and his fear that he was somehow "different" than his peers made him less likely to attempt to get involved.

During each interview with these students, I asked them about their level of involvement on campus. I assumed that their involvement could change from week to week, depending upon their interests and the opportunities that presented themselves to the students. In my fourth interview with Bryant (11/4/01), I again posed this question to him. Bryant responded by saying that college was "no big deal" to him, and that it was "just school." Since this interview occurred shortly after Bryant had a fight with his parents about Bryant's attitude towards college, Bryant seemed to be telling me, and his parents, "Stop making such a big deal out of college." But Bryant also had acknowledged earlier his desire to make friends on campus in order to make his experience more enjoyable. He just did not know how to go about getting involved in order to make college more than "just school."

Richardson and Skinner (1992) found that first gens hold multiple responsibilities and that they are minimally involved with the college campus as a result. This seemed to hold true for TJ, Patrick and Bryant. Joe, however, was trying to break this pattern. Of the four participants in this study, Joe was the one who wanted to be the most involved. Joe acknowledged that a large part of his excitement about attending college was due to his involvement with a fraternity: 
R: How do you feel about college right now?

$\mathrm{J}: \mathrm{I}$ am in love with it. I love the freedom and the responsibility. It makes me feel older and more mature. I love the work at UPS, participating in this study, and joining a fraternity. I am also working on the orientation program this summer to help the new students. From my high school I learned a valuable lesson. What you put into it is what you get out of it. I missed out on a lot in high school. I didn't get involved until late in high school, and I saw how much fun it was, so I am mad at myself and I want to make the most of my college experience. I just love the atmosphere of being here, and there are girls here for once, since my high school was an all-male school. I guess it is the freedom and the atmosphere. And I love this campus. There are a lot of recreational facilities. The money and the loans I receive are great. My friend and I are going to move out of my home at the end of this semester as well and I can't wait for that. The commuting has got to go. $(9 / 21 / 01)$

In London's (1992) study among first gens, he found that while most first gens found college to be a time of deep conflict, for some it was a time of great excitement and intense pleasure. In this first interview Joe seemed more like the first gens London found who were excited about college. Joe was motivated to become involved on campus. He did not want the opportunities to pass him by, as he felt they had in high school. And he wanted to meet girls since he went to an all-boys high school. Joe also expressed a desire to move into a residence hall when we talked early in the semester as well. Unfortunately as the semester wore on, Joe found it difficult to get involved on campus to the level he wanted, primarily because of work, but also because he ended up moving into an apartment twenty minutes from campus. Joe wanted to become an orientation assistant but because that would mean missing time at work, UPS would not give him the necessary release time to participate in the program.

Joe's attempts to join the fraternity during the semester consumed a great deal of his time. In return, though, the fraternity seemed to provide Joe with a sense of belonging to the campus. Although it also seemed at times that Joe had strong ties to his 
home, his grade school friends and his work associations, the fraternity was clearly an important part of Joe's college experience.

As the semester went on, Joe was seeing that the limits his work with UPS put upon him academically, also extended to his social life:

Our fraternity has had one social so far with a sorority. I also went bowling with the brothers and I went tailgating with them once. The rest of the events I couldn't make because of work. (10/16/01)

In discussing his fraternity involvement, it seemed at times that it, like work, offered opportunities for belonging, but also limited other opportunities. In this exchange with Joe, he discussed how he was motivated to achieve a 2.5 GPA so that he could join his fraternity, and how the fraternity rush hindered his studies:

$\mathrm{J}$ : I am trying to get a 2.5 to get initiated into my fraternity. I am working to get those grades up but it is different from high school where you have grade reports so I don't really know how I am doing. But I don't feel comfortable with what I think I have in these classes. Three of my classes I really have to work hard in. $\mathrm{R}$ : Are you finding that the pledge period is causing problems with studying? J: Yes. They want you to be involved with things, which draws you out of your house and disrupts your study schedule. It hasn't had a major impact, but it has had a little influence on my study habits.

$\mathrm{R}$ : So, it has been a diversion.

J: Yeah, that is what I am trying to say. That's the word I'm looking for. $(10 / 30 / 01)$

Joe also talked felt that he really fit in with his fraternity:

They have helped me adjust to the atmosphere here, and helped me meet new people. That was kind of hard for me. When we see them out, they are so friendly, it just kind of calms you down and eases you. So you don't worry so much about what people are thinking about you. It makes you comfortable. $\mathrm{R}$ : So do you feel like you belong here then?

J: Yes. $(10 / 30 / 01)$

Joe mentioned his fraternity as the major reason he wanted to do well in college. Since this was the only club Joe was involved in, he had invested a considerable amount of personal time and energy into the fraternity organization. The repercussions of not 
getting in could be quite severe for Joe's attitude towards the college. Should he not get in, the organization that was providing him with the majority of his support, and made him feel that he belonged, would no longer be available to him.

The fraternity provided support for Joe's social activities, which helped provide a sense of belonging to the college, but it also seemed to conflict with the academic role of the college. However, if the fraternity was not there to provide this link to the campus for students like Joe, something else would need to provide this link. The fraternity seemed to provide major incentive for Joe to achieve at least a 2.5 GPA while at the same time it worked against his academic success because of the time commitment involved with pledging the fraternity.

In our fifth and final interview of the semester, Joe again talked about his fraternity, and indicated the importance he placed upon his fraternity, perhaps more so than any other aspect of his college experience at that point:

Right now, school is my highest priority. I don't plan on taking any initiatives to move up at work, at least until March or April, 'cause right now I am trying to pump that GPA up to get initiated into my fraternity. So right now school is more important. (11/30/01)

Once again Joe indicated his extreme desire to do well at school for the purpose of being initiated into his fraternity. It showed the importance that belonging to this organization played in Joe's life at that point. His reason for doing well in college was to become a part of this organization. Joe felt that he belonged more to the fraternity than to any other part of the campus. The fraternity may have been a small part of the college, but for Joe it seemed to be a large part of his world. 


\section{Campus Culture}

TJ, Bryant and Joe were all required to take a campus culture course designed for incoming freshmen. Patrick was also required to take the course but had somehow been able to postpone this requirement by talking to his advisor. Despite the course's goals of helping these students transition to college, the student's failed to see the course as important to their orientation to the campus. Joe went so far as to call the course "worthless." Both Bryant and Joe failed the course. The course syllabus stated that its main purpose was to help students successfully make the transition to the academic unit, and to the college. One of the course outcomes was that, "Students will have an understanding of basic student strategies that will enable their success." Further, the course required that when students were unable to attend a class, they notify their instructor. Each student was also required to meet with his instructor at least once in the instructor's office during the semester. Given that the course description read that "students will gain an understanding of various parts of the college, the administration, the faculty, the learning resources, support services, extra-curricular activities and how these parts contribute to the learning process," it appeared that the course was attempting to create an overall sense of belonging for these students. It was an ambitious endeavor. Unfortunately, based on the comments Bryant made, this goal of creating a sense of belonging was never achieved:

I am in the business school and I am in the campus culture for business. And we go in there and sit, and listen to my instructor talk, or we discuss things. But we don't do any physical work there. And we had to order the W all Street Journal, and I guess we are supposed to read it. (11/14/01)

Sitting, listening, discussing and even reading the Wall Street Journal, which Bryant had not been doing, was not seen as important. Nor was it particularly satisfying to Bryant. 
Bryant wanted to do "physical work" in his class. In this same conversation Bryant admitted that he was concerned that he had missed too many campus culture classes and was in danger of failing the class:

B: I found out that if you miss more than two classes you are supposed to fail. And I have missed three.

R: Have they said anything to you?

B: No. Every time I miss it is because of traffic. I get up at 8 a.m. or 8:30 a.m. Try to leave at 8:45 a.m. or 9 a.m. but there is just traffic.

$\mathrm{R}$ : Class is at 9:30 a.m.?

B: Uh huh. And usually I have done it where I come in late. But this time I was so late, that there would have been only five minutes left of class.

$\mathrm{R}$ : So are you going to talk to your professor about it?

B: Yeah. I am going to get up super early this next Tuesday. I don't try to miss class but I come from the other part of the county and it is such a jam, especially at rush hour in the morning. (11/14/01)

Bryant does not seem to have been going out of his way to get to class early. He knew there was significant traffic in the morning, which meant he had to leave home early, but he did not see the class as important enough to do so. And he had not contacted the faculty member about his absences, despite the fact that the syllabus required it. Neither did his instructor say anything to him about this, either. Despite Bryant's stated intentions of getting up early and talking to his instructor before his next class, he admitted in our next interview that he had failed to talk to his campus culture instructor because he once again missed class due to traffic. Bryant received a failing grade in the course.

Joe stopped attending his campus culture course after he missed three classes. Joe ascribed his poor performance to "sheer laziness" on his part, but in fact it appeared that work conflicts were also played a major role, as was his living in his new apartment:

R: So tell me what happened with campus culture?

$\mathrm{J}$ : Sheer laziness. Class is once a week but it was so worthless of a class. The teacher that we had, it was her first year doing it. She is an economics person, 
and when we got on to marketing and management, she was like, "I don't have anything to say, does anyone who is majoring in those two have anything to say? No? Then class dismissed." But when economics came up she had a lot to say about that. Plus that class is at $1 \mathrm{p}$. $\mathrm{m}$. on Tuesdays and I have math lecture at 4 p.m. so I have to come up for campus culture class and then hang around for two hours. After my third absence, I was gone.

$\mathrm{R}$ : Did they send you a letter?

J: No, I haven't heard anything.

R: So you just assumed...

J: Well, she stressed that after two you would fail, so...

R: But you didn't go and talk to her after the third class?

J: No.

R: Did you just start missing cause you didn't feel like going?

$\mathrm{J}$ : I hate it but, yeah. Plus living in my new apartment is not helping.

$\mathrm{R}$ : Is that when you started to miss the class?

$\mathrm{J}$ : Yep, yep, yep. When you get off work you are wired and you are kind of physically tired but you can't just go home and go to bed cause it has been nonstop. So I am up to 6 a.m. or 7 a.m. and then I go to bed. So when the alarm goes off I just keep hitting snooze. Turn it off. Unplug it. Throw it. (11/30/01)

Joe accepted some responsibility for his failing the class, and he also attempted to put some of the responsibility for his failure on the part of the faculty member's teaching. There were also several other issues at work here, however, that conspired to work against Joe's success in the class. One was the issue of commuting. His campus culture course was in the early afternoon and after that he had no other class until four o'clock in the afternoon. Another issue was one of social class and cultural capital. Parents who have been to college might be more likely tell their son to go speak to the professor because of their own personal experience at college. Certainly, Joe needed to accept some personal responsibility for his non-attendance. However, his professor did not attempt to make contact with Joe, or try and find out why Joe was not attending class either. This course was designed to help first year students transition to the college, which would seem that in this course more than any other, the faculty would take a particularly strong interest in how students were doing. Instead there seemed to be a lack 
of contact by the faculty members even as Joe and Bryant were ready to fail the course. Joe had to re-take the course in the spring but what was the point of making him take the course again, other than because it was a requirement? Curiously, in a final paper Joe wrote for this campus culture course but never submitted, he wrote that in the spring he intended to meet with his faculty to get to know them better. Unfortunately he never submitted the paper because he discontinued attending the class after missing three of them. Since the professor said that missing three or more would mean failing the course, Joe simply stopped attending the course and accepted the failing grade rather than speaking to the faculty member about it.

What is Normal?

Feeling "weird" or "not normal" was something that both Patrick and Bryant verbalized feeling during the study. This spoke to the issue of feeling caught between cultures that first gens often feel. And it was both the academic and the non-academic nature of the campus culture that seemed to be causing the conflict for them. Patrick often verbalized his feelings that his Southern accent labeled him as "different" and he worried about people's perceptions of him because of his accent:

P: I used to live in a residence hall on campus. I walked around and people were nice but once they start talking to me they say, "Oh my god, it's a hick." You know?

R: Even if they don't say that, you are thinking they are saying that.

P: Yeah. They look at you when you first start talking. They get this shocked look, you know? I got made fun of all the time when I was a waiter here. This is a whole other world for me here. This is nothing I have ever experienced. When I first was here I was looking up at all of these tall buildings. I was just the quintessential rube. Something still surprises me everyday. It gets to me after a while. I can take so much, but after a while it gets old, you know? I haven't really felt, like I said, good about being in college. I thought coming up here would be a pleasant change, but still, when I am walking on campus, I don't feel like a college student. I feel like someone carrying a back-pack. And it is not 
like it suits me. I am not one to tune in to things like that, but sometimes it is so overwhelming it just can't be ignored. (10/03/01)

Patrick saw himself as a country rube against a backdrop of big-city slickers, or at least people with more exposure than he. He seemed to value his naiveté/simplicity as well. Patrick again showed signs of being insecure. Was he college material? If he concluded that he was not, what would that mean for him? Was this tirade then ego protection? Or was it a defense mechanism? It did not appear that up to now, college attendance had worked to help Patrick develop a strong sense of self-esteem that might help him be successful in college. In his last statement, Patrick admitted how much this bothered him when he said that he usually never thinks about his stuff, but it is so strong for him that he cannot help but think about it.

After one particular interview, Patrick stayed behind for a few minutes to ask me if he was alone in his feelings of not fitting in on campus, or was I finding that the feelings he had were common for first gens, or at least for the others in the study:

P: That feeling is something that goes throughout? But there are a lot of differences, right? Everyone's story is different, right?

$\mathrm{R}$ : Yeah.

P: But is there any type of, you know, like...Am I weird? I know there are differences, but am I someone who is just so completely out there?

$\mathrm{R}$ : No, you are not weird. A lot of the stuff that you are saying is very typical. Well, I don't want to say typical, but similar to the others in the study. $(11 / 14 / 01)$

After our formal interview had concluded, Patrick stayed for another 10-15 minutes to ask me questions about the research, and what I was learning from the research. At one point he specifically asked me if I was finding areas of commonality among the participants, or was he "a freak?" Although I assured him that he was not "a freak," I also felt that perhaps he wanted his story to at least be somewhat different from the others. Clearly, though, Patrick was concerned that he was the only one having these 
feelings of being abnormal. I asked him in a subsequent interview if he felt better knowing that others felt as he did, and in answering he admitted that it was nice to know that others felt as conflicted as he did about college.

Bryant also shared a concern that he was somehow "abnormal." His feelings were partly due to his stereotype of what "normal" college students did in their spare time:

B: I feel like maybe I am just, not the normal person, that is expected to come to college. You know, they want you to study and do good, but then they want you to go out and party and have fun and that is just not for me at all.

R: It might not be a problem for other people...

B: But it is for me. I feel like sometimes I am the only one who has that problem. And Eric, I guess, he is the same way, but we sort of, stick with each other, you know? It seems like most people are pretty socially active. People just seem to have an abundance of friends. But not me. I am just different, I guess. Which I think is good. I just feel just awkward sometimes, not being very social. Maybe I should try to be more social, but I guess, at the college, I just wouldn't know where to start cause I've never been very social with people my own age before. And so I had no idea where to start. Seems that only place you would meet people is at parties, and I am not one to party. When the man was speaking at our orientation and saying that you shouldn't just work, and do schoolwork, I was thinking, "That is all I am doing." Some people go out, party, drink, and pass out and get drunk and just do horribly wild things and that is just not me at all. $(10 / 11 / 01)$

Even in the middle of the semester it appeared that Bryant was still struggling to acclimate himself to the college culture. Bryant felt he had received mixed messages about what he was expected to do in college. He said "they" expected him to study, but "they" also expected him to party and to have fun. And this message was reinforced during freshmen orientation. Bryant felt this description of what a college student was expected to do did not describe him, leading him to feel he was an abnormal college student. Bryant described himself as "not normal," "different," and "awkward," all in this one brief conversation. Bryant wanted to talk about his feelings that he was 
"different" from his college peers. Like Patrick, Bryant had the sense that everyone else fit in on campus except him.

This section analyzed the themes that emerged from my interviews with related to the issue of belonging. In doing so it described the boys feelings about college, discussed some of the ways they chose to remain separate from the campus, and identified ways that the campus made the boys feel that they did not belong to it.

All four of these students struggled to find a true sense of belonging to the college. Even Joe, who was the only person who actively attempted to join an organization during the study, had difficulty negotiating the culture clash between his family and college. In addition, Joe struggled as to balance fraternity life, work life, school life and home life. Also, the students enrolled in the campus culture course failed to make connections to their course instructors, despite the goal of this course to do just that. This lack of connection contributed to the feelings these four students that they were "just another face" at the college.

Several of these students mentioned their insecurity about making friends at college as an issue as well. All four of them either lived with friends of theirs from high school, or lived at home and three of the four had only one close friend that they spent virtually all of their off-campus time with. The enactment of a sense of belonging these students felt seemed to be directed somewhere other than college. In this interview with Patrick, which was the last one of the semester, we talked about whether or not it was helpful to him to know that other first gens share his feelings:

It is helpful to know that others feel like I do. No one likes to be alone in something, at least not in that. A lot of people want to be at the top of their class, be alone in this, that and the other. Things that are good. But when it is a bad thing you don't want to be by yourself. And a lot of being a first gen is bad. It 
plays hard on your psyche, you know? It makes you feel a little inferior sometimes. And your parents maybe aren't the upper crust maybe, or well-bred people, and you are just an ignorant hick from Thousand-Sticks. (11/28/01)

This was the essential conflict. These students did not feel that they belonged to the college. They did not feel comfortable at college, but neither did they feel that they fit in at home anymore. They did not feel prepared for college in many respects, or feel particularly supported for their efforts at college, either, and they were unsure if anyone else shared their conflicted feelings. So where did these first gens belong?

The next section will deal with the issue of social class. It will look at how issues of social class in the estrangement these students felt towards the college. The section also discusses ways in which social class might have hindered these students preparation for college, and the support that they felt for enrolling in college.

\section{$\underline{\text { Social Class }}$}

A typical college student to me is just what l've seen. To me, they all dress alike in those fancy clothes, and they go out and party all the time. And they drive those fancy cars, and listen to rap music really, really loud. And some of them are weird. And I don't do any of those things. Being well off is one thing about them. I find a lot of them drive nicer cars than I do. And I don't think that I am the smartest person in the world but I know for a fact that I am a lot more intelligent than some of them. And I see a lot of stupid things going on. Typically, they are spoiled, rich kids to me but a lot of them aren't so that is a very bad thing for me to say. A lot of them worked their way up here just as much as I did, if not more. So, I am saying that the ones that irk me the most, are the ones I refer to, which are the majority, I believe. Of course I might be wrong. (Patrick, 11/14/01)

James Vander Putten (2001) argues that educators and multiculturalists have a narrow view of diversity, and define it solely in terms of race and gender. The problem of using these two lenses exclusively, is that, "Bill Gates and a white male Appalachian coal miner will be seen as equal" (ibid, p.15). Further, Vander Putten asserts, this limited view of only using race and gender can be attributed to the widely held myth in the 
United States that everyone belongs to the middle class. White male does not mean middle class.

Patrick did not see himself as a "typical" college student. To Patrick, "typical" college students are rich, spoiled, dress alike, party, and behave stupidly. He tried to correct himself when he said that some of them had to work their way into college, but then he went on to clarify that he felt the majority did not. Patrick was a college student now, which was something no previous generation in his family had ever achieved. However, now he was in danger of being seen as one of "them" and he wanted to make it clear that he was not like those "other" students. He did not fit the stereotype that he and his friends and his family had of college students. "They" were like Bill Gates. He was like the Appalachian coal miner. Van Putten is correct when he argues that when colleges ignore social class, white students from working class backgrounds become largely invisible on the college campus, which further adds to the feelings of working class students that they do not belong on the campus.

For this study, I intentionally sought out students who considered themselves to be members of the working class, in order to assess how the nexus of their first generation and social class status affected these students' collegiate experience. The issue of social class was deeply imbedded in the experiences of these students and, as a result, this section on social class also overlaps with the other sections. Social class was woven into these students' lives as they lived through issues related to preparation for college, support for college, and belonging to college. For example, McDonough (1994) asserted that most low income and working class students and the high schools that they attend do not participate in college choice behaviors that are designed to gain them 
admission into selective colleges. Instead, financial resources heavily influence students from these social classes. TJ, Patrick and Joe all chose their college based on the financial resources available to them. For TJ and Joe this meant working at UPS in order to avoid school loans. Patrick's initial school choice also offered him an opportunity to attend college without having to go deeply into debt. For Bryant, money was not the overriding concern, but the high school he attended did not participate in college choice behavior that would have allowed him to attend a college in Alabama, as he desired to do.

Sennett and Cobb (1972), in their study of working class families in Boston, found that many working class college students experience a phenomenon they called, "status incongruity." Students from working class backgrounds have ambivalent feelings about which social class they belong to. They feel caught between two cultures and sense that "something" is wrong. This "something," is "The discontent as a result of upward mobility from the social class of one's origin to a higher social class" (Sennett and Cobb, p. 71). On the one hand, their working class upbringing exerts a powerful influence on how they view the college campus, and on the other, the middle-class culture of higher education, coupled with the middle-class backgrounds of many of their classmates provides a conflicting view (Vander Putten, 2001).

Vander Putten maintains that status incongruity is the reason why "feeling out of place on the college campus is not the sole domain of students of color; gay, lesbian, bisexual, and transgendered students; students with disabilities; or women students" (p.16). Social class has a powerful influence on a student's experience as well. The image of working class students trying to "better" themselves often ignores the conflict between working class culture and the academic culture, or of the conflict between 
students and home that occurs as a result of the changes college students experience. According to Weber's theories (1946) of class structure, working class students are unlikely to be accepted into the middle class until they have satisfactorily been educated into the norms of the middle class.

In this section, through a review of previously shared data and new excerpts I will attempt to shed light on six aspects of how social class impacted or defined or delineated the participant's experience. I want to start with this idea of status incongruity, and look at other aspects of social class that I am calling, financing the dream, college vs. reai work, the development of back up plans, intrinsic motivation and hegemony.

\section{Status Incongruity}

The incongruity caused by the conflict between the social class background of the students in this study, and the perceived social class of their current environment at the college, created confusion and discontent for these students. The significant shift in social class environment created feelings of being out of place in a social class higher than their origins. Status incongruity resulted in these students feeling as if they were living on the margin, not belonging to either of two distinct worlds. The students in this study were not always aware of the changes that were occurring in their lives, but in the sharing of their experiences it seemed that several, if not all, of them were having trouble with the phenomenon of status incongruity. In attempting to adjust to it, they often fought to differentiate themselves from the "typical" college student. At other times they seemed to want to "pass" for something they were not sure they were, or wanted to be. I want to explore the comments of Patrick and Bryant as exemplars of these incongruities as they exemplified the lived experience of the student's incongruity. 
Patrick had difficulty feeling that he belonged on the campus, and could definitely sense that something about his college experience was "wrong." Patrick struggled with what the norms of the campus were:

Sometimes I look around and when I look at my fellow students, they look so different from me. They say that you develop your own style, and that you are a unique individual, but that is bullshit. Pardon my language. It angers me. That is fine, but you know, these kids, a lot of them don't know struggle. They don't know what it is to not have enough money to go to the grocery store for food. They haven't had to buy their own car. Mom and dad always provided for us. They sacrificed themselves and I am sure I don't even know the half of it. I don't know how bad it has been, but I feel as if these kids driving around in these brand-new cars, right off the assembly line, don't know sacrifice. Their parents buy their cars for them. That is something I will never know. I feel a lot of resentment towards them. I'm like, "Why am I working my rear end off, and studying?" It's like they are looking down on me 'cause I sound different. And I don't dress as nice, and my hair isn't done up as nice. But I don't care. $(10 / 03 / 01)$

Clearly, Patrick did care. He saw himself outside of the social class of his peers, and he resented it immensely. Patrick had said in one interview that he thought his collegiate experience could have been significantly improved if only his parents had gone to college. Now he seemed to be saying that if his parents had belonged to a different social class, things would have been easier on him as well. Like the lads in Willis' (1977) study, Patrick was attempting to differentiate himself from his fellow college students. His peers never knew sacrifice, but he did, he felt. But it was unclear whether Patrick wanted his peers to feel sacrifice as he did, or if he wanted not to feel sacrifice. Still, Patrick admitted that despite the struggles he faced due to his social class, he felt a great sense of pride over what he had accomplished:

We are not rich people. My parents can't pay a dime for my college education. So I say, "That is one mark for me, I got this for me. I am going to college, getting good grades, and I did that myself. I have the best GPA of any of my friends. Of all the people that I know, I am the only one who has his own place. And a lot of this is that I saved money, and I did it. And I am the only one." And 
in that sense I feel good. It gives me that sense of accomplishment. But the whole concept of being here and going beyond your friends and everything just seems odd, 'cause I am out here by myself. (11/28/01)

Patrick felt great pride that he did it all himself, but he still felt some resentment towards others. And he was lonely. He felt that he had accomplished all of this on his own, but now that he had gone beyond his friends, he felt that he was "out here" by himself. He was feeling the status incongruity that Sennet and Cobb talked about. He was bettering himself, but there was no one in his world that he could share his accomplishments with. He felt himself leaving the working class of which his friends and parents were still a part, but he still did not feel that he had been accepted into the culture of academia with its middle-class orientation.

Another issue Patrick was dealing with was the self-consciousness he felt because of his thick Southern accent and his hometown. Patrick felt that these two parts of his identity negatively distinguished him from his peers, and labeled him as a "hick." Early in the semester, during his sociology class, Patrick's sociology professor showed a video concerning racism. The video had been filmed in Patrick's hometown, and it discussed incidents of alleged racism that had occurred in the town. Patrick was already feeling unsupported and unwelcome on the campus and the video heightened these feelings in Patrick:

I know the town is not as bad as the video makes it look. But, you know, if I was to say that I was from this town, it would be worse for me "cause then I would definitely be labeled, "racist, redneck" by the class. You know, I have heard "racist, stupid, inbred redneck" comments before. And I feel like I have never done anything to anybody. I mind my own business. I work, but I am guilty by association. You can't judge the few by the whole, you know? I have a lot of resentment. But you deal with it. If you don't, you let them get to you. It is like my mom always said, "If you let them get to you, you let them win. And you can't let anybody control you." And I said, "Well, that is a good way of looking at it." $(10 / 03 / 01)$ 
Patrick felt as if his professor had exposed him to his classmates. Patrick already felt out of place in the class and on the campus because he was a working class, first gen, but now Patrick felt that his professor was alleging Patrick was a racist as well, because Patrick's hometown had engaged in alleged racist behavior. Patrick was willing to acknowledge that perhaps his hometown had acted badly, but he argued that not only was it not as bad as it was portrayed in the video, he also wanted to argue that he was not like the people in the video. Patrick felt that he was "guilty by association," and he dared not let on to his peers that he was from the town depicted in the video, or he would have been seen as a "racist, red-neck." Patrick had been labeled a racist redneck before, and now he was dealing with the issue again. Patrick felt that he minded his own business, and did not deserve to have this happen to him. Still, Patrick was determined to deal with it by differentiating himself from his classmates and his professor, as he physically did by leaving his class, and making a determination not to let "them" get to him. Patrick was determined to win out over "them." His mother's words, cautioning him not to let anyone control him, encouraged him to remain independent from his faculty and peers.

Bryant first experienced the phenomenon of status incongruity in high school. It was in high school that Bryant's father became employed at a logistics firm and received a high salary, which caused class conflict between Bryant and his friends:

My best friends, at one point, were my youth group. They were all a year younger, but we did everything together until we all had to get jobs. I was a lot more fortunate than most kids are. I didn't have to pay for insurance on my car, or my car, or gas, and they had to work to pay for all of it. That was weird for me because I think, I don't want to say jealous, but they were upset that I could skate by without paying much and they had to work and that sort of grated on our friendship. Not that we disliked each other but it was just uncomfortable talking about our jobs. And they looked at me. I sit at a desk, and type stuff and figure computer systems and type on spreadsheets. And one is a valet parker and does it 
late at night for his uncle, and another friend has three different jobs at a coffee shop and valet parker, and now he works at a Shoe Carnival. And there I am, the rich man's son, who never had to work. And then he gets a job and it is a job that actually will be something in life. $(9 / 13 / 01)$

Bryant described how his friends were resentful of the type of job he had. It sounded like Bryant experienced the type of resentment Patrick had for "typical" college students, yet Bryant did not see himself as a typical college student, either. Bryant said that he was friends with this particular group of friends in high school but as a result of the change in his family income, and the changes it was bringing, Bryant felt uncomfortable being around these friends. It appeared that Bryant had bought into hegemonic notions of what it means to be "something." To Bryant, valet parkers and employees at Shoe Carnival are working dead-end jobs that have no chance for mobility. Bryant felt he was more complex and capable than that.

Bryant experienced conflict in his English class when he talked about his family's annual hunting trip. His classmates expressed their displeasure with Bryant's hunting activities when he presented his paper in the course. This conflict with his classmates, according to Bryant, was a culture clash based on class conflict. Bryant seemed comfortable in this working class setting. He enjoyed the better economic picture his family now had, but he did not want to change his friends or his recreational activities. However, Bryant was beginning to feel awkward around his working class friends, as he discussed with the high school employment scenario. Bryant was uncomfortable at college and perhaps by using his mantra, "It's just school," he was trying to convince himself that he did not need to change. After listening to Bryant talk about the conflict he experienced in his English class, I posed some questions to him about hunting as it related to social class: 
$\mathrm{R}$ : Hunting clearly is something that has gone through your generations and is part of your traditions, and I think it is something that people might think is a sport of the working class. What would you say to that?

B: I would probably agree. People think of hunters as rednecks in camouflage, and a lot of it is rednecks in camouflage. My dad, he's been blue collar and white collar, and he still has his roots. That's the way he grew up. He hunted. But it is not as big a deal for him, as it is for me. To me, I love it. And, even if I became a white-collar worker, I am pretty much set on making time to hunt each year. I don't think I will ever stop. I don't see how I could ever get tired of it. I could still be white collar I believe, and still do the same stuff. There might not be as many people around, wanting to do it, but I will always make sure that I do this stuff. $(10 / 11 / 01)$

Hunting was one way that Bryant kept in touch with his working class roots. Even if he became white-collar, he believed he would continue to hunt, regardless of whether or not anyone participated with him. He did not see how a change in his social class could possibly affect his recreational activities. An interesting change, in the hunting patterns of Bryant and his family members, was that although their recreational activity, hunting, had not changed, where they hunted had changed significantly. As opposed to hunting on public grounds and camping out in tents, like they did when Bryant was young, the group now went to a private reserve and rented heated cabins. It appeared that stratification based on economics was possible even within the hunting community.

This next excerpt from one of my interviews with Bryant is perhaps the most revealing about the status incongruity Bryant felt, and how he was experiencing his own internal conflicts:

$\mathrm{R}$ : Do you consider yourself a redneck?

B: Well, if I said that, my parents would get mad. "You're not a redneck," they say. They don't think there is anything wrong with being a red neck, but I see myself as almost as an oxymoron: quite wealthy, with a white collar job, don't want to work a blue-collar job, comfortable with the finer things in life, but what I do for fun, and what I get my kicks from, what I enjoy doing, is redneck, country things. My roots are in the South, and I am quite proud of that and all of the things that the South has to offer, like hunting, fishing, four-wheeling. R: So, your recreational outlets could all be considered redneck and Southern? 
B: Yes, depending on what you think of hunting as. We go around and some people drink. We play darts at night, ride four wheelers, everyone is sitting around in camouflage. We are kicking it back, telling jokes and stuff like that.

R: But your parents don't want you to be considered redneck?

B: They don't care. They are just like, "You are our son, an upper-class kid." Our family is redneck. Both my uncles on my dad's side are rednecks. My dad says they are rednecks, and my mom calls them rednecks, and we don't mean anything wrong by it. That is just who they are. They are family. My dad dresses in camo. He doesn't act like a red neck but he has fun when we go out hunting and stuff. I think I act more redneck, or more countrified when I am down in Alabama with my family, and when I am around Eric. Some people, like my aunt, will call me the "preppy redneck." I enjoy all the stuff that we do and I wouldn't trade it for anything. I think I have worn camouflage here at college, and people look down on me like, "Ooohh, you are wearing camouflage. You must be some poor, redneck, white guy." And I am thinking, "If you only knew." $(10 / 11 / 01)$

Bryant's status incongruity was reflected in his parent's desire that he would stop calling himself a redneck. Bryant's family did care that he labeled himself a red neck. That was not how they wanted him to be seen. They wanted him to be seen as "our son, an upperclass kid," which was more dignified for the family. Bryant had his working class culture and when he was with Eric, or in Alabama, he felt freer to show it. When he was at college he became the "rich man's son." But even at college, Bryant resisted becoming part of the culture. Bryant, also, believed that he could "pass" for something that he was not. At times he attempted to pass as a wealthy student, and, at other times, he attempted to pass as a working class person and a "redneck." Was he a wealthy student pretending to be a redneck, or a redneck pretending to be wealthy? Bryant was straddling both cultures. He may have passed as wealthy at times, as he seemed to do with his high school friends, but he also thought that he could pass as working class as well. In his English class, it appeared that Bryant's classmates considered him to be working class, and his Southern roots and his redneck ways differentiated him from his classmates. This differentiation may have been intentional or unintentional on Bryant's part, but either 
way it seemed to prevent him from being fully accepted by his peers. This notion of being partly in two cultures, but not belonging to either, Anzuldua (1987) called being in the borderlands. Patrick and Bryant's quotes exemplified the experiences of all the students.

Financing the Dream

For the students in this study, college was a dream. It was also the fulfillment of their parents' dream of a better life for their sons. However, this dream had an expensive price tag which some of the parents were unable to afford. This led three of the participants to consider alternative ways to finance their education, besides relying on their parents for assistance. Foremost in these students' minds was how to pay for college without them, or their parents, going deeply into debt. For TJ and Joe, this meant participating in the college/UPS partnership program. For Patrick, it meant seriously contemplating the benefits of the military.

Avoidance of Debt

The fear of loans was an issue clearly articulated by TJ, Joe and Patrick during our interviews. Even though loans were available to all three of them, they chose to forgo them and looked at alternative ways to finance their college education. For these students and their parents, loans were to be avoided. In Patrick's case, they even appeared to be an unknown quantity:

When I received bad grades in high school, my parents would ask me, "What are you going to do? How are you going to get a scholarship?" And I would say, "Well, there are loans." And they would say, "Loans?" And $\mathbf{I}$ had to tell them about subsidized loans. (10/03/01)

Patrick had an older brother in college, yet it appeared that his parents knew little about the role subsidized government loans could play in financing their sons' education. 
During this same interview, Patrick reported that his parents relied on a book of scholarships to pay for Patrick's schooling:

At the time, they got all of these books on scholarships, and of course none of them really applied to me. But their heart was in the right place. I had to keep saying, "No, no, I can't do this or that, and you have to have a certain GPA for this." And they kept saying, "Well, why not? Why can't you get this one?" And then, they said, "You are not taking this seriously," which led to a lot of arguments between us. (10/03/01)

Patrick's parents felt that surely Patrick must be eligible for one of the scholarships that were listed in the books that they had purchased. Patrick seemed to have more information about the financial aid process than his parents did, but when he tried to explain why he didn't fit the criteria for the scholarships, his parents accused him of not taking the process seriously. Patrick's parents were trying to help Patrick as best they could. They, too, wanted Patrick to avoid going into debt, and if they could find him a scholarship they would have fulfilled their obligation as good parents. But Patrick saw them as misinformed, and seemed somewhat patronizing when he said, "Their heart was in the right place."

The roles of parent and child became reversed. Patrick ended up educating his parents and his parents resented it:

My parents kind of get angry with me about things and I tell them, "Look this is how it is. You all don't know about college." But when I say that they don't appreciate it. When I say, "You all don't understand," or, "You all didn't do this." They say, "But we have lived." And I have to say again, "Yeah, but you didn't do this." (10/03/01)

Eventually, through the help of his high school guidance counselor, Patrick was able to obtain enough financial aid to finance his education. Patrick had avoided serious loan debt, and felt satisfied that he had enough money for college: 
I got a couple of loans and grants from the state, but I didn't get a federal grant. I am capped scholarship wise, but it doesn't really matter 'cause I live off campus so I ended being over granted and I get a residual check from the college. My dad wanted to put the money I got from the state towards paying off my loans, but I told him I need it now. $(10 / 03 / 01)$

Patrick's father wanted Patrick to use the money Patrick received from the state to pay off the loans he had taken out in order to remain debt-free. Patrick's father was fearful that Patrick was going into debt, but Patrick felt he needed the money in order to attend college. Eventually, though, Patrick felt that he did not have enough money for college, and began to seriously consider the campus ROTC program as an option. Not only would the ROTC program pay for his tuition, but he would be avoiding debt as well:

They will pay for my books, and I can get rid of the loan that I took out, so no more loans. And there are a lot of other things. It will definitely help me out financially. (11/28/01)

Patrick saw the ROTC program as a way to pay for tuition and books, and he also saw it as a way to pay off the student loan that he had taken out previously. He intended to put some of the money that he received from the ROTC program towards debt repayment, just as his father had wanted him to do. If he were to do that, though, he might find himself in a situation such as TJ did, where having one job but no loans, was insufficient to cover his college costs.

As the semester wore on, $\mathrm{TJ}$ found it increasingly difficult to pay for college, his apartment, and his car. He began to work two additional jobs. Mid-way through the semester TJ talked about his car problems and tried to figure out how to pay for another car:

TJ: My dad had the car I am driving now, since 1988. He let me have it in July. $\mathrm{R}$ : Can you afford a new car, or are you talking about getting a newer one?

TJ: Probably just a newer one.

$\mathrm{R}$ : Can you afford that? 
TJ: Well, my dad said that he would pay my insurance for a year, if I got a new used car. But that is if we have to.

R: But he doesn't really want you to get a new one?

TJ: I have two jobs now, and with those two jobs I get about $\$ 300$ a week. Then I am getting a loan from UPS that will be $\$ 2000$ and if I stay with UPS all year, I don't have to pay any of it back. Plus, my dad said if I need to get a new car, he will help me get a loan from the bank for $\$ 1500$, so I can try and do that and figure out how much I can pay a month. (11/12/01)

TJ was attempting to ascertain how he could afford a new car, or at least a newer car. In his attempts to piece together enough money, the enticement to stay working at UPS, despite its obvious negative impact on grades, became greater due to the possibility of the "loan" that UPS was making available to TJ, which he would not have to pay back if he continued to work for them. The academic problems TJ had were tightly linked to his monetary situation. This caused $\mathrm{TJ}$ to begin thinking of stretching his undergraduate degree out beyond four years:

TJ: Well, I plan on taking five years to complete my degree now. See, I thought that you could only work for UPS if you graduated in four years, but then I found out that you could take as long as you want, and UPS will still pay. So, that was good news for me.

R: So, now you don't feel rushed?

TJ: Yeah. I would have to take 18 credit hours a semester hour just to graduate in four years. Now I don't have to. (11/12/01)

$\mathrm{TJ}$ was forced to postpone or at least prolong his dream of obtaining a college degree. To paraphrase Supreme Court Justice Thurgood Marshall, though, a dream deferred is a dream denied. Now UPS had TJ for the remaining five or six years of his collegiate career. If TJ left UPS, he would not be able to finance his education, he felt. And if TJ left college, he could no longer receive all of the benefits UPS offered. The relationship between TJ, the college, and UPS had gone from symbiotic to parasitic. UPS appeared to have firmly attached itself to TJ. 
Like TJ, Joe took the UPS job because he saw it as a way to avoid having to take out student loans. It even appeared that Joe had received enough financial aid to pay for college without working:

R: Did you apply for financial aid?

J: Yeah, you have to, to be a part of UPS, and I was awarded a total of $\$ 5000$ in financial aid. I received $\$ 3200$ in scholarships, and the rest was a government loan, and work-study. I had enough to pay for college, but I decided I didn't want to pay back loans after I graduate. One thing about this program with UPS is that they will pay your tuition. And so that $\$ 3200$ in scholarship money, since I earned it, I get it directly. So, after this first semester I will have a big check coming to me, and it will be all mine. $(9 / 21 / 01)$

Joe was concerned about the amount of debt he would be left with after college, and UPS provided a way to avoid debt. The plan seemed simple and straightforward. Joe looked at the bottom line and, as a business major, he saw debt as red ink, and he knew that red ink was something to avoid. When he received that $\$ 3200$ scholarship check, though, he knew that he would be in the black. In addition, many of Joe's support systems, his high school, his guidance counselor, and the college itself, were touting the benefits of the UPS/college partnership program. There was no one who was offering a counter message that school loans were an acceptable debt to incur in order to be able to fully participate in the college experience.

This actually seemed to be true for all three of the participants discussed here. None of them spoke about messages that they should accept debt as a "necessary evil." It might be argued that the students here resisted one "capitalist scheme," (i.e., debt). However, it could also be argued that the choice to avoid debt came from the lack of access to capital that plagues the working and lower classes. 


\section{UPS and the Military: For Now and For Later, Maybe?}

UPS provided TJ with the financial support that he needed to attend college, by paying his tuition. UPS also provided TJ with incentive to remain in college by supplying him with money for books and rent, and by providing him with an $\$ 8.50$ perhour stipend. Though family and institutional support was important to these students, as TJ's comments indicated, there was also no denying the importance of financial support:

$\mathrm{R}$ : If your parents were offering to pay for college, why did you go to work for UPS? If your parents said that they were going to pay for college, you would not have had to work.

TJ: Yeah, but UPS also pays a stipend at $\$ 8.50$ an hour as well, so, I just thought it would be better on my parents and better on me as well. I figured it would be a lot cheaper for my parents and me.

R: Tell me what you mean by that.

TJ: What I mean is that the money I owed would be a lot less, 'cause while my parents were going to pay as much as they could, they could only afford so much. So, I would have to get a job and help pay what they couldn't afford. And when I saw that UPS would pay for everything, all my parents would have to pay me is a little money like in tight spots. And all I have to pay for is groceries or rent or gas and like that.

R: So you were talking about it from a purely financial point. You wouldn't have loans. You wouldn't have to have a separate job, things like that.

TJ: Yeah, plus too, I heard that UPS was a good job to get into. So, I thought even if I couldn't figure out what I wanted to do later, I heard you can advance with UPS, like in accounting. (9/17/01)

TJ wanted to attend college, but he did not want to burden his parents with having to pay for his schooling. Further, he doubted that his parents could pay for college, even if they wanted to. UPS was offering an unbeatable deal, in TJ's mind. They paid for his college tuition, paid him a stipend, which meant no second job, and he had "heard that UPS was a good job to get into" because of potential advancement. UPS did pay TJ's tuition and a salary. However, TJ failed to anticipate how costly it would be for him to attend college. In TJ's talk there was also the development of a "back up" plan. In TJ's mind he was beginning to formulate a plan that he could implement in case college did not work out. I 
want to return to this concept of "developing back up plans" later in this section. It seemed, though, that $\mathrm{TJ}$ had failed to anticipate the hidden costs associated with working at UPS, since things did not go as smoothly for him as he had anticipated.

Like TJ, Joe learned about the UPS program in high school. It seemed to be an answer to his concern over how to finance his college dream:

I found out about UPS from my guidance counselor from high school and through advertisements and so forth. And my mother and stepfather, their way of thinking is that once you reach 18, you're a grown man. You have everything and you are on your own. And after high school my brother was on his own and he had to pay for his college and everything. I saw him go through some financial troubles. And me, I have some poor money management skills and I couldn't pass up the free tuition UPS was offering. I couldn't get it from my mom, you know, and I couldn't get it on my own from a job like working at the mall or something. So, this way UPS pays for my tuition and they have loans that you don't have to pay back, so, after a few years working for UPS that is like free money. And I just couldn't pass it up. That's what sold me. (9/21/01)

The lack of financial support from home was an important factor in Joe's decision to "choose" the UPS program. In some respects, though, this was a "forced choice." Joe's parents could not afford to send him to college. Joe's brother also indirectly influenced Joe's decision to work at UPS. Since Joe's brother had paid for his own college costs, Joe felt obligated to do the same. Plus, it was Joe's parent's expectation that Joe pay for college. Primarily, though, Joe felt that the "sales pitch" UPS made, "sold" him on their offer.

The UPS "sales pitch" was wide-ranging and had a number of partners who served as salesmen and women for the program. TJ referred to the UPS people who came to his high school as "recruiters." Joe found out about the program through his high school. His high school, his guidance counselor and the college Joe was attending, all of who participated in the "recruitment" of students for the UPS program, encouraged 
the program. Through their participation in this recruitment, these officials and agencies all conspired to give the program legitimacy to Joe and others like him. College maps given out to prospective students advertised, "UPS has truckloads of money to give to college students. Honest." One entire wall of the recreation facility, which is part of the campus tour for prospective students and parents, was devoted to a mural portraying industrious college students hard at work at the UPS facility, with brochures about the benefits of working for UPS sitting on a nearby counter. Although it was not specifically stated as such, the program was aimed at low income and working class students who thought that they needed assistance with paying for college. However, nowhere in the "small print" of these sales pitches did the advertisements for the program say, "Warning, participating in this program will severely curtail the time you have available to spend on other campus activities, will physically and mentally exhaust you, and will have a negative impact upon your grades in college." Yet, for TJ and Joe, these were exactly the costs they incurred as a result of their participation in the UPS/college partnership.

Throughout the semester, Patrick contemplated enlisting in the military. His consideration was based upon complex feelings that he needed the emotional, financial, and social support that the military offered, as well as his feelings of negative self-worth that he wasn't perhaps qualified to be "in the big leagues." When Patrick talked about how prepared he felt for college, he said that college was the big leagues, and he thought that perhaps he did not belong here. However, in our final interview of the semester, Patrick also confessed that much of the appeal he felt towards joining the campus Air Force ROTC program, was monetary:

P: I would get a monthly income and $\$ 200$ if I took the ROTC class next spring, plus $\$ 1500$ towards my tuition if I join up. 
R: But if you only take the class, you get the $\$ 200$ anyway? Even if you are not in the ROTC program?

P: Yep. And later on they give you more money.

$\mathrm{R}:$ So, is it mostly the money?

P: Mostly money. And a lot of it is, it's a good opportunity. It gives me more of a door to my career. It opens up another way to accomplish what I want to accomplish. Just a lot of things like that. You know, federal agencies are more inclined to take someone with military experience. $(11 / 28 / 01)$

Clearly, the money was a substantial influence in Patrick's thinking about the military as an option for him. Plus, as both $\mathrm{TJ}$ and Joe had mentioned in relation to working at UPS, the military was a way to avoid accruing debt. Additionally, Patrick talked about the ROTC program as being a "door" to his career, even though he was unsure what his career goal was, precisely.

The ROTC program also targeted students from low income and working class families who felt that they could not afford college. Like UPS, the ROTC program had recruiters and participated in an extensive ad campaign to try and lure students into the program. Patrick's parents initially felt strongly that they did not want their son to enlist in the program because they were afraid that he would have to face active duty, which would require him to drop out of college. They felt that once Patrick was in active duty, he would not return to college to complete the dream of obtaining a college degree. However, after several conversations with Patrick in which Patrick convinced his parents of the financial benefits of the ROTC program, his parents reluctantly agreed that Patrick could enlist in the program. One of the reasons Patrick's parents relented was that they realized they could not provide Patrick with the level of financial support that the ROTC program was promising, both during and after college. They simply could not compete with the ROTC program. 


\section{College vs "Real Work"}

Education can bring respect, both Sennett and Cobb (1972) and Willis (1977)

said, but members of the working class do not always see education and white-collar jobs as "real work." In the same way, the students in this study felt the need get a job because they felt that by simply going to college, they were not working. This sentiment was voiced by Patrick, "I was actually thinking of getting a job "cause as long as I am not working it begins to feel weird to me after awhile. I kind of miss working" (10/31/01).

In our second interview, Patrick was talking about his grandparents and how they, specifically his maternal grandmother, did not support his attempts at earning a college degree. Although this was an issue of family support for Patrick, it was also an issue of social class because learning a trade invariably would have kept Patrick in the same social class, while earning a bachelor's degree and doing white collar work would likely lead to his ascension into another social class, thus creating class conflicts within the family:

P: My grandparents didn't believe in college, apparently. They always told mom when they talked, "Well, why don't you instead of paying for all this college, and that nonsense, why don't you send them somewhere and let them learn a trade?" But like I said, anymore you can't get a job without a four-year degree. It seems like having a trade doesn't work.

R: But your grandparents would say to your mom and dad, "Why doesn't Patrick just go get a trade, and learn to be a carpenter or something?"

P: Yeah, "Why don't I learn how to repair engines or survey or something?" That worked back when my grandparents were growing up. After high school, if you graduated, you went and learned a trade. You learned to do something. They see school as just, you know, you're not learning anything valid. You are just filling your head with useless knowledge, I guess, and then you get a piece of paper saying you can do something and it means nothing. I guess they don't see who runs things, who your presidents are, and who runs city governments and things. I guess it is all black and white to them.

R: Yeah, it's not tangible. You're not learning how to "do something." P: Right, you're not learning a skill. You're learning about learning, or something. I can't explain how they look at it but it's weird. I don't understand it 
myself. If you're not learning a specific, hands-on skill, that can actually go out and be used, they don't see anything in college, except maybe learning to be a doctor. That is something you can use, something that you can apply. "OK, you're in justice administration. What do you do there? Do you fix police cars? Do you clean their uniforms? What is it you do?" They don't understand, I guess. $(10 / 17 / 01)$

Patrick was conflicted over the nature of knowledge and what counted as knowing. The social class of Patrick's grandparents, coupled with the fact that his grandparents have never been to college, affected their view about what counted as worthwhile knowledge. And this affected Patrick's ability to adjust to the academic community. To be accepted by his grandparents, he must earn a degree in something that "matters." But Patrick's grandparents did not appear to expect that Patrick would become a doctor. They appeared to have the expectation that he learn a trade. These expectations could be linked to his grandparents, and Patrick's, social class. His grandparents did not believe that working class people became doctors. At one point Patrick considered majoring in history but his concern about the type of job he could get with a history major made him decide to go into justice administration. Even Patrick needed at some level to see a clear occupational link or payoff to his time at college. How long Patrick could go along without experiencing some inner dissonance was a question, and it seemed on some level that he already was experiencing some.

Bryant also saw college as an easier route than "real work," and this attitude was reinforced by his father:

B: I could do construction if I had to, like my dad. He's been on both sides of the wire and I could see myself doing construction if I had to and I needed extra money, or if I had a family or something.

R: Did your dad ever say anything to you like, "I know what it is like not to go to college, and you are going to college "cause the alternative is not good?"

B: I say to him sometimes, "You didn't go to college and you have done pretty well," and he says, "Yes, but there has been a lot of struggle and sweat and you 
don't have the work ethic to do what I have done." I was like, "Yeah. You are probably right." So, I will go to college. $(9 / 13 / 01)$

Bryant's father wanted Bryant to go to college, but it appeared that it was partly because he did not think that his son worked hard enough to get ahead without a college degree. His father did not see college as hard work, certainly not as hard as what he had done. Bryant apparently concurred. Work required a strong work ethic, Bryant's father felt, which Bryant lacked. College did not require a strong work ethic, his father felt, so Bryant would have more success in college. To Bryant and his father, work required struggle and sweat, while college did not.

But this easiness of college was not always good, either, even if it could have huge financial payoffs. There is an honor in "real work" that left unexplored can work against the "real workers" in our society. In one of our interviews, when Patrick and I were discussing him enlisting in the military, he also talked about how, while people in the military might not be the best and the brightest, they still work harder than highly educated people such as doctors and lawyer:

The military doesn't get the best and the brightest. The best and brightest become doctors, and lawyers, and make a lot of money with less work doing what they want. $(10 / 31 / 01)$

Patrick implied that doctors and lawyers don't "really work," they just make a lot of money "doing what they want." Doctors and lawyers do have more control over their lives. Blau and Duncan (1967) observed that the occupations thought to have the most freedom are the occupations Americans feel have the most prestige. Patrick felt the same way.

In American society, certain positions are perceived as more prestigious than others, and these careers often require significant academic work and success. Patrick 
did not believe that he was worthy of becoming a doctor or a lawyer. Anyon (1980) says that the schools for these careers prepare only students from certain social classes. Patrick explained that the military got less than the best and he was considering the military, therefore he was less than the best. Still, he was almost dismissive of what doctors and lawyers did. In his dismissiveness, Patrick could protect some level of selfdignity. This was certainly understandable. Surely, we cannot expect Patrick to take this goal on for himself, not that it would if he did. Even if he was successful in achieving the role of doctor or lawyer, members of society, in order to demonstrate how the system works, could use him as an example. However, in not considering the occupations or his lack of choice in this work, Patrick may be seen as perpetuating a class structure that works to oppress him. Again, to place this on the back of any one person is unreasonable. What is at question, though, is to what extent universities and colleges do not work to assist all students to access the opportunities they purport to do. Further, to what extent do we as a society continue to position students, through education and other institutions, to not see their own and others' oppressions.

The Development of "Back-Up Plans"

The students in this study were not at all confident that they would make it through to graduation. They were not always sure that they wanted to stay in college through graduation. At times, it seemed that they were "trying out" college to see what it would be like. Because of their concerns about whether college was going to be what they hoped it would be, or perhaps because of their insecurity about whether or not they would be able to make it in college, I found these students developing what I called "back 
up plans" in case college did not work out for them. They "hedged their bets," making sure that college was not their only option.

The concept of "hedging his bets" in case college did not work out came out in my conversations with Patrick as we discussed him going into the AFROTC. He was not willing to totally commit to college, so he considered the ROTC as his "back up plan:"

My parents say I can go to school and do the military as well, but I don't really like going to school so if I join the military I would want to only do the military, and not college. I don't want to stay in college and join the ROTC, 'cause if you do, then you gotta do good in college. And if I am working as hard as I am now, and doing as bad as I am, that's gonna cause trouble for me 'cause the Air Force won't want me anymore, and I don't want to blow both. I need to pick one and run with it. My buddy is in the Air Force and he tells me that it's not that way. He says that the Air Force will make sure you make it, 'cause the Air Force doesn't get the best and the brightest.

If he joined the Air Force ROTC program, Patrick was committed to both, and he ran the risk of failing in both endeavors. And, by considering the military, Patrick was intimating that he was not one of the "best and brightest." Since Patrick felt at times that he did not belong "in the big leagues," it was not surprising that he considered enlisting where he felt he would fit in. Patrick felt that if he joined the ROTC program, he would fit in there. The ROTC would take care of him and make sure that he succeeded. They would support him and work with him, unlike the faculty at the college, he felt. His friend also gave him the feeling that the Air Force would support him, which helped. This supported Anyon's (1980) argument that schools prepare students differently based on their social class. Patrick did not feel prepared for college, but he did feel that he was prepared for the ROTC program. While the college had students who were among the "best and the brightest," the Air Force did not, according to Patrick. Patrick felt he would be more at home with the ROTC program than he would in college. 
TJ devised his "back up plan" with UPS in mind. Not only could TJ finance his education through UPS, but, in case college did not work out for him, he could always go to work for UPS:

I heard that UPS was a good job to get into. So I thought even if I couldn't figure out what I wanted to do later, I heard that you could advance with UPS, like in accounting. (10/01/01)

TJ had entered college with little preparation as far as a career was concerned. As early as our second interview, TJ indicated that he was unsure about his major and his initial career choice. While this is not unusual for any college freshmen, since TJ was already behind in his credits towards graduation, any further change would place him even further behind his peers. However, UPS would provide TJ with an opportunity for a good job that might lead to something, TJ believed. At various points in the semester, UPS seemed to be offering $\mathrm{TJ}$ an opportunity to be successful that he was not sure the college was offering him.

Joe also had heard that UPS was a good company with which to get involved. While Joe seemed more sure than the other three that college was where he belonged, he still seemed to be hedging his bets in case college did not work out for him:

I have heard, although I don't know if it is a fact, that you can make a lot of money if you move up the chain at UPS. They say that UPS loves to hire from within, so, if there wasn't anything else I was interested in at college besides business, I could work for them. (9/21/01)

Like TJ, Joe had heard from "someone" that UPS was a good company with which to be associated. How Joe differed from TJ, though, is that Joe emphasized his interest in moving up the chain at UPS, while TJ emphasized working in the accounting department. UPS had entered the folklore lexicon as being a place where anyone could move up the 
chain and be successful. Once you start working for them, you just have to show that you are a hard worker and you will be given an opportunity to move up the chain.

As I wrote earlier, there were costs associated with working for UPS that neither TJ nor Joe expected. The implications of "back up plans" can be interpreted in at least two ways. First, these plans may be nothing more than words. These words can protect these students from academic failure. That is, there seemed to have been some security in believing that these jobs would be there and the student had found a job with some perceived "possibilities." Second, the plans can be seen as cop-outs. The students can blame the job if they are unsuccessful at school. They can claim that the job was more of an enticement than college, when in reality it could be that college was simply too difficult for them.

Intrinsic Motivation

By intrinsic motivation I mean notions of self-worth, ability and esteem. The participants in this study talked frequently about their individualism during this study. They felt that their success was dependent on their efforts alone. Their resolve to succeed despite the obstacles they encountered might have developed from messages they received from their parents, or it could have been a resistance like Sennett and Cobb (1972) or Willis (1977) talked about. Working class college students often need to work through their feelings of "status incongruity", which is caused by not knowing the rules of a new position, Sennett and Cobb said. Working class college students commonly feel caught between two worlds and sense that something is wrong, but are not sure what. Out of this sense that something is wrong, Willis found, working class students often differentiate themselves into "them," meaning college faculty, administrators and peers 
who embrace the academic climate, and "us," meaning working class students. The students in my study saw the faculty and staff as working against them, not with them. And at times they also saw their parents as unsupportive. Out of this feeling, then, of non-support, might have come the development of an intrinsic sense that if they were going to succeed at college, they would have to do it by themselves. I'm not sure the resistance will be a successful motivator or a successful strategy, but it seemed like these students were defining their role as a resistance to what they perceived as the institution's expectations/oppression.

The students talked metaphorically about the college experience being difficult but "good in the long run." This "pull yourself up by your bootstraps" philosophy is deeply ingrained in American social consciousness, and it was voiced by $\mathrm{TJ}$ when he said, "I guess, if you can make it through working at UPS and going to college, you can make it through later on." (10/01/01)

Patrick expressed a similar feeling that he was somehow being tested when he said, "Sometimes I feel like I am being weeded out and sometimes, sometimes I think it is a test of my resolve. And I will get through it like I always do. I always seem to come out OK" (10/31/01). Both TJ and Patrick assumed that college was supposed to be making them prove they were serious about college, so they took it in stride that they were being "put to the test." Both of them seemed to be intent on making it through the test as well. TJ also saw that UPS was now participating in the boot camp that college had become for him.

Pratt and Scaggs (1989), in their study on attrition rates of first gens, hypothesized that some first gens are very aware of the opportunity for socioeconomic mobility that 
college offers and have a singleness of purpose that other students may lack. In addition, Pratt and Scaggs felt, since first generation students experience less parental encouragement for their college enrollment than other students, their aspirations may be more internalized, and therefore more focused. The students in this study had a singlemindedness regarding their purpose for attending college. However, this singlemindedness and focus did not appear to result in either their academic or social success at college.

\section{Hegemony}

Weber (1946) argued that a few members of the working class will always find a way to "make it" into the middle class, and perhaps the upper class, but the entire working class can never follow because the social class structure of education and society does not allow it to happen. However, it is through a good number trying, that the class structure is legitimated. When one person from the working class manages to "make it" into the upper class, the upper class can then point to this one person as "proof" that the system works, and does not need to be altered. Joe had seen one of his colleagues "make it" into the middle class, and he was determined to do so as well:

$\mathrm{J}$ : I am working on the assembly line now, but I have already talked to my supervisors and they say that you can make it to supervisor in a few months, and I have been there for three months. So, as soon as I apply, they say I will get it. But I am not ready yet. I want to see how it works. I want to get my feet wet before I do it.

$\mathrm{R}$ : So, you can move up pretty quickly? And you said that they do a lot of internal hires as well?

J: Yeah. They love to promote and I have heard stories of people who have started out on the line and now they are in the offices. My friend started out doing what I did, and now he is 28 years old, and making six digits. That is nice. $(9 / 21 / 01)$ 
Joe was participating in his own oppression by continuing to work at UPS even though he was congnizant of the negative consequences of working there. These negative consequences included doing poorly in his courses, feeling tired and sleep deprived, and missing out on many of the campus life activities he wanted to participate in. He saw that his friend started out on the line as he did, and was now making in excess of $\$ 100,000$. Therefore, Joe thought, "If he can make it, surely I can." And if Joe did not succeed, the system would reinforce in Joe the feeling that he failed due to his own shortcomings, not because the system conspired to work against him. Someone just like Joe managed to make it, so Joe continued to want to work because he was chasing the dream.

In this section previously shared data and new excerpts were examined. All shed light on different aspects of how social class impacted the collegiate experience of these students. The issue of social class was deeply embedded in the experiences of these students. As a result, the issues explored in this section on social class at times overlapped with the data analyzed in the sections on preparation, support, and belonging.

The students in this study often felt caught between two cultures and experienced numerous examples of status incongruity due to their upward mobility from one class, that of their origin, to a higher social class (Sennett and Cobb, 1972). They were confused about which social class they belonged to. These students also attempted to pay for college without taking out student loans because they considered the accumulation of debt to be unacceptable. Traversing the boundaries and living in the borderlands between these cultures proved to be a painful experience for them.

This study looked at the experiences of four working class, first generation, white males in their first semester at a selected college. Because of their first generation, 
working class background, these students negotiated their campus experience differently than those students who were second generation, or who were from more affluent families. In addition to negotiating academic and social issues in transitioning to college, these students also found themselves grappling with the college culture that often conflicted with their working class traditions, values, beliefs and assumptions. The students in this study thought of college primarily as a place that was going to prepare them for a career, without realizing that it might also be responsible for changing the way they thought, and the way they would come to perceive their world. These were difficult changes to accept. The families and peers of these first gen students seemed unable to help the students through the transition process. Further, at times they seemed unwilling to accept the changes that were occurring. In the next chapter I will explore ways that educators can improve the experience of future first generation, working class students who are dealing with these monumental changes in their lives. 


\section{CHAPTER FIVE}

\section{CONCLUSIONS}

I guess if I could have one thing changed about college, it would be to make it easier for people to become socially involved. It seems like they expected people to just come in and be these teenagers with adrenaline and hormones pumping, and be wanting to party all the time. We had this one guy from the college at orientation, who said, "Don't just work and go to school. Have fun. Party. Do stuff that you wouldn't do 'cause this is the only time in life that you can do something stupid and say, 'I'm in college' and it's OK." I'm sure everyone else in the auditorium went, "Yeah. Wow." Maybe I am just not the normal person that is expected to come to college. They want you to study and do good, but then they want you to go out and party and have fun and that is just not for me at all. (Bryant, 10/11/01)

Bryant felt that he was the only one who had these feelings of being "left out." Yet the other students in this study felt the same way at times. For example, Patrick indicated that it was a relief for him to know that he was not alone in his feelings, that there were others like him, first gens, who felt isolated and "weird" like he did. Bryant might take have taken some consolation in knowing this as well. Certainly, Bryant was indicating a need for the institution to broaden its notion of student support so that he did not feel like he was the only one on campus dealing with these issues.

This study looked at the experiences of four working class, first generation, white, first year, male college students. The focus of the study was how the students' first generation status and working class backgrounds affected their college experience. However, I want to remind the reader that these were working class, first generation white males and the reader should remember this even when I present this issues as 
separate constructs. By analyzing the experiences of these students, it became clear that for these students, enrollment in college was a risky venture, full of hidden problems and unexpected demands. The study supports Anyon's (1980) argument that the educational experience students receive is differentiated according to their social class. This study expands Anyon's theory beyond the K-12 setting, and into the post-secondary level. Bryant and Patrick both indicated they felt "abnormal," and "weird" at college, but in fact they were not weird or abnormal at all.

This chapter is divided into four sections: important findings, recommendations, context and areas for future research. The important findings section is organized along the lines of the study itself, with sections on social class, preparation, support, and belonging. I have chosen to invert the order somewhat, and to present the section on social class before discussing the issues related to preparation, support and belonging. While I acknowledge that the complexity of social class reaches beyond this college, given my theoretical framework I assume that one of the roles of the institution is, through its own practices, to ameliorate the effects of social class and to teach in ways that facilitate a broader access to all aspects of United States society. Therefore, I will begin the following section with a discussion of social class.

\section{Important Findings}

\section{Social Class}

In 1947, the President's Commission on Higher Education published a report that concluded:

American colleges and universities must envision a much larger role for higher education in national life. They can no longer consider themselves merely the instrument for producing an intellectual elite; they must become the means by 
which every citizen, youth, and adult is enable and encouraged to carry his education, formal and informal, as far as his native capacities permit. (p.101)

Since 1947, the demographics of student populations at colleges have changed drastically, and the number of working class students attending college has increased significantly. This increase in the numbers of working class students at college, however, has not negated the continued differences in educational achievement between the affluent and the non-affluent in American society. The largest barrier to the assumed meritocracy that is inherent in the statement by the President's Commission is social class (Hearn, 1984). In 1996, only 36 percent of poor students attended college, compared to 88 percent of affluent students (Howard, 2001).

Working class students often lose out on opportunities that more selective colleges provide, due to a lack of financial, cultural, and social capital (McDonough, 1994). In addition, public colleges, in an attempt to emulate private colleges, are narrowing access to college for working class students by raising their tuition rates.

Contrary to the norms of this assumed meritocracy, entry into the most prestigious and selective colleges is not a function of test scores and grades. Colleges are also limiting access to working class students by an increased reliance on SAT and other standard test requirements (Soliday, 1999). Research has shown that standardized tests such as the SAT are biased against working class, first gens (Saks, 2001). Rigid adherence to these scores increasingly stratifies colleges.

Since different types of colleges have differing graduation rates, the affect of not gaining access to a certain type of college can be devastating for working class students. Elite colleges have graduation rates between 85 and 95 percent. Four year public colleges have graduation rates of approximately 45 percent (Snyder, 1987, in 
McDonough). In the meantime, only 20 percent of students who attend a community college transfer to a four-year college (Adelman, 1988, in McDonough). Close to 80 percent of first gens begin college at community college (Willett, 1989), and of the ones that successfully transfer to a four-year college, only 20 percent manage to graduate (Adelman, 1988 in McDonough). Working class, first gens, who are forced to begin their dream of a college education at a community college, then, are already faced with an uphill struggle.

However, it is not simply enough to get less affluent students into college. Colleges need to focus on helping these students successfully complete their degree (Gladieux and Swail, 1996). Working class, first gens experience a phenomenon that Sennett and Cobb (1972) called status incongruity. All of the students in this study grappled with this issue to various degrees. Their working class background was exerting an influence on what they expected and experienced as higher education, and the middle class culture of higher education as it was enacted on this campus, was providing them with a conflicting viewpoint.

\section{Faculty/Student Relations}

The students in this study did not feel that their faculty members or advisors understood what they were going through. They were reluctant to reach out because they perceived college employees to be at best indifferent, and at worst, hostile towards them. It appeared from this study that the faculty was waiting for the students to come to them with their issues. These students did not perceive a reaching out on the part of the faculty to the students. This college and its employees could not assume that working class 
students would ask for help, because, as the students in this study showed, they often will not.

Bryant wrote two articles for his English class that touched on the subject of social class, but he felt attacked in his class when he brought the issue up. Patrick walked out of his sociology class when his faculty member showed the video about his home town. Although the course description for the sociology course stated that, "Poverty, racial/ethnic conflict, work and occupations, and the environment may be among the topics considered," Patrick and Joe, who each took the sociology class but were in separate sections, both perceived that the course focused solely on race, missing the opportunity to discuss social class. Campus culture had as its goal helping students transition to college, yet status incongruity, the main stumbling block for working class students, remained unexamined. Besides these young men, how many other students experienced an expectation to reject the values and norms of their family and home town because they were now in college? "Status incongruity" can explain why feeling out of place on the college campus extends beyond the issue of race and gender.

Valadez maintained that the cultural capital of the upper classes is legitimized and reinforced through school's selection of textbooks, teaching styles, curricula and classroom discourse. According to Gos (1995), working class students are reluctant to challenge statements made in class because their upbringing maintains that when a statement is challenged, it is the relationship that is challenged, not the statement itself. The authoritarian environment of working class families discourages questioning, Gos contended. This then limits working class students' ability to think critically, to analyze and to question what is being presented. Gos argued that working class students are 
under intense pressure to successfully achieve a "border crossing," which may not be possible for most working class students.

The English classes that these students had required them to critique each others papers on a regular basis. Bryant was very vocal about feeling uncomfortable with this style, from both perspectives of giving feedback and receiving it. The class was teaching students to analyze each other's work critically, but Bryant had no experience doing this in his high school courses. Similarly, Patrick talked about how in his sociology class, he did not actively participate and never raised his hand when given the opportunity to engage in class discussion.

\section{The Role of Student Life}

Student affairs staff members also have a role in supporting first generation, working class students, and in helping them successfully transition to the college campus. During this study there appeared to be a lack of interaction between the students and the various student life offices on campus, once classes began. Although it is somewhat speculative, it appeared that the social class of these students impacted their perceptions of what the college campus was supposed to provide for them. All of these students considered the purpose of college to be a place where they were prepared for a job or a career. Their working class background did not allow them to see that their preparation might extend beyond the classroom. The working class background and the accompanying lack of college experience of their parents also prevented them from considering interaction with student life. Since their parents had limited social and cultural capital, they did not advise them to reach out to explore the various programs that student life offered on the campus. 
A survey of former students of this college indicated a high level of dissatisfaction they felt while they were students at the campus. In addressing the bad publicity that resulted from the survey, the provost stated that the students who had responded to the poll were enrolled at the college prior to the changes she and the college president had implemented over the last few years. She indicated that students enrolled today felt very differently about the campus. In this study, however, the participants seemed dissatisfied as well, indicating that the issues to which the previous students were responding had not disappeared.

The participants in this study expressed frustration, ambivalence, distrust, and hostility about student life and support staff. These students never indicated they knew the channels to use to rectify their displeasure. Further, given their social class, it would have been highly unlikely that any of the participants' families could have made the necessary connections to change the students' circumstances.

\section{Financial Need}

Patrick Healy (1998) wrote in the Chronicle of Higher Education that higher education is currently experiencing an era of tight money and higher standards. Both of these issues disproportionately impact working class, first gens. Sufficient financial aid is absolutely essential to the success of first generation, working class students. Rather than relying on their parents for assistance, three of the students in this study considered alternative ways to finance their college education. However, the alternatives were limited by a strong desire/need to avoid debt.

Since 1980, there has been a significant shift in how financial aid is distributed to college students. In 1980, $54 \%$ of financial aid was in the form of grants, while $41 \%$ 
were loans. In 2000 , loans accounted for $59 \%$ of the financial aid available, while grants amounted to only $40 \%$ (Howard, 2001). The major consequence of this shift, combined with the substantial increase in college tuition, is that higher education has become less affordable for working class families.

There has also been an upsurge in "merit grants" during the 1990s. These grants are distributed to students as "rewards" for doing well, academically, in high school. The state where this study took place participated in such a program. These types of grants are not need-based and end up being overwhelmingly distributed to more affluent families who generally can afford to pay for the cost of college tuition. These non need-based merit grants reduce the available pool of money that many states have available for needbased grants that could go to working class students.

Pell grants are the primary source of need-based aid for working class students. The size of these loans has failed to keep pace with inflation, and as a result the maximum amount of a Pell grant is rarely enough to fund a student's tuition. Since the amount of money the federal government has allocated to the Pell grants has not kept pace with inflation, Pell grants are generally now only awarded to very low income students. This means that many working class students, who need the grants, are unable to obtain them.

TJ, Patrick and Joe all seemed to have received sufficient financial aid to attend college, while Bryant relied entirely on his parents to pay his tuition and fees. The financial aid "packages" that TJ, Patrick and Joe received, included student loans, which to them was problematic. Patrick attempted to attend school in the first semester without working, but by the end of the semester he felt financially strapped, and did not want to 
take out any further loans. Because these students considered debt unacceptable, they considered participating in programs that would pay their tuition, in exchange for their participation. However, these programs made it difficult for them to fully participate in campus life. TJ also found that the financial support offered by the UPS program was not sufficient to cover all of his college costs.

Because of their work at UPS, both TJ and Joe were unable to take advantage of the academic and social opportunities that the college provided. For example, Joe was unable to attend all of the programs required by his fraternity for initiation into the fraternity. Both TJ and Joe said that work caused them to miss classes, and they attributed some of their academic problems to the time commitment that work required of them. TJ also suffered physical problems due to work-related fatigue. These were all unexpected difficulties because the "recruiters" used by UPS never mentioned these hidden costs. Instead, the program seemed to have the complete support of these students' respective high schools and the college, which gave this program credibility in their eyes.

During the 2000 election, I had the opportunity to ask one of the local candidates for Congress what she would do to help students from working class families pay for college. She stated at a forum attended primarily by college students, that she would encourage more partnerships like UPS for students as a way to finance their college education. This gave further support to the idea that this is an appropriate way for students to pay for their education. Given the community and state this institution served, the college had to explore creative ways to support working class, first gens. However, the institution also has an obligation to protect its students from exploitation. It seems 
unreasonable and perhaps unacceptable to hold students who must work to the degree that Joe and TJ did, to the same standards and expectations, as those students who could afford to focus solely on their education without having to work as they did. It is unreasonable, perhaps even irresponsible and unethical, to promote programs like the UPS partnership without a complete understanding of its effects on the students who participate. At a minimum the students who are considering entering these programs should be able to expect an explanation of these effects before they enter into the programs.

ROTC is a government-funded program available on most college campuses. It is promoted as a career move, a patriotic commitment, and a reasonable way to finance one's education. The ROTC program on campus was very enticing to Patrick, who had decided at the end of the semester that he was going to join the program. First generation, working class students, such as Patrick, who are attempting to avoid debt, may find ROTC, and other military-oriented programs such as the National Guard, too enticing to pass up. While facilitating access to college for Patrick, the ROTC would compete with the academic mission of the college, rather than support it. According to Patrick, students in the program take mandatory military history courses and receive both college credit and pay for their enrollment. These courses offer at best a limited version of history and do little, if anything, to encourage the critical thinking skills that the college attempts to develop. In addition, according to Patrick, students are required to spend hours marching and taking part in military drills, which limit the time that they have available to participate in other co-curricular and/or academic activities. In short, the students in these programs become a sub-culture on the campus. I recognize that 
most programs, clubs and organizations on campus also place demands upon students' time. I also am cognizant of the various sub-cultures on campus that are successful at college. However, what makes ROTC different is that it requires spending time with a group because of the financial carrot being presented. This is also true for UPS. The ROTC subculture is also negative, because of the faux academic pretense that it presents. Students are led to believe that they will be taking a college-level history class that in reality, according to Patrick who attended the class, a brief lecture on United States military superiority, followed by 40 minutes of calisthenics. In order to pay for their college education, and be a part of the campus, students in the ROTC program, at this college and at other colleges nationwide, are unable to fully participate in college activities because of their ROTC commitments.

Preparation

This study found that working class, first gens did not have a high level of parental involvement in either preparing for college, or in applying for college. This study also found that there was not sufficient involvement on the high school's part to overcome this lack of parental involvement, at least not for TJ and Bryant. The type of high school these students attended was important to the level of preparation these students received for college. Joe participated in a larger array of college-preparation programs than the other three participants, and he was also the only one who attended a private high school.

Patrick appeared to receive substantial personal attention from his high school guidance counselor who was attempting to recruit Patrick to attend the counselor's alma mater; but there was no indication that the guidance counselor, or the school in general, 
organized college preparation workshops, or worked with the students as a whole, like Joe's high school did.

The students in this study were relatively uninvolved in high school activities and this set a pattern for them that continued into college. Unless working class, first gens are mentored into participating in co-curricular activities this study suggests that they will be unlikely to do so. While there are many activities for students to choose from in high school, the schools cannot leave it up to the student's own initiative, to participate. There are a number of reasons why working class, first gens do not participate in co-curricular activities in high school. Patrick needed to work after school, TJ and Bryant were more community-oriented than school-oriented, and all of the students in this study seemed to lack sufficient role models and peer support for becoming involved. With the possible exception of Joe, their non-involvement in high school seemed to set a pattern of noninvolvement that continued once they were enrolled in college. Again, the effects of class cannot be ignored. Joe is a case in point. Here was a student who had heard that involvement was important but he also needed to work. Even if he wanted to follow the advice his work commitments would not allow him to get involved.

Rigid adherence to test scores to determine academic eligibility helps to create a stratified system within a college. The college in this study relied on SAT scores and math/English placement test scores to determine what level of English and math students needed to take at college. Three of the students in this study were required to take remedial math and English for which they received no college credit. Only one student, Joe, was not required to take the remedial classes or to take the placement tests. This difference seemed to be a function of the type of high school Joe attended. Joe attended a 
small, private, Catholic high school, which actively prepared Joe for college. The other students attended large, public high schools. Given their equivalent GPAs and ACT scores, it appeared that Joe was rewarded for attending a high school that actively worked to prepare him for college, while TJ, Patrick and Bryant were all penalized by having to take remedial classes for no credit.

Support

Stanton-Salazar and Dornbusch (1995) found that success within the educational system for working class students was dependent upon the formation of genuinely supportive relationships with mentors. They found, however, that these supportive relationships were difficult to find and maintain, and that they generally came from outside the family in either the school setting or in the community.

Patrick talked in one of our interviews about how the parents of first gens from working class families respond when their children go to college. He contemplated ways in which the parents of working class, first gens supported their children. In many ways his comments supported the findings of Stanton-Salazar and Dornsbusch:

My parents still feel responsible for me. They don't know what's going on, but it either makes them feel out of power, or they just feel like they have to wash their hands of it and let you do what you want. There is no in-between. They don't feel like they are in any position to guide you. So they tell you to do this, that or the other, but they know that that is probably not going to work. Our parents see college as this place where everything that they have ever taught you, everything that they have ever said, all of the values they instilled in over the years, are put to the test. They are going to see how good a job they did, 'cause you are out on your own. And as they see it, the college will tell you your classes, and where you live, and where to get your food, and they will provide you with the basic things. But everything else is yours to figure out. Mom and dad say that they cannot do it. They say, "No one can do this except for you." People who have been through college say, "We think the university needs to do this, and do that." People, who have people to guide them, who have people who have been through college, seem to be the ones that complain the most. But people like us we don't. I say, "Well, it is all there." They give us a library, it's free and it has a thousand 
friggin' books in it. I mean, it is all there and if you are up here, and you have made good enough grades to get accepted, then you should know how to balance your time to do this. Our parents instilled in us that it is our job, and not anyone else's, to look after us up to this point. They've gotten us this far, "Let's throw "em out there and see how they do." Here it is, and you go in and they close the door. $(11 / 14 / 01)$

Patrick said that "people like him" don't complain about college. It is his secondgeneration peers who complain. He felt as though his parents got him into college, and now it was up to him to finish his education. Patrick felt that the college had no obligation to support him in his efforts to go to college. If he accepted support from the college, if he even asked for help, he could no longer say that he did it all himself. Being able to say that he did it all himself gave Patrick a great sense of pride, but it disadvantaged him during college. He missed out on opportunities to gain the support he needed from his faculty and peers because he was unwilling to acknowledge that he needed help, or that the college was obligated to provide him with any assistance. Once Patrick walked through the "door," there was no turning back because he closed the "door" behind him. He could not look back to his parents for support, and he did not expect help from the college. Patrick thought that he was strong enough and smart enough to figure out college for himself.

Faculty members are usually willing to help students, but many of them also expect students to do the reaching out. As Patrick pointed out, though, it is usually not first gens who are the quickest to ask for help. Whether because of pride or due to a lack of cultural capital about how and where to turn for assistance, or perhaps out of fear about how the faculty will react to them, they hesitate. Their parents, not knowing the process, are unable to guide first gens to where they need to go for assistance, either. The students in this study needed artive mentors to help make their college dream a reality. 
If this study is any indication, mentorship was not being provided by student life, either. The students in this study discussed their faculty members a great deal during our interviews, but members of the student life staff never came up in conversation. For these students, student life played no significant part in their collegiate experience beyond their freshmen orientation. Their lack of student life involvement might have been indicative of the experience of commuter campuses everywhere. However, for these participants the missed opportunity that members in student life might have offered seemed more risky. These working class, first gen students had learned and perceived a distance with faculty already. They had no reason to expect that student life professionals would respond any differently to them. Their campus culture course did not unteach these perceptions. These students then perceived they had nowhere else to turn.

Although these working class, first gens understood on an intellectual level that they needed to obtain a college degree, on an emotional level they questioned whether they could deal with the problems they were confronted with long enough to obtain their degree

\section{Belonging}

Belonging refers to how comfortable these students felt when they were on the college campus, both in class and out of class. Patrick and Bryant questioned whether or not they were "normal," "weird," or "typical." This, among other comments, indicated that they felt out of place at the college they attended. It is important for students to feel that they belong to the campus. Status incongruity puts pressure on these students to "choose" between the college culture, and their working class culture. Without this 
feeling of belonging, these students were left with a feeling that their presence did not matter.

The students in this study considered academics their first priority, and were reluctant to participate in co-curricular activities due to time constraints. However, many academic units have clubs, organizations and activities that could have provided a sense of belonging for these students. In many ways these clubs also support, reinforce and supplement the academic mission of the unit, which could have aided these students academically as well. TJ, Bryant and Joe might have gotten involved in a businessrelated club through their academic unit, if given the opportunity. Since Patrick had already shown interest in joining the justice administration organization, it might not have taken much encouragement from his faculty or peers to attend a meeting.

The students in this study were reluctant to take the first steps to join clubs and organizations on campus. They seemed unaware of the various clubs that were on campus. Yet, belonging to a club or an organization might have made these students feel more like they belonged on the campus. Without this attachment, these students often felt like "something" was missing from their experience. Joe said that he "learned an important lesson in high school," that participation was important to his education. $\mathrm{He}$ saw campus involvement as an integral part of his development as a well-rounded person. His campus involvement overlapped into each of the four areas of study. Joe was prepared by his high school to become involved, his fraternity was serving as a source of support for him at times, and his association with the fraternity provided him with a sense of belonging. Joe attempted to extend his involvernent by becoming a orientation 
assistant, but his work obligations prevented him from doing so, which was a piece of social class.

Patrick talked about joining the military during this study. Initially he saw the military as a "back up" plan since he considered joining the military and dropping out of college. This was also part of social class since he saw the military as offering great financial benefits. Later, though, he decided to join the ROTC on campus. The ROTC was perceived by Patrick as a solid "back up plan," it offered significant financial incentives, and Patrick also perceived it to be a place that would offer him significant support and provide a sense of belonging. Patrick seemed to perceive that he needed all of these things to be successful in college. TJ and Bryant did not seem to perceive that they had this same need. Although Bryant heard the message at orientation that he should get involved, he rejected the message. Bryant perceived himself as being outside the norm and not open to new situations so he was reluctant to take the risk of becoming involved. He felt that his association with his church group was a sufficient source of support and provided him with a sense of belonging. TJ seemed to simply be overwhelmed with all that was required from work and college and did not perceive that he had any time for anything else.

This study seems to support those programs across the country that require all new students to live on campus, because living on campus helps students become part of the campus environment. These four students commuted, and this might have added to their feelings that they did not belong on campus. At the very least, one can assume commute time alone diminished the opportunity for involvement and belonging. All four boys lived off campus. Three of the four lived with people who had no affiliation or 
association with the college. Further, TJ and Bryant were not convinced that location mattered. The utilitarian vision of the students might not have allowed them to hear and understand the importance that residing on or at least near to the campus has on their sense of belonging, and ultimate success.

\section{$\underline{\text { Recommendations }}$}

Part of research is the goal of making a difference with the information gleaned. This study is no different in that belief. According to this study, working class, first year, white male students were at a disadvantage in this college context. The recommendations that follow are given with the primary purpose of facilitating success for this population. That is not to say that these changes will not benefit other students, indeed I would argue that they will. It is to say, however, that the reader should understand the ultimate goal extends beyond the college community and the time that students spend on college campuses. Therefore, this section makes recommendations for national, high school and college policies.

National

Working class students should not be forced to take jobs that severely curtail their ability to become full participants in the college community in order to avoid the accumulation of debt due to loans. They should not have to compromise their level of academic and social participation in college in order to finance their education.

The shift from need-based grants towards loans and other non need-based "merit grants" should be slowed or eliminated altogether. Further, the federal government needs to increase both the size and the availability of Pell grants. By allocating more money to the Pell grant program, additional numbers of working class students would benefit from 
the program and their debt limit could be reduced. I recognize that this is a political stance, and it requires colleges to more actively lobby their state legislatures and the Congress on behalf of their students, but it is clearly needed. Colleges currently spend a considerable amount of time lobbying alumni for donations, which may or may not be targeted to financial aid for students. Money for working class, first gens is not "sexy" as compared to having ones name on a basketball arena, but it is needed if these students are going to be able to both afford college, and be able to access all that the college offers both inside the classroom and out.

This is not to say that colleges must rely solely on the government, though one might argue the need for a free education to protect and promote a democratic society. Colleges have considered and should continue to consider new and creative ways to support students' access to affordable education. The institution that was the site for my research offered students at least two programs to assist in financially supporting their education, ROTC and the partnership with UPS. The focuses of these programs are different, but for the students in this study the programs greatest attraction seemed to be the financial support they provided for the students' education. However, the experiences of these students indicate that colleges need to examine carefully the impact of programs such as UPS and ROTC on working class students.

TJ and Joe both felt that working at UPS from 11 p.m. to 4 a.m. was a better option than accruing debt from student loans. Weber (1946) argued that a few members of the working class will always find a way to "make it" into the middle class, and perhaps the upper class, but the entire working class can never follow because the social class structure of education and society does not allow it to happen. However, it is 
through a good number trying, that the class structure is legitimated. TJ and Joe both said that UPS liked to hire from within and they saw themselves as being able to use UPS in order to "make it" into the middle class. In the meantime, UPS was also using TJ and Patrick in order to get its needs met. While TJ and Joe were hoping to use UPS, they were also participating in their own oppression by allowing UPS to use them.

The United States has been portrayed as an open society where upward mobility is relatively easy to attain. Vander Putten (2001) argues that the United States is also portrayed as a middle-class society where everyone lives more or less the same life. This erasure of class denies individuals an important source for understanding their experiences. Class does exist and it should be rigorously examined both in and out of the classroom. By examining social class as part of the larger issue of diversity, we can bring more attention to the unique experiences and contributions of working class students, and help these students feel as if they belong.

High School

This study echoes the work of others who assert a need to implement programs at both the high school and the college level that would help ease the transition to college for first gens, which might increase their persistence to college graduation. Choy (2001) recommends that high schools implement programs to counsel first gens and their parents about preparing early for college. These programs would encourage students to take academically challenging courses in high school. The findings of this study support the studies by Choy, and Horn and Nunez (2000), and seem to support Choy's recommendations as well. 
Preparation for college should not begin in high school, either. All of the students in this study mentioned that they began to think about college in middle school. Therefore, programs to assist first gens and working class students should begin at this early stage. GEAR UP is an example of a program attempting to work with middle school students to prepare them for college. GEAR UP is a federally funded program that matches middle schools with a high number of first generation and working class students with nearby colleges. The purpose of the program is to have the students become knowledgeable about college at an early age. As participating students become aware of the college campus by taking classes on campus, it is hoped that they will feel more comfortable with the idea of attending college, and will have a better idea what to expect in college. It is hoped that the program will avoid feelings such as the one Bryant expressed when he said, "Going into college, I really had no idea what to expect." GEAR UP is an example of a program that is attempting to develop social and cultural capital in students. Still this program, and others like it, view students from the deficit model, and run the risk of blaming the victim. There is an attempt to change the individual to make him more comfortable on the campus, but there is no expectation on the part of the campus to change itself to make it more accessible and amenable to working class, first gens.

In preparing students for college, high schools and colleges have an obligation to better inform students and their parents about their financial aid options, and to provide financial aid counseling that would allow students to explore these options. Patrick reported that he met with his high school counselor many times as his counselor attempted to obtain a financial aid packet that would allow Patrick to attend college. In 
the meantime, his parents purchased books on scholarships and tried to find Patrick a scholarship to fund his education. When the scholarships in the book did not match Patrick's situation, Patrick felt he needed to educate his parents about subsidized student loans. This is not a role reversal with which either Patrick or his parents felt comfortable, and it is a role better suited to school officials.

According to Joe, Joe's mother similarly left the job of securing financial aid for college to her son and the high school. Joe said that she would have gotten involved if she felt the high school was not doing their job. College attendance is a partnership and programs designed to educate both students and parents allows the parents to feel as if they are more fully participating in the process. Students can reach informed decisions by looking at life after college only if they have the support they need to explore the various options for financing college and to learn important life skills such as budgeting money (Howard, 2001).

College

Currently, many colleges have haphazard methods of providing students with the social support they need for college. There needs to be an institutional commitment on the part of a college to work towards an awareness of the challenges working class, first gens face. Nunez and Cuccaro-Alamin recommend that colleges learn more about the unique needs of first gens, who they are and what their experiences are, in order to help them overcome the barriers they face in becoming academically successful. Similarly, London (1992) also feels that colleges need to learn more about first gens:

It is only when we see that negotiating cultural obstacles involves not just gain but loss - most of all the loss of a familiar past self - that we can begin to understand the attendant periods of confusion, conflict, isolation, and even anguish reported by first generation students. (p. 10) 
The campus culture course in which the students in this study were enrolled had support for their efforts as one of its goals. Yet, none of the students felt particularly supported by the course, its faculty, or their peers in the course. That two of the students failed the course is reason to suggest that the course did not, in its current form, provide adequate support for these students. Many colleges across the country are currently considering implementing these types of courses, as a way to help students transition into the college culture, which is an excellent idea in theory. However, there needs to be sufficient curricular changes in this particular course, and others like it, that will make the courses part of a support network for the students.

My research suggests three broad areas for consideration as colleges work to create positive and successful experiences for working class, first gens: faculty/student relations; the role of student life; and financial need.

\section{Faculty/Student Relations}

This study indicates a need for curricular changes in the classroom. Gos (1995), Bernstein (1971) and Valadez (1996) maintain that behavior, communication, manner of speaking, and values are all social class markers. Middle-class children demonstrate the types of markers that are honored and respected by academic institutions. Thus, in order to succeed in college, working class students must overcome these markers and adopt those of the middle class. Otherwise, working class students, who continue to exhibit their working class markers, are at a disadvantage while attending college. As working class students enter territory where their own cultural resources and values are not celebrated or even recognized, their cultural capital remains subordinated to that of middle-class students (Hanson, 1994). 
Given the context of this college's high attrition rates and high numbers of first generation, working class students, this institution should consider efforts to create learning climates that both affirms and nurtures this population. The reality is that this population is increasing in number nationally. Administrators and faculty members need to develop a greater awareness of the issues that working class students face, including status incongruity. Students' transition to college requires adjustment not only to the new culture of college, but also to a new social class. Embracing this focus can be from either the top down, or the bottom up. However, given the hierarchical structures of most colleges, a top down approach might be more successful.

Administrators must provide sufficient funding, resources and time to train campus faculty and staff, and carry out, promote, and support research on the effects of these efforts to ameliorate status incongruity. Further, advisement and mentoring first generation, working class white male students needs to be valued by the institution and honored within the tenure process.

The students in this study resisted reaching out because they thought their faculty did not care about them. This lack of faculty mentors seemed to inhibit the success of these students. The institution needs to determine the best way to build bridges and relationships with these students, and to educate them about the importance of establishing relationships with faculty and student life staff on campus. My research suggests that there are several possibilities, including faculty, student life administrators, and family members, who were in a position to take the first step when these students needed assistance, but who were probably waiting to be approached. 
It could be that faculty members at this college were both unwilling and unable to provide the level of support that these students needed. As one who is enrolled in a program designed to prepare me for a job as a college professor, I know that faculty members are not generally prepared to be counselors or mentors for their students. They are prepared to be teachers, researchers, and to do service for the college. Faculty are not always willing to take on the role of mentor for working class, first gens, but there should be someone on campus who is given that role. I acknowledge that this is can be a difficult role for faculty who are often under enormous pressure to teach, publish and serve on committees, which leaves precious little time for mentoring students. Those faculty members who do mentor students can find themselves overwhelmed by the needs of students as well, especially when they are the only one in the department who is attempting to mentor students. This is an institutional issue, one that the college needs to address. My research indicates that these students looked first and foremost to their faculty for help and assistance. Yet they were afraid to ask for it when they needed it. Quite possibly the faculty would have been willing to provide help and assistance, but being unaware of these students needs, they were unable to provide any.

Schools need to develop well-thought-out and effective support structures such as mentoring programs, one-on-one advising, counseling, group sessions, and comprehensive orientation programs that focus on the particular challenges that working class, first gens face while attending college (Howard, 2001). Some of these social support programs and services are already established at college. But the structure and methods of providing both social and academic support to working class first gens needs to be strengthened. Advisors and counselors need sufficient training and adequate 
resources to better support these students. The advisors and counselors need to be made aware of the specific social challenges these students face. This requires an institutional commitment to work towards a broader awareness of the social challenges working class, first gens face. Terenzini (1996) suggested that colleges promote the awareness of how different students handle the transition process to college. Compared to second gens, first gens undergo a dramatically different transition, yet most campuses policies and procedures recognize few differences. Terenzini also acknowledged that while early validation appears to be a central element in every student's successful transition to college, academic validation appears to be particularly important for first gens.

Further, faculty members can assist students with the transition to college, by using social class as a lens in their college courses. In this study, three courses, English, sociology and campus culture, provided prime opportunities for at least discussion about the issues of social class and status incongruity. The experiences of the participants in these classes indicate the need for a more thoughtful inclusion of social class in the curriculum, and sensitivity on the part of faculty to the effect of status incongruity for working class, first gens.

For curriculum changes to occur, however, faculty members need to be provided with the resources and training necessary to create classroom environments that make learning more accessible to working class students. Many faculty members have not had the necessary training to create teaching and learning environments that respond to different levels of academic skill and knowledge. As a result, college educators neglect the talents, strengths, weaknesses and voices of many students (hooks, 1994). 
Some colleges, aware of the unique struggles faced by first gens, have gone beyond merely instituting campus culture type courses on their campuses, and have begun to design courses and residential communities specifically designed to help support first gens. St. John Fisher College in New York recently opened a special interest community for their first gen students, and paired it with a freshman English class that these students took together. Berea College, in Kentucky, a college where half of the students come from families making less than $\$ 16,000$ per year, offers a year-long writing and literature course where students become better writers, and readers. They meet with tutors and student affairs counselors as well, to help them with their transition to the college culture.

College courses need to adapt their curriculum to be more inclusive of social class. In this way working class, first gens will see their issues presented and feel as if they belong. Faculty members who disclose their own working class, first gen backgrounds to their students communicate to their working class, first gen students that they understand what they are experiencing (Howard, 2001). In doing so, they can provide students with a role model.

\section{Student Life}

There are four areas in which the administrators and staff in student services agencies should concentrate in order to help first generation, working class, white male students successfully transition to the college and become successful. These areas are: training, student services, student organizations and leadership. In some respects, it may be easier for student life professional to take this on than academic faculty and administrators. Student life divisions are designed to create climates that support the 
work of the institution and the lives of the students. Being in tune with the changing demographics of the student body can strongly and more quickly impact the student life program. In addition, lack of tenure among student life employees can facilitate change. It is easier to remove a non-tenured employee who is not helping produce the desired change. However, as some of the suggestions in this section are linked to the academic side of the institution, it cannot be assumed that one branch of the campus can work without the other.

Terenzini, et al. (1996) make two recommendations for new student orientation that they feel could help first gens transition to the college community, and that would help prepare them for college. First, they recommend that faculty nembers become actively involved in new student orientation programs. Faculty members play an important role in the lives of students, and it is important that faculty make contact with first gens as early as possible, the authors feel. The campus culture course faculty at the college under study could begin the course earlier than the first week of school by making contact with their students during orientation, for example. TJ and Patrick both came from a town several hours away from the campus, were living off-campus, and only knew a few people at the college. They never seemed to feel that they were a part of the campus. Perhaps if they were connected to the college via their faculty earlier, they might have more successfully made the transition to the college campus.

Second, Terenzini suggests that colleges orient parents as well as students. Parents of all students, but particularly first gens, must be helped to understand the time demands that will be place on college students, the changes these students will experience, and how to deal with the stresses that will occur as a result of their 
enrollment in college. Siegel and Barefoot (2001) suggest that orientation be required of all students new to the campus before they are allowed to enroll in the college. One suggestion would be to incorporate a similar requirement for parents before their child graduates. While these recommendations seem to make sense on the surface, a deeper examination of them suggests that not only might they be difficult to implement, they might also be seen as invasive by working class families. These recommendations also appear to view working class students from a deficit perspective. In reality, many working class families would not be able to take the time off of work to attend additional meetings, and the sons might not want them to attend. Patrick made it clear that his parents "got me this far," and now it was his obligation to succeed. Patrick said that his parents had gotten him "to the door," meaning college, and they made sure that he got through the door. While Patrick felt that once he walked through the door he was on his own, I would suggest that once he walked through the door it was up to the college to greet him on the other side and make sure he was successful.

In order to meet the needs of working class, first gens, and increase the numbers of these students who graduate, colleges must improve their structures of support. There needs to be genuine commitment to provide working class, first gens with the academic, financial, and social support they need to overcome the obstacles they face in college. Billson and Terry (1982) recommend that colleges encourage residential learning and participation in on-campus events/activities in order to more fully integrate first gens into the life of the campus. This can only happen if there are sufficient residence hall spaces on campus, however, that are offered at an affordable price. The college where this study took place had very little residential space on campus and probably could not house all 
new students even if it wanted to do so. This makes it even more important that participation in co-curricular activities be stressed during orientation and in courses such as campus culture. Given these students' utilitarian viewpoints towards college, it was unlikely that they would have lived in a residence hall unless they were specifically forced to do so by the college, or they were more meaningfully informed about the benefits that can be derived from residing on campus, and they received financial support for doing so.

Training. Much like my assertions for faculty, the professionals who work in the various administrative/student life roles need training to assist them in developing an awareness of these issues. Most student life divisions, as well as the various departments within these divisions, have a commitment to on-going professional development for their employees. Often these professional development sessions are diversity-related. Student life programs should expand their definition of diversity to include social class. Further, given the context of the college campus population, first generation, working class students should be considered as members of a discernable culture. As this study and others indicate, the concerns and experiences of this group are different from second, third and so on, generations. To that end, professional development sessions dealing with topics like social class in America, the notion of status incongruity, and the experiences of first generation college students should also be incorporated into professional development.

Student Services. Student services, which was a part of student life on this campus, needed to be more "student friendly" in order to overcome the "us versus them" perceptions of these students. Several of the students in this study referred to the 
administration as "them," and while the use of this word alone does not necessarily signify an adversarial relationship, other comments these students made indicated that they saw administrators as actively working against the students. Training for administrators should focus on ways to overcome this barrier, so that working class students see the student service departments as potential places they can go to for support. A new definition of "student friendly" is in order, where student services works tirelessly to overcome the "them versus us" mentality.

Siegel and Barefoot (2001), directors of the Policy Center on the First Year of College, encourage a first year focus in all divisions or departments of student affairs to assist first year students in making a connection to the campus. In Siegel and Barefoot's opinion, the first year is when most students are most amenable to the idea of becoming involved in co-curricular life activities. They suggest that admissions officers who help recruit students into the college maintain contact with students during orientation and into the first semester, so that students can benefit from continued contact with the person who was responsible for bringing them to campus. This would especially benefit working class, first generation white males who, according to this study, appear to have little idea what to expect in college. Further, the students in this study seem reluctant to ask for assistance when it was needed. Feeling that they knew at least one person who they could have turned to, and who could explain how the system worked, might have prevented these students from having to start the semester feeling as if they were navigating the system without the benefit of any support from the college.

New student orientation is a key ingredient of the first year experience. All of the students in this study talked about attending orientation, so it appeared that new student 
orientation made an impact on them. Siegel and Barefoot suggest that faculty become a part of new student orientation, so that students can begin to engage with their faculty members. On this campus, one suggestion is to have faculty members who are teaching the campus culture courses meet with their students during orientation so that the students know at least one faculty member before they begin their transition to college. In order to make this a reality, however, the institution need to adequately compensate faculty for their willingness to take on this additional task, and to reward them for it by recognizing it during the tenure review process.

Student Organizations/Leadership. Joe was in a fraternity where he perceived there to be a mixture of social classes. The Greeks at this college were required to attend mandatory training for alcohol awareness whenever they intended to serve alcohol at an event. Due to the "black face" incident that occurred in the fall when this study occurred, the fraternity involved was required to attend a diversity awareness workshop. Although these workshops targeted certain groups and originated because of certain events, it appeared that student leaders and student organizations are in need of diversity training. I would suggest expanding the diversity training to include social class as well. Misperceptions about class are an issue in the Greek system. Vander Putten (2001) described periodic internet searches with the keyword "white trash" as regularly turning up photos and references to sorority and fraternity "white trash parties." Campus officials could take an active role to prevent such parties from occurring on campus, and providing a role model for other schools as well. This type of training should not be limited to Greeks, however. By discussing the issue of social class during training sessions for student leaders, student life would be demonstrating that they support 
working class students and understand the issues they are dealing with. These discussions will also heighten affluent students awareness of the issues of social class. Including social class in a definition of campus diversity would help educate students that perpetuating stereotypes based on social class are inappropriate and painful for working class students, witness Patrick's experience with the video in his sociology class.

The masters degree programs on this college, designed for student development specialists and higher education administrators, could also consider including social class and status incongruity, in their curriculum. This would include courses on college student sub-cultures and multicultural issues in education, at a minimum.

\section{Financial Need}

Financial support throughout college is also crucial to working class, first gens. As has been mentioned, three of the students in this study worked hard to avoid going in debt, opting to participate in programs that, while providing them with money for tuition, also prevented them from participating fully in campus life. Gladieux and Swail (1998) contend that many working class students who drop out of college are worse off than if they had never attended college in the first place. These students leave college with no degree, and most of them have large loans to repay as well. Financial aid and student affairs staff members need to collaborate in providing students with financial counseling through workshops, presentations, and individual meetings in order to establish lines of communication and support with working class, first gens. This would help the students to see administrators as people who are there to assist them, and it would be an active approach, instead of relying on the student to seek them out. As this study showed, many working class, first gens are reluctant to approach staff and faculty out of a fear that they 
will be perceived as "bothering" them. This would show support for these students, and it would provide them with the guidance to make informed financial decisions about their future. Once students have the support they need to explore the various financial options available to them, they will be better equipped to overcome the myriad challenges they face in trying to pay for tuition and other expenses. These types of support programs can be incorporated into existing student life programs and services.

\section{Further Research}

More research needs to be done on the needs of working class, first gens, white males and the effects of status incongruity in relation to student life. This study suggested that these students were unaware and uninvolved with student life, but it might be a reflection of their first year status as well as their social class and first gen status. One recommendation would be to conduct longitudinal studies to see if these students become involved with student life over the course of their college career.

Research is also needed on how best to develop and implement programs and workshops designed to train student life staff and student leaders. This is an area that would benefit many colleges that are struggling with how best to develop student leaders on campus.

Another area that requires further research is in the area of the UPS/college partnership. My findings are based on the experiences of two students, but the findings seem to have significant potential for increasing our understanding of how these programs negatively affect working class, first gens. Before this UPS "partnership" is held up as a national model for other colleges, research needs to be conducted about the impact on students who take part in these programs, and their educational experiences. 
Further research is required to determine the affects of social class on other groups of first generation students. This study focused on one particular race and gender, but more research needs to be conducted among working class students of various races, ethnicities, sexual orientations, and with women, to see if their experiences mirror the experiences of the students in this study, or if it differs in substantial ways.

The impact of residential living is an area that needs further study as well, to determine if working class, first gens who live on campus feel the same lack of belonging to the campus that the working class, first gens in this study did. A great of research has been conducted by Tinto (1987), showing the significant positive impact that living in a residence hall on campus can have on a student's college experience. Colleges need to realize that residence halls are a service and that living on campus is an integral part of a students' collegiate experience. Allowing for-profit companies to run residence halls runs the risk of pricing them out of the reach of working class students. For-profit companies are also potentially less interested in the student development aspect of residential living, which is an integral part of living on campus. Residentialliving is not a business, devoid of educational value and should not be treated as such.

For commuter campuses that have few or no residence halls available to undergraduate students, more research needs to be done to determine the best way to develop a sense of community on the campus. First generation, working class students who attend college where a genuine sense of community exists are more likely to be supported for their efforts at college and feel that they belong to that community. This greatly enhances their chances of persisting to graduation. 


\section{Final Thoughts}

First gens are becoming a significant force in higher education. There is general agreement that the numbers of first gens are growing as a college degree becomes a prerequisite for more and more jobs (London, 1992; Terenzini, et al., 1996; Levine, 1989). Nunez and Cuccarro-Alamin (1998) found that 43 percent of all students attending post-secondary institutions in the United States could be considered first gens. First gens face unique challenges in their quest for a degree because they encounter conflicting obligations at home and at college, are straddling two cultures, lack much of the academic preparation needed for the work they are expected to do in college, and are not fully supported in their pursuit of a college degree by friends and family members (Hsiao; London, 1992).

First gens often feel that they are on the border of two very different cultures. The college culture into which they are attempting to gain acceptance may have one set of values and expectations, while the culture of their family and friends has another. College attendance may be seen as a rite of passage for some students, but it marks a significant separation from the past for first gens.

According to Astin (1993), the decision to attend college involves three issues for most prospective college students. The first is whether or not to go. If the decision is made to go to college, the issue then becomes where to go. Finally, there is the issue of how to pay in order to go. The matter of "whether" is particularly critical for working class, first gens, whose academic interests and achievements are minimal and/or whose financial situation is tenuous. Will these students be able to succeed? Is it likely to be a 
worthwhile investment in their time and money? These are two big questions with no simple answers.

Many working class families think of college simply as a place that prepares students for a career, without realizing that it also is responsible for other changes. While the college experience can be exciting, changing the way students think and the way students perceive the world, the families and peers of working class, first generation college students may be unable to accept these confusing, and often alienating changes. Never having been to college themselves, they are not always aware of the cognitive and developmental changes that occur during college.

Somebody has to care. Working class, first generation college students need to feel as if their presence on campus matters. All students, but particularly first gens, need a variety of people willing to help them succeed. If colleges are to reach the lofty goal of the 1947 President's Commission on Higher Education to become the means by which every citizen is enabled and encouraged to carry his education as far as possible, they must do more than simply help working class, first gens gain access to college. Colleges need to focus on helping working class, first gens successfully complete their degree. Focusing on these students, and attempting to eradicate their perceived "deficits" is only part of the solution. The other is to alter the college culture itself so that working class, first gens feel prepared for college, supported for college, and that they belong on the college campus. With both of these solutions in place, colleges are more likely to reach this lofty goal. 


\section{REFERENCES}

Anyon, J. (1980). Social class and the hidden curriculum of work. Journal of Education, 162, 67-92.

Anzuldua, G. (1987). Borderlands/La Frontera: The new mestiza. San Francisco: Aunt Lute Books.

Astin, A. (1993). What matters in college: Four critical years revisited. San Francisco: Jossey-Bass.

Astin, A., Green, K., Korn, W. \& Schalit, M. (1988). The American freshmen: National norms for fall, 1987. Cooperative Institutional Research Program, American Council on Education. University of California, Los Angeles: CA.

Berkner, L. \& Chavez, L. (1997). Access to postsecondary education for the 1992 high school graduates. U.S. Department of Education, NCES. NCES 98-105.

Bernstein, B. (1977). Social class, language and socialization. In J. Karabel \& A. H. Halsey, (Eds.), Power and ideology in education. (pp. 511-534). New York: Oxford University Press.

Biklen, S. K. \& Pollard, D. (1993). In S. K. Biklen and D. Pollard, (Eds.), Gender and Education. Chicago, IL: National Society for the Study of Eduction.

Billson, J. M. \& Terry, M. B. (1982). In search of the silken purse: Factors in attrition among first generation students. College and University, 58, 57-75. York: Wiley.

Blau, P. \& Duncan, O. D. (1967). The American occupational structure. New

Bourdieu, P. (1977). Cultural reproduction and social reproduction. In J. Karaabel and A. H. Halsey (Eds.), Power and ideology in education. (pp. 487-511). New York: Oxford University Press. Basic Books.

Bowles, S., \& Gintis, H. (1976). Schooling in capitalist America. New York:

Bullough, R. V., Jr. \& Pinnegar, S. (2001). Guidelines for quality in autobiographical forms of self-study research. Educational Researcher, 30, 13-21. 
Choy, S. (2001). The condition of education, 2001. Washington, DC: National Center for Education Statistics (Publication No. 2001072), [on-line], available: www.nces.ed.gov.

Coleman, J. S. (1988). Social capital in the creation of human capital. American Journal of Sociology, 94, 95-120.

Dougherty, K. (1987). The effects of community colleges: Aid or hindrance to socioeconomic attainment? Sociology of Education, 60, 86-103.

Education Resources Institute (1997). Missed opportunities: A new look at disadvantaged college aspirants. (ERIC Document Reproduction Service No. ED 420 257).

Felski, R. (2002, January 25). Why academics don't study the lower middleclass. The Chronicle of Higher Education. B24.

Fernstermaker, S., West, C. \& Zimmerman, D. (1991). Gender Inequality: New conceptual terrain. In R. L. Blumberg, (Ed.), Gender, Family, and Economy (pp. 289307). Newbury Park, CA.: Sage Publications, Inc.

Giroux, H. (19). Rewriting the discourse of racial identity: Towards a pedagogy and politics of whiteness. Harvard Educational Review, 67, 285-320.

Gladieux, L. \& Swail, W. (1998). Postsecondary education: Student success, not just access. [on line], http://www.collegeboard.org/policy/html.

Gos, M. W. (1995). Overcoming social class markers: Preparing working class students for college. Clearing House, 69, 30-34.

Gose, B. (1999, July 23). Working nights for $\$ 8.50$ an hour and a free college education. Chronicle of Higher Education, A68-70.

Guillaumin, C. (1999). I know it's not nice, but...The changing face of race. In R. D. Torres, L. F. Miron \& J. X. Inda (Eds.), Race, identity and citizenship: A reader (pp. 39-46). Brighton, UK: Blackwell Publishers, Inc.

Hassan, T. E. \& Reynolds, J. E. (1988). Working class students at selective colleges: Where have they gone? College Board Review, 146, 4-9,30-31.

Healy, P. (1999, July 7). Can city college restore its luster by ending open admissions? Chronicle of Higher Education, A24-26.

Hearn, J. C. (1984). The relative roles of academic, ascribed, and socioeconomic characteristics in college destinations. Sociology of Education, 57, 22-30. 
Helms, J. E. (1984). Toward a theoretical explanation of the effects of race on counseling: A black and white model. The Counseling Psychologist, 12 (4), 153-165.

Hooks, b. (2000). Learning in the shadow of race and class. Chronicle of Higher Education, B14-16.

Horn, L. \& Nunez, A.-M. (2000). Mapping the road to college: First generation students' math track, planning strategies, and context of support. (NCES 2000-153). [On-line], available: www:necs.ed.gov. Washington, DC: U.S. Dept of Education.

Howard, H. (2001). Students from poverty: Helping them make it through college. About College, 6(5), 5-12.

Hsaio, K. P. (1992). First generation college students. ERIC Document Reproduction Service No. ED 351079.

Jackma, M. R. \& Jackma, R. W. (1983). Class Awareness in the United States. Berkeley, CA: University of California Press.

Jordan, J. \& Plank, S. (1996). Reducing talent loss: The impact of information, guidance and actions on post-secondary enrollment. (CRESPAR Rep. 9), Baltimore, MD: Center for Research on the Education of Students Placed at Risk.

Kalmijn, M. \& Kraaykamp, G. (1996). Race, cultural capital and schooling: An analysis of trends in the United States. Sociology of Education, 69, 22-34.

King, J. E. (2000). Gender equity in higher education: Are male students at a disadvantage? Washington, DC: American Council on Education, Center for Policy Analysis. [On-line], available: www.acenet.edu.

Kuh, G. D. \& Hall, J. E. (1993). Using cultural perspectives in student affairs. In G. D. Kuh (Ed.), Cultural perspectives in student affairs work (pp.1-20). Washington, D.C.: American College Personnel Association.

Lareau, A. (1987). Social class differences in family-school relationships: The importance of cultural capital. Sociology of Education, 60, 73-85.

Lareau, A. \& Horvat, E. M. (1999). Moments of social inclusion and exclusion: Race, class and cultural capital in family-school relationships. Sociology of Education, $\underline{72}, 37-53$.

Levine, A. \& Associates (1989). Shaping higher education's future: Demographic realities and opportunities, 1990-2000. San Francisco: Jossey-Bass.

Lincoln, Y. S. \& Guba, E. G. (1985). Naturalistic inquiry. Beverly Hills: Sage Publications. 
Liu, W. M. (2001). Expanding our understanding of multiculturalism: Developing a social class worldview model. In D. P. Pope-Davis and H. L. K. Coleman (Eds.), The intersecton of race, class and gender in multicultural counseling. Thousand Oaks, CA: Sage Publications, Inc.

London, H. B. (1989). Breaking away: A study of first generation college students and their families. American Journal of Education, 97,144-1 70.

London, H. B. (1992). Transformations: Cultural challenges faced by first generation students. In H. B. London and L. S. Zwerling (Eds.), First generation Students: Confronting the Cultural Issues. New Directions for Community Colleges, 20, $5-11$.

London, H. B. (1996). How college affects first generation students. $\underline{\text { About }}$ Campus, 1, 9-13,23.

Marinara, M. (1997). When working class kids "do" the academy: How we negotiate with alternative literacies. Journal of Basic Writing, 16(2), 3-16.

McDonough, P. (1994). Buying and selling higher education: The social construction of the college applicant. Journal of higher education, 65, 427-444.

McDonough, P. (1997). Choosing colleges: How social class and schools structure opportunity. New York: State University of New York Press.

McIntosh, P. (1998). White privilege: Unpacking the invisible knapsack. In P.S. Rothenberg (Eds.), Race, Class and Gender in the United States: An integrated study (Fourth Edition). New York: St. Martin's Press.

Merriam, S. B. (1998). Qualitative research and case study application in higher education. San Francisco: Jossey-Bass.

Miles, M. B. \& Huberman, A. M. (1984). Qualitative data analysis: A sourcebook of new methods. Beverly Hills, CA: Sage Publications.

Mills, R. \& Torres, R. D. (1999). Does 'race' matter? Transatlantic perspectives on racism after 'race relations'. In R. D. Torres, L. F. Miron and J. X. Inda (Eds.), Race. Identity and Citizenship: A reader (pp. 19-38). Brighton, UK: Blackwell Publishers

Nunez, A.-M. \& Cuccaro-Alamin, S. (1998). First generation students: Undergraduates whose parents have never enrolled in postsecondary education. (NCES 98-082). U. S. Department of Education, NCES. Washington, DC. [on-line], available: www.nces.ed.gov/

Okun, B. F., Fried, J., \& Okun, M. (1999). Understanding diversity: A learningas-practice primer. Pacific Grove, CA: Brooks/Cole Publishing Co. 
Ortiz, A. M. \& Rhoads, R. A. (2000). Deconstructing whiteness as part of a multicultural educational framework: From theory to practice. Journal of College Student Development, 141, 81-93.

Pascarrella, E. T. \& Terenzini, P. T. (1991). How college affects students: Findings from twenty years of research. San Francisco: Jossey-Bass.

Peshkin, A. (2000). The nature of interpretation in qualitative research. Educational Researcher, 29,5-9.

Piorkowski, G. K. (1983). Survivor guilt in the univesity setting. Personnel and Guidance Journal, 61, 620-622.

Portes, A. (1998). Social capital: Its origins and applications in modern sociology. Annual Review of Sociology, 24, 1-24. HM 1 .A763.

Pratt, P.A. \& Skaggs, C. T. (1989). First generation college students: Are they at greater risk for attrition that their peers? Research in Rural Education, 6, 31-34.

President's Commission on Higher Education (1947). Higher education for American democracy. New York: Harper Collins.

Reich, R.B. (2000, September 15). How selective colleges heighten inequity. The Chronicle of Higher Education.

Rendon, L. I. (1996). Life on the border. About Campus, 1(5), 14-20.

Richardson, R. C. Jr., \& Skinner, E. F. (1992). Helping first generation minority students achieve degrees. In L. S. Zwerling and H. B. London (Eds.), First generation Students: Confronting the Cultural Issues. New Directions for Community Colleges, 80, 29-43.

Rothenberg, P. (1988). Integrating the study of race, gender and class: Some preliminary observations. The Feminist Review, 3, 37-42.

Sacks, P. (2001, June 8). How admissions tests hinder access to graduate and professional schools. The Chronicle of Higher Education, B11.

Siegel, M. J. \& Barefoot, B. O. (2002). Meeting the needs of first year students: Findings from a national survey of first year, co-curricular practices. NASPA Netresults, March 26, 2002. [on-line], available: http://www.naspa.org/netresults/

Sennett, R. \& Cobb, J. (1972). The hidden injuries of class. New York: Knopf.

Soliday, M. (1999). Class dismissed. College English, 61, 731-741. 
Stake, R. (1995). The art of case study research. Thousand Oaks, CA: Sage Publications.

Stanton-Salazar, R. D. \& Dornsbusch, S. M. (1999). Social capital and the reproduction of inequality: Information networks among Mexican-origin high school students. Sociology of Education, $68,116-135$.

Stierlin, H. (1974). Separating parents and adolescents. New York: Quadrangle.

Terenzini, P. T. , Rendon, L. I., Upcraft, M. L., Millar, S. B., Allison, K. W., Gregg, P. L. \& Jalomo, R. (1994). The transition to college: Diverse students, diverse stories. Research in Higher Education, 35,57-73.

Terenzini, P. T., Springer, L., Yaeger, P. Pascarella,E. T., \& Nora, A. (1996). First generation college students: characteristics, experiences, and cognitive development. Research in Higher Education, 37, 1-22.

Tierney, W. G. (1992). An anthropological analysis of student participation in college. Journal of Higher Education, 63, 603-618.

Tinto, V. (1975). Dropout from higher education: A theoretical synthesis of recent research. Review of Higher Education Research, 45, 89-125.

Tinto, V. (1982). Limits of theory and practice in student attrition. Journal of Higher Eduction, 53, 687-700.

Tinto, V. (1987). Leaving college: rethinking the causes and cures of student attrition. Chicago: University of Chicago Press.

Torres, R. D., Miron, L. F. \& Inda, J. X. (Eds.). (1999). Race, identity and citizenship: A reader. Brighton, UK: Blackwell Publishers.

Tseng, M. S. (1971). Social class, occupational aspiration and other variables. The Journal of Experimental Education, 39, 88-92.

Valdez, J. R. (1996). Educational access and social mobility in a rural community college. The Review of Higher Education, 19, 391-409.

Vander Putten, J. (2001). Bringing social class to the diversity challenge. About Campus, 6(5), 14-19.

Van Galen, J. A. (2000). Education and class. Multicultural Education, 7, 2-11. 
Weber, M. (1946). Class, status and party. In H. H. Gerth and C. Wright Mills (Eds.), From Max Weber: Essays in Sociology (pp. 180-195). New York: Oxford University Press.

Willis, P. (1977). Learning to labour: How working class kids get working class jobs. New York: Columbia University Press.

Willett, L. H. (1989). Are two-year college students first generation college students? Community College Review, 17,48-52.

Yin, R. J. (1994). Designing case studies. In R. K. Yin, Case study research: Design and methods (Second Edition). Thousand Oaks, CA: Sage Publications. 


\section{APPENDIX 1 \\ University of Louisville \\ Educational and Counseling Psychology \\ Information Sheet For Research Project}

Name

Address

Phone \#

Email Address

Parent's Occupations: (Mother) ( Father)

Level of parents education:

(Mother) Less than $8^{\text {th }}$ grade

GED

High School diploma

Some college

College

Graduate

(Father) Less than $8^{\text {th }}$ grade

GED High School diploma Some college College

Graduate

Major

Are you currently employed? If yes, where are you

employed and how many hours a week?

Race/Ethnicity \# of Brothers and Sisters

Brothers/Sisters who attended or are attending college:

I am interested in participating in this research project on the experiences of working class, freshmen males who are the first in their families (not including siblings) to attend college. I understand that I will need to meet with the researcher every few weeks during the semester for interviews and/or observations, and that each of these interviews/observations will last approximately one hour. If I have any questions I can call the researcher (Rob Longwell-Grice) at 852-6415 or email him at rmlong01@athena.louisville.edu. If I have questions about this research I can contact the researcher's supervisor (Dr. Michael Cuyjet) at 852-0628.

(Signature) (Date) 


\section{APPENDIX 2 - Informed Consent Letter}

August, 2001

Dear Participant:

You are being invited to participate in a study about the experiences of first generation college students. There are no risks or penalties for your participation in this research study. The information you provide may help universities understand the needs of first generation college students better. The information collected will be stored at the University of Louisville. Four students will be selected for interviews.

Individuals from the Department of Educational and Counseling Psychology and the University Human Studies Committee may inspect these records. In all other respects, however, the data will be held in confidence to the extent permitted by law. Should the data be published, your identity will not be disclosed.

Please remember that your participation in this study is voluntary. By signing this form, you are voluntarily agreeing to participate. You are also indicating that all your present questions have been answered in language that you can understand. All future questions will be treated in the same manner. You may refuse to participate without being subject to any penalty or losing any benefits to which you are otherwise entitled.

If you have any questions about this study, please feel free to call Rob Longwell-Grice at 502-852-6415. If you have any questions about your rights as a research subject, you may call the University Human Studies Committee office at 502-852-5188 and will be given an opportunity to discuss any questions in confidence, with a member of the Committee. This is an independent committee composed of faculty and staff of the University of Louisville and its affiliated hospitals, as well as lay members of the community not connected with these institutions. The Committee has reviewed this study. You may also contact my research supervisor, Dr. Michael Cuyjet at 852-0628 if you have any questions or concerns.

Sincerely,

Robert Longwell-Grice 


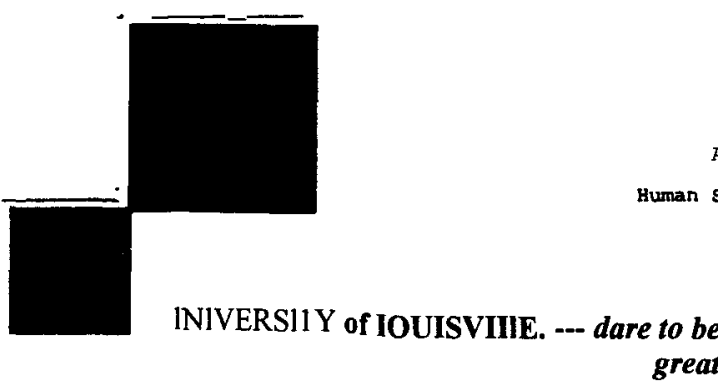

February 28,2001
DR RICHARD L MILLER I

CHAIRMAN

HUMAN STUDIES COMMIITEI

Instructional Building

Room 230

500 South Preston Street University of Louisville Louisville. Kentucky 40292

Office $502-852-5188$ Fax

502-852-2164

research.louisville edu

\section{Dr Robert Longwell Grice \\ Educational and Counseling Psychology School of Education -384}

RE: 148-01 Experiences of First Generation, Working Class College Freshman

Dear Dr. Grice:

The $\sim$ bove study has been received by the Human Studies Committees and was approved through the Expedited Review Procedure, Category 7.

The study has approval through February 27, 2002, when the approval expires. You should complete and return a Progress Report/Continuation Request Form four weeks prior to this date in order to ensure that no lapse in approval occurs. It will be necessary to send the completed form promptly for Committee review and reapproval of the study. Federal regulatory agencies have indicated that studies must be re-approved by the Committee by the expiration date otherwise the approval will expire. Regulatory agencies have indicated that no further subjects may be entered until the study is re-approved by the Committee (study suspension), nor may any data from that period be used. It is the investigator's responsibility to send this form on time.

Please visit our website to obtain the form at http:llresearch.louisville.edu/uhsc/Forms.htm

Best wishes for a successful study.

Sincerely,

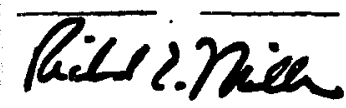

Richard L. Miller, D.D.S., Ph.D. Chair, Human Studies Committees

Rlm:rsh 


\section{APPENDIX 4}

Initial interview questions

Questions related to demographics on sheet they filled out

Tell me about your family background

Why did you decide to attend college?

Who or what influenced your decision to attend college?

How and why did you choose the University of Louisville?

Tell me about your family's reaction to your decision to attend college

Tell me about your friends and their reaction to you going to college

What would do if you did not go to college?

What are your feelings about attending college?

What is your career aspiration? 


\section{CURRICULUM VITAE}

NAME: Robert Longwell-Grice

ADDRESS: 1415 S. Second St. \#3

Louisville, KY 40208

DOB: $\quad$ Elmira, New York - September 14, 1955

EDUCATION \&

TRAINING:
A.A., Liberal Arts
Corning Community College
1973-1975
B.A., Social Work
University of Dubuque
1976-1978
M.Ed., Counselor Education
Pennsylvania State University
1981-1983
Ed.D, Educational and Counseling Psychology
University of Louisville
1998-2002

AWARDS: Outstanding graduate adult learner. University of Louisville, 2001.

John Dewey fellow. University of Louisville Fall, fall, 2000.

Advisor of the year. Central Atlantic Association of College and

University Residence Hall Association (CAACURA), 1998.

Outstanding Mentorship to Undergraduate Students. Gold Key Honor Society, University of Delaware, 1997

Merit award for outstanding contributions to the University cornmunity. University of Delaware, 1996. 
PROFESSIONAL SOCIETIES: National Association of Student Personnel Administrators

American College Personnel Association

American Educational Research Association

NATIONAL MEETING PRESENTATIONS:

The Revolutionary Life Changes of First Generation, Working Class, White Males. NASPA. 2002

In Our Own Best Interest: Historical Roots of Tribal Colleges. ACPA. 2000.

REFEREED JOURNALS: Longwell-Grice, R. \& Longwell-Grice, H. (2001). Chiefs, braves and tomahawks: The use of American Indians as university mascots. NASPA Journal.

Portes, P., Longwell-Grice, R. \& Sandhu, D. (2000). Understanding adolescent suicide. Adolescence. 